Florida International University

FIU Digital Commons

3-25-2019

\title{
Project Performance Rating Model and IPD Implementation Guideline Metric for Water and Wastewater Treatment Plant Projects
}

Elie G. Andary

eelan001@fiu.edu

Follow this and additional works at: https://digitalcommons.fiu.edu/etd

Part of the Civil Engineering Commons, and the Construction Engineering and Management Commons

Recommended Citation

Andary, Elie G., "Project Performance Rating Model and IPD Implementation Guideline Metric for Water and Wastewater Treatment Plant Projects" (2019). FIU Electronic Theses and Dissertations. 3955. https://digitalcommons.fiu.edu/etd/3955

This work is brought to you for free and open access by the University Graduate School at FIU Digital Commons. It has been accepted for inclusion in FIU Electronic Theses and Dissertations by an authorized administrator of FIU Digital Commons. For more information, please contact dcc@fiu.edu. 


\section{FLORIDA INTERNATIONAL UNIVERSITY}

Miami, Florida

\section{PROJECT PERFORMANCE RATING MODEL AND IPD IMPLEMENTATION GUIDELINE METRIC FOR WATER AND WASTEWATER TREATMENT PLANT \\ PROJECTS}

A dissertation submitted in partial fulfillment of the

requirements for the degree of

DOCTOR OF PHILOSOPHY

in

CIVIL ENGINEERING

by

Elie G. Andary

2019 
To: Dean John L. Volakis

College of Engineering and Computing

This dissertation, written by Elie G. Andary, and entitled Project Performance Rating Model and IPD Implementation Guideline Metric for Water and Wastewater Treatment Plant Projects, having been approved in respect to style and intellectual content, is referred to you for judgment.

We have read this dissertation and recommend that it be approved.

$\begin{array}{r}\hline \text { Berrin Tansel } \\ \hline \text { Ton-Lo Wang } \\ \hline \text { Irtishad Ahmad } \\ \hline \text { Caesar Abi Shdid } \\ \hline \text { Arindam G. Chowdhury, Major Professor }\end{array}$

Date of Defense: March 25, 2019

The dissertation of Elie G. Andary is approved.

Dean John L. Volakis College of Engineering and Computing

Andrés G. Gil Vice President for Research and Economic Development and Dean of the University Graduate School

Florida International University, 2019 
C Copyright 2019 by Elie G. Andary

All rights reserved. 


\section{DEDICATION}

I dedicate this dissertation to my wife Sally, my daughter Isabelle, and my son

George for their love and devotion; and to my parents and siblings, Nadine, Aline, and Nazih, for their continuous encouragement, support and prayers. 


\section{ACKNOWLEDGMENTS}

I wish to thank Dr. Caesar Abishdid, who influenced me to enroll in the Ph.D. program at Florida International University and for guiding me through this research in its entirety with his breadth of knowledge. His guidance in selecting a research topic and devising a scientific methodology, his time and tireless efforts in critically improving the work and editing the manuscript are appreciated.

I wish to thank my major professor Dr. Arindam Chowdhury for his input in the research design and execution. His questions continuously exposed critical issues in the research. I also wish to thank the members of my committee for their support and guidance, Drs. Irtishad Ahmad, Ton-Lo Wang, and Berrin Tansel. I would especially like to acknowledge Dr. Irtishad Ahmad, not only for his constructive comments and contributions, but also for his insight and demonstrated experience and wisdom, which were essential for my research.

I profoundly appreciate the support of the Department of Civil and Environmental Engineering at FIU. I gratefully acknowledge the participation of many stakeholders and professionals in this research and especially South Florida water utilities. This includes those whom I conducted the focus group interviews, along with those that participated in providing data and other useful sources of information. I wish to acknowledge my colleagues at Hazen and Sawyer for providing their tremendous support.

I am also thankful to everyone that contributed to my development academically, professionally, and as a person. 


\begin{abstract}
OF THE DISSERTATION
PROJECT PERFORMANCE RATING MODEL AND IPD IMPLEMEMTATION

GUIDELINE METRIC FOR WATER AND WASTEWATER TREATMENT PLANT

PROJECTS

by
\end{abstract}

Elie G. Andary

Florida International University, 2019

Miami, Florida

Professor Arindam Chowdhury, Major Professor

The public nature of water and wastewater construction capital projects has rendered Design-Bid-Build (DBB) as the delivery method of choice for such projects over the past years. Shortcomings inherent to DBB have had a negative effect on the Key Performance Indicators (KPIs) of these projects. Numerous studies have argued that Integrated Project Delivery (IPD) improves the delivery performance of DBB projects. Project delivery performance is, however, a complex concept that is not easily measured. It involves several criteria with many factors that need to be accounted for. Water and wastewater construction projects do not have well-established overall performance rating models, and to date, no study has scientifically established links that correlate IPD principles to improvements in KPIs of DBB construction projects. The aim of this research is to develop a new model for rating the performance of water utilities major capital projects delivered using a project delivery method that combines IPD and DBB and use this model to find what correlation exists between the implemented IPD principles and the KPIs of these projects. 
Data for water and wastewater projects were collected from water utilities in the three counties of South Florida. Forty-three projects were selected from the total population of water and wastewater construction projects and delivered using the traditional DBB delivery method. Selective IPD principles that are applicable to public projects in the water and wastewater field were then applied to two control projects, and their respective performance was measured using the previously identified KPIs.

A Project Performance Rating (PPR) Model was developed to combine the key performance factors of a project into one performance index for water and wastewater construction projects and to gauge the overall project performance. Regression analysis and a focus group were then utilized to determine the effect of each implemented IPD principle on various project KPIs.

Results showed enhancements in the performance of the delivery of public water and wastewater construction projects through the implementation of certain IPD principles. A guideline metric was developed that can significantly help utility owners aiming to predict how implementation of certain IPD principles can impact various project KPIs. 


\section{TABLE OF CONTENTS}

CHAPTER

PAGE

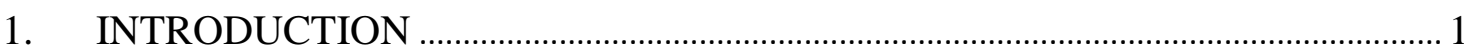

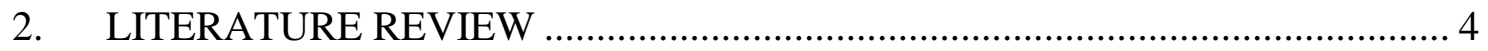

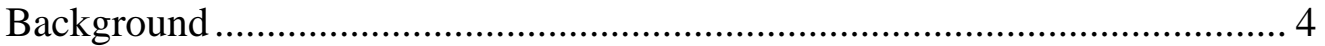

Alternative Delivery Methods in Public Projects ............................................. 4

Project Delivery Methods Used in the Public Sector......................................... 6

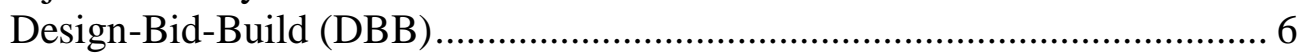

Construction Manager at Risk (CMR)..................................................... 7

Design Build (DB) ................................................................................ 9

Integrated Project Delivery (IPD) .............................................................. 10

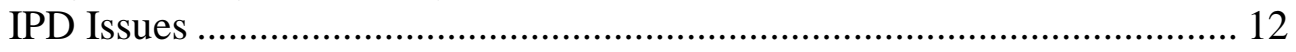

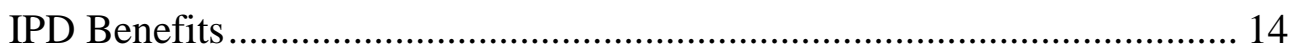

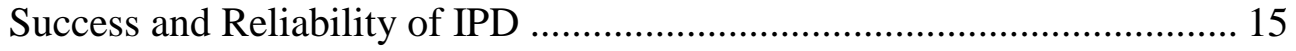

IPD and Collaboration Levels.............................................................. 15

IPD and Public Projects .......................................................................... 17

Water and Wastewater Related Projects ........................................................ 20

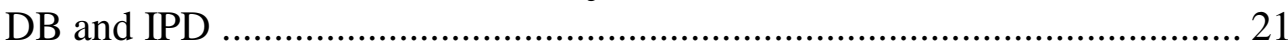

How Risks and Rewards are Distributed in IPD ....................................... 23

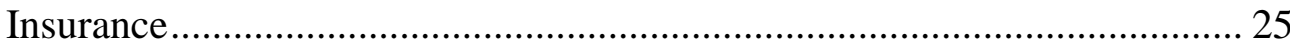

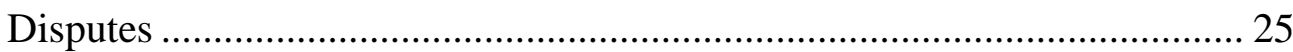

Building Information Modeling (BIM) and Integrated Project Delivery

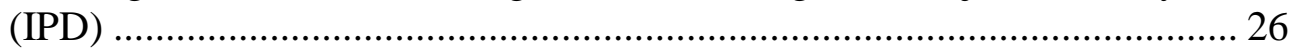

Adopting New Approach...................................................................... 27

Project Performance Rating (PPR) …………………............................. 28

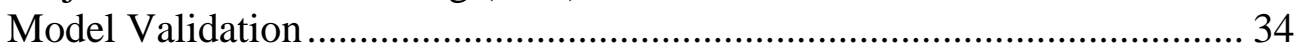

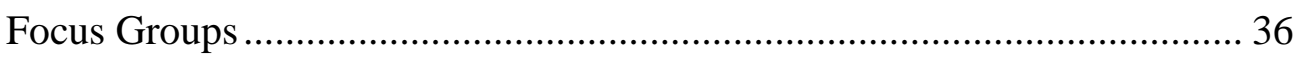

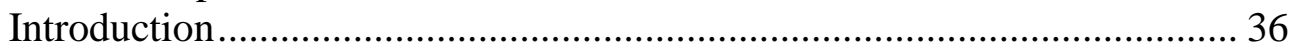

Format of Focus Groups ............................................................................. 36

Future Research as Recommended by Other Researchers ........................... 39

Distinguishing Characteristics of Water and Wastewater Projects .............. 40

Large Variety in Size, Scope, and Cost .................................................... 40

High Level Security ................................................................................... 40

Construction during Facility Operation ...................................................... 41

Complexity of Water and Wastewater Projects ............................................ 41

Public Projects Funding and Legality of Delivery Methods......................... 42

3. AIM, OBJECTIVES AND SIGNIFICANCE OF RESEARCH............................ 43

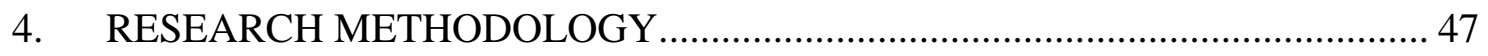

Identifying Key Performance Indicators (KPIs) ............................................ 50 
Cost Overrun as a Percentage of the Total Project Award Price, ................... 50

Change Order Cost as a Percentage of Total Project Cost, .......................... 50

Time Overrun as a Percentage of the Original Project Schedule, .................. 50

Number of RFIs per Unit Price, .............................................................. 50

Error and Omissions Change Orders Cost as a Percentage of Total Cost of

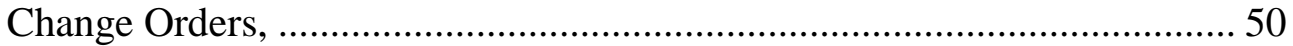

Total Claims Cost as a Percentage of the Total Project Cost, ...................... 50

RFI Response Time per Project Cost, ...................................................... 50

Cost of Field Rework as a Percentage of Total Project Cost, and ................. 50

Owner Requested Change Orders Cost as a Percentage of Total Cost of

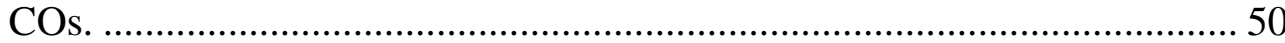

Cost Overrun as a Percentage of the Total Project Award Price................. 50

Change Order Cost as a Percentage of Total Project Cost ......................... 51

Time Overrun as a Percentage of the Original Project Schedule: ................ 51

Number of RFIs per Unit Price................................................................. 52

Error and Omissions Change Orders Cost as a Percentage of Total Cost of

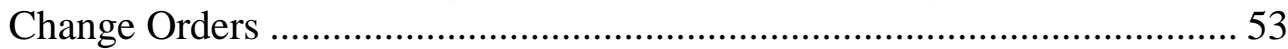

Total Claims Cost as a Percentage of the Total Project Cost ..................... 53

RFI Response Time per Project Cost .................................................... 53

Cost of Field Rework as a Percentage of Total Project Cost....................... 54

Owner Requested Change Orders Cost as a Percentage of Total Cost of

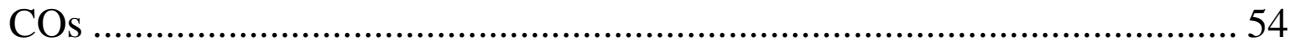

Collection of Project Data........................................................................... 55

Identification of IPD Principles that can be Used and Implemented in Public

Treatment Plant Projects ....................................................................... 55

IPD Implementation with DBB Public Projects ...................................... 58

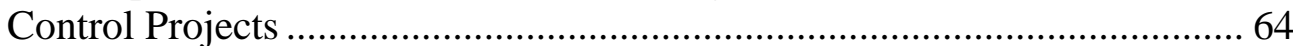

IPD Implementation in Wastewater Control Projects................................... 66

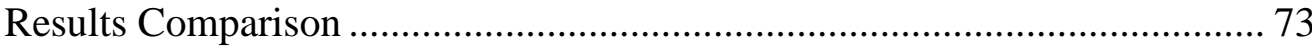

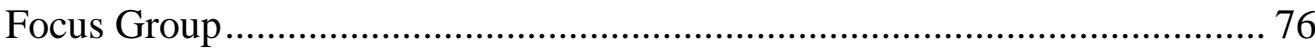

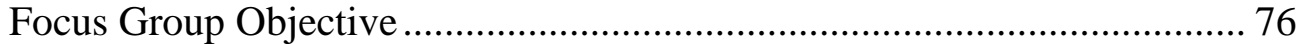

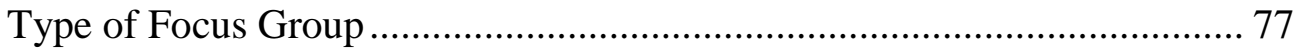

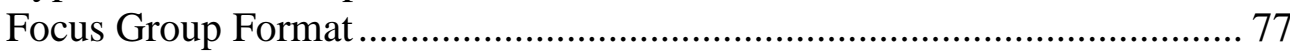

Focus Group Discussions and Questions................................................ 79

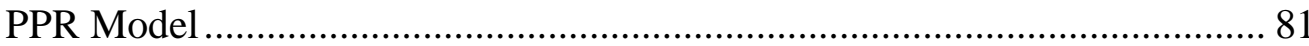

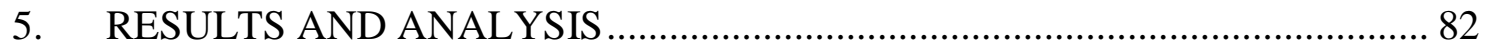

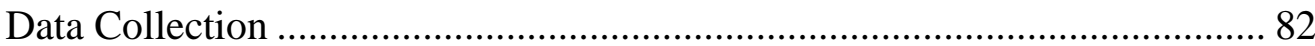

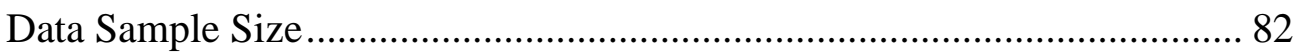

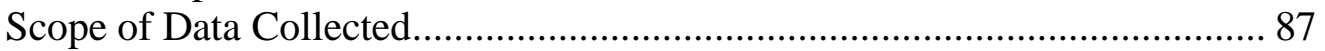

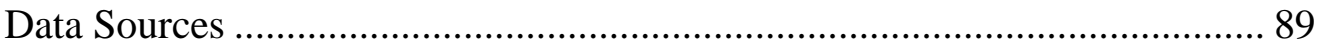

Project Performance Measures ............................................................. 93

Project Categories ............................................................................... 93

Performance Evaluation with Regard to Cost .......................................... 94

Performance Evaluations with Regard to Time...................................... 100 
Performance Evaluation with Regard to Change Orders (CO)s ................ 107

Request for Information (RFI) Evaluation .......................................... 121

Construction Claims ............................................................................... 129

Summary of Findings......................................................................... 131

Obtaining Input from Project Participants ................................................ 133

Focus Group Results......................................................................... 135

6. PROJECT PERFORMANCE RATING (PPR) MODEL AND

CORRELATION BETWEEN IPD PRINCIPLES AND PROJECT KPI .......... 139

PPR Purpose................................................................................. 139

Success Criteria and Performance Factors................................................. 141

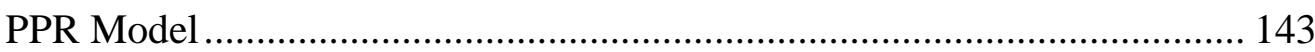

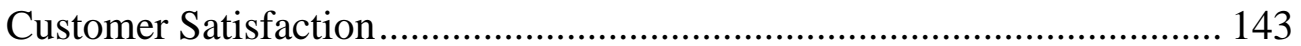

Project Schedule ....................................................................................... 144

Project Cost..................................................................................... 144

Design Quality............................................................................. 144

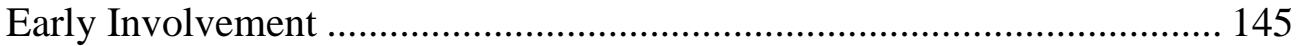

Weighting of Success Criteria (SC) and Performance Factors (PF) ......... 145

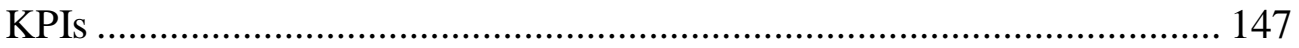

Scoring Mechanism ......................................................................... 149

KPIs Mathematical Formulation and Normalization............................... 149

Scoring Computation of KPIs and SC for PPR .................................... 156

SC No. 1: Customer Satisfaction .......................................................... 156

SC No. 2: Project Schedule................................................................... 157

SC No. 3: Project Cost ............................................................................ 157

SC No. 4: Design Quality ..................................................................... 158

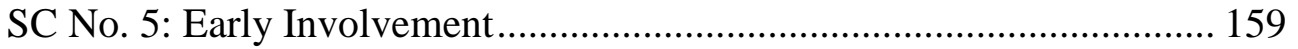

Performance Index (PI) Formula ......................................................... 160

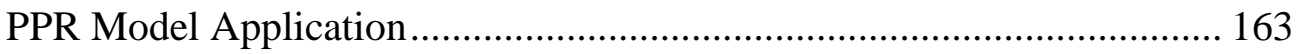

Control Project Model Simulation .......................................................... 163

Model Simulation Results and Conclusions .......................................... 167

Correlation between IPD Principles and KPIs ......................................... 170

Integrated Project Delivery (IPD) Principles............................................ 171

IPD Principles Scoring Mechanism..................................................... 171

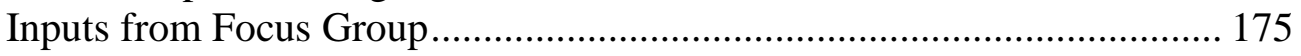

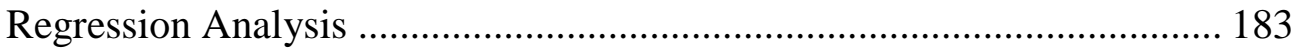

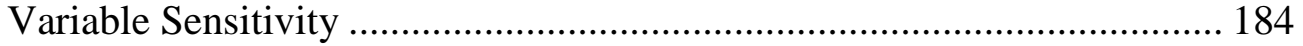

Variable Correlations ....................................................................... 185

Results and Conclusions .................................................................. 208

7. CONCLUSIONS AND RECOMMENDATIONS .................................... 214

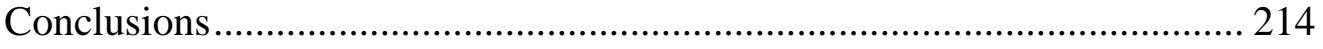

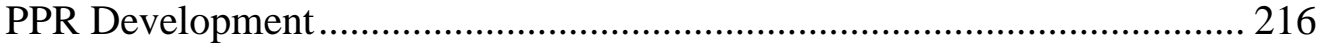

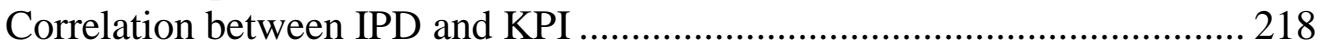

Recommendations ......................................................................... 220 


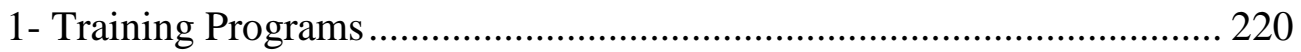

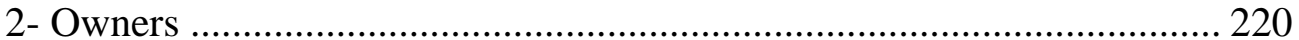

3- Engineers and Contractors .................................................................. 221

4- Future Research......................................................................... 221

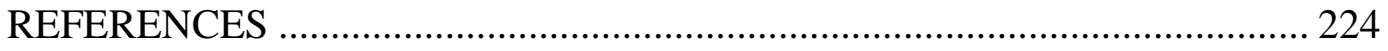

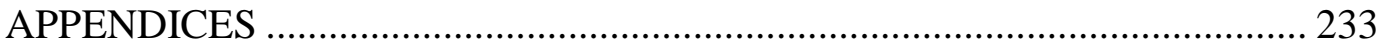

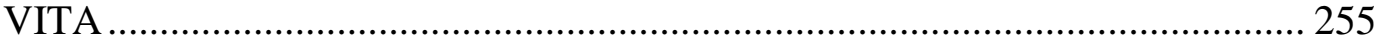




\section{LIST OF TABLES}

TABLE

PAGE

2-1: Comparison of Existing Performance Models .................................................... 31

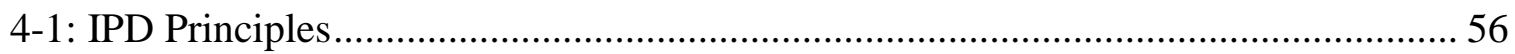

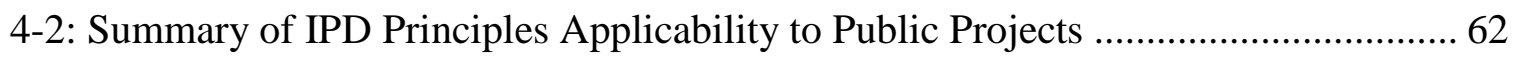

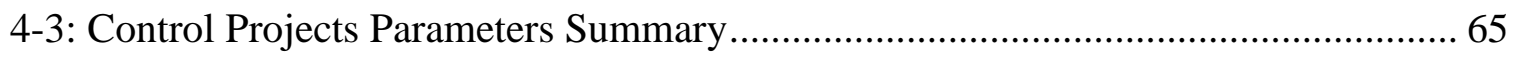

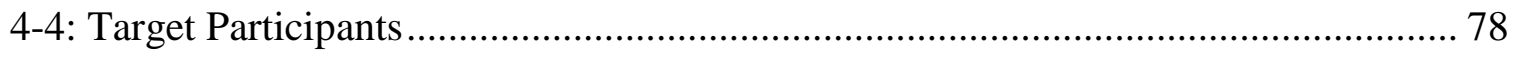

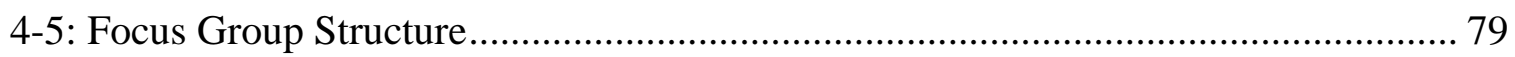

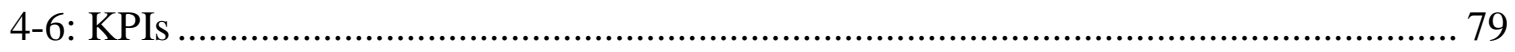

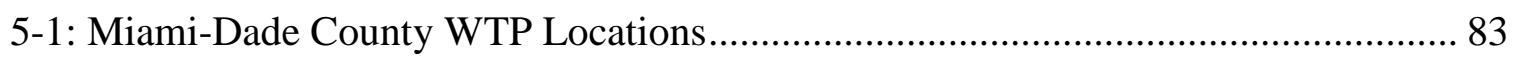

5-2: Broward County Water Treatment Plant (WTP) Locations .................................... 84

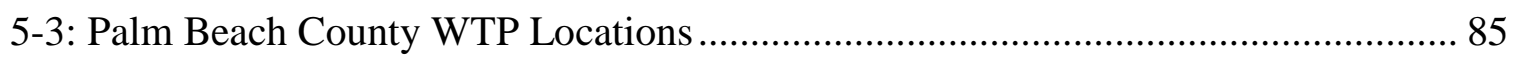

5-4: Miami-Dade County Wastewater Treatment Plant (WWTP) Locations................... 86

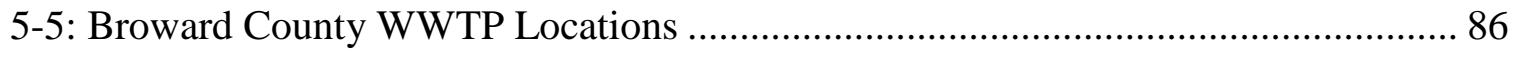

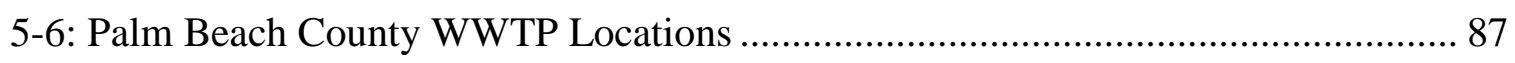

5-7: Percentage of Projects at Different Levels of Time and Cost Overrun ................... 106

5-8: Statistics of the CO Performance Measure ..................................................... 110

5-9: Ranking of the KPIs based on their Most Influence in Improving the Delivery Method.

5-10: Participants' Opinions Concerning Characteristics of MD-SDWWTP Control

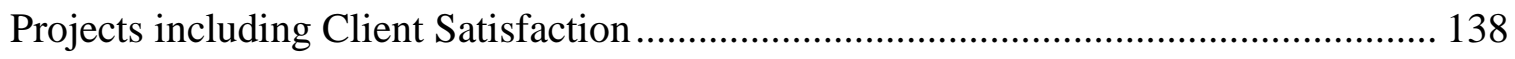

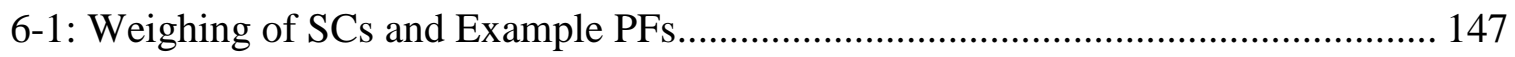

6-2: KPI Mean and Standard Deviation of the Dataset........................................... 148 


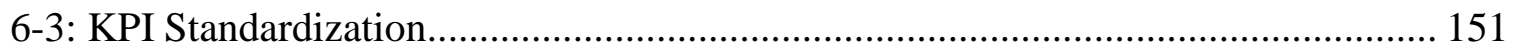

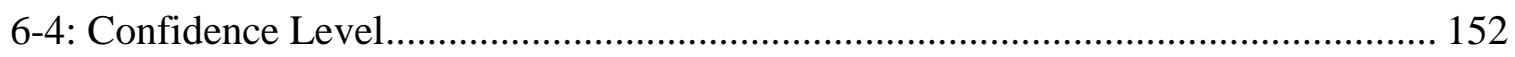

6-5: KPI Standardization with 3 Standard Deviations .................................................. 154

6-6: Control Projects KPIs and PFs Scores............................................................... 155

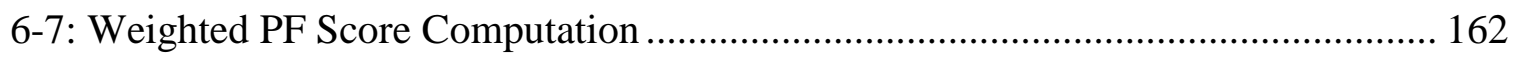

6-8: Total Weighted Success Criteria Score Computation .............................................. 162

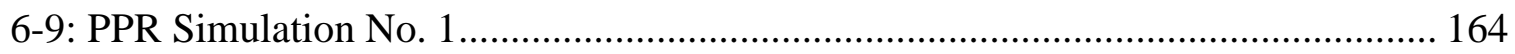

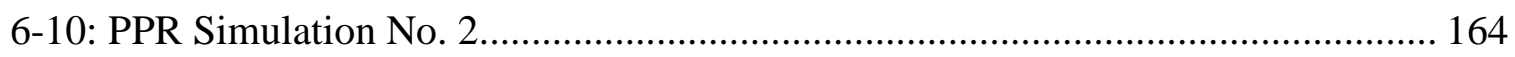

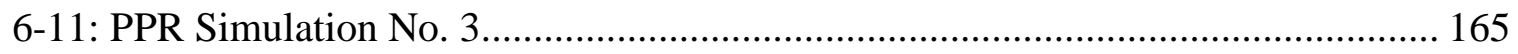

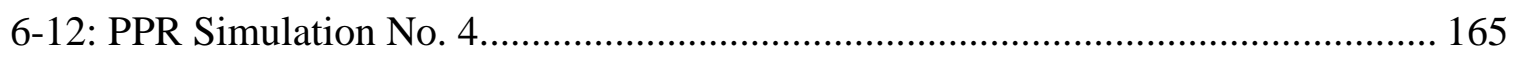

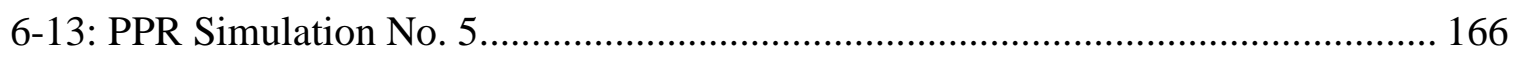

6-14: PPR Simulation Output Summary ................................................................. 166

6-15: Scoring Mechanism for Open Communication ................................................... 172

6-16: Scoring Mechanism for Integrated and Collaborative Teams ............................... 172

6-17 Scoring Mechanism for Mutual Respect and Trust ................................................. 173

6-18: Scoring Mechanism for Jointly Developed Project Target Criteria ...................... 173

6-19: Scoring Mechanism for Collaborative Decision Making ....................................... 174

6-20: Scoring Mechanism for Lean Principles ............................................................... 174

6-21: Scoring Mechanism for Co-location of Teams …………………..................... 175

6-22: Scoring Mechanism for Performance Evaluations ............................................... 175

6-23: IPD Principles Score Means of the Dataset............................................................ 183

6-24: Control Projects IPD Principles Scores ……………………............................. 184 
6-25: Polynomial Regression Curves between Open Communication with the Project Team and Ability to Address Issues and KPIs

6-26: Correlation between Open Communication with the Project Team and Ability

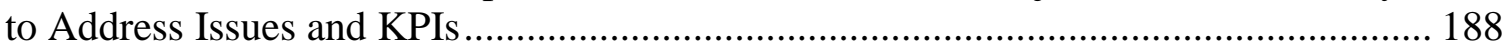

6-27: Polynomial Regression Curves between Lean Principles and KPIs ..................... 190

6-28: Correlation between Lean Principles and KPIs ...................................................... 191

6-29: Polynomial Regression Curves between Co-Location of Teams and KPIs .......... 193

6-30: Correlation between Co-Location of Teams and KPIs........................................... 194

6-31: Polynomial Regression Curves between Collaborative Decision Making and

6-32: Correlation between Collaborative Decision Making and KPIs

6-33: Polynomial Regression Curves between Project's Staff Performance Evaluation and KPIs

6-34: Correlation between Project's Staff Performance Evaluations and KPIs 201

6-35: Polynomial Regression Curves between Jointly Developed Project Target Criteria and KPIs 202

6-36: Correlation between Jointly Developed Project Target Criteria and KPIs 204

6-37: Polynomial Regression Curves between Mutual Respect and Trust and KPIs ..... 205

6-38: Correlation between Mutual Respect and Trust and KPIs 207 


\section{LIST OF FIGURES}

FIGURE

PAGE

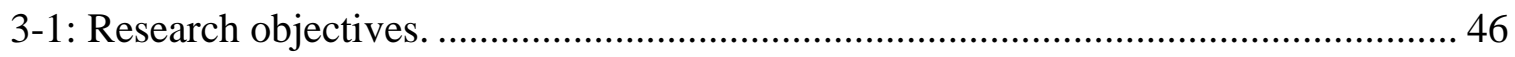

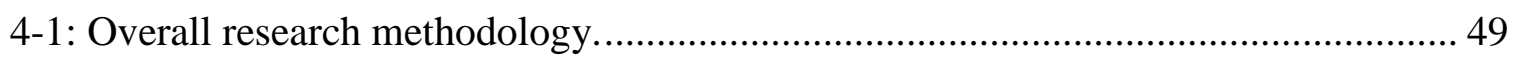

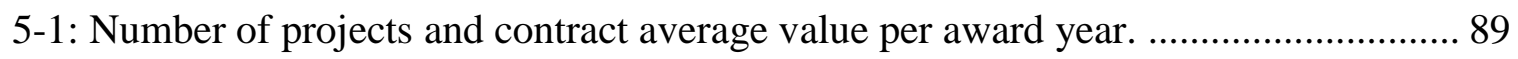

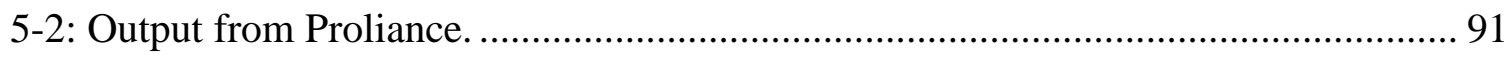

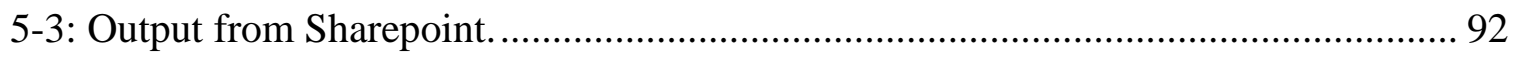

5-4: Number and percentage of projects for specified range of contract value............... 94

5-5: Distribution of projects with respect to the cost overrun percentage. ..................... 97

5-6: Cost overrun percentages for specified contract base amount range. ..................... 98

5-7: Comparison of cost overrun average of all projects to time overrun of control

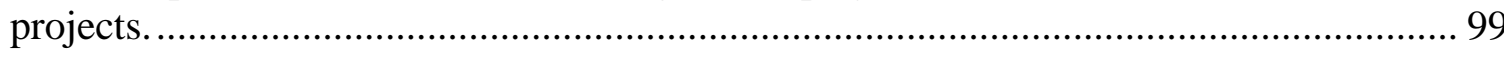

5-8: Comparison of average cost overrun of all projects to control projects................. 100

5-9: Distribution of projects with respect to the time overrun percentage. ................... 102

5-10: Time overrun percentages for specified contract base amount. ......................... 103

5-11: Comparison of time overrun average of all projects to time overrun of control

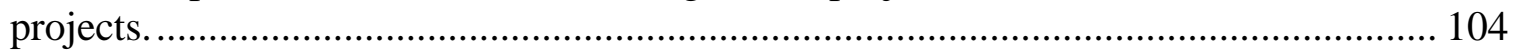

5-12: Comparison of average time overrun of all projects to control projects.............. 105

5-13: Comparison of percent time overrun to percent cost overrun per project............. 107

5-14: Total CO cost for specified contract base amount range.................................... 109

5-15: Owner requested $\mathrm{CO}$ cost for specified contract base amount range................... 112

5-16: Owner requested CO cost for specified actual expenditure range. ...................... 113

5-17: Error and omission CO cost for specified contract base amount range. ............... 114

5-18: Error and omission CO cost for specified actual expenditure cost range.............. 115 
5-19: Time overrun for specified total number of RFPs. 116

5-20: Time overrun for specified percent range of total RFP cost to contract base amount.

5-21: Time overrun to specified percent range of total CO cost to actual paid amount. 118

5-22: Cost overrun to specified percent range of total CO cost to contract base amount.

5-23: Cost overrun to specified percent range of total CO cost to actual paid amount. . 120

5-24: Comparison of average number of RFPs of all projects to control projects.

5-25: Total number of RFIs by specified contract base amount range. 123

5-26: Cost overrun by specified total number of RFIs range. 124

5-27: Time overrun specified total number of RFIs range. 125

5-28: RFI response time per unit price by specified base amount cost range................ 126

5-29: RFI per unit price to specified base amount cost range.

5-30: Comparison of average RFI response time per unit price and average RFI per unit price of all projects to control projects. 128

5-31: Comparison of average number of RFIs of all projects to control projects. 128

5-32: Cost of claims to specified contract base amount cost range. 130

5-33: Comparison of percent of cost of claims to contract base amount cost range. ..... 131

5-34: Comparison of cost of claims to contract base amount of projects.

5-35: Comparison of KPIs between dataset and control projects.

5-36: KPIs ranking based on effectiveness in determining the success of a construction project. 136

5-37: Characteristics based on experience with control projects. 136

6-1: Flowchart of model development process.

6-41: Flowchart of PPR model 143 
6-3: Normal distribution density curve.

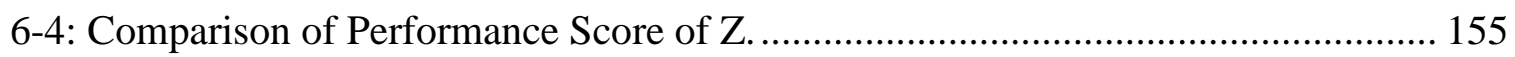

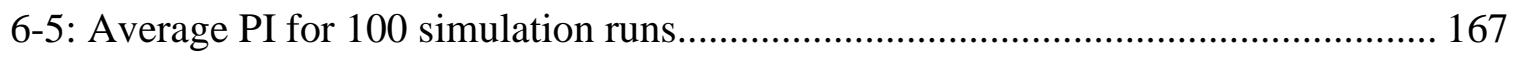

6-6: Comparison between KPI values of control projects and dataset. .......................... 169

6-7: Comparison between PF scores of control projects and dataset............................ 170

6-8: Effect of IPD principles on reduced percentage cost overrun................................ 176

6-9: Effect of IPD principles on reduced percentage time overrun. .............................. 176

6-10: Effect of IPD principles on reduced percentage cost of CO............................... 177

6-11: Effect of IPD principles on reduced percentage cost of error and omissions. ...... 177

6-12: Effect of IPD principles on reduced percentage cost of owner's CO.................... 178

6-13: Effect of IPD principles on reduced number of claims....................................... 178

6-14: Effect of IPD principles on reduced number of RFIs......................................... 179

6-15: Effect of IPD principles on reduced time to respond to RFIs. ............................. 179

6-16: Effect of IPD principles on reduced amount of field rework. ............................. 180

6-17: Links between IPD principles and KPIs identified by focus group. ...................... 182

6-18: Polynomial regression curve between cost overrun and open communication with the project team and ability to address issues..................................................... 186

6-19: Links between IPD Principles and KPIs identified by regression analysis........... 210

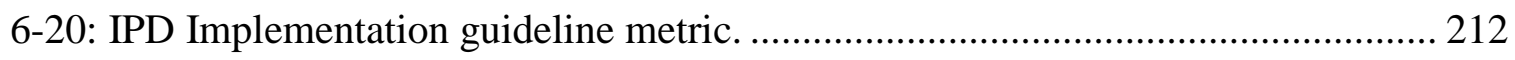

6-21: Regression analysis between PI and Lean Principles Sore......................213 


\section{ABBREVIATION SNF ACRONYMS}

$\begin{array}{ll}\text { CDM } & \text { Collaborative Decision Making } \\ \text { CLT } & \text { Co-Location of Teams } \\ \text { CMR } & \text { Construction Manager at Risk } \\ \text { CO } & \text { Change Order } \\ \text { CP1 } & \text { Control Project Number One } \\ \text { CP2 } & \text { Control Project Number Two } \\ \text { DB } & \text { Design-Build } \\ \text { DBB } & \text { Design-Bid-Build } \\ \text { GPM } & \text { Guaranteed Maximum Price } \\ \text { KPI } & \text { Key Performance Indicator } \\ \text { IPD } & \text { Integrated Project Delivery } \\ N & \text { Number of Standard Deviations } \\ \text { OCPTAAI } & \text { Open Communication with the Project Team and Ability to Address } \\ \text { PI } & \text { Issues } \\ \text { PF } & \text { Performance Index } \\ \text { PPR } & \text { Performance Factor } \\ \text { PQR } & \text { Project Performance Rating } \\ \text { RFI } & \text { Project Quarterback Rating } \\ \text { RFP } & \text { Request for Information } \\ \text { SC } & \text { Request for Proposal } \\ \text { Success Criteria } \\ \text { User Assigned Weight }\end{array}$


Z Score

xix 


\section{CHAPTER 1 \\ INTRODUCTION}

Designed to remove biological or chemical waste products from water, water and wastewater treatment facilities are essential infrastructure for communities in providing clean water and allowing the wastewater to be used for other purposes. Water and wastewater treatment facilities include a network of pipes and pump stations to distribute water or collect wastewater from/to a municipal treatment plant which acts as a centralized system. Water and wastewater treatment facilities are therefore engineeringdriven, requiring a higher level of expertise during the preconstruction and construction phases than ordinary residential and commercial construction projects.

The complex nature of processes in water and wastewater treatment plants, henceforth referred to as 'treatment plants' or 'treatment facilities,' require highly specialized expertise in planning, cost estimating, design, and construction of such facilities. This type of construction requires a highly skilled team of individuals to ensure a successful project undertaken by large construction firms. The design and execution of the infrastructure in question must consider the environmental impact of the job, the successful scheduling, budgeting, construction site safety, availability of building materials, logistics, and inconvenience to the public caused by construction delays and unforeseen conditions.

The project delivery method adopted for such critical projects will greatly influence the factors mentioned above, which are in a way the key indicators of the success of a project. With the increasing number of major water and wastewater projects 
— planned and in construction — and the availability of several project delivery methods for constructing those projects, guidance in rating the performance of such construction projects is needed to assist water utility owners and operators in meeting their expectations.

For recent years, the dominant project delivery method for treatment plants has been the Design-Bid-Build (DBB) approach. Some water utility owners are turning to the Design-Build (DB) approach to save time in the delivery process. However, the DBB and DB approaches have some shortcomings and pertinent issues, and need to be improved in order to keep up with the water utility owners' demands and expectations. The past decade has also seen a large increase in the use of Integrated Project Delivery (IPD) as the method of choice for privately owned residential and commercial construction projects. This new method, which promises increased productivity and less waste (time and money) through aligning the interests, objectives, and practices of all involved parties, has been slow to be adopted or implemented in public projects, such as water and wastewater facilities, for several legal and procedural reasons.

This research is developing a new model for rating the performance of water utilities major capital projects delivered using a project delivery method that combines IPD and DBB.

Combining IPD method with the commonly used DBB project delivery method has the potential to improve the performance of project delivery by overcoming the challenges of these traditional methods in delivering treatment plant projects. In order to demonstrate this, a model has to be developed first in order to measure and compare the performance of various water and wastewater treatment plant projects. Second, statistical 
analysis and focus group have to be used in order to demonstrate any correlation between the implementation of IPD principles and any improvement in project performance as measured by the developed performance rating model.

Using a combination of IPD and DBB approach will help owners of treatment plants get a detailed look into critical problem areas that are likely to impact performance rating and in promoting better performances for future projects Correlation between the implemented IPD principles and the KPIs of these projects can significantly help utility owners who are aiming to predict how implementation of certain IPD principles can impact various project KPIs. 


\section{CHAPTER 2}

\section{LITERATURE REVIEW}

\section{Background}

Various types of project delivery methods are currently available to the owners and managers of public projects, and specifically for water and wastewater utilities in the United States. Each of the existing delivery methods has disadvantages and poses challenges that render them inappropriate for the case of large and complicated water and wastewater projects. A need exists to develop a new and more appropriate project delivery method that will overcome the challenges of the traditional delivery methods. Project delivery method selection depends on the preferred contractual relations, current laws and regulations, risk allocation, procurement procedures, and payment methods. Water and wastewater projects can be constructed using any project delivery method. Nevertheless, each construction project has unique characteristics that will render a particular project delivery method to be the ideal method. Integrated Project Delivery (IPD) methods have seen a steep rise in the recent years with the advent of building information modeling (BIM) (Touran et al., 2009).

\section{Alternative Delivery Methods in Public Projects}

Public procurement law has historically limited public entities to using only DBB project delivery. DBB functions as the benchmark against which all other methods are compared. The current wide range of project delivery methods is a relatively recent development for publicly funded projects in the United States. The public procurement laws have limited the public entities to use the DBB project delivery method as noted in 
the Brooks Act (Touran et al., 2009). This strongly helped the proliferation of DBB delivery method in the public sector. Moreover, numerous laws and statutes throughout the United States have limited the procurement of constructors in the public sector to the lowest responsible, responsive bidder.

In 1996, the Federal Acquisition Reform Act explicitly authorized the use of a DB project delivery method for federal projects. Subsequent to the successful implementation of DB in several projects, many states passed new legislation and codes to allow alternative project delivery methods, such as DB and Construction Manager at Risk (CMR). Some projects added the responsibility of operation and maintenance to DB projects and called the delivery method Design-Build-Operate-Maintain (DBOM) (Touran et al., 2009).

For the past four decades, owners of various public and private facilities have been looking into different methods to improve quality, reduce cost, and reduce the construction schedule of their projects. The Associated General Contractors of America (AGC) defines project delivery method as: "the comprehensive process of assigning the contractual responsibilities for designing and constructing a project. A delivery method identifies the primary parties responsible for the performance of the work" (AGC, 2004). Therefore, project delivery methods are distinguished by the way the contracts and relationships among the owner, the engineer, and the contractor are established.

The management method "is the mechanics by which construction is administered and supervised" (AGC, 2004). This function is either retained by the owner agency or is outsourced by hiring an agency Construction Manager (CM) to represent the owner during the design and construction phases. Ideally, any management method, such as a 
$\mathrm{CM}$, may be used with any delivery method, such as DBB, DB, CMR, or IPD.

Procurement methods are broken down into three categories: low-bid, qualificationsbased, and best value. Descriptions of project delivery methods used in the public sector (DBB, CMR, DB, and IPD) are described next.

\section{Project Delivery Methods Used in the Public Sector}

\section{$\underline{\text { Design-Bid-Build (DBB) }}$}

DBB is the traditional project delivery method. In this method, a project owner retains a designer to furnish complete design services and then advertises and awards a separate construction contract that is based on the designer's completed construction documents. In DBB contract documents are 100\% complete prior to selecting a contractor and separate contracts are formed between the owner and the engineer and between the owner and the contractor. The owner is responsible for the details of design and demands the quality of the construction design documents to the construction contractor. DBB has been used on projects of all sizes.

In DBB the owner can cancel the project or modify the design, with losing the design cost incurred. In DBB, the owner has the opportunity to verify the maintainability and the quality of the design before awarding the project. DBB gives the owner the most control over the project. However, as projects grow in size and complexity, oversight of DBB can become burdensome since the owner's responsibilities in DBB are spread throughout the project lifecycle of design and construction. DBB uses a sequential process that makes significant schedule compression difficult due to the need to complete project designs prior to the award of the construction contract (Gordon, 1994). 
This delivery method can create an adversarial relationship among the parties to the contract-mainly between the owner and the construction contractor (Mahdi and Alreshaid, 2005). Furthermore, the engineer and the contractor may assume adversarial roles as one is in charge of approving the other's work. This method typically has the highest occurrence of claims and disputes typically arising over authority, responsibility, errors and omissions, and quality. Potential change orders and errors in design may cause considerable cost overruns. There is no incentive for the builder to minimize the cost of change orders in this delivery method (Touran et al., 2009).

\section{$\underline{\text { Construction Manager at Risk (CMR) }}$}

In CMR projects a contract is signed between the owner and the CM who will handle the details of the entire project. In this delivery method, the CMR is selected based on procurement method qualifications and final project cost and duration will be the responsibility of the CM. Typically, CMR contracts contain a provision in which the CMR stipulates a Guaranteed Maximum Price (GMP) above which the owner is not liable for payment. In public projects, the owner retains the traditional responsibility by having a separate design contract and furnishing the CMR with a full set of plans and specifications upon which all construction subcontracts are based. The CMR will usually be paid for providing preconstruction services such as cost engineering, constructability review, and development of subcontractor bid packages, budgeting, cost estimating, and scheduling.

In CMR, the CM essentially becomes the General Contractor (GC) at the time the GMP is established. Most public CMR laws require competitively bidding out the 
construction trade subcontract work packages. This delivery method is typically awarded with a GMP system and it allows the contractor to be involved in the design phase for providing current cost information. This helps the engineer with adhering to the budget and helps the owner manage the project costs. Normally in CMR contracts, there is less possibility for claims and disputes (Touran et al., 2009).

The American Institute of Architects (AIA) noted that, "transparency is enhanced, because all costs and fees are in the open, which diminishes adversarial relationships between components working on the project" (AIA, 2005). The main advantages of CMR method are the speed of execution and locking the project cost at the early stages of the project lifecycle. One of the challenges is to gauge the validity of the GMP in comparison with the traditional delivery methods.

One of the disadvantages of CMR is the difficulty to agree on a GMP between the owner and the CMR which may affect the project schedule and increase the project costs. Usually, the owner the GMP can be set and agreed on at about $60 \%$ design completion (AGC, 2004). Failure Also, public projects require competitive bidding; however, the issue with this requirement is that the CM may not be able to set a GMP until the bids from all the subcontractors have been submitted. This will lead the owner to cancel the CMR contract, pay the CMR for its preconstruction services, and put the construction project out for bids with the completed design. The cost associated with design errors and omissions is a valid risk because the owner executes separate contracts with the engineer and CMR. Additionally, the increase in the number of parties directly involved in the project and some overlaps among their duties may make the risk allocation more difficult (Touran et al., 2009). 


\section{Design Build (DB)}

DB is a project delivery method in which the owner procures design and construction services in the same contract from a single, legal entity referred to as the design-builder. A variety of approaches exist for selecting the design-builder. In public projects, DB generally follows Request-for-Qualifications (RFQ) or Request-for-Proposal (RFP) procedures to be submitted for the owner to evaluate and to award the contract. As in CMR, the builder has early constructability input into the design process. As the owner no longer owns the details of design, the owner's relationship with the design-builder must be based on a strong degree of mutual professional trust (Beard et al., 2001).

The DB method is normally chosen for large and complex projects, and it branches out to several methods such as Design-Build-Operate-Transfer, Design-BuildOperate-Own, and Design-Build-Operate-Maintain (DBOM). In these methods the contractor is responsible for operating the new facility after construction is complete based on contractual agreements for a determined duration (Kessler et al., 2007). According to Konchar and Sanvido (1998), DB results in faster project delivery because the engineer and the contractor are one entity. DB performs better than CMR in operations and costs and the errors and omissions cost is shifted from the owner to the DB contractor. According to Riley et al. (2005), having a single entity of contractor and engineer reduces disputes with the owner and limits responsibility for changes in cost or time. From the owner's perspective, the DB approach reduces the size and frequency of change orders (Riley et al., 2005).

DB delivery method is less prone to claims and disputes, assuming a wellstructured contract. As the design criteria is handed to the design-builder in DB while the 
detailed design has not been completed yet, concerns about the maintainability and quality of the end product have been raised due to loss of owner's control over the design. Additionally, because the contract is awarded before the design is complete, subcontractors are assuming risk for pricing work without completed construction documents. Also, the design-builder is assuming risk for committing to a design and a firm price early in the process (Touran et al., 2009).

\section{Integrated Project Delivery (IPD)}

Integrated Project Delivery (IPD) is a "project delivery approach that integrates people, systems, business structures and practices into a process that collaboratively harnesses the talents and insights of all participants to optimize project results, increase value to the owner, reduce waste, and maximize efficiency through all phases of design, fabrication, and construction. IPD principles can be applied to a variety of contractual arrangements and IPD teams can include members well beyond the basic triad of owner, architect, and contractor. In all cases, integrated projects are uniquely distinguished by highly effective collaboration among the owner, the prime designer, and the prime constructor, commencing at early design and continuing through to project handover" (AIA, 2007). In Australia, the construction industry has been working with IPD for about 15 years on major infrastructure projects and they have realized the benefits of the process (Carbasho, 2008).

Kim and Dossick (2011) listed five elements that contribute to the integration of the project delivery: Contract Type, Integrated Form of Agreement (IFOA), Culture, Organization, Lean Construction and Building Information Modeling (BIM). 
Furthermore, Kent and Becerik-Gerber (2010) used the following common principles to define IPD: Multi-party agreement, shared risk and reward, and early involvement of all parties. Kent and Becerik-Gerber (2010) also listed the most important factors for IPD success as: well defined contractual relationships, early definition of project goals and early project participants' team formation.

Singleton and Hamzeh (2011) defined attributes that differentiate IPD from traditional contracts. These attributes can be summarized as: Integrated Teams, Integrated Governance, High Performing Teams, Lean Construction Techniques, Lean Principles, Collective Risk Sharing, Painsharing and Gainsharing, Profit Pooling, Contingency Sharing, Goals and Incentives and Award Fees/Performance Evaluations (Singleton and Hamzeh, 2011).

National Association of State Facilities Administrators (NASFA) used the following common principles to define IPD: Contractual Principles, Key Participants Bound Together as Equals, Shared Financial Risk and Reward Based on Project Outcome, Liability Waivers between Key Participants, Transparent Financials between Key Participants (Open Books), Early Involvement of Key Participants, Intensified Design, Jointly Developed Project Target Criteria and Collaborative Decision Making. NASFA also noted the IPD main behavioral principles as: Mutual Respect and Trust, Willingness to Collaborate, Open Communication within the Project Team, and Ability to Address Issues. NASFA presented different project participants' team structures that can be arranged to best suit IPD projects: 
SMT: The Senior Management Team compromises one person—typically a project executive, representing each of the three primary parties: owner, designer, and contractor.

PMT: The Project Management Team compromises one person representing each of the three primary parties, and is responsible for project schedule, budget, and day-today decision making.

PIT: The Project Implementation Team is a larger group that compromises members from the three teams, in addition to design consultants and subcontractors (NASFA et al., 2010). The selection process of the design team and construction team partners in IPD includes two criteria: Qualification Based Selection (QBS), and Best Value-Fee Proposal (Touran et al., 2009).

\section{IPD Issues}

According to Hatem (2008), one of the more important issues in IPD is the extent of project design responsibility with the design professional and its engineering consultants. The design responsibility issue and the associated contractually defined risk sharing for the economic consequences of defective design, continue to be discussed and debated in agreements for IPD projects. Hatem (2008) also questioned whether multiple parties can share design responsibilities or that one entity should be responsible for the entirety of the project design. Another related issue is whether the professional liability insurance industry should develop "wrap-up" coverage for design risk exposures for all design related project participants in IPD, or that the conventional professional liability insurance coverage is adequate. 
Hatem (2008) noted three principle areas of concern surrounding design responsibility in IPD:

- Defining public law requirements,

- Developing appropriate contractual risk allocation terms, and

- Developing adequate insurance coverage for design responsibility exposures by working with the professional liability insurance industry.

Ilozor and Kelly (2012) have covered significant issues in IPD including guidelines for implementation, contracting forms and structure, cultural and interpersonal issues, and process changes resulting from implementation. Another issue with IPD is that liability management standards, and the resulting practices currently used, discourage integration of project information for numerous reasons, including the reluctance to share unresolved or incomplete information prior to formal release (The Construction Users Roundtable, CURT, 2004).

Based on a survey by Kent and Becerik-Gerber (2010) that was designed to target a wide range of professionals in the construction industry, the biggest concern for participants in IPD projects was risk allocation and insurance, $43 \%$ of experienced respondents indicated that there is not enough evidence that these concerns have been addressed. Survey groups also noted that cultural barriers and technology limitations are the most common obstacles for IPD (Kent and Becerik-Gerber, 2010).

In IPD, the designers and the contractors are in very different positions with different risks that need to be tackled. A poorly managed contract can easily turn an IPD project into a disaster. In IPD projects, the elements of trust must be taken to a higher level for the delivery to be a success (NASFA et al., 2010). 


\section{IPD Benefits}

In order to achieve the desired outcomes, owners must collaborate through information sharing early in the project process. These desired outcomes range from speedy completion and efficiency to effectiveness and cost-bound buildings. Such collaboration shifts the bulk of analysis, design, and decision making to be done earlier in the design process, giving the collaborators the maximum opportunity for good decisions (CURT, 2004).

Based on survey results administered by experienced respondents on a specific IPD project, $70.3 \%$ of respondents noted that IPD projects had fewer change orders, $70.3 \%$ noted that IPD projects had shorter schedule, and $69.4 \%$ noted that IPD projects had fewer RFIs (Kent and Becerik-Gerber, 2010).

Baiden and Price (2011) stated that project participants' team integration is a very important tool in improved project delivery. It requires a spirit of cooperation to overcome the traditional adversarial attitudes and barriers. IPD and Lean Construction offer significant improvements in all three areas of construction: project organization (integrated, high performance team), operating systems, and commercial terms (minimize waste, add value, improve reliability and foster collaboration) (Thomsen et al., 2009).

Collaboration through IPD made redundant detailing unnecessary, and in many cases, eliminated all shop drawings. IPD also allowed the design team to spend more time on the construction site and less time processing RFIs and submittals. The projects studied by AIA all met or exceeded the owner's expectations with regards to cost, time, design quality, and sustainability. Interviews with the participants showed enthusiasm about IPD and willingness to use it again. IPD requires a significant amount of effort in 
the planning stages, which in turn makes execution easier. By comparison, DBB focuses more on design and less on planning, primarily because proponents of this method have no idea who is actually going to deliver and operate what they are designing (AIA, 2010).

Misguided design decisions, unreliable cost estimates, value engineering rework, poorly coordinated drawings, withheld documentation, an inefficient RFI/shop drawing process, and costly claims and disputes are some of the factors that plague traditional project delivery practices. IPD was a response to affecting change in the current system (Lancaster and Tobi, 2010).

\section{Success and Reliability of IPD}

Based on the previously mentioned definitions and characteristics, it is clear that every delivery method has advantages and limitations. However, IPD has shown to be the most promising delivery method and hence a detailed research will be needed to reveal more of its characteristics. The intent is to combine IPD principles with the commonly used DBB delivery method to improve the performance of water and wastewater projects.

\section{IPD and Collaboration Levels}

More than any other stakeholder or project participant, owners pose the most influence on the degree of collaboration they receive on their projects. This influence comes early in projects in the form of their procurement and contracting process (NASFA et al., 2010).

Collaboration, according to NASFA, is divided into three levels:

- Collaboration Level One is typical and is not required contractually. 
- Collaboration Level Two is more enhanced and requires some contractual collaboration.

- Collaboration Level Three requires collaboration from multi-party contract.

NASFA et al. (2010) also divided IPD into two areas based on levels of collaboration.

1- IPD as a Philosophy. This does not require multi-party contracts; Collaboration Levels One or Two. This is also known as IPD "Lite” or "IPD-ish", Non-Multiparty IPD or Hybrid IPD.

IPD as a Philosophy is suitable for owners who are not able to use a multi-party contract, but who try to improve the collaboration level. In this case, owners can apply integrated practices to more traditional delivery approaches such as CMR, $\mathrm{DB}$ or $\mathrm{DBB}$, where the owner is not a party to a multi-party contract.

2- IPD as a Delivery Method. This requires multi-party contracts; Collaboration Level Three. This is also known as "Pure" IPD; Multi-party IPD; Lean Project Delivery; Relational Contracting or Alliancing. IPD as a Delivery Method ("Pure" IPD or Multi-Party IPD) is when the owner chooses to sign a multi-party contract with the engineer, contractor and/or other key members of the project team. NASFA et al. (2010) noted that IPD as a philosophy with Level Two Collaboration has proven capable of being more successful. Project participants can work more collaboratively to achieve less cost, shorter duration, and more efficient change management. Level 2 projects have demonstrated the ability to encourage project participants to focus on optimizing the whole, rather than optimizing their own best interests. This leads to higher quality, satisfied clients, and overall better value. 
NASFA et al. (2010) noted that Level 3 IPD has a relational multi-party contract, in which one agreement is signed by the Owner, Engineer and Contractor. Decisions are made by collaboration with the stakeholders and are geared to the best interest of the project and not necessarily in favor of any one party. The principles of implementing IPD include early involvement of all key participants, joint project management, zero litigation, and joint risk sharing.

The Division of Capital Common Asset Management (DCAM) of the common wealth of Massachusetts applied IPD "Lite" in its CMR process. DCAM uses a collaborative approach, uses BIM, develops work plans and decision-making structure early in the project, and holds face-to-face meetings. NASFA et al. (2010) suggested other IPD principles that can be applied by DCAM under current laws such as: basing the selection of the engineer on its experience with IPD and willingness to work collaboratively, providing bonuses for certain achievements and conditions, identifying desired IPD-type services to be provided by engineers and CMs, forming contracts to reimburse the project participants for the extra work, and co-locating project team.

Single Purpose Entity (SPE) has "Level 4" collaboration where all the key project participants including the owner, designer, contractor and $\mathrm{CM}$, are under a legal entity such as a limited liability company for the purpose of a specific project (NASFA et al., 2010).

\section{IPD and Public Projects}

In public projects the owner is a public entity such as the state, federal government, county, municipality, or even the army. Public projects are different from 
private projects in the way they are managed, the way they are procured, and the way they are funded; they therefore need to be addressed separately.

Aldrich (2011) mentioned the challenge to IPD in public projects where local government procurement laws have competitive bidding requirements. The winning contractors and subcontractors may or may not have worked together before and they certainly would not be coming in on the project toward the beginning because of the DBB nature of delivery (Aldrich, 2011).

Public agencies, whose procurement policies are often constrained, can get some of the benefits of IPD. New forms of public agency contracts should be explored, including modified DB contracts, and contracts with single purpose entities (AIA, 2010).

NASFA et al. (2010) noted that many public owners do not have the authority to enter into multi-party agreements, to bring subcontractors into the design process, and to use insurance policies that do not meet current statutory requirements. However, to take advantage of IPD-type delivery, contract provisions and project procedures can be modified to obtain additional benefits by applying principles and practices with IPD as a philosophy. These principles and practices include:

- Using BIM,

- Bringing the $\mathrm{CM}$ into the project early during design phase,

- Co-locating team staff,

- Establishing a collaborative decision-making process and structure, and

- Resolving issues in a timely manner and at an appropriate level. 
According to NASFA et al. (2010), owners who do not have the authority to implement true IPD projects can still enhance collaboration and benefit from many features of these collaborative models such as:

- Including key elements of Level 2 collaboration in DB contracts (co-location of team members, involvement in performance incentives, participation in risk sharing, and construction team incentivized for productivity); and

- Selecting project team members to have experience with IPD and collaborative projects.

According to NASFA et al. (2010), public owners are often unable to share in the risk or the reward except if it was done under traditional collaborations. Owners may select one project and get special permission to apply some levels of IPD on that particular project. It is recommended to try IPD expeditiously rather than trying to change applicable rules, regulations, or legislation. NASFA et al. (2010) noted that both public and private owners are taking a more proactive approach in establishing integrated teams and ensuring that they receive the desired level of integration.

Darrington (2011) noted that DB has a longer track record than IPD and its use on public projects is growing at a significant rate; therefore, DB contracts could be a gateway to embracing IPD. Also, Ghassemi and Becerik-Gerber (2011) studied case studies in the public sector and concluded that contracts in the public sector utilized design-build with IPD principles. The transportation project sector is observing an increased usage of integrated project delivery methods. The DB approach has become one of the most popular alternatives (Gibson et al., 2008). 
Currently, the Federal Acquisition Regulation (FAR) does not permit the government to participate in IPD-related financial incentive techniques such as risk sharing, profit pooling, or contingency pooling. The FAR also does not allow for relational contracts or multiparty agreements and required competitive bidding for construction contracts with limited exceptions (Singleton and Hamzeh, 2011).

According to Aldrich (2011), IPD has been used in Europe for decades whereas most American designers have never played a part in IPD. Another challenge to IPD is the local government procurement laws in many states where the emphasis is on competitive bidding requirements. Aldrich discussed a method of suggesting a construction management firm to act as an owner's advocate to provide the constructability input during the design phase. This is in lieu of the contractor's participation in the design phase by each of the trades. The CMAR (construction manager at-risk) commits to deliver the project within a GMP and can then act as an advisor to the owner through the development and design phases of the project. However, without a contract in place that takes into account the IPD principles, an imbalance of power between the CM and the architect can be created (Aldrich, 2011).

\section{Water and Wastewater Related Projects}

The consulting firm AECOM used Building Information Modeling (BIM) to design a new water and wastewater treatment facility for the town of Davie Florida. AECOM utilized Autodesk BIM technology with the DB project to collaborate effectively among multiple architectural, engineering, and construction teams. BIM was 
helpful in producing a more comprehensive design, identifying design conflicts, and communicating what the project was going to resemble (Stitt, 2011).

According to Hoover (2013), waterworks projects are complex and have longterm durations, which lead them to collaborative delivery methods. The Water DesignBuild Council, www.waterdesignbuild.org, Washington, D.C., states that $70-80 \%$ of all water and wastewater projects are still traditional DBB-type contracts. Several successful water infrastructure projects have incorporated the concepts of collaboration and accountability through new technologies. Signs of change are already visible today and industry stakeholders are showing a tendency toward creative, non-traditional solutions (Hoover, 2013).

In an attempt to research delivery methods related to water and wastewater projects, the Water Design-Build Council (WDBC) was founded in 2006 to promote DB and CMAR best practices to facilitate relationships between owners and service providers. WDBC tries to use the DB and CMAR methods of project delivery to improve the nation's municipal water and wastewater systems development (WDBC, 2013).

\section{$\underline{\text { DB and IPD }}$}

The difference between IPD and DB is that IPD uses relational contract, and subcontractors and suppliers are contractually involved as project participants in the design phase (Kim and Dossick, 2011).

Darrington (2011) mentioned that not all owners are legally allowed or institutionally prepared to enter a three-party relational contract. Another option would be a DB contract format. A DB contract can be structured as a relational contract in order to 
more fully implement IPD. It can be structured as a transactional contract using a traditional DB form in which the supply chain chooses to implement Lean IPD principles without an owner mandate. Darrington (2011) discussed two major alternatives in using DB contracts to implement IPD: (1) a relational DB contract that allows for full implementation of IPD. It would look quite similar to a three-party relational contract. The major difference would be that contractual rights and lines of communication flow to and from the owner and the DB entity. However, other rights and obligations could still flow down to project team members through the design-builder. Many major features of the Integrated Form of Agreement (IFOA) could still be utilized in this two-party context. (2) A transactional DB contract (traditional contract) where IPD is implemented within the supply chain and not through the owner's mandate. Darrington (2011) believes that it is possible for a project team to largely implement IPD using a transactional DB contract and using many of the key elements of IPD such as early and intensive involvement of major trades in design, increased collaboration, implementing Lean methods, and optimizing the whole project.

Where project participants are implementing IPD under a traditional DB agreement, they may consider addressing the above points using contractual language in their joint venture agreement and/or agreements between the design-builder and the major design and trade partners. Such agreements could also include liability limits or waivers, or set aside an incentive fund (Darrington, 2011).

In a case study by Singleton and Hamzeh (2011) for Orlando Utilities Commission, the North Chiller Plant project studied was not a pure IPD project. The IPD team signed a relational contract wand bid the project as a design bid entity. The owner 
was not part of the relational contract agreement. The study shows that the project demonstrated that IPD can be highly beneficial even if the owner is not part of the relational contract agreement. Thomsen et. al. (2009) noted that an owner could choose to use a traditional approach, contracting with designers and builders independently but still use some of the aspects of IPD.

\section{$\underline{\text { How Risks and Rewards are Distributed in IPD }}$}

IPD, just as any other delivery method, has both risks and rewards. Carbasho (2008) stated that in relational contracts, potential savings would be shared among the IPD team. An incentive pool could be established strictly with money saved on contingency and/or labor costs. The IPD team may set up the incentive pool at the beginning and it will be placed at risk. The incentive pool is made up of the profits of the IPD contingency or a percentage of the profits for the IPD team (designers, contractors, and the major subcontractors). The pool is the maximum amount for which the parties are at risk. If the IPD team can make cost savings, the IPD team can increase its profits and the amount in the pool would get bigger. If any team member loses money or if any team member depletes the pool, the entire IPD team shares the losses. Teams do not go down as independent companies, and that is what establishes the integration (Carbasho, 2008).

In an IPD case study for Autodesk Inc. AEC Solutions Division Headquarters in Waltham, Massachusetts, it was noted that, in conceptual design, everyone should work at cost until all parties achieve a deep understanding of the project and a level of comfort around the program and budget. Contingency can create problems and could be eliminated. Because of the financial incentives in IPD, the IPD team would want to treat 
every change as a change of scope instead of an item to be subtracted from the contingency. This would create some sense of discomfort and unwelcome changes in behavior

In an IPD case study for Sutter Health Fairfield Medical Office Building Fairfield, California, it was noted that financial incentives should be flowing down to the subcontractors' level and would be critical to separate profit from fee. That way, as the team would continue to decrease the cost, and the actual return as a percent of revenue would increase.

In an IPD case study for Cardinal Glennon Children's Hospital Expansion in St. Louis, Missouri, it was noted that financial incentives were the key to the success of the IPD team. Financial incentives whether they are used to reward or punish are controversial. While some believe that financial incentives are essential to insure the alignment of goals for the benefit of the project, others consider these incentives to be in conflict of interest when they are based project cost and duration. From the lessons learned in this IPD case study, it was noted that owners are not ready to commit to taking responsibility equally with designer and contractor and taking some risk themselves. The owner has to be involved, the study concludes, for the IPD to be successful. The oldfashioned relationships lean more towards the idea of, "How can I shift that risk to the other two parties?" However, when a team is willing to take responsibility and perform as needed, the end result is that the risk goes down for everybody (AIA, 2010).

In a survey conducted by Kent and Becerik-Gerber (2010) on IPD projects, $45.8 \%$ of experienced respondents noted that they shared risk and reward based on value, which incentivizes the project team by offering a bonus linked to adding value to the project. 
Of the respondents, $25.2 \%$ selected "incentive pool," which reserves a portion of the project team's fee into a pool, and 17.8\% selected "performance bonus," which provides an award based on quality.

\section{Insurance}

With respect to insurance, umbrella project policies are most appropriate for IPD projects, but they are pricey policies. Because IPD is expected to have fewer number of claims among project participants, the insurance industry needs to provide affordable project policies for IPD projects which have inherently lower risk profile. In the IPD case study for Sutter Health Fairfield Medical Office Building, Fairfield, California, the owner, designer, and contractor agreed to indemnify each other and to carried standard general and professional insurance, at limits established in the IFOA. (AIA, 2010).

\section{$\underline{\text { Disputes }}$}

Many IPD projects use dispute resolution processes. If project stakeholders can't resolve the dispute, it may go to a group of senior executives from each of the disputants. Then disputes may escalate to a third-party neutral for investigation and recommendations, mediation or both. Then arbitration or litigation would be the forum of last resort to resolve the problems. Very few IPD projects make it to litigation between the parties. Many IPD projects provide constraints on the players' abilities to sue one another, which make the players focus more directly on meeting the owner's objectives rather than on protecting their balance sheets. (Thomsen et. al., 2009) In IPD case study for Sutter Health Fairfield Medical Office Building, Fairfield, California, there was not a "not to sue" agreement. Alternative dispute resolution was 
agreed to be used among the parties: first it starts with the Core Team, then relying on an expert third party for resolution, and last to mediation if needed. In IPD case study for Cardinal Glennon Children's Hospital Expansion in St. Louis, Missouri, there was not a "not to sue" phrase in the IFOA. Every team provided standard general and professional liability insurance (AIA, 2010). IPD requires an established mechanism and setting procedures for dealing effectively with problem solving and dispute resolution (Ghassemi and Becerik-Gerber, 2011).

\section{Building Information Modeling (BIM) and Integrated Project Delivery (IPD)}

The use of BIM is not necessarily required to adopt IPD. IPD indicates that full collaboration and participation of contractors, estimators, designers, and the owner in an ongoing information sharing process, can save time and increase the value of the project more than that possible under the traditional process. Also, sharing a BIM model promotes a continuous participation in the process by all parties (Lancaster and Tobi, 2010).

NASFA et al. noted that BIM facilitates the process by recording and sharing project information (NASFA et al., 2010). BIM is "a tool, not a project delivery method, but IPD process methods work hand-in-hand with BIM and leverage the tool's capabilities," as defined by AIA. The AIA's commentary does not regard IPD as a vehicle of BIM implementation (AIA, 2007). A BIM model improves the design, improves coordination, reveals construction problems, and helps the IPD team optimize both product and process (Thomsen et al., 2009). 


\section{Adopting New Approach}

Adopting a new approach to procure services for delivery of construction projects for any organization requires significant organizational changes, including significant modifications to both their work processes and existing organizational structures. Research at the Center for Construction Industry Studies is investigating the adoption of integrated project delivery methods within the transportation project sector to better understand the dynamics of this change (Gibson et al., 2008).

In order to implement IPD, owners need to get their organization ready once they decide that IPD is the desired direction for a change. Selling the concept of IPD to facility managers, legal staff, and purchasing departments may be a huge challenge (NASFA et al., 2010).

Ghassemi and Becerik-Gerber (2011) indicated through case studies that some owners established a continuous IPD learning plan for training purposes by using internal and external resources. Training was conducted to ensure that all team members were comfortable with the methodology and with their commitment to the project. The authors stated that project participants needed to build confidence in each other in order to overcome the cultural barriers. The case studies by the authors demonstrated that trust is either preexisting or forced. Achieving successful transitioning to IPD is crucial. A successful transition requires companies to have the procurement ability and to be inherently structured to implement IPD.

The current traditional project organization is structured such that operational silos exist between design, procurement, construction, and ownership, creating a barrier to collaboration. This is the case because each participant works for its own interest, 
rather than that of the overall project, and project information remains in individual silos and does not effectively cross boundaries (CURT, 2004).

\section{Project Performance Rating (PPR)}

Success factors of a construction project are a number of conditions and parameters that if fully satisfied can lead to the successful completion of the project. Chan et al. (2001) identified a set of critical success factors in design and build construction projects and examined the relative importance of each of these factors on project outcome. Examined factors included: client capability for managing the project, understanding of end users' needs, prequalification of tenderers, satisfaction of financial return from the projects, acceptance of risk and legal liability, and adequacy of channel of communication. Such factors were overly narrow in scope and not as encompassing as IPD. Odeh and Battaineh (2002) examined the factors necessary for a project to be completed on time and concluded that labor productivity, adequate contractor experience, and absence of owner interference were among the most important factors. Other studies focused on predicting the performance of DB and DBB projects using multivariate regression analysis. Gross floor area and the contractor's design capability are two factors used to predict the delivery speed of DBB projects. (Ling et al. 2004).

Previous research attempted to develop models and frameworks to quantify project success at three different levels: (1) construction industry, (2) company, and (3) project (Elyamany et al., 2007). Yang et al. (2010) summarized the major frameworks for performance measurement in the construction industry at the organizational and project level. They included the European Foundation for Quality Management (EFQM) 
excellence model, Balanced Scorecard (BSC) model, and Key Performance Indicator (KPI) model. According to Yang et al. (2010), further studies are needed for each framework presented in their study to establish a more comprehensive and applicable performance measurement method. Several studies proposed methodologies to assess the performance of construction companies (Elyamany et al., 2007 and Yu et al., 2007). Kangari et al. (1992) developed a model using multiple linear regression analysis to analyze the financial performance of construction companies. The model determines a performance grade, $\mathrm{G}$, which is defined as the percentage of construction companies that have performance measures lower than that of the company under consideration.

On the project level, various studies developed lists of criteria that can be used to evaluate the performance of construction projects in general or based on delivery methods. For example, Cha and Kim (2011) developed a system for measuring the performance indicators for building construction projects and suggested a new quantification method on three levels: performance category, performance indicator, and performance score. A survey, in which construction experts in project assessments participated, was used to weigh the performance categories and examine the measurability and representativeness of the indicators. The performance score value was based on the probability of a normalized performance level. The amount of data collected through surveys was, however, not sufficient to generalize the findings. The study therefore could only suggest a performance score calculation process to quantify the project performance. Alarcon and Ashley (1996) presented a methodology for the evaluation of project performance based on construction experts' knowledge and experience, decision analysis, and cross-impact analysis. The study presented a 
conceptual general performance structure that combines concepts to perform probabilistic inference that measures cost, schedule, value, and effectiveness. The many assumptions used in the study limit the validity of assessments made for the model.

Lam et al. (2007) developed a project success index for benchmarking the performance of DB projects based on 92 survey responses of the Hong Kong construction industry. The performance measures are in terms of time, cost, quality, and functionality. Liu et al. (2015) developed a conceptual model that can be used to monitor and improve the performance of public-private partnerships while the project is still under construction. The model's five measurement facets are: (1) Stakeholder satisfaction, (2) Strategies, (3) Processes, (4) Capabilities, and (5) Stakeholder Contribution. However, no validation of the model was conducted in the study for the developed framework.

National Aeronautics and Space Administration (NASA) utilizes an award fee contracting guide for their award fee contracts, which contains clearly defined performance requirements. The factors evaluated by NASA are: Technical Performance, Project Management, and Cost Control (O’Toole, 2001). Mohamed (2003) examined the relationships between risk and success factors and the performance of international construction joint ventures.

Kim et al., (2009) presented a model of 64 variables that predicted the performance of an overseas project by utilizing structural equation modeling (SEM), which combines multiple regression analysis, confirmatory factor analysis, and path analysis. The performance categories were: (1) condition of host country and project owner, (2) bidding process, (3) project characteristics and contractual conditions, (4) characteristics of organization and participants, and (5) contractor's ability. Other studies developed a 
system for measuring the performance in construction projects at the process level (Haponava and Al-Jibouri, 2012). The proposed system was, however, not designed to produce accurate performance measurements that would provide management with guidelines on how to monitor performance by focusing on critical issues.

Generally, it is not sufficient to deem that a given project is successful assuming it is completed on time and within budget. Hanna et al. (2014) used the rating method of the quarterback position on American football teams, which combines key sports metrics to compare quarterbacks' performances, as an approach to assess the performance of construction projects. In comparing IPD and non-IPD projects, El Asmar and Hanna (2016) used a project quarterback rating model to combine seven performance areas, into one comparable score for each project. These seven areas are: (1) customer relations, (2) safety, (3) schedule, (4) cost, (5) quality, (6) profit, and (7) communication. A survey was used to collect project performance data from industry participants, with various delivery systems and mostly related to private sector projects. More recently, Francom et al. (2016) used pipeline construction projects to develop a baseline of performance metrics and compared the cost and schedule performance metrics of construction manager at risk to the DBB delivery method.

Table 2-1 presents a comparison of existing models showing their main advantages and main criticisms.

Table 2-1: Comparison of Existing Performance Models

\begin{tabular}{|l|l|l|l|}
\hline Model & Reference & Main Advantages & \multicolumn{1}{c|}{ Main Criticisms } \\
\hline $\begin{array}{l}\text { Performance } \\
\text { Measurement of } \\
\begin{array}{l}\text { Public Private } \\
\text { Partnerships }\end{array}\end{array}$ & $\begin{array}{l}\text { Liu, J. et al. } \\
\text { (2015) }\end{array}$ & $\begin{array}{l}\text { - Provides specific } \\
\text { performance rating } \\
\text { for public private } \\
\text { partnerships }\end{array}$ & $\begin{array}{l}\text { - Conceptual framework } \\
\text { - Framework was not } \\
\text { tested or validated }\end{array}$ \\
\hline
\end{tabular}




\begin{tabular}{|c|c|c|c|}
\hline & & $\begin{array}{l}\text { - Monitors dynamic } \\
\text { lifecycle for } \\
\text { different phases of } \\
\text { project }\end{array}$ & $\begin{array}{l}\text { - Framework was not } \\
\text { implemented on case } \\
\text { studies; authors suggest } \\
\text { using case studies for } \\
\text { future research } \\
\text { - Lack of practicability of } \\
\text { the framework } \\
\text { - Lack of mathematical } \\
\text { formulation to measure } \\
\text { the performance } \\
\text { - No projects dataset was } \\
\text { used in the framework } \\
\text { - Difficult and time } \\
\text { consuming to } \\
\text { implement in large } \\
\text { projects }\end{array}$ \\
\hline $\begin{array}{l}\text { Quantitative } \\
\text { Approach for } \\
\text { Project } \\
\text { Performance } \\
\text { Measurement }\end{array}$ & $\begin{array}{l}\text { Cha, H.S. and } \\
\text { Kim, C.K. } \\
\text { (2011) }\end{array}$ & $\begin{array}{l}\text { - Covers several } \\
\text { performance areas } \\
\text { - Used a survey } \\
\text { with experts to } \\
\text { validate the model } \\
\text { structure } \\
\text { - Provides a tool to } \\
\text { benchmark project } \\
\text { performance }\end{array}$ & $\begin{array}{l}\text { - According to the } \\
\text { authors, the data used is } \\
\text { cross-sectional and data } \\
\text { collection was not } \\
\text { extensive } \\
\text { - No significance to the } \\
\text { model result score. The } \\
\text { score is only useful to } \\
\text { be compared among } \\
\text { different projects } \\
\text { - Strong relationship } \\
\text { exists between the } \\
\text { model categories, which } \\
\text { may significantly } \\
\text { influence the outcome } \\
\text { - The model is not very } \\
\text { useful in the industry as } \\
\text { it does not cover a } \\
\text { specific target project, } \\
\text { such as commercial, } \\
\text { residential, industrial, } \\
\text { etc. } \\
\text { A survey with experts } \\
\text { was used to weigh the } \\
\text { performance categories } \\
\text { and examine the } \\
\text { measurability and } \\
\text { representativeness of }\end{array}$ \\
\hline
\end{tabular}




\begin{tabular}{|c|c|c|c|}
\hline & & & $\begin{array}{l}\text { the indicators leaving } \\
\text { no flexibility for the } \\
\text { end users. } \\
\text { - Some KPI measurement } \\
\text { cannot be calculated } \\
\text { practically. } \\
\text { - The model was not } \\
\text { tested or validated. }\end{array}$ \\
\hline $\begin{array}{l}\text { Modeling } \\
\text { Project } \\
\text { Performance for } \\
\text { Decision } \\
\text { Making }\end{array}$ & $\begin{array}{l}\text { Alarcon, L. } \\
\text { and Ashley, D. } \\
(1996)\end{array}$ & $\begin{array}{l}\text { Measures cost, } \\
\text { schedule, value, } \\
\text { and effectiveness } \\
\text { - Shows relationship } \\
\text { between the } \\
\text { different indicators }\end{array}$ & $\begin{array}{l}\text { - Conceptual general } \\
\text { performance model } \\
\text { - Model is based on } \\
\text { assumptions used by } \\
\text { experts } \\
\text { - Limit of validity of } \\
\text { model due to expert } \\
\text { assumptions } \\
\text { - Complicated and } \\
\text { difficult in terms of } \\
\text { implementation and } \\
\text { assessing indicators } \\
\text { - Vague in the area of } \\
\text { scoring mechanism and } \\
\text { strategies }\end{array}$ \\
\hline $\begin{array}{l}\text { Award Fee } \\
\text { Contracting } \\
\text { Guide }\end{array}$ & $\begin{array}{l}\text { O'Toole, T. } \\
(2001)\end{array}$ & $\begin{array}{l}\text { - Provides specific } \\
\text { performance rating } \\
\text { for NASA projects } \\
\text { - Measures cost, } \\
\text { schedule, quality, } \\
\text { and project } \\
\text { management } \\
\text { factors } \\
\text { - Calculates a single } \\
\text { score to compare } \\
\text { with previous } \\
\text { projects }\end{array}$ & $\begin{array}{l}\text { - Only the framework of } \\
\text { the model was } \\
\text { presented } \\
\text { - Does not include } \\
\text { detailed data analysis } \\
\text { showing normalization } \\
\text { or other statistical } \\
\text { analysis } \\
\text { - Validation was not } \\
\text { discussed in the paper }\end{array}$ \\
\hline
\end{tabular}




\begin{tabular}{|c|c|c|c|}
\hline $\begin{array}{l}\text { Summary of } \\
\text { major } \\
\text { frameworks for } \\
\text { performance } \\
\text { measurement }\end{array}$ & $\begin{array}{l}\text { Yang et al. } \\
\text { (2010) }\end{array}$ & $\begin{array}{l}\text { - They included } \\
\text { European } \\
\text { Foundation for } \\
\text { Quality } \\
\text { Management } \\
\text { (EFQM) and Key } \\
\text { Performance } \\
\text { Indicator (KPIs) } \\
\text { model. } \\
\text { - Performance at the } \\
\text { organizational and } \\
\text { project level }\end{array}$ & $\begin{array}{l}\text { Further studies are } \\
\text { needed for each } \\
\text { framework presented in } \\
\text { their study to establish a } \\
\text { more comprehensive } \\
\text { and applicable } \\
\text { performance }\end{array}$ \\
\hline $\begin{array}{l}\text { Measuring the } \\
\text { performance in } \\
\text { construction } \\
\text { projects at the } \\
\text { process level }\end{array}$ & $\begin{array}{l}\text { Haponava and } \\
\text { Al-Jibouri, } \\
2012\end{array}$ & $\begin{array}{l}\text { Provides } \\
\text { management with } \\
\text { guidelines on how } \\
\text { to monitor } \\
\text { performance by } \\
\text { focusing on } \\
\text { critical issues }\end{array}$ & $\begin{array}{l}\text { A proposed system that } \\
\text { needs to be further } \\
\text { developed. } \\
\text { - Not designed to } \\
\text { produce accurate } \\
\text { performance } \\
\text { measurements }\end{array}$ \\
\hline
\end{tabular}

\section{$\underline{\text { Model Validation }}$}

A review of model validation literature shows that there are no established definitions of model validity and validation or basic established validity tools. The validation process of a model ultimately entails the validity of its purpose too (Barlas, 1996).

According to Barlas (1996), models can be classified in two types:

1- Correlational (purely data driven). If the model's results match the expected output within a predefined range of accuracy, then the model is considered to be valid. This type of output validation is referred to as a classical statistical testing problem. 
2- Causal Descriptive (theory driven). These models are focused on how real systems actually operate in some aspects. In this case, what is critical is the validity of the internal structure of the model and not the output behavior.

Validation of causal descriptive models is much more complicated than that of correlational models because formal tests are not established, such as statistical hypothesis tests, to be used in comparing the structure of a proposed model to the "real" structure. There are two types of validations: structure validation and behavior validation. The typical order of validation is to first test the validity of the structure, and then to test the behavior accuracy.

Structure validation assesses the validity of the model structure, by comparing the model structure or the model equations with generalized knowledge about the real system. The information needed for structure validation is highly qualitative in nature. Most methods that are suggested for structure validation are informal such as specialist reviews, assessments, walkthroughs, data flow analyses, reliability checking, etc.

The second general category of validation is behavior tests, which assess the validity by applying certain behavior tests on model-generated behavior patterns. These tests involve simulation and can help the modeler uncover potential structural defects. Modified-behavior prediction can only be accomplished if data about the behavior of a modified version of the real system is available. The test consists of comparing the "expected" behavior under specific test conditions with actual simulation results. The model passes the test if the experiments show that both results are statistically similar (Barlas, 1996). 


\section{Focus Groups}

\section{Introduction}

A focus group, also called a group depth interview or a focused interview, is an established method that involves collecting data through a dynamic and interactive group discussion led by a moderator (Leung and Chan, 2012). A focus group targets to obtain perceptions, feelings, and experiences, on specific topics in a certain environment or the area of interest (Leung et al., 2014).

The focus group technique has become the subject of many methodological discussions and it is now considered a very innovative research method. Focus groups have two main goals: (1) to create interaction among participants, and (2) to maximize the collection of high-quality information in a short time frame. Well-run focus groups reveal issues and provide richer sources of information than personal interviews or surveys (Acocella, 2011).

The focus group method is normally chosen as the method of research for the following reasons (El-Gohary and El-Diraby, 2010):

1- It is a fast and cost-effective method for obtaining the required information,

2- It can collect information that is difficult to capture with other research methods,

3- It explores the reasons behind what participants think, and

4- It facilitates targeting a particular type of participants with a predefined selection criterion.

\section{Format of Focus Groups}

There are three types of focus groups: exploratory, confirmatory, or a combination of both (University of Wisconsin-Madison, 1999). 


\section{Exploratory focus groups:}

- Explore how a group identifies a problem,

- Help in brainstorming for potential solutions,

- Identify areas of further investigation or action,

- Help design surveys for wide distribution,

- Help interpret unclear information, and

- Tend to use open-ended questions.

\section{Confirmatory focus groups:}

- Evaluate solutions already enacted,

- Assess opinions on proposed efforts,

- Confirm and expand results from a survey or other data collected, and

- Tend to use closed-ended questions.

Groups are guided by the researcher who is referred to as a moderator or

facilitator. The moderator serves as a conversational catalyst to monitor the exchange of views and ideas among participants (Hutt, 1979). The main roles of the moderator are to clearly state the purpose and the expectations of the group, facilitate interaction by outlining the topics to be discussed, control the direction of the conversation, promote open debate by using open-ended questions, probe deeper into the subject, and ensure that the conversation does not drift but stays focused on the key topics of interest (Blackburn, 2000; Gibbs, 1997).

The moderator will launch a discussion topic and allow the participants to interact freely, rather than asking questions to each participant. The moderator will also 
encourage a group discussion rather than a group interview by avoiding asking questions related to attitudes, motivations, or individual experiences (Acocella, 2012). Question development is a major step in preparing for the focus group interview. Questions should be formed in a way that encourages participants to respond and that helps the moderator collect the information needed from the group. Questions are conversational, natural, short, open-ended, and include one question at a time.

The average number of questions in focus groups is four or five. The number of questions depends on how time consuming each topic is estimated to be. Questions should be generated ahead of time and aligned with the purpose identified for the focus group. Types of questions include (Krueger and Casey, 2008):

1- Behavior: what participants do or have done, 2- Knowledge: what participants know based on experience, and 3- Opinions and feelings: what participants think or feel. The typical duration of a focus group can be one to two hours (Gibbs, 1997). Full information on the purpose and objectives of the study will be given to the participants beforehand (Gibbs, 1997). For collecting reliable qualitative data, the focus group session will be audio taped and immediate note taking will be used in the discussion. (Blackburn, 2000; Ouimet, et al. 2004). The confidentiality of the participants will be ensured by not identifying individuals in any publications (Blackburn, 2000).

The moderator encourages the participants to freely express both positive and negative opinions. In addition, the moderator will be seated as one of the group members whether in a circular seating pattern or in a conference table pattern. This enhances 
group environment and promotes informality, which is a prerequisite for an effective focus group. The moderator will mention that conflicts of opinion are normal in focus groups (Hutt, 1979).

\section{Future Research as Recommended by Other Researchers}

Singleton and Hamzeh (2011) discussed the creation of a step-by-step process for executing IPD techniques. They defined a process checklist, which could be used to manage IPD implementation to standardize the process and ensure that IPD techniques are receiving the required level of attention. Further research should be conducted to verify if IPD techniques affect the workload of employees. The author also mentioned that further research exists in the area of public sector IPD.

Ilozor and Kelly (2012) noted that some critical future research ideas need to be investigated as "the concept of one virtual database versus linked information; coordination with sustainable design; rethinking of IPD as a method to promote BIM; educational ramifications, and management issues throughout the life cycle of the project." They also recommended that further study is needed to better understand the relationship between IPD adoption and project performance such as rate of return, cost, schedule, and safety measures. More research utilizing quantitative methods applied to actual project data is required to properly measure and evaluate the effect of both technologies on the industry.

Ilozor and Kelly (2012) also noted that the literature is very optimistic with respect to the positive potential of BIM and/or IPD. Several research problems arising from the deficiencies identified are as follows: 
1- The effect IPD adoption on labor productivity,

2- The effect of IPD adoption on the frequency of lost time accidents,

3- The relationship between IPD adoption and construction cost, and

4- The effect of IPD adoption on contractor profits.

\section{Distinguishing Characteristics of Water and Wastewater Projects}

\section{Large Variety in Size, Scope, and Cost}

There is a wide range in the variety of water and wastewater projects, and they are characterized by having both horizontal and vertical types of projects. These projects have a wide range of costs where megaprojects can be worth hundreds of millions of dollars. The construction might consist of maintenance and rehabilitation of existing treatment facilities, expansion of existing treatment facilities, or new treatment facilities.

\section{High Level Security}

Security consideration is another important characteristic of water and wastewater projects. Water and wastewater treatment facilities contain chemicals such as chlorine gas, which is highly toxic and deadly in case of a chlorine gas leak. Water treatment facilities are highly secured to avoid attempts of water contaminations, which will affect the population receiving that water. Construction activities occurring in the secured zones are time consuming and their cost is 15 to $25 \%$ more than the cost of similar construction in non-secured area (Adrem et. al., 2006). Workers must obtain special security badges to enter the plant. This requires specific training in case of a chlorine leak and completion of a security clearance process, which is time consuming. Every day, the workers are required to enter the secured site via static security checkpoints. All of these 
issues reduce the daily production rate of construction, adding time and money to the project.

\section{Construction during Facility Operation}

Water and wastewater projects are usually executed while facility operations are ongoing. Because of this, it is important to manage design and construction in a way that minimizes impact on the plant operations. For example, shutdowns of existing facilities for tie-in purposes occur during low flow rates incoming to the wastewater facilities. This forces some of the construction to occur at night. In large projects, a multi-phased scheduling approach is adopted that divides the project into phases to minimize the interference with the plant operation.

\section{Complexity of Water and Wastewater Projects}

Water and wastewater projects are often complex with special systems. Some of these systems include very large pumps and pipes, tunnels, sophisticated equipment that is not typically used anywhere else such as belt presses, reverse osmosis membranes, and sophisticated electrical and data systems. In addition to water, treatment facilities include chemicals and gasses such as methane, chlorine, sodium hypochlorite, oxygen, etc. Also, water and wastewater treatment facilities usually add or remove structures in existing facilities instead of building new facilities. These projects require increased coordination for ensuring that new structures are designed to be compatible with existing structures in terms of architecture, quality, and material. The goal is to integrate the new and old structures within the facility in an effective way. 


\section{Public Projects Funding and Legality of Delivery Methods}

Water and wastewater treatment plant financing comes from federal assistance, state assistance, bond sales, and water and wastewater treatment plant cash and revenue funding. Using any of these funds imposes regulations like competitive pricing of construction facilities and includes Disadvantaged Business Enterprise (DBE) firms. DBB has been traditionally used all over the United States, and all state codes give authority to apply DBB in public projects. Alternative delivery methods do not have this clear statutory support. Other states have imposed limitations on the application of alternative delivery systems. 


\section{CHAPTER 3}

\section{AIM, OBJECTIVES AND SIGNIFICANCE OF RESEARCH}

A variety of project delivery methods are available to the developers of public projects in the United States. Design-Bid-Build (DBB) is the most prevalent delivery method for construction projects in the United States' construction industry and specifically in water and wastewater projects. While the traditional DBB remains the most commonly used delivery method, there is significant interest on water utility owners in alternative delivery methods, for saving money and time.

The aim of this research is to develop a new model for rating the performance of water utilities major capital projects delivered using a project delivery method that combines Integrated Project Delivery (IPD) and Design-Bid-Build (DBB) and to find what correlation exists between the implemented IPD principles and the Key Performance Indicators (KPIs) of these projects.

The project delivery method is the process by which the contractual responsibilities for designing and constructing a construction project are comprehensively identified for an owner including all the contractual relations, roles, and responsibilities of the entities involved in a project and assigning the contractual responsibilities for designing and constructing a project.

Hence, the various project delivery methods are perceived by the way the contracts among the owner, the engineer, and the contractor are formed and the technical relationships among the groups within those contracts. With the fast improvements in construction services in the private sector, public owners are acquiring unconventional project delivery methods such as CMAR, DB, IPD, and other hybrid systems. 
In order to achieve the aim of this research as mentioned above, a series of objectives are set forth as intermediate steps necessary to attain the desired aim.

The first objective of this research is to identify KPIs that measure, directly or indirectly, the success of a construction project. The KPIs of success of a project delivery method are identified in parameters for benchmarking projects in order to achieve and compare a good performance.

The second objective is to collect data from various water utility owners to gather related information on the KPIs of the construction projects of their respective facilities that were delivered using DBB. This objective is key to assessing current and traditional delivery methods. The collected data is evaluated and used for benchmarking the KPIs.

The third objective is to identify which aspects of IPD can be used and implemented in treatment plants, and which of these can be implemented in this research. Due to regulations and limitations of public projects, not all IPD principles can be integrated in the delivery of public projects. Therefore, selective principles and practices that can be integrated with DBB need to be identified in this step.

The fourth objective is to implement the full range of IPD principles in control projects and measure the KPIs identified per the first objective.

The fifth objective is to compare the results obtained from measured KPIs of the control projects obtained in Objective 4 with the KPIs of past projects obtained from Objective 2. This comparison will form the basis for measuring any improvement in the delivery of treatment plants through the implementation of IPD principles in the fourth objective. This will in turn validate the aim of assessing the performance of projects that 
integrate certain aspects of IPD with DBB principles in the delivery of such projects. This methodology approach is illustrated visually in the flowchart shown in Figure 3-1.

The sixth objective is to develop a project performance rating model that can combine the performance factors $(\mathrm{PF})$ of a project into a single number, rating, or index which represents the performance of a given project and that owners can use to realize the benefits of implementing various IPD principles.

The seventh objective is to utilize regression analysis and a focus group on the collected and measured data to determine what correlation exists between the implemented IPD principles and the KPIs of these projects and to develop a guideline metric for owners to predict how implementation of certain IPD principles can impact various project KPIs.

The significance of this research lies in the ability of this new model to rate the performance of treatment plants' major capital projects delivered using a combination of IPD and DBB approach to help owners of treatment plants get a detailed look into critical problem areas that are likely to impact performance rating and in promoting better performances for future projects through lower costs, fewer Change Orders (COs), shorter schedules, fewer Request for Information (RFIs), fewer error and omission COs, fewer construction claims, faster response time to RFIs, less field rework and fewer owner requested COs, performance factors to the success of a construction project. Correlation between the implemented IPD principles and the KPIs of these projects can significantly help utility owners who are aiming to predict how implementation of certain IPD principles can impact various project KPIs. 


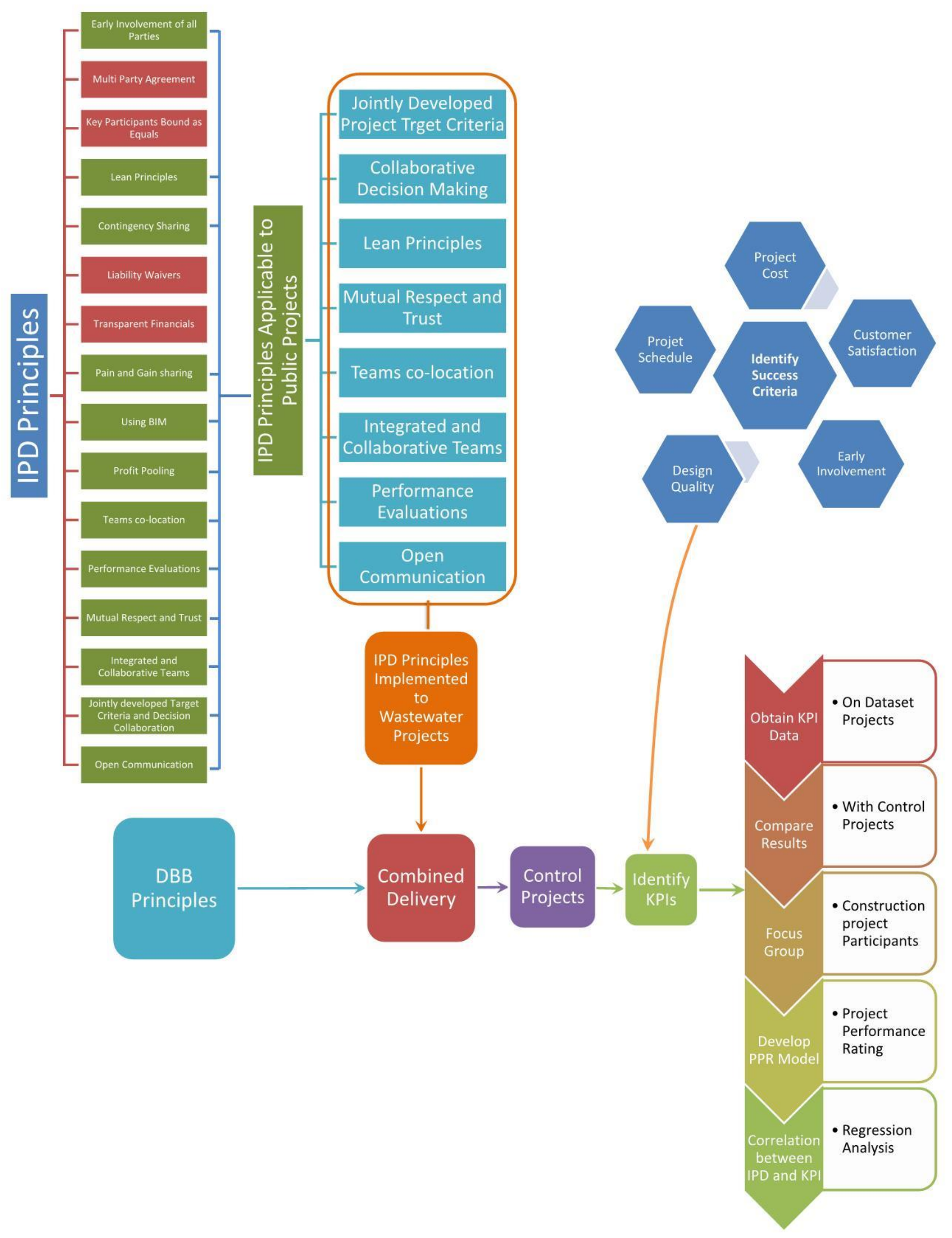

Figure 3-1: Research objectives. 


\section{CHAPTER 4}

\section{RESEARCH METHODOLOGY}

Design-Bid-Build (DBB) is the traditional project delivery method. In DBB the owner has the opportunity to cancel the project or alter the design and scope. Also, the owner can check the maintainability of the finished design and can ensure the quality of the design of the end product before awarding the project. This is very critical in treatment plant projects due to the nature of complexity of these projects and due to the high level of details involved and required. These include and are not limited to the various types of material to be used, the various equipment selection and brands, the owner's preference to use a certain supplier or manufacturer, the satisfaction of regulatory agencies provisions, etc.

DBB gives the owner the most control over the project, which is a great advantage for treatment plants. Furthermore, the researcher's field experience in treatment plants with different delivery methods applied shows that DBB is the most promising while providing the most satisfaction to the owners. The researcher's discussions with water and wastewater owners, engineers, and contractors also show the preference of DBB over other delivery methods. However, some improvements are needed for the KPIs of DBB, and IPD has the most promising aspects to improve these KPIs.

The approach, therefore, is to integrate the key principles of DBB and IPD project delivery methods and measure the performance of DBB project delivery method for treatment plants projects. The study implemented this integration by applying a full array 
of IPD principles to control projects that were being constructed through a DBB delivery method. The data from these KPIs obtained by implementing this integrated approach was then compared to the same KPI's data from similar size projects in which the traditional DBB delivery method was used.

A Project Performance Rating (PPR) Model is developed to combine the key performance factors of a project into one performance index for water and wastewater construction projects and to gauge the overall project performance. Regression analysis and a focus group were then utilized to determine the effect of each implemented IPD principle on various project KPIs. A guideline metric is developed that can significantly help utility owners aiming to predict how implementation of certain IPD principles can impact various project KPIs. An overall research methodology chart is shown in Figure $4-1$. 


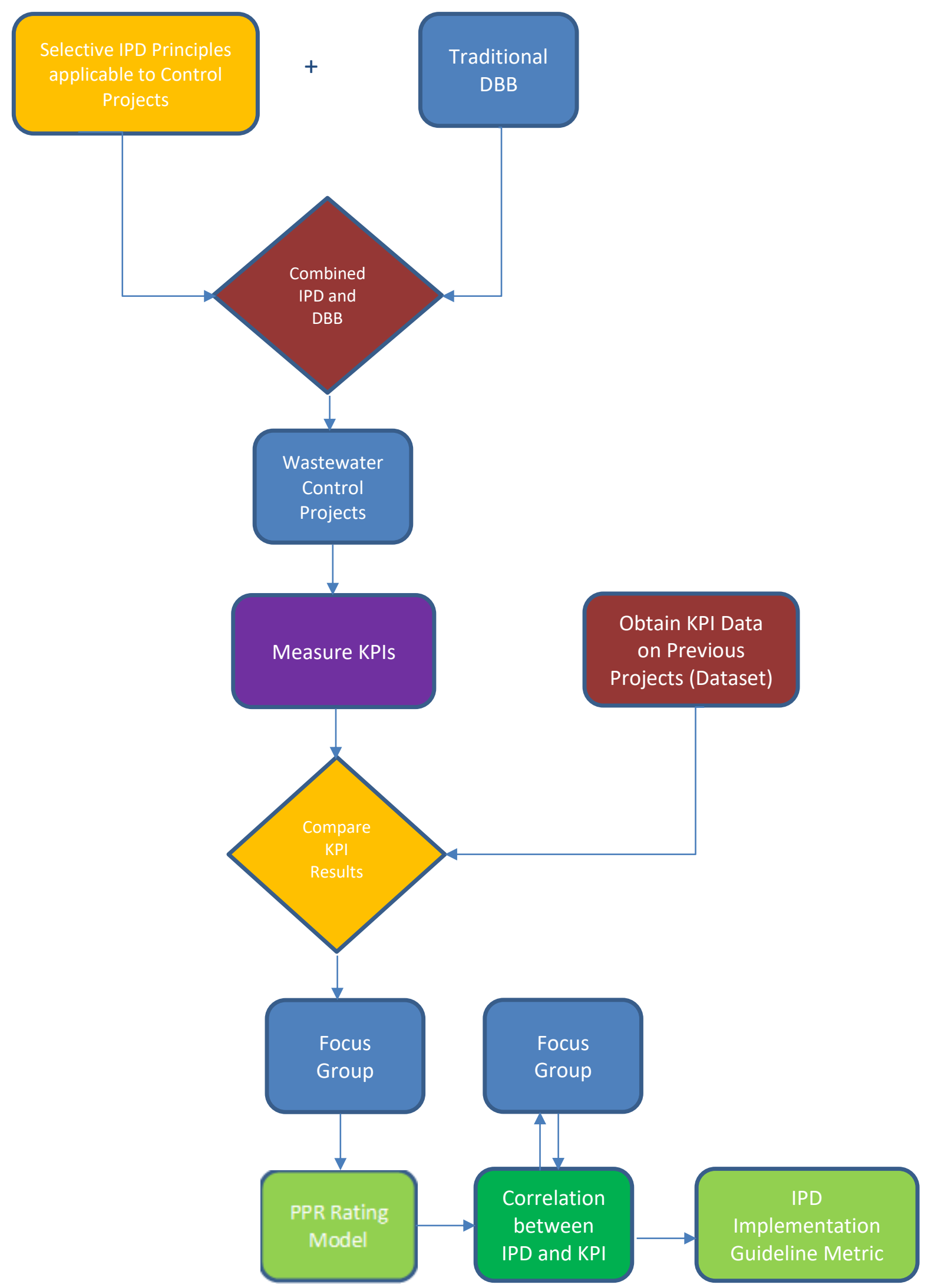

Figure 4-1: Overall research methodology. 


\section{Identifying Key Performance Indicators (KPIs)}

The KPIs of a successful project delivery method are identified as parameters to benchmark projects for performance comparison. These indicators provide objective framework criteria that are quantifiable and measurable. In order to eliminate any bias resulting from the project size, KPIs were normalized by the total project cost. The parameters used in this research consist of nine performance indicators, listed below and described briefly in the following sections.

- Cost Overrun as a Percentage of the Total Project Award Price,

- Change Order Cost as a Percentage of Total Project Cost,

- Time Overrun as a Percentage of the Original Project Schedule,

- Number of RFIs per Unit Price,

- Error and Omissions Change Orders Cost as a Percentage of Total Cost of Change Orders,

- Total Claims Cost as a Percentage of the Total Project Cost,

- RFI Response Time per Project Cost,

- Cost of Field Rework as a Percentage of Total Project Cost, and

- Owner Requested Change Orders Cost as a Percentage of Total Cost of COs.

\section{Cost Overrun as a Percentage of the Total Project Award Price}

A cost overrun involves unexpected costs incurred in excess of the contract amounts. Value engineering has the ability to control and adjust the project contract costs and cost reductions. The main consideration when evaluating project cost is the measurement of the contractor's performance against the bid cost of the contract. Cost 
overrun is relatively easy to track because project teams keep useful records of several cost items for different project phases. Cost overrun amount presented in this study as a KPI is calculated as a percentage of total project cost in order to normalize the cost overrun amount based on the project cost. This will eliminate any bias in the comparison due to project size.

\section{Change Order Cost as a Percentage of Total Project Cost}

A change order is work that is added to or deleted from the original scope of work of a contract. COs may alter the original contract amount and/or the completion date of the projects. AIA (2007) defines contingency as a predetermined amount or percentage of the contract held in a separate account to financially prepare owners for addressing changes within the project. Contingency not managed properly during construction can result in cost overruns and unnecessary losses.

Common causes for change orders are: 1) design errors and/or omissions, 2) unforeseen conditions that are realized on site during construction, and 3) owner's request substitutions or changes. However, most common causes for change orders can lead to legal issues, disputes and arbitration. A project with a large number of COs indicates design negligence, lack of pre-construction coordination, lack of owner's involvement during design, or lack of collaboration among the parties during construction.

\section{Time Overrun as a Percentage of the Original Project Schedule:}

Construction project delay is when a project is completed later than the planned duration of execution to which all the concerned parties agreed. Project delay is an issue commonly faced on construction projects. These delays can be costly to all parties 
concerned in the project, and can often result in cost overrun and claims. The main factors affecting the duration of a construction project are the involvement and performance of parties, contractual relations, design errors and omissions, environmental and site conditions, resources availability, and others. On-time completion of a project is an indicator of many successful aspects of the project delivery, such as efficiency, proper project management, and good contract management. Therefore, a project completed on or ahead of its scheduled completion date is a good indicator of efficient involvement and performance of parties, good contractual relations, adequate design, and sufficient resources availability.

\section{Number of RFIs per Unit Price}

The RFI process is one in which contractors and subcontractors formally request clarification of information regarding the contract documents supplied. This process is very common but inefficient due to the non-value-added delays, which occur in obtaining the necessary information. In DBB, the design and contract documents provided for construction projects are expected to be complete, precise, and unambiguous. Unfortunately, this is rarely the case, and quite often contractors are supplied with contract documents that are incomplete, conflicting, or erroneous, thereby requiring revisions and clarifications to be provided by the designers.

A project with a high number of RFIs indicates low quality of the design and construction documents. Such low-quality construction documents are a symptom of lowquality assurance (QA) and quality control (QC) on part of the design team, and lack of coordination among the project participants. 


\section{Error and Omissions Change Orders Cost as a Percentage of Total Cost of Change}

\section{$\underline{\text { Orders }}$}

Errors and omissions are common during the design process due to the unique nature of human beings. A design error is an instruction in the plans and specifications that, if followed by the contractor, will require replacement or correction, or it could result in a construction failure. On the other hand, an omission occurs when the plans and or the specifications are missing a detail or a description that is needed to complete a certain activity.

\section{$\underline{\text { Total Claims Cost as a Percentage of the Total Project Cost }}$}

Construction claims are common in construction projects and can typically arise from many root causes related to schedule and cost overruns. Disputes often arise between contractors and owners based on project performance of involved parties, scope discrepancies, and quality of work performed and materials delivered. Therefore, the number and nature of construction claims is a KPI that provides insight into the team's relationships and their ability to resolve disputes before escalating to claims. A high number of claims on a project reflects poor working relationships between involved parties, lack of a team approach to project gains and losses, and disintegration of communication lines.

\section{$\underline{\text { RFI Response Time per Project Cost }}$}

Delays in response to RFIs cause adverse impact on project productivity. Project participants shall follow RFI tracking and monitoring systems to efficiently manage the 
RFIs, maximize control of the RFI process, and mitigate the potential for negative impacts arising from the delay in responding to the submitted RFIs.

\section{Cost of Field Rework as a Percentage of Total Project Cost}

Unsurprisingly, defects are one of the major causes of disputes and construction litigation. The Construction Industry Institute (2001), defined rework as: "activities in the field that have to be done more than once in the field or activities that remove work previously installed as part of the project". Field rework could be as a result of the following four components:

1- A design that fails to meet the Professional Standards;

2- The failure of the contractor to execute the work in accordance with the plans and specifications;

3- The failure of the contractor to execute the work in accordance with the acceptable standards of workmanship in the construction industry; and/or

4- The improper installation of systems, equipment, or materials that are of a lesser quality than required by the plans and specifications.

A high number of construction defects indicates that the project delivery method may suffer from inadequate project supervision on the part of the general contractor, inadequate design specifications, lack of proper inspection by the designer, and others.

\section{Owner Requested Change Orders Cost as a Percentage of Total Cost of COs}

Change orders can lead to legal issues, disputes, and arbitration. A project with a large number of owner requested COs indicates lack of pre-construction coordination with the owner and lack of owner's involvement during design. 


\section{Collection of Project Data}

For this study several water utility facilities and consultants in South Florida were contacted to obtain data on completed projects delivered via a DBB project delivery method. The data collected measured the KPIs of these projects, in an effort to compare their performance to that of the control projects where IPD principles are combined with DBB delivery method in the water and wastewater industry.

\section{Identification of IPD Principles that can be Used and Implemented in Public Treatment Plant Projects}

This study applied certain IPD principles that are applicable to public projects in the water and wastewater field and measured the performance of the projects in terms of the five success criteria.

As discussed in Chapter 2, Literature Review, there is no agreement in the literature on a single set of project delivery practices that comprise the IPD principles. For example, some researchers considered BIM as an IPD principle while others consider BIM as a practice that only facilitates the IPD process by recording and sharing project information and helping the IPD team optimize both product and process (Thomsen et al., 2009, NASFA et al., 2010). While the AIA published IPD principles are the most commonly accepted and used in the industry, several researchers, as listed in Table 4-1, have identified other principles that distinguish IPD from other delivery methods. 
Table 4-1: IPD Principles

\begin{tabular}{ll}
\hline Authors & IPD Principles \\
\hline AIA (2007) & $\begin{array}{l}\text { Mutual respect and trust, mutual benefit and reward, collaborative } \\
\text { innovation and decision making, early involvement of key } \\
\text { participants, early goal definition, intensified planning, open } \\
\text { communication, appropriate technology, organization and leadership }\end{array}$ \\
\hline AIA (2010) & $\begin{array}{l}\text { Early involvement of key participants, shared risk and reward, } \\
\text { multiparty contract, collaborative decision making and control, } \\
\text { liability waivers among key participants, jointly developed and } \\
\text { validated project goals }\end{array}$ \\
\hline $\begin{array}{l}\text { Forbes \& Syed } \\
\text { (2011) }\end{array}$ & $\begin{array}{l}\text { Multiparty contract, close team collaboration for optimizing the } \\
\text { project }\end{array}$ \\
\hline Kent \& Becerik- & $\begin{array}{l}\text { Multiparty agreement, early involvement of all parties, shared risk and } \\
\text { reward }\end{array}$ \\
\hline Kim \& Dossick & $\begin{array}{l}\text { Integrated form of agreement (IFOA), lean construction and using } \\
\text { BIM }\end{array}$ \\
\hline $\begin{array}{l}\text { Matthews \& } \\
\text { Howell (2005) }\end{array}$ & $\begin{array}{l}\text { Multiparty contract, shared risk and profit } \\
\text { Multiparty agreement, trust and mutual respect, mutual benefit and } \\
\text { reward, collaborative decision making, early involvement of key } \\
\text { project participants, early goal definition and intensified planning, } \\
\text { open communication within the project team and ability to address } \\
\text { issues, liability waivers between key participants, jointly developed } \\
\text { project target criteria, key participants bound together as equals, } \\
\text { shared financial risk and reward, transparent financials between key } \\
\text { participants }\end{array}$ \\
\hline $\begin{array}{l}\text { NaSfegrated teams, lean construction techniques, lean principles, } \\
\text { collective risk sharing, painsharing and gainsharing, profit pooling, } \\
\text { contingency sharing, goals and incentives, and performance } \\
\text { evaluations }\end{array}$ \\
\hline
\end{tabular}

Not all these principles are applicable to public projects and, more specifically, those using DBB project delivery method. Some principles are not applicable to public projects, but can be modified to allow their integration in public projects. The IPD principles that cannot be applied to public projects and cannot be modified include:

1- Multi-party Agreement 
This means the owner, the engineer, and the contractor shall all sign a single agreement. In public projects, owners are not capable of signing multi-party agreements; separate single contracts are the norm for public projects especially with the contractors, where competitive bidding is required such as in DBB delivery method;

2- Liability Waivers between Key Participants;

3- Transparent Financials between Key Participants (Open Books); and

4- Key Participants Bound Together as Equal. These four principles are also not applicable to public owners and not all liabilities can be waived among key participants. The project participants are still liable for damage inflicted on third parties and for willful default, which occurs when, a party abandons the project. Job site safety, structural collapse, or other liability concerns must still be addressed. Moreover, the nature of the bidding process and competition among contractors put them in a situation where the winning contractor cannot have financial transparency, to waive liabilities with key participants, or to be bound as equal with key participants. These three principles need prior negotiations, discussions, and agreements among all key participants before executing the construction contracts, which is not practical in the DBB delivery method.

Selective principles applicable to DBB public projects are discussed in the following section. 


\section{IPD Implementation with DBB Public Projects}

DBB offers the owner the market advantage of open competition through a design phase followed by separate bid and construction phases. The competitive nature of DBB delivery method results in a process that lacks integration. Therefore, DBB does not naturally lend itself to integration with IPD principles and offers the least possibility for integration. However, to take advantage of IPD-type delivery, contract provisions and project procedures can be modified to obtain additional benefits by applying principles and practices with IPD as a philosophy. Due to public projects regulations and limitations discussed in Chapter 2, not all the IPD principles can be integrated with public projects. Therefore, selective principles and practices that can be integrated with DBB in public projects are defined below.

\section{1- Early Involvement of All Parties}

The main characteristic of IPD is early involvement of all the primary project participants. Under a traditional DBB process, the contractor is not involved until after the design is complete. Public projects dictate that "open bidding" be used in public construction projects, thus prohibiting the early involvement of the prospect constructor in the design process. This can be resolved by bidding the project at the earliest stage possible and the owner and the engineer would express their intent and desire to proceed in an integrated team upon acceptance of bids. In this case the project could be bid with less complete design than is the case with traditional DBB projects. This early bid process allows the owner to obtain the benefits from integration by allowing the constructor to bring its constructability expertise to participate at a much earlier stage in 
design. This will also lead to developing a strong team, improved communications, and a willingness to resolve disputes by avoiding adversarial mentality (AIA, 2010).

To avoid loss of accuracy and the receipt of bids containing large contingencies, bids could be allowed to be adjusted following the constructors' contribution to developing more complete implementation documents. Another way to allow early involvement of all parties is to bring the Construction Manager (CM) into the project early during design.

\section{2- Integrated and Collaborative Teams}

For a successful integrated and collaborative process, owners need to steer the process and guide the team in the collaborative direction, by working as a team member not as an adversary. This process can be applied to DBB by requiring more staff time than traditional DBB process. Staff needs to be empowered to make decisions at meetings with the project participants. Chemistry among all the key project participants shall exist, and owners shall recommend if staff or members' changes are needed to ensure that the goals for collaboration are met.

\section{3- Pain and Gain Cost Sharing, Profit Pooling and Contingency Sharing}

This involves a major commitment to providing pain and gain cost sharing for all parties. Some public owners have legal restrictions that limit the extent of owner's ability to share risk of cost overruns and profit sharing. However, owners can implement some type of bonus program for contractors and may include designers by involving additional creative approaches. According to NASFA, painsharing and cost sharing can be implemented in DBB where the parties execute separate contracts with the owner, such as through the establishment of incentive pools. The non-owner participants will or will not receive any corporate overhead or profit depending on the project's success. The 
project's success is determined by comparing the direct costs with the anticipated target costs. Owners also include a gain share bonus if the project exceeds its goals. The nonowner participants never place their direct costs at risk. The contract shall include a formula for gain and painsharing and shall consider the parties' respective contributions, rather than a general percentage of costs.

\section{4- Lean Principles}

To maximize the efficiency of lean principles, they shall be applied during the design process of the DBB contract and shall be focused on maximizing value and elimination of waste. Adhering to the construction project schedule can also increase the efficiency of the lean principles. Monthly progress schedule updates lead to a more detailed schedule that clearly and accurately displays all the links to the activities that must occur during that particular month. The continuous process of targeting flawlessness, eliminating waste, meeting or exceeding all project expectations, focusing on the entire value, and streaming the execution of a construction project are a natural fit for IPD projects.

\section{5- Using Building Information Modeling (BIM)}

The tool of BIM can significantly enhance collaboration, sharing of information, and streamlining of project design and construction. For large public projects such as water utility projects, where facility operations depend on construction data to run the water or wastewater facility, owners need to save important project information for their use after construction such as long-term facility management. Most owners have difficulties doing so and they depend on consultants to collect, organize, manage, and store the varieties of the required information. BIM also saves time and money by allowing the project participants to communicate better and to design what will be built instead of designing 
for intent. The BIM model assists in creating 2-D or 3-D drawings needed for the fabricator and for review by the Architect/Engineer (AE) team. BIM assists in making the shop drawing process concurrent with design, eliminating waste, and saving time and duplication of effort.

\section{6- Co-location of Teams}

Co-location increases opportunities for collaboration and innovation and helps in meeting project goals and commitments. In DBB, co-location can involve the design and construction project participants, including trade contractors and suppliers. This can be achieved after the contract is awarded as the earliest involvement of all parties. Both the owner and engineer can have a direct relationship with subcontractors during construction and during final design. In large public projects the owner can provide space on the construction site to allow for physical space for all parties onsite.

\section{7- Performance Evaluations}

Performance evaluation measures the positive project outcomes based on the resources invested. Evaluation is useful to determining defects in a program and providing information necessary to improve the current performance. Evaluation can help improve the project's effectiveness and improve the program.

\section{8- Jointly Developed Project Target Criteria}

Carefully defining project performance criteria early in the design phase with the input, support, and acceptance of all project participants ensures that maximum attention will be paid to the project. The IPD team will establish a Target Cost and a Target Value design plan to focus on delivering value to the owner through the design process. 


\section{9- Mutual Respect and Trust}

A team culture based on risk sharing and trust is required to tie the parties together in order to have a successful project within the contractual relations. For a successful IPD project, a level of trust needs to be developed among the parties so that the participants will not be taken advantage of during the project. Owners play a big role in aligning the goals appropriately to ensure project success by encouraging respect and trust. In DBB, owners do not have the ability to select a team that will treat the owners fairly. This can be sought after in a DBB project but cannot be guaranteed.

10- Open Communication within the Project Team and Ability to Address Issues

IPD promotes greater communication among all project participants. Essential team meetings and collaboration among parties help in opening venues for more communication. Nonetheless, there is still a need to document decisions taken in these meetings.

A summary of the IPD principles, their applicability to treatment plant public projects, and those that are used in conjunction with DBB in the control projects is shown in Table 4-2.

Table 4-2: Summary of IPD Principles Applicability to Public Projects

\begin{tabular}{|l|r|l|l|}
\hline & & \multicolumn{1}{|c|}{ Require } & \\
& & Modifications & Cannot \\
& Can be & to be & be \\
& Implemented & Implemented & Implemented \\
\hline Multi-party Agreement & & & $\sqrt{ }$ \\
\hline
\end{tabular}




\begin{tabular}{|c|c|c|c|}
\hline Early Involvement of all Parties & & $\sqrt{ }$ & \\
\hline $\begin{array}{l}\text { Key Participants Bound Together } \\
\text { as Equals }\end{array}$ & & & $\sqrt{ }$ \\
\hline $\begin{array}{l}\text { Liability Waivers between Key } \\
\text { Participants }\end{array}$ & & & $\sqrt{ }$ \\
\hline $\begin{array}{l}\text { Transparent Financials between } \\
\text { Key Participants (Open Books) }\end{array}$ & & & $\sqrt{ }$ \\
\hline $\begin{array}{l}\text { Painsharing and Gainsharing } \\
\text { (Shared financial Risk and } \\
\text { Reward Based on Project } \\
\text { Outcome) }\end{array}$ & & $\sqrt{ }$ & \\
\hline Profit Pooling & & $\sqrt{ }$ & \\
\hline Contingency Sharing & & $\sqrt{ }$ & \\
\hline Lean Principles & $\sqrt{ }$ & & \\
\hline $\begin{array}{l}\text { Using Building Information } \\
\text { Modeling (BIM) }\end{array}$ & $\sqrt{ }$ & & \\
\hline Co-location of Teams & $\sqrt{ }$ & & \\
\hline $\begin{array}{l}\text { Jointly Developed Project Target } \\
\text { Criteria and Collaborative } \\
\text { Decision Making }\end{array}$ & $\sqrt{ }$ & & \\
\hline Performance Evaluations & $\sqrt{ }$ & & \\
\hline
\end{tabular}




\begin{tabular}{|l|l|l|l|} 
Integrated and Collaborative & $\sqrt{ }$ & & \\
Teams & $\sqrt{ }$ & & \\
\hline Mutual Respect and Trust & $\sqrt{ }$ & & \\
\hline Open Communication within the & & & \\
Pddress Issues. & & & \\
\hline
\end{tabular}

\section{Control Projects}

The study used two wastewater construction projects that were underway as control projects for implementing the IPD principles. The projects are Final Site Work and Screening System Improvements. Both projects are located at 23200 SW 97th Avenue, Miami, Florida 33190.

Contract S-863, Screening System Improvements for Plant 1 and Plant 2:

Notice to Proceed date was issued on May 20, 2013 with a Final Acceptance date of December 6, 2014. The contract cost at bid time for this project was $\$ 5,720,050$. This project consisted of two grit facilities referred to as Plant 1 and Plant 2. Each grit facility consisted of an east and a west grit chamber/flume for a total of four grit chambers/flumes. Construction included installation of four new Huber Screens, modifications and rehabilitation of all grit chambers and bypass channels, new construction of the screen channels with associated stop gates and sluice gates. In addition to construction of new Electrical Building, complete with all structural and architectural work, miscellaneous 
items including HVAC system, building electrical services, Motor Control Center (MCC), panel boards, transformer, and installation of RTU panel were also provided.

\section{Contract S-810, Final Site Work:}

Notice to Proceed date was issued on March 15, 2013 with a Final Acceptance Date of April 6, 2014. The contract cost at bid time for this project was $\$ 3,017,000$.

Construction under this contract included a main access gate, site drainage, catch basins, exfiltration trenches, complete site irrigation system, light poles and lighting, rough and fine grading with suitable fill, removal of on-site excess fill material, polymer system piping, asphalt overlay, and ground cover including sod, seed, and rock. Critical project parameters were collected by the research team for the control project, as summarized in Table 4-3.

Table 4-3: Control Projects Parameters Summary

\begin{tabular}{clcc}
\hline $\boldsymbol{i}$ & Project Parameter & $\begin{array}{c}\text { Final Site } \\
\text { Work }\end{array}$ & $\begin{array}{c}\text { Screening } \\
\text { System }\end{array}$ \\
\hline 1 & Project Award Price & $\$ 3,017,000$ & $\$ 4,858,774$ \\
2 & Project Total Actual Cost & $\$ 3,119,826$ & $\$ 5,070,762$ \\
3 & Total Cost of Change Orders & $\$ 254,115.27$ & $\$ 184,725.00$ \\
4 & Number of RFIs & 10 & 25 \\
5 & Notice to Proceed Date & $3 / 15 / 2013$ & $5 / 20 / 2013$ \\
6 & Actual Completion Date & $4 / 17 / 2014$ & $12 / 07 / 2014$ \\
7 & Project Scheduled Duration & 399 days & 562 days \\
8 & Cost of Errors and Omissions CO & $\$ 18,107.91$ & $\$ 42,849.00$ \\
9 & Total Cost of Claims & $\$ 0.00$ & $\$ 0.00$ \\
\hline
\end{tabular}




\begin{tabular}{llcc}
\hline 10 & Cost of Owner's CO & $\$ 135,210.77$ & $\$ 72,766.67$ \\
11 & Cost of Field Rework & $\$ 0.00$ & $\$ 0.00$ \\
12 & Average RFI Response Time & 3 days & 10.8 days \\
\hline
\end{tabular}

\section{IPD Implementation in Wastewater Control Projects}

Since the control projects were already under construction by the time the IPD principles were implemented, this imposed limitations on applying certain IPD principles to the project delivery. For instance, Early Involvement of all Parties, Pain and Gain Cost Sharing, Profit Pooling, Contingency Sharing, Building Information Modeling, and Jointly Developed Project Criteria need to be planned, designed, and agreed upon with the project participants during the design, bidding, and preconstruction phases. Since design and bidding were already completed on the control projects, these IPD principles will not be applicable in this process.

The IPD principles that can be practically applied are:

1- Open Communication within the Project Team and Ability to Address Issues,

2- Integrated and Collaborative Teams,

3- Lean Principles,

4- Co-location of Teams,

5- Project's Staff Performance Evaluations,

6- Mutual Respect and Trust,

7- Jointly Developed Project Target Criteria, and

8- Collaborative Decision Making. 
The study applied these eight IPD principles in the two control projects and measured the KPIs of these projects. These principles can be applied because they do not require any design or preconstruction aspects to be set prior to construction. They can be implemented during construction after all parties meet each other and after all roles are assigned. The exceptions are Lean Principles and Jointly Developed Project Target Criteria, which were already included in the design phase of these projects. The implementation of selective IPD principles are illustrated in this section.

\section{1- Open Communication within the Project Team and Ability to Address Issues} Essential team meetings and collaboration among project participants help in opening venues for more communication. One weekly progress meeting is held each week with the contractor, consultants, and owners who are involved in the planning, coordination, and performance of work and who have the ability to address issues. Discussions in weekly meetings include the progress of each element of current work, schedule revisions, milestone dates, and total contract time. Within three days after each meeting, the construction manager distributes copies of the minutes of the meeting, including a brief summary of progress of the work since the previous meeting, to all project participants.

In addition to weekly meetings, the construction manager meets with the general contractors on a daily basis, regardless of the presence of any issues. These daily meetings are informal and are held in the engineer's office, in the contractor's office, or in the construction field. Daily construction issues and conflicts are addressed immediately rather than accumulating them to be discussed during the weekly meetings or to be issued as RFIs. Open communication through phone 
conversations between the engineer and the general contractors are kept frequent as well. For example, the contractor would call to notify the engineer of any engineering documents requested by the Miami Dade Building Department officials. The engineer would also call the contractor requesting clarifications or supplemental information during the shop drawing review process to expedite its approval. This helps in addressing issues faster and conveying messages right on the spot. Whether issues are related to design or water utility operations, phone calls to different parties involved can expedite resolving problems and addressing issues.

\section{2- Integrated and Collaborative Teams}

The team is led in a collaborative manner, by having the project participants work as team members not as adversaries. This is accomplished by having a good relationship between the owner, engineer, and contractor. The project manager for the Final Site Work Project was a Miami Dade Water and Sewer employee for 20 years. He still maintains a good relationship with the owner, his previous employer. Moreover, the project manager for the Final Site Work Project has performed several projects with the construction manager's and engineer's employer firm and has established a good working relationship. The project manager for the Screens Improvements Project has been building projects for Miami Dade Water and Sewer Department for over eight years and has established a good working relationship. Additionally, the construction manager has been involved in the design and construction management of several projects in which the same project manager for the Screens Improvements Project 
was also involved. The construction manager has been providing engineering and construction management services to Miami Dade Water and Sewer Department since 2006, and was able to build a good relationship with the owner. The past experience on previous construction projects among the owner, engineer, construction manager, and contractors helped to promote a collaborative team environment and chemistry between the key project participants on the control projects.

Integration and collaboration were also promoted by introducing social activities outside the workplace, including Halloween pumpkin carving, breakfast fundraising for breast cancer awareness, Thanksgiving lunches, Christmas lunches, an Easter egg decorating contest, and other activities. All parties participated in these activities and helped in organizing the events. These activities were essential in bringing people together and promoting friendship. For both control projects, the owner provided more staff time than in the traditional DBB process. These project participants were empowered to make decisions at meetings with the project participants.

\section{3- Lean Principles}

Lean principles were applied during the design process of these DBB projects and are focused on maximizing value and eliminating waste. Since the efficiency of the lean principles can be increased by adhering to the construction project schedule, monthly progress schedule updates were submitted for review and approval by the engineer. Three week "look ahead" schedules were also prepared in detail and reviewed weekly during the weekly progress meetings. A 
sample of the three-week "look ahead" schedule is shown in Appendix A. The process of eliminating waste, meeting or exceeding all project requirements, aiming on the entire value stream, and pursuing perfection in the execution of a construction project is a continuous process that will be monitored closely, and actions taken will be documented. For example, inspections will be made of existing equipment and products that need to be upgraded but can be saved to eliminate waste. A $\log$ for documenting the waste elimination is shown in Appendix B.

\section{4- $\underline{\text { Co-location of Team }}$}

Co-location increases opportunities for collaboration and innovation and help in meeting project goals and commitments. On the control projects, this was achieved after the project was awarded to the contractors. The owner provided space on the construction site to allow for approximately one acre of physical space for the owner, consultants, engineers, contractors, and subcontractors. This space includes a $700 \mathrm{~m}^{2}$ pre-engineered metal building for the owner, engineers, and construction managers; $2,880 \mathrm{~m}^{2}$ of field office parking; and a 2,323 $\mathrm{m}^{2}$ of trailer city for contractors and subcontractors' trailers, all in the same parcel of land. In addition to the engineers and contractors, the onsite team included schedulers, accountants, inspectors, state inspectors general, document control staff, safety officers, and auditors. A site layout drawing and the office building interior drawing are shown in Appendix C. 


\section{5- Performance Evaluations}

Evaluation is useful to determine defects in a program and to provide information necessary to improve the current performance. On both control projects, the owner used to fill a contractor's and consultant's performance evaluations once every four months. Also, the consultants evaluate their personnel yearly including engineers and construction managers. Evaluations can help improve the project's effectiveness and improve the program. Evaluation forms samples are shown in Appendix D.

\section{6- Mutual Respect and Trust}

For a successful IPD project, a level of trust needs to be developed among the project participants so that they will not be taken advantage of during the project. Ghassemi and Becerik-Gerber (2011) demonstrated through control projects that trust comes in two ways: preexisting trust and forced trust. Where preexisting trust does not exist, a set of tools and activities will need to be implemented to allow the project team members to acquire trust forcefully. As previously mentioned in "Integrated and Collaborative Teams," the owner, the consultant, and the contractors have repetitive work and good long-lasting work relationships from the previous projects. This assists tremendously in promoting an environment of mutual respect and trust among the key participants in the control projects. A key indicator of trust and respect is when there are changes and extra work needed on the projects and the contractors proceed with the changes prior to receiving executed change orders or documentation to assure the contractors that they will be compensated for the extra work. 


\section{Jointly Developed Project Target Criteria}

Carefully defining project performance criteria early in the design phase with the input, support, and acceptance of project participants ensures that maximum attention is paid to the project. For the control projects, Jointly Developed Project Criteria was planned and agreed upon with the project participants during the design and preconstruction phases. During the execution phase, the construction manager held monthly meetings with the contractor, consultant, owner, and other stakeholders to monitor and update the jointly developed project target criteria. For example, the control projects were among other projects that were required to be in compliance with a Consent Order with the Florida Department of Environmental Protection (FDEP). One of the main project target criteria was to meet the milestone dates and satisfy all other Consent Order requirements. Structured jointly developed project criteria meetings were key in meeting those requirements.

\section{Collaborative Decision Making}

On the control projects, the construction manager formed a leadership team for decision-making purposes that included the contractor, consultant, owner, and other stakeholders. The team held monthly meetings and provided recommendations on decision-making priorities and activities and communication tools towards enhancing system efficiencies for the project. The team also assigned specific tasking to develop options for potential opportunities that could be beneficial for the project. 


\section{Results Comparison}

Results of the measured KPIs obtained from the control projects were compared with the KPIs data of past projects.

\section{1- Performance Evaluations with Regard to Cost}

Cost overruns in the two control projects were compared with the past project's data results. The researcher used to update a Cost Summary Log for the control projects on a monthly basis. A sample of the Cost Summary Log is shown in Appendix E.

Cost overrun during construction delivery is an important cost performance indicator.

Equations 4-1, 4-2, and 4-3 are used for cost performance evaluations with regard to cost overrun performance during project delivery.

Cost Overrun Performance:

Actual Cost $=$ Actual Expenditure + Contracting Adjustment

Average Cost Overrun $\Delta=\frac{\sum \text { Actual Cost }-\sum \text { Award Cost }}{\text { Number of Projects }}$

Cost Overrun $\%=\frac{\text { Actual Project Cost-Award Price }}{\text { Award Price }} \times 100$

\section{2- Performance Evaluations with Regard to Time}

The construction schedule was reviewed monthly and the projects' actual completion times were compared with the proposed schedule completion times. Time overrun during construction delivery is an important time performance indicator. Equations 4-4 and 4-5 are used for time performance evaluations with regard to time overrun performance during project delivery. Time Overrun Performance:

Average Time Overrun $\Delta=\frac{\sum \text { Actual Time }-\sum \text { Award Time }}{\text { Number of Projects }}$ 
$x_{3}=$ Time Overrun $\%=\frac{\text { Actual Project Duration }}{\text { Scheduled Project Duration }} x 100$

where Actual Project Duration is calculated as the time span between the Notice to Proceed date and the date when all work has been completed.

\section{3- Performance Evaluations with Regard to COs}

The number of COs and COs' cost amount obtained from the control projects were compared with the past project's data results as a percentage value of the total project cost. The control projects utilized CO Log that was updated weekly by the researcher. A sample of CO Log is shown in Appendix F.

Equations 4-6, 4-7, and 4-8 are used for performance evaluations with regard to Change Orders.

Change Order Cost $\%=\frac{\sum \text { Cost of Change Orders }}{\text { Actual Total Project Cost }} x 100$

Percent of changes that are owner requested:

Owner's CO Cost $\%=\frac{\text { Total Cost of Owner's Co }}{\sum \text { Cost of Change Orders }} \times 100$

Percent of changes that are due to design errors and omissions:

Errors and Omissions CO Cost $\%=\frac{\sum \text { Cost of Errors and Omissions CO }}{\sum \text { Cost of Change Orders }} \times 100$

\section{4- Request for Information (RFI) Evaluation:}

The number of RFIs obtained from the control projects was compared to those of past projects delivered using DBB. The control projects utilized RFI Log that was updated weekly by the researcher. A sample of RFI Log is shown in Appendix G. RFI performance measures include two components:

1- Number of RFIs, 
2- Average RFI response time per unit price.

Equations 4-9 and 4-10 are used for performance evaluations with regard to RFIs.

RFIs per Unit Price $=\frac{\text { Total Number of RFIs }}{\text { Actual Total Project Cost }}$

RFI Response Time per Unit Price $=\frac{\text { Average RFI Response Time }}{\text { Actual Total Project Cost }}$

\section{5- Field Rework:}

The number of post-completion construction defects at the control projects was compared with those obtained from the past project's data results. The researcher used to update a Construction Defects Log for the control projects on a monthly basis. A sample of the Construction Defects Log is shown in Appendix H.

Defects performance measures were measured based on cost of field rework, which could be as a result of these four components:

1- A design that fails to meet the Professional Standards,

2- The failure of the contractor to execute the work in accordance with the plans and specifications.

3- The failure of the contractor to execute the work in accordance with the acceptable standards of workmanship in the construction industry, and

4- The improper installation of systems, equipment or materials that are of a lesser quality than required by the plans and specifications.

Equation 4-11 is used for defects evaluations with regard to cost of rework.

Total Cost of Field Rework $\%=\frac{\text { Total Direct Cost of Field Rework }}{\text { Actual Total Project Cost }} \times 100$ 


\section{6- Construction Claims:}

Project claims cost obtained from the control projects was compared with those obtained from the past projects. The researcher used a Construction Claims Log for the control projects. A sample of the Construction Claims Log is shown in Appendix I. Construction claims measures was measured based on cost of claims which could be as a result of these six components:

1- Cost escalation,

2- Time for completion and construction delays,

3- Changes in project scope,

4- Geotechnical and site-related problems,

5- Weather and force majeure conditions, and

6- Negligence in both design and construction.

Equation 4-12 is used for claims evaluations with regard to cost of claims.

Total Claims Cost $\%=\frac{\sum \text { Direct Cost of Claims }}{\text { Actual Total Project Cost }} \times 100$

\section{Focus Group}

\section{Focus Group Objective}

The questions asked during the focus group depended on the purpose of the group and the intended use of the results. The primary objective of focus groups is typically to collect opinions, beliefs, and attitudes of the participants. In this study, the main objective behind the use of a focus group is to assess the outcomes of implementing the IPD principles in water and wastewater projects. This is done primarily by comparing the results obtained from measured KPIs of the control projects with the KPIs obtained from 
data collected from various water utility facilities owners of past projects that were delivered using DBB method in South Florida. The participants in the focus group, who are major players in the control projects, can help provide this study with a better insight into whether any improvements in measured KPIs can be directly correlated to the integrated IPD principles, or whether they are correlated to other coincidental factors specific to the control project.

\section{Type of Focus Group}

As discussed in the literature review section, there are three types of focus groups: exploratory, confirmatory, or a combination of both. For this study, the focus group was to be confirmatory, because its main objective is to assess and confirm the findings of data analysis in comparing the performance of DBB project delivery.

\section{Focus Group Format}

The focus group for this study consulted stakeholders in the control projects to evaluate the comparison of KPI results of the dataset with the KPIs of the control projects. The focus group involved different types of stakeholders such as owners, engineers, consultants, and contractors. Two main criteria were established for participants' selection: influence and experience in construction projects at Miami Dade South District Wastewater Treatment Plant (MD-SDWWTP), and to have been involved in the projects used for the control projects. A secondary criterion is the years of professional industrial experience, which is a minimum of ten (10) years.

The focus group of this research consisted of seven participants who were active participants during the design and construction of the wastewater projects at the MD- 
SDWWTP. An effort was made to form an overall sample that covers different sub domains of wastewater construction, such as design, construction, project management, planning, etc.

A few days before the focus group meeting, the moderator communicated copies of the interview questions to the participants so that they might have time to prepare for answers.

The target participants are shown in Table 4-4.

\section{Table 4-4: Target Participants}

\begin{tabular}{lll} 
& Employment & Target Participants \\
\hline 1 & Client & Design Engineer \\
2 & Client & Construction Manager \\
3 & Consultant & Design Engineer \\
4 & Consultant & Construction Manager \\
5 & Contractor & Project Manager \\
6 & Contractor & Project Manager \\
7 & Contractor & Scheduler \\
\hline
\end{tabular}

A location was selected to conduct the focus group meeting for this study that takes into consideration convenience for the participants and neutrality. This study convened one focus group session. The focus group in this study was scheduled for one and a half hours, with flexible time allocation. According to Gibbs (1997) it is important to select a neutral location for the focus group sessions.

Audio recordings were made to permit subsequent transcription. Direct quotations that seem important were written down. Immediately, following the focus group, notes were reviewed and information analyzed.

The focus group session was structured as shown in Table 4-5. 
Table 4-5: Focus Group Structure

\begin{tabular}{|c|l|c|c|}
\hline Item & \multicolumn{1}{|c|}{ Description } & Duration & Responsible \\
\hline 1 & Focus Group Introduction & $5 \mathrm{~min}$ & Moderator \\
\hline 2 & Purpose and Methodology of the Study & $30 \mathrm{~min}$ & Moderator \\
\hline 3 & Discussion Points & $50 \mathrm{~min}$ & All \\
\hline 4 & Ranking of IPD principles & $5 \mathrm{~min}$ & All \\
\hline & & & \\
\hline
\end{tabular}

\section{Focus Group Discussions and Questions}

An introduction included in Appendix $\mathrm{J}$ was presented to the focus group.

Participants signed Consent to Participate in Focus Group Study as part of the MD-

SDWWTP. A consent sample is presented in Appendix K. Participants were provided

with summary details of the research (Appendix L). The moderator provided a short

presentation of the research and focus group discussion areas followed by self-

introductions. Summary sheets were provided to enhance the participants' understanding and to prompt discussion, as shown in Tables 4-6 and 4-7.

\section{Table 4-6: KPIs}

\begin{tabular}{|c|l|}
\hline Item & \multicolumn{1}{c|}{ Key Performance Indicators (KPIs) of Project } \\
\hline 1 & Cost overrun as a percentage of the total project award price \\
\hline 2 & Change order cost as a percentage of total project cost \\
\hline 3 & Time overrun as a percentage of the original project schedule \\
\hline 4 & Number of RFIs per unit price \\
\hline 5 & $\begin{array}{l}\text { Errors and omissions change orders cost as a percentage of total cost of } \\
\text { change orders }\end{array}$ \\
\hline 6 & Total claims cost as a percentage of the total project cost \\
\hline 7 & RFI response time per project cost \\
\hline 8 & Cost of field rework as a percentage of total project cost \\
\hline 9 & Owner requested change orders cost as a percentage of total cost of COs. \\
\hline
\end{tabular}




\section{Table 4-7: IPD Principles Applied to DBB Projects in Treatment Plant Projects}

\begin{tabular}{|c|l|}
\hline Item & \multicolumn{1}{|c|}{ IPD Principles } \\
\hline 1 & Open communication within the project team and ability to address issues \\
\hline 2 & Integrated and collaborative teams \\
\hline 3 & Lean principles \\
\hline 4 & Co-location of teams \\
\hline 5 & Performance evaluations \\
\hline 6 & Mutual respect and trust \\
\hline 7 & Jointly developed project target criteria \\
\hline 8 & Collaborative decision making \\
\hline
\end{tabular}

Two discussion areas were conducted with the focus group:

1- Effect of IPD principles on KPIs of water and wastewater projects delivered using DBB delivery method, and

2- Ranking of IPD principles.

A list of summarized discussion points is included in Appendix L. Participants were encouraged to engage in free discussion to express their opinions. The researcher documented the following:

1- What was discovered and what was learned about the effects of IPD principles on the KPIs of DBB project delivery method from the point of view of the participants,

2- Whether the focus group confirms the existence of a direct correlation between the implemented IPD principles and any possible improvements in measured KPIs of the control projects, and

3- Evaluate the focus group interview process. What went well and what did not? Questionnaire included in Appendix M was distributed to the participants with the IPD principles implemented in the control projects listed. Participants were asked to rank the IPD principles from one to five based on which they felt is most influential in improving 
the KPIs. Participants shared their experiences of the KPIs in the group. Their opinions and views were analyzed.

\section{PPR Model}

Chapter 6 discusses the development and implementation of the Project Performance Rating (PPR) model. The PPR is a comprehensive rating of performance for treatment plant projects and can be used to gauge the overall project performance.

\section{CORRELATION BETWEEN IPD PRINCIPLES AND PROJECT KPI}

Chapter 6 illustrates the regression analysis and the focus group were then utilized to determine the effect of each implemented IPD principle on various project KPIs. A guideline metric is developed that can significantly help utility owners aiming to predict how implementation of certain IPD principles can impact various project KPIs. 


\section{CHAPTER 5}

\section{RESULTS AND ANALYSIS}

\section{Data Collection}

\section{Data Sample Size}

A comprehensive list of inventory of water and wastewater facilities in the South Florida region was compiled, and their performance data corresponding to the KPIs of this study were identified. To accomplish this task, several water utilities in South Florida were contacted in order to identify the population of water and wastewater projects executed in the past decade inside water and wastewater treatment facilities. Project performance data were collected for water utility construction projects selected from several water utilities

in the South Florida geographic region. The population was found to be 60 projects of varying sizes completed between 2003 and 2015, and contracted and delivered using the traditional Design-Bid-Build (DBB) delivery method. Some projects had insufficient records with missing data with regard to one or more performance factor, and thus had to be excluded from the analysis. The remaining 43 projects were therefore chosen to make up the data population for this study and to compare with the data of the two control projects. This projects' database included projects of varying, but somewhat uniformly distributed size. Seventeen projects analyzed for performance indicators were under $\$ 6 \mathrm{M}$, 16 were between $\$ 6 \mathrm{M}$ and $\$ 14 \mathrm{M}$, and 10 were over $\$ 14 \mathrm{M}$. 


\section{Water Treatment Facilities}

\section{A. Miami-Dade County}

There are seven water treatment facilities in Miami-Dade. These facilities provide clean, potable water to the entire population throughout the county. The design capacity of the water treatment facilities is approximately 500 million gallons a day (mgd). Table 5-1 summarizes these facilities' capacities and locations.

Table 5-1: Miami-Dade County WTP Locations

\begin{tabular}{lcc}
\hline \multicolumn{1}{c}{ Plant Name } & $\begin{array}{c}\text { Design } \\
\text { Capacity } \\
(\mathrm{mgd})\end{array}$ & Location \\
\hline Alexander Orr & 217 & Miami \\
City of Homestead & 16.7 & Homestead \\
City of N. Miami Winson Water Plant & 9 & North Miami \\
Florida City & 4 & Florida City \\
Hialeah-Preston & 225 & Hialeah \\
Norwood Water Plant - N. Miami Beach & 16 & Miami Gardens \\
South Miami-Dade WTP4 & 12 & Miami \\
\hline
\end{tabular}

\section{B. Broward County}

There are 27 water treatment facilities in Broward County. The design capacity of these facilities is $490 \mathrm{mgd}$. Table 5-2 shows a summary of the water treatment facilities of Broward County. 
Table 5-2: Broward County Water Treatment Plant (WTP) Locations

\begin{tabular}{|c|c|c|}
\hline Plant Name & $\begin{array}{c}\text { Design } \\
\text { Capacity } \\
(\mathrm{mgd})\end{array}$ & Location \\
\hline Broward County 1A Water Treatment Plant & 16 & Lauderdale Lakes \\
\hline Broward County 2A Water Treatment Plant & 40 & Pompano Beach \\
\hline City of Coral Springs & 16 & Coral Springs \\
\hline City of Dania Beach Water Treatment Plant & 3 & Dania Beach \\
\hline City of Hallandale Beach & 10 & Hallandale Beach \\
\hline City of Lauderhill & 16 & Lauderhill \\
\hline City of Margate Water Treatment Plant & 18 & Margate \\
\hline City of Tamarac Utilities West & 20 & Tamarac \\
\hline Cooper City Utilities & 7 & Cooper City \\
\hline Coral Springs Improvement District & 7.1 & Coral Springs \\
\hline Davie Water Treatment Plant System I & 3.4 & Davie \\
\hline Davie Water Treatment Plant System III & 4 & Hollywood \\
\hline Deerfield Beach East Water Plant & 16.8 & Deerfield Beach \\
\hline Deerfield Beach West Water Plant & 18 & Deerfield Beach \\
\hline Ferncrest Utilities & 1 & Fort Lauderdale \\
\hline Fiveash Water Plant & 75 & Fort Lauderdale \\
\hline Hillsboro Beach Water Plant & 2 & Pompano Beach \\
\hline Hollywood Water Treatment Plant & 61 & Hollywood \\
\hline Miramar West Water Plant & 7.5 & Miramar \\
\hline North Springs Improvement District & 6.8 & Coral Springs \\
\hline Park City Water Treatment Plant-Sunrise \#2 & 6 & Fort Lauderdale \\
\hline Pembroke Pines Water Treatment Plant \#2 & 18 & Pembroke Pines \\
\hline Plantation Central Water Treatment Plant & 12 & Plantation \\
\hline Plantation East Water Treatment Plant & 12 & Plantation \\
\hline Pompano Beach Water Treatment Plant & 50 & Pompano Beach \\
\hline Sawgrass Water Treatment Plant-Sunrise \#3 & 18 & Sunrise \\
\hline $\begin{array}{l}\text { Southwest (S. Broward) Water Treatment } \\
\text { Plant }\end{array}$ & 2 & Davie \\
\hline Springtree Water Treatment Plant-Sunrise \#1 & 24 & Sunrise \\
\hline
\end{tabular}




\section{Palm Beach County}

There are 11 water treatment facilities in Palm Beach County. The design capacity of these facilities is $320 \mathrm{mgd}$. Table 5-3 shows a summary of these water treatment facilities.

Table 5-3: Palm Beach County WTP Locations

\begin{tabular}{lcc}
\hline Plant Name & $\begin{array}{c}\text { Design } \\
\text { Capacity } \\
\text { (mgd) }\end{array}$ & Location \\
\hline Lake Worth Utilities Authority & 17.4 & Lake Worth \\
Riviera Beach WTP & 17.5 & Riviera Beach \\
Boynton Beach City of & 19.24 & Boynton Beach \\
Seacoast Utilities & 23 & \\
Water Treatment Plant No. 2 & 14.5 & \\
Water Treatment Plant No. 3 & 30 & \\
Water Treatment Plant No. 8 & 30 & Boca Raton \\
Water Treatment Plant No. 9 & 27 & West Palm Beach \\
Glades Road & 70 & \\
Southern Regional Water Reclamation & 47 & Delray Beach \\
Facility (WPB) & & \\
The City of Delray Beach Water & 26 & \\
Treatment Plant & &
\end{tabular}

\section{Wastewater Treatment Facilities}

\section{A. Miami-Dade County}

There are four wastewater facilities in Miami-Dade County with a total wastewater design capacity of $556 \mathrm{mgd}$. The City of Homestead wastewater treatment facility provides wastewater service to 10,100 residential and non-residential customers. The three Miami-Dade Water and Sewer Department (WASD) wastewater facilities provide direct sewer service to approximately 315,000 retail customers and 13 wholesale 
customers. Table 5-4 shows a summary of the wastewater treatment facilities in Miami

Dade County.

Table 5-4: Miami-Dade County Wastewater Treatment Plant (WWTP) Locations

\begin{tabular}{lcc}
\hline Plant Name & $\begin{array}{c}\text { Design } \\
\text { Capacity } \\
\text { (mgd) }\end{array}$ & Location \\
\hline City of Homestead & 6 & Homestead \\
WASD Central District WWTP & 143 & Virginia Key \\
WASD North District WWTP & 120 & Miami \\
WASD South District WWTP & 287 & Miami \\
\hline
\end{tabular}

B. Broward County

Broward County has 13 wastewater facilities, the total wastewater design capacity of which is $275 \mathrm{mgd}$. While Broward County does operate and provide sewer service to many areas, several municipalities operate their own facilities. Table 5-5 summarizes the wastewater treatment facilities and shows the location of each plant.

Table 5-5: Broward County WWTP Locations

\begin{tabular}{lcc}
\hline Plant Name & $\begin{array}{c}\text { Design } \\
\text { Capacit } \\
\text { y (mgd) }\end{array}$ & Location \\
\hline Broward County N. Regional & 84 & Pompano Beach \\
City of Margate East WWTP & 5 & Margate \\
City of Margate West WWTP & 5 & Margate \\
Cooper City Utilities & 3.75 & Cooper City \\
Coral Springs Improvement District & 8.33 & Coral Springs \\
Ferncrest Utilities, Inc. & 0.6 & Fort Lauderdale \\
G.T. Lohmeyer Plant & 55.7 & Fort Lauderdale \\
Hollywood Southern Regional WWTP & 48.75 & Hollywood \\
Pembroke Pines WWTF & 9.5 & Pembroke Pines \\
Plantation Regional WWTP & 18.9 & Plantation \\
Sawgrass Regional WWTF-Sunrise \#3 & 20 & Sunrise \\
South Broward (Southwest) WWTF & 1 & Davie \\
Springtree Regional WWTF-Sunrise & 10 & Sunrise \\
\#1 & & Davie \\
Town of Davie WWTP & 5 & \\
\hline
\end{tabular}




\section{Palm Beach County}

A total of 13 wastewater facilities operate in Palm Beach County, with a total wastewater design capacity of $171 \mathrm{mgd}$. Similar to Broward County, several municipalities operate their own facilities and provide sewer services to their areas. Table 5-6 shows the wastewater treatment facilities and their locations.

Table 5-6: Palm Beach County WWTP Locations

\begin{tabular}{lcc}
\hline Plant Name & $\begin{array}{c}\text { Design } \\
\text { Capacity } \\
\text { (mgd) }\end{array}$ & Location \\
\hline Boca Raton, City of - WWTP & 17.5 & Boca Raton \\
Loxahatchee Env Control Dist WWTP & 11 & Jupiter \\
South Central Regional WWTP & 24 & Delray Beach \\
Seacoast Utilities PGAWWTP & 12 & Palm Beach Gardens \\
East Central Regional WWTP & 70 & West Palm Beach \\
Palm Beach County Southern Regional & 30 & Boynton Beach \\
WWTP & 6.5 & Belle Glade \\
Western Region WWTP & & \\
\hline
\end{tabular}

\section{Scope of Data Collected}

Data for treatment plant projects were collected from water utilities in the three counties of South Florida; namely Palm Beach County, Broward County, and Miami Dade County. This study included a total of 43 projects selected from the total population of projects completed in the period of time spanning between years 2003 and 2015. The type of projects selected included construction projects inside water and wastewater facilities contracted and delivered using the traditional DBB delivery method.

The projects completed between years 2003 and 2015 totaled 43 projects, hereafter referred to as the "dataset", and were subsequently used for the analysis with control projects. 
The researcher personally obtained the required data on the projects from different databases for the water utilities in South Florida. Statistical analysis was performed on the data in order to develop statistical measures, such as minima, maxima, averages, and standard deviations of grouped data.

The performance of the construction projects in the dataset was compared to that of the two control projects delivered using the combined IPB and DBB approach. This was done through the comparison of KPIs identified earlier in Chapter 4, such as cost overrun $\%$, time overrun $\%$, total claims cost $\%$, cost of field rework $\%$, RFI response time per unit price, RFI per unit price and change order cost \%, error and omissions CO cost $\%$, and owner's $\mathrm{CO} \operatorname{cost} \%$.

Figure 5-1 shows a graphical summary of the dataset categorized per award years, and notes the contract average amounts. For example, in 2008, seven projects were awarded, with a contract average base amount of $\$ 231 \mathrm{M}$, an average contract base amount plus contingency of $\$ 262 \mathrm{M}$, and an average actual amount paid to the contractors of $\$ 247 \mathrm{M}$. 


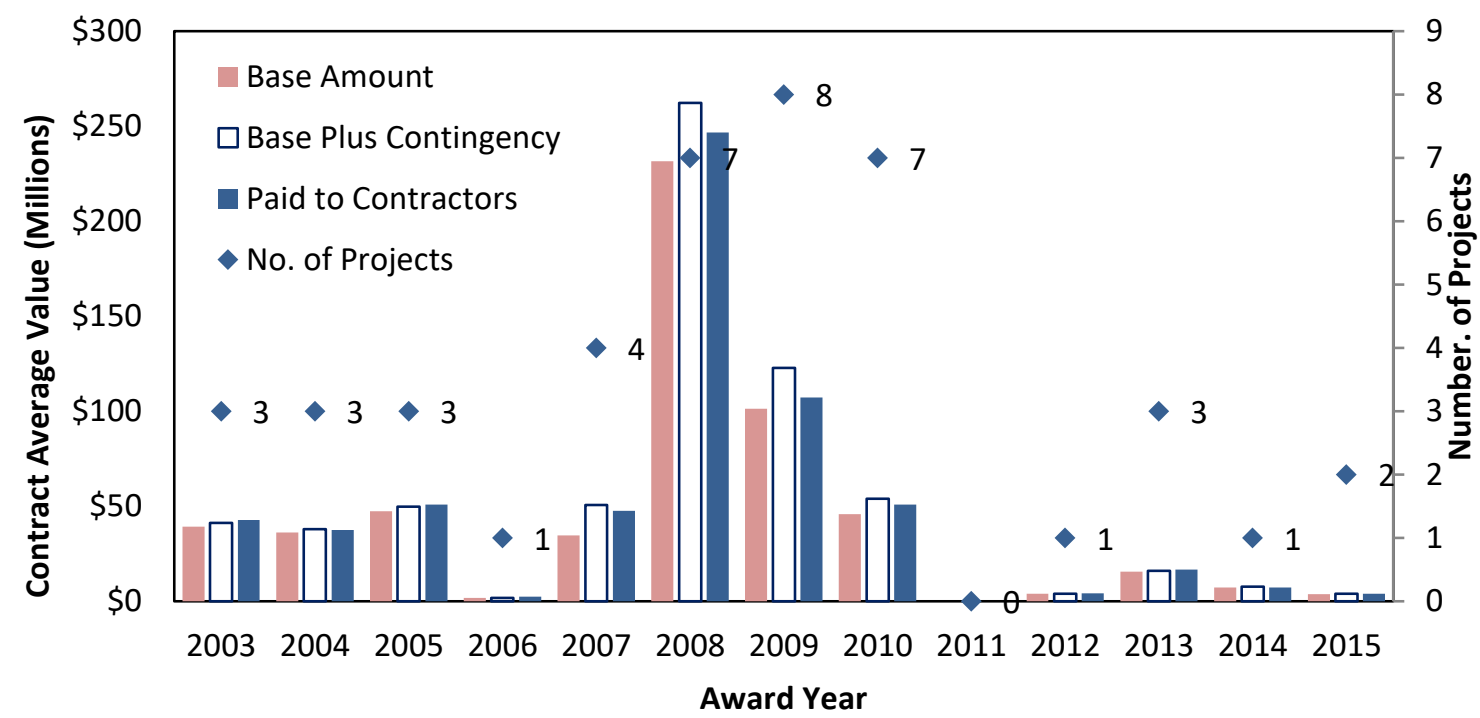

Figure 5-1: Number of projects and contract average value per award year.

\section{Data Sources}

Water utility construction projects data used in this research were obtained from several water and wastewater facilities in South Florida, including in-house documents

and databases. The data from Broward County and Palm Beach County was in both hard copy and electronic formats.

Miami Dade Water and Sewer Department (MDWASD) uses Proliance and SharePoint, which are intranet websites available for MDWASD's personnel and approved users. Proliance and SharePoint include detailed and extensive construction projects data records. Construction projects started before 2006, however, were not available in Proliance or SharePoint.

Proliance and SharePoint serve as the foundation of MDWASD's project control tracking system (PCTS) operating on a single database. They include projects 
information as well as search capabilities. Figures 5-2 and 5-3 are example output screens for typical Proliance and SharePoint searches, respectively. 


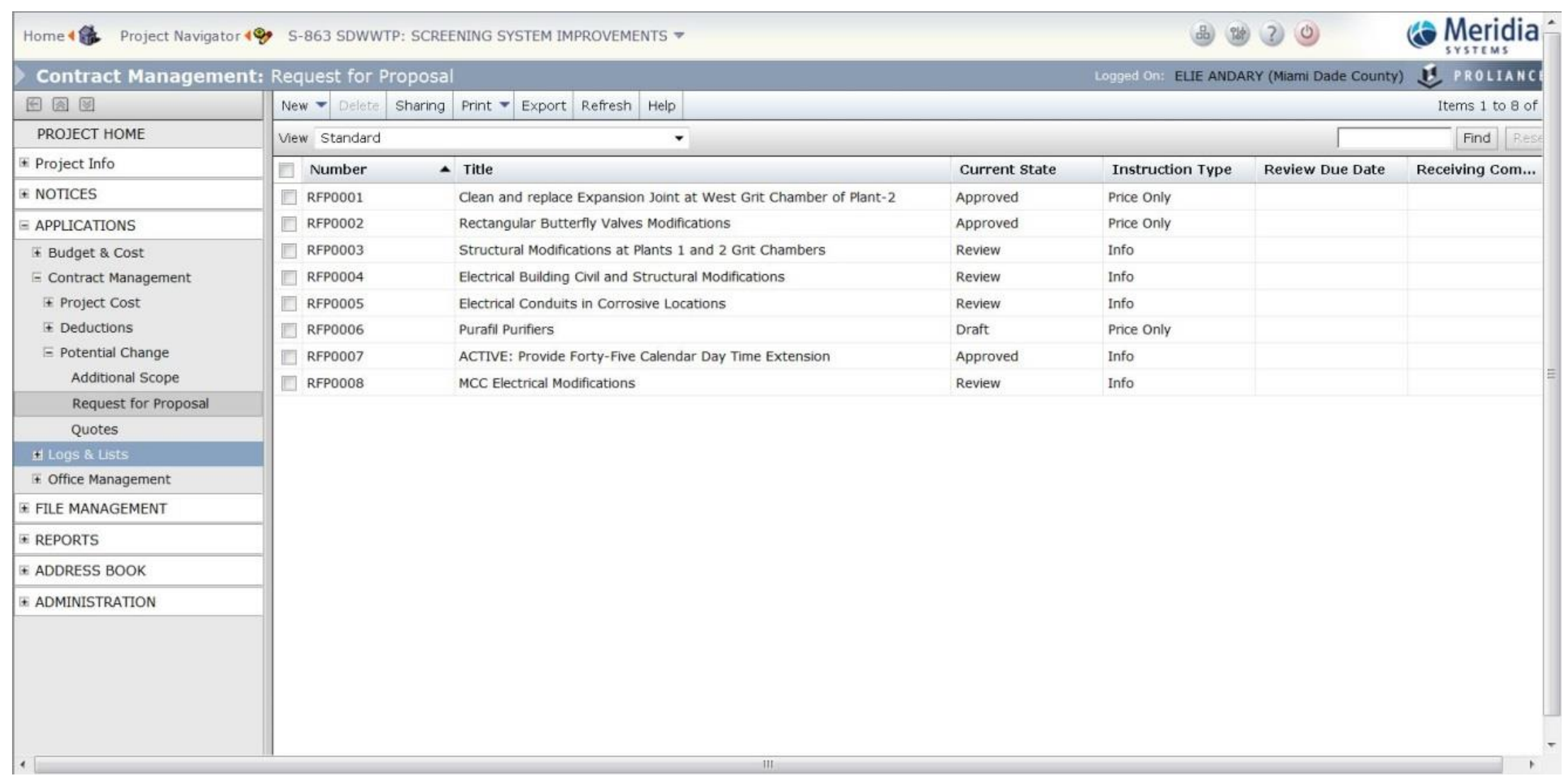

Figure 5-2: Output from Proliance. 


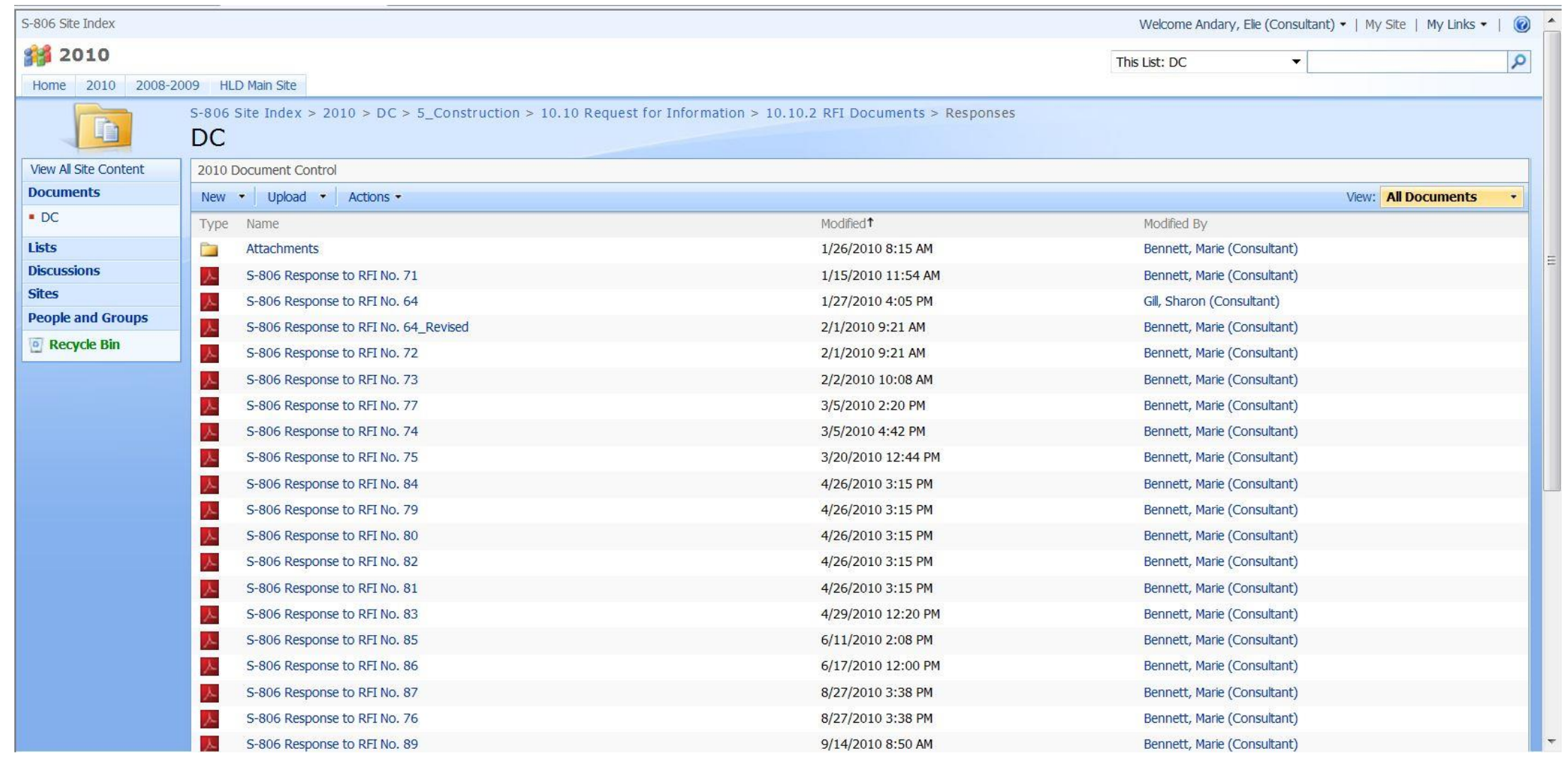

Figure 5-3: Output from Sharepoint. 


\section{Project Performance Measures}

Overall and individual project performance of projects comprising the dataset were evaluated and compared to the performance of the control projects. This was done by comparing the project outcomes in several key areas that were determined in Chapter 4 to constitute the KPIs of any construction project. Results of these comparisons are presented in the following sections.

\section{Project Categories}

The study categorized the projects by their total base contract value. Even though KPIs were normalized by the total project value to eliminate any bias introduced by the project size, such categorization would still add some value by providing insight into whether certain KPIs have any particular trends in large or small projects. The cost categories selected are as follows (cost in millions of dollars):

- Base contract value: $\$ 0 \mathrm{M}-\$ 1 \mathrm{M}$,

- Base contract value: $\$ 1 \mathrm{M}-\$ 2 \mathrm{M}$,

- Base contract value: $\$ 2 \mathrm{M}-\$ 6 \mathrm{M}$,

- Base contract value: $\$ 6 \mathrm{M}-\$ 10 \mathrm{M}$,

- Base contract value: $\$ 10 \mathrm{M}-\$ 14 \mathrm{M}$,

- Base contract value: \$14M-\$22M,

- $\quad$ Base contract value: $\$ 22 \mathrm{M}-\$ 40 \mathrm{M}$, and

- Base contract value: \$40M-\$120M.

Figure 5-4 provides a summary of the categories, showing the total number and percentage of overall projects falling into each category of the dataset. For example, the 
figure shows that for the base contract amount category between $\$ 2 \mathrm{M}$ and $\$ 6 \mathrm{M}$, there are eight projects, which constitute $18.6 \%$ of the 43 projects in the dataset. Figure $5-4$ shows the distribution of projects.

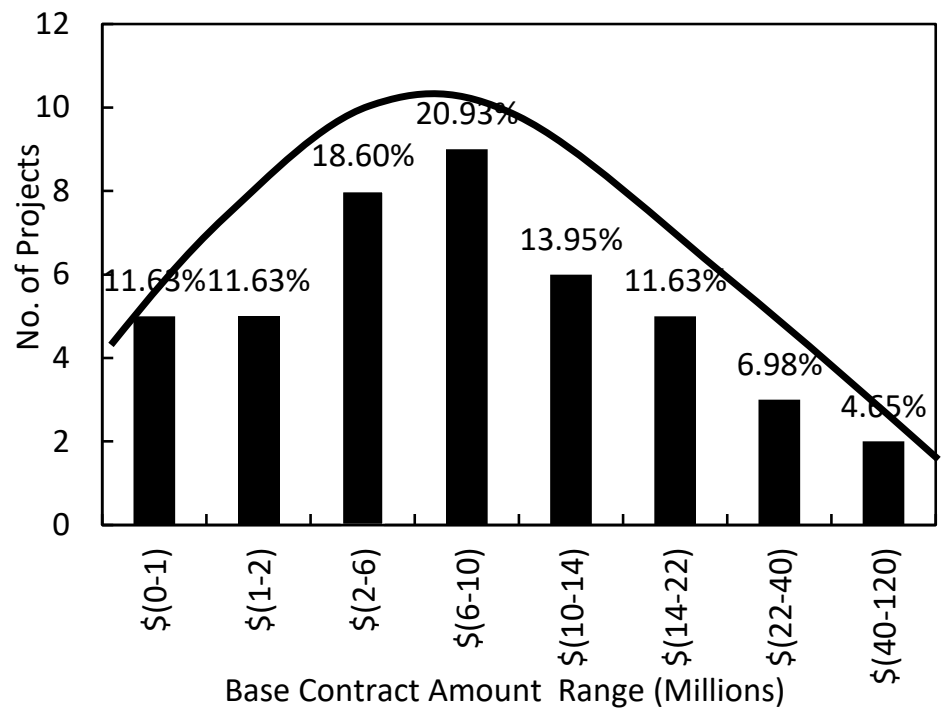

Figure 5-4: Number and percentage of projects for specified range of contract value.

Figure $5-4$ shows that nearly $23.2 \%$ of the projects in the dataset were under $\$ 2 \mathrm{M}$, nearly $19 \%$ of the projects were between $\$ 2 \mathrm{M}-\$ 6 \mathrm{M}$, nearly $21 \%$ of the projects were between $\$ 6 \mathrm{M}$ to $\$ 10 \mathrm{M}$, nearly $25 \%$ of the projects were between $\$ 10 \mathrm{M}-\$ 22 \mathrm{M}$, and nearly $11 \%$ of the projects were over $\$ 22 \mathrm{M}$. The average base contract value in the dataset was $\$ 12.8 \mathrm{M}$, and the maximum was $\$ 117.5 \mathrm{M}$.

\section{Performance Evaluation with Regard to Cost}

Project cost is of major interest as it shows the resource usage in economic terms. Another important aspect is cost predictability, which predicts whether the final overall cost is in line with the base contract amount (Swan and Khalfan, 2007). Following contract award, the bid price becomes the benchmark for cost control purposes. 
Contractors are required to submit a cash flow schedule or schedule of values that the water utilities will use to assess project performance by comparing actual costs to the original base contract amount. At project completion, the final cost is compared to the original bid price to assess the project delivery performance in terms of any sustained cost overruns.

It is very common for water related projects to experience cost overruns. While the causes of the cost overrun can be numerous, there is always a need to revisit how the estimate was originally established and identify any errors. This study analyzed the cost performance of the dataset projects at contract completion. Cost overruns, also referred to as cost growth, in the two control projects were compared with those of the dataset delivered using traditional DBB. Cost overrun during construction delivery is an important cost performance indicator. Equations 5-1, 5-2, and 5-3 were used to obtain the numerical values of the KPIs for cost performance evaluation.

$$
\begin{aligned}
& \text { Actual Cost }=\text { Actual Expenditure }+ \text { Contracting Adjustments } \\
& \text { Average Cost Overrun } \Delta=\frac{\sum \text { Actual Cost }-\sum \text { Award Cost }}{\text { Number of Projects }} \\
& \text { Cost Overrun } \%=\frac{\text { Actual Project Cost-Award Price }}{\text { Award Price }} \times 100
\end{aligned}
$$

The cost overrun results are presented in Figure 5-5 as percentages of the base contract amount. The average cost overrun percentage on traditional DBB projects of the dataset was $7.8 \%$. The average cost overrun on the control projects of the two case studies was at 3.9\%. The cost performance of the control projects is almost half that of the dataset projects delivered using traditional DBB. 
Figure 5-5 shows a wide range of the cost overrun percentage for projects in the dataset. It also shows that almost all projects tend to exceed the original contract price. Of all projects in the dataset, $22 \%$ have a cost overrun of $10 \%$ or more. This reflects the high variance of the projects, for which the average cost overrun was $6.85 \%$ and the standard deviation was $1.03 \%$. The columns in Figure 5-5 marked in yellow represent the cost overrun of the two control projects, which are at $3.41 \%$ and $4.36 \%$, respectively. The data in Figure 5-5 shows two clear outliers, one with a 39\% cost overrun, and the other with a negative $8 \%$ cost overrun. Such data outliers deserve an elaboration to the underlying reasons for uncommon cost overrun. The project with $43 \%$ cost overrun was a water treatment plant upgrade in the City of Fort Lauderdale. This contract's base amount cost was $\$ 1.75 \mathrm{M}$ and the actual cost was $\$ 2.43 \mathrm{M}$. Total change orders were $\$ 678,975.27$ of which $85 \%(\$ 578,158)$ were owner requested changes. The owner requested change order was rehabilitation of underdrains and filter media replacement for two large water filters, which was not part of the scope of work of this contract. The second project with negative $8 \%$ cost overrun was a wastewater treatment plant upgrade in Palm Beach County. This contract's base amount cost was $\$ 1.18 \mathrm{M}$ and the actual cost was $\$ 1.06 \mathrm{M}$. The reduction in total cost was due to three change orders that were initiated by the owner for deleted work and resulted in a total credit of $\$ 114,699$. 


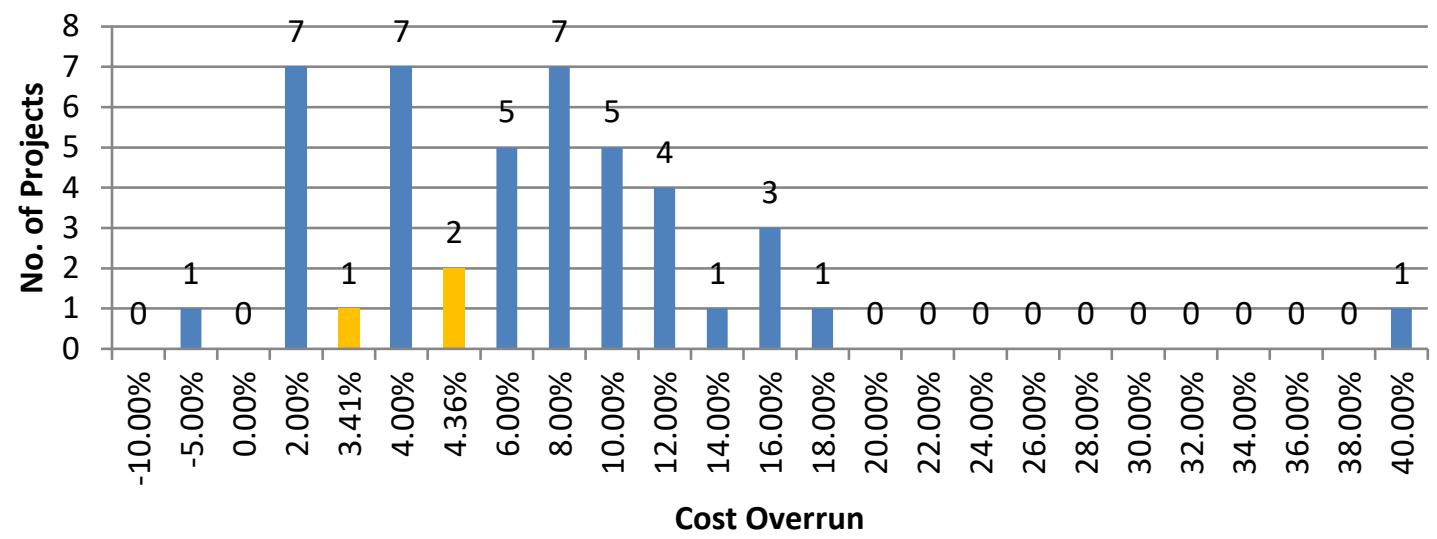

Figure 5-5: Distribution of projects with respect to the cost overrun percentage.

Figure 5-6 shows the cost overrun percentages for both projects of the dataset and the control projects, categorized according to the base contract amount categories discussed earlier. In examining all the categories of the base contract amount in Figure 56 , the average cost overrun can be seen to fluctuate between 6 and $9 \%$ for all categories except the second $(\$ 1 \mathrm{M}-\$ 2 \mathrm{M})$. The wider range observed in the second category is a direct consequence of the $39 \%$ cost overrun outlier project discussed in Figure 5-5. Removal of this outlier data point would result in a much narrower range that is between 0 and $6.05 \%$. While the average was reasonable, the range between the minimum and maximum cost overrun for every category was quite substantial. For example, the $\$ 2 \mathrm{M}$ $\$ 6 \mathrm{M}$ category, which comprises 8 projects from the dataset and in which the control projects fall, had a minimum of $0.83 \%$ and a maximum of $15.76 \%$ cost overrun. The minimum and maximum figures represent the lowest and highest cost overrun incurred by projects. The cost overrun percentage for the control projects are shown to be at $4.36 \%$ and $3.41 \%$ - well below the $5.54 \%$ average for their category, and the $7.2 \%$ overall for the entire dataset. 
If the distribution of cost overrun amounts is examined by bid amount category, it is seen that the average amount of cost overrun is the highest for an original bid amount greater than $\$ 1 \mathrm{M}$. It can be noticed that for base amounts less than $\$ 1 \mathrm{M}$, the average cost overrun is lower than for those bid amounts greater than $\$ 1 \mathrm{Mwith}$ the exception of $\$ 22 \mathrm{M}$ - $\$ 40 \mathrm{M}$ range. Only three projects of the dataset belonged to the $\$ 22 \mathrm{M}-\$ 40 \mathrm{M}$ range, of which the cost overrun percentage range was between $2.94 \%$ and $7.55 \%$. The project with 2.94\% cost overrun is a project for Miami Dade Water and Sewer Department, which included approximately $\$ 2 \mathrm{M}$ of fuel costs, in the base amount, for testing new generators and for filling the fuel storage tanks with 200,000 gallons of fuel for emergency cases such as hurricanes. The amount of fuel used was less than what was in the contract documents and there was no need to fill the fuel storage tanks, which resulted in a cost reduction of $\$ 1.16 \mathrm{M}$ or $3.3 \%$ cost reduction, thus resulting in a lower cost overrun than would be expected.

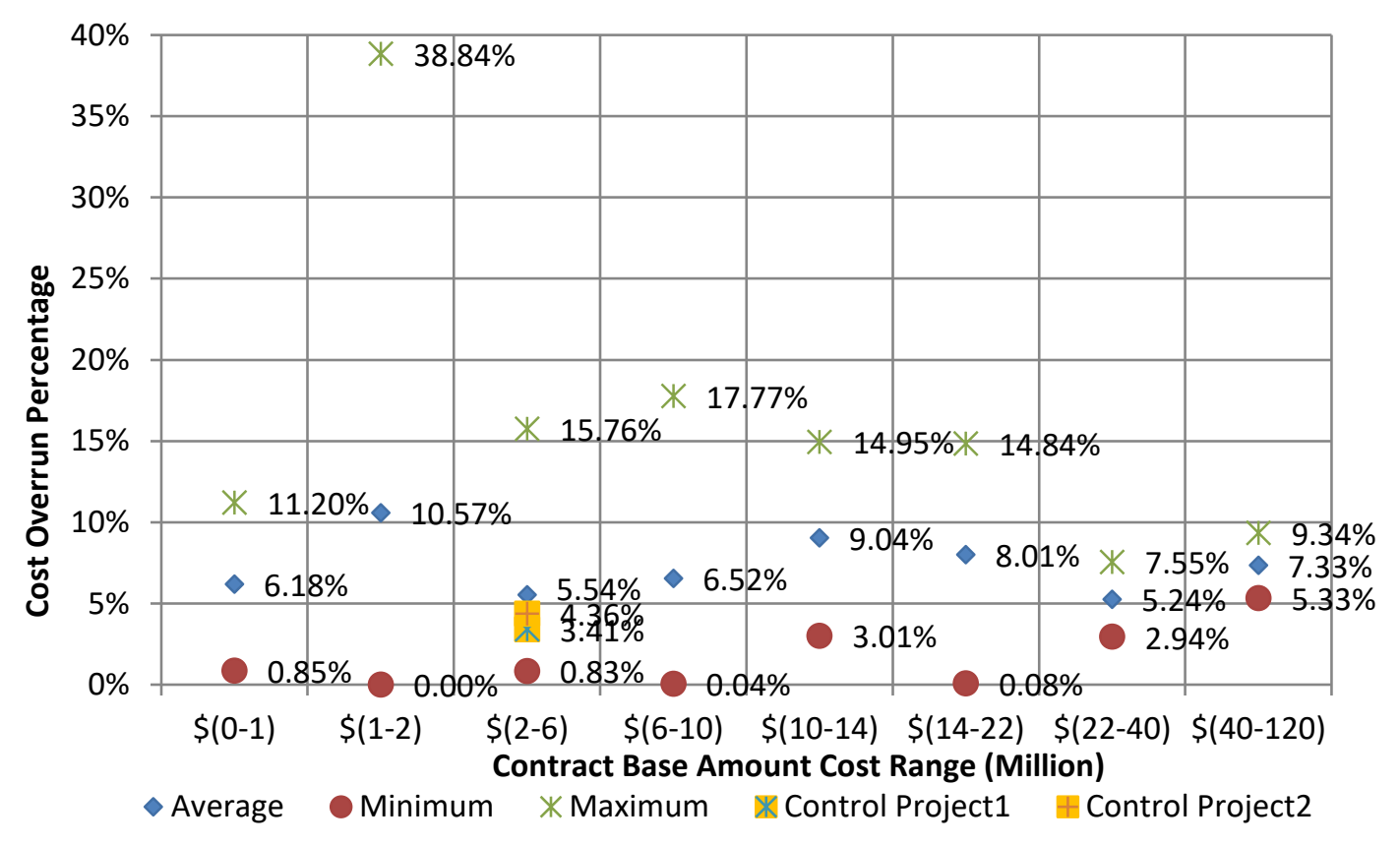

Figure 5-6: Cost overrun percentages for specified contract base amount range. 
Figure 5-7 compares the cost overrun averages of all projects in the dataset to the cost overrun percentage of the control projects.

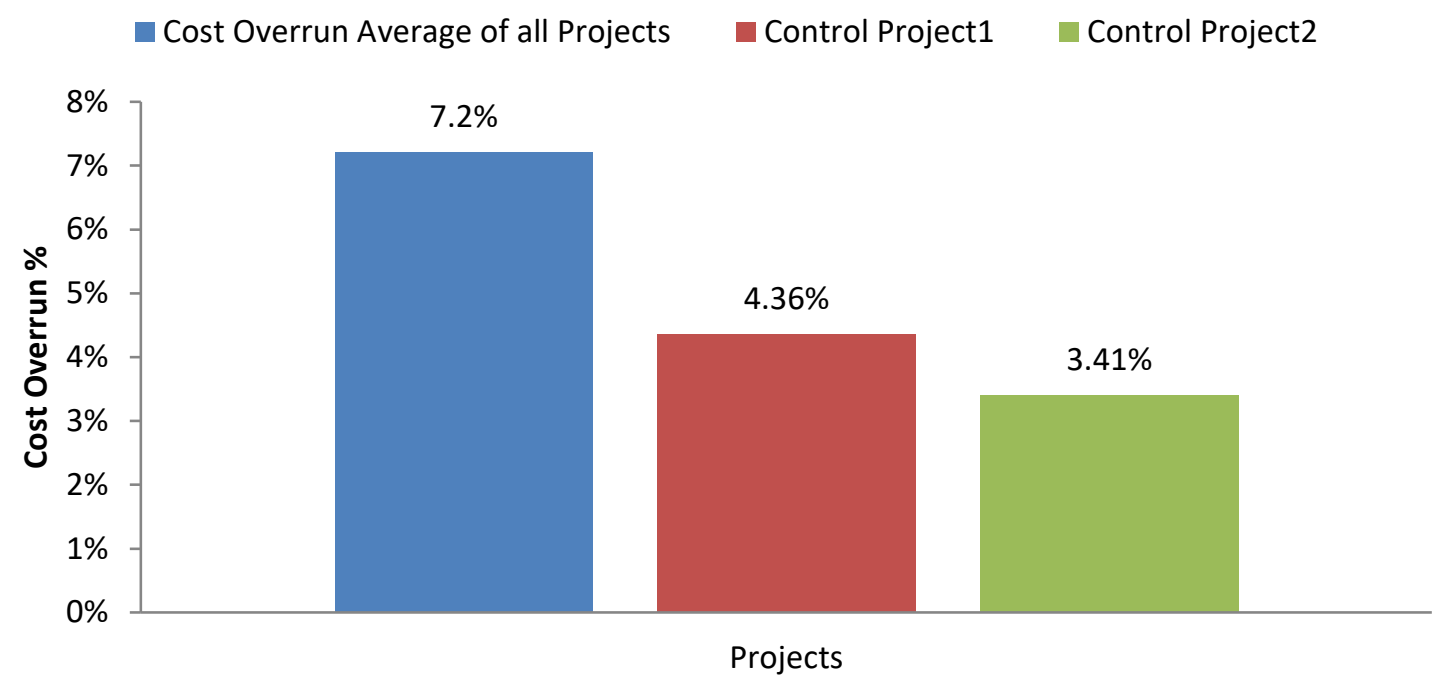

\section{Figure 5-7: Comparison of cost overrun average of all projects to time overrun of control projects.}

The cost overrun measures the difference between the award cost and the actual cost of the projects divided by the number of projects, as is demonstrated in Equation 5-2. For the traditional DBB projects the average cost overrun was calculated to be at $\$ 936,147$ while the average cost overrun for the control projects was calculated to be at $\$ 157,407$ as shown on Figure 5-8. The control projects show an average cost overrun that is $83.2 \%$ lower than the traditional $\mathrm{DBB}$ projects of the dataset. This is an indication that the actual expenditure of the control projects was very close to the award cost in comparison to that of the dataset projects. 


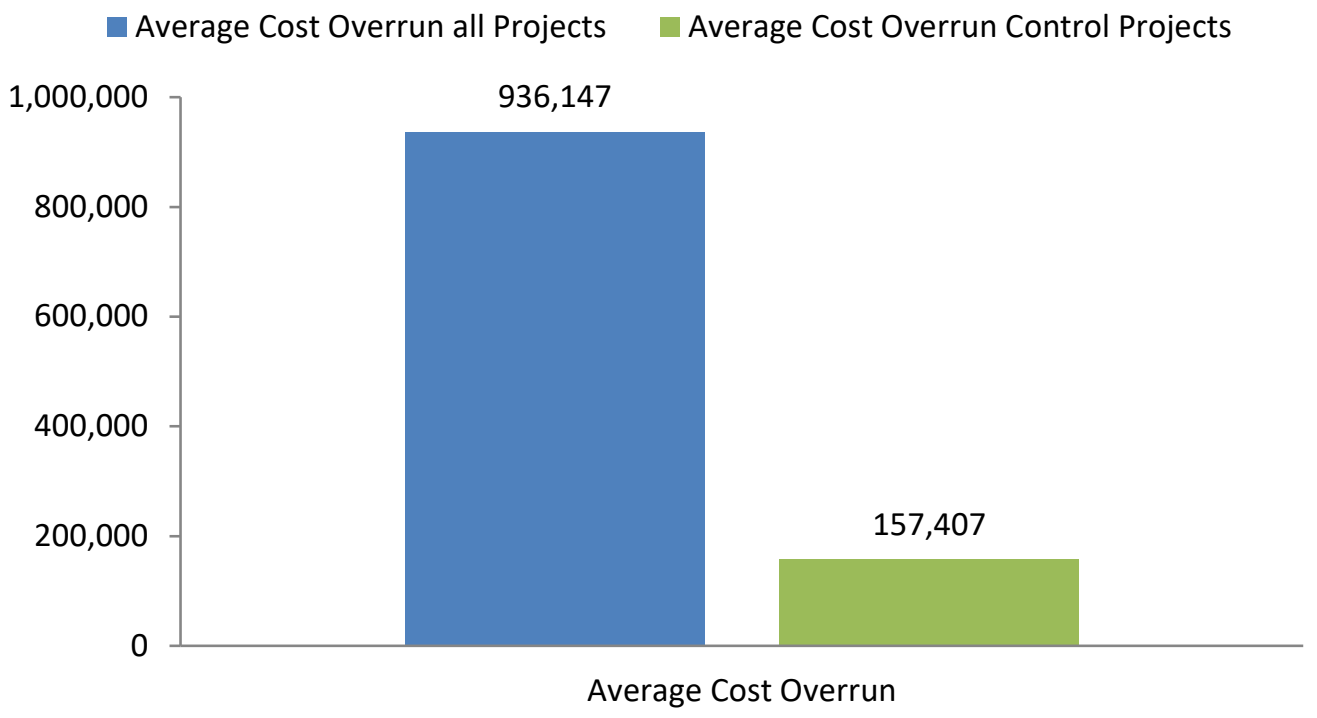

Figure 5-8: Comparison of average cost overrun of all projects to control projects.

\section{Performance Evaluations with Regard to Time}

Since time can be a critical factor for many clients, project duration is often of prime interest. However, schedule overruns may be an even more important issue. Time overrun, also referred to as time growth, during construction delivery is an important KPI. Time performance measurement can be established on the basis of a relationship among a number of project time variables, such as original contract duration and actual contract duration. The performance measure adopted in this study is the time overrun percentage, which measures the deviation of a project's actual duration from the original contract duration. Equations 5-4 and 5-5 are used to determine numerical values of the KPIs for time performance evaluation.

Average Time Overrun $\Delta=\frac{\sum \text { Actual Time }-\sum \text { Award Time }}{\text { Number of Projects }}$

Time Overrun $\%=\frac{\text { Actual Project Duration }}{\text { Scheduled Project Duration }} \times 100$ 
where Actual Project Duration is calculated as the time span between the Notice to Proceed date and the date when all work has been completed.

Figure 5-9 shows the time overrun as a percentage of the original project duration for both projects in the dataset and the control projects. The same figure shows a substantial range in the time overrun of completed projects and illustrates that most projects tend to exceed their original contract durations. Of all the projects in the dataset, $72.1 \%$ finished later than originally planned with 50\% having a time overrun greater than $10 \%$. Around 9.3\% of the projects finished sooner than originally planned. One of these projects was a Miami Dade Water and Sewer Department project with an engineer's duration of 5.5 years and base amount of $\$ 82 \mathrm{M}$. This project included building four new clarifiers and was completed 153 days ahead of schedule. The engineer's schedule on this project was over estimated and the contractor was able to sequence the construction activities in parallel and crashed activities by pouring large amounts of concrete at once. Another $\$ 4.4 \mathrm{M}$ project with 2.5 years duration in Broward County was completed 39 days ahead of schedule. The project's scope of work entailed demolitions of existing ground storage tank and pump station; construction of a new 1.5 million gallon tank, service pumps, ammonia and hypochlorite system. This project had a $-3.86 \%$ time overrun since the contractor was able to save time in building the tank using new construction techniques. The contractor used special wall forms, which allowed the casting of the walls faster than could be done by traditional methods. This reflects the high variance of the projects, for which the average time overrun was $22.2 \%$, and the standard deviation was $34.99 \%$. The control projects had time-overrun percentages $0 \%$ and $-0.71 \%$ and are shown in yellow in 
Figure 5-9. Implemented IPD principles with DBB delivery method is shown to have a time performance superior to the traditional DBB delivery method. Figure 5-9 shows that the distribution of time overrun in the chosen categories is normal, and has a somewhat bell shape.

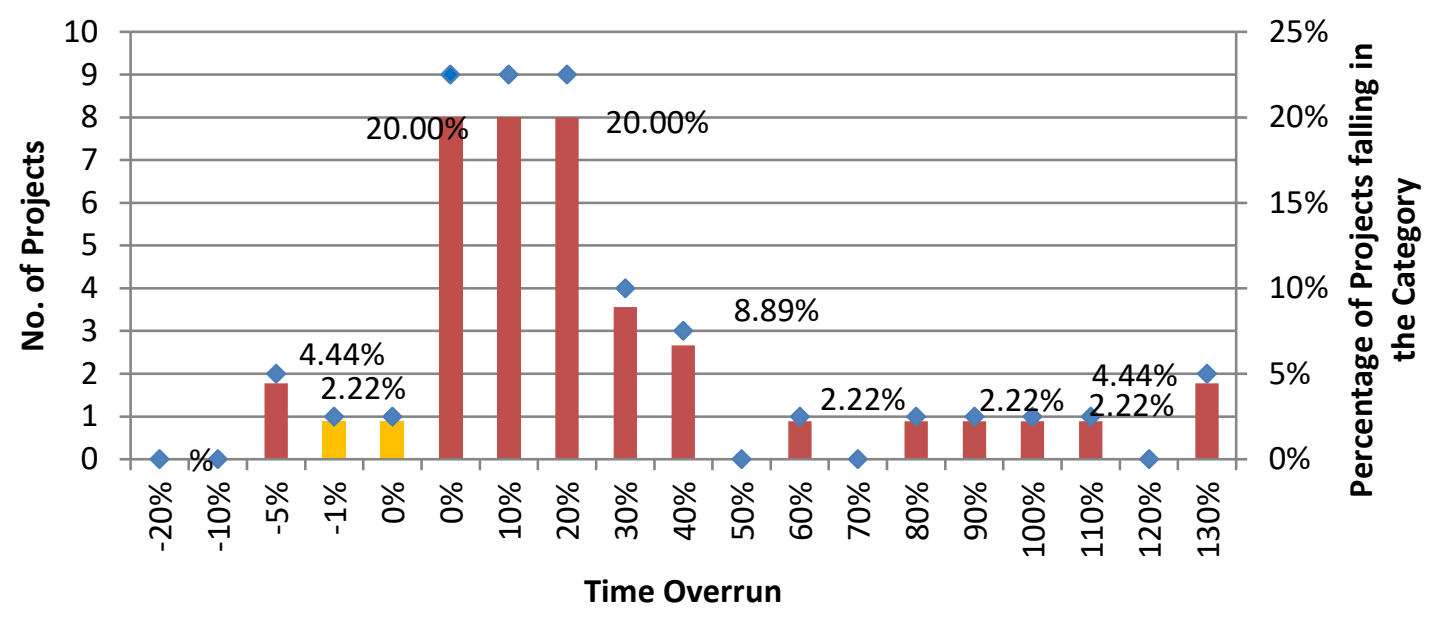

Figure 5-9: Distribution of projects with respect to the time overrun percentage.

To further analyze the time performance of the control projects, Figure 5-10 was used to show the variation of the average time overrun percentage in relation to the project base contract value categories defined earlier. For example, the $\$ 2.0 \mathrm{M}-\$ 6.0 \mathrm{M}$ category has an average time overrun of $28.56 \%$. The maximum time overrun percentage has substantially extreme values also, with an average of $122.2 \%$. The control projects, which fall in the same category, had a time overrun percentage that is very close to the minimum overrun line for that particular category. A comparative analysis of cost and time overrun between the projects revealed interesting trends. The majority of the dataset projects experience time overrun and the overrun amounts vary and are dependent on the volume of contract. The distribution of time delays exhibits a wider range of variation. 
This may be attributed to unforeseen conditions, error in the owner's original contract time estimate, and/or management deficiencies.

An interesting result was that longer contract duration and higher project cost are associated with a smaller time overrun. This finding seems rather surprising as longer contract duration and larger projects would typically be expected to have a greater time overrun due to the nature of complexity of these projects. It is possible that such unexpected finding was caused by correlation between the project duration and other variables, which could result in a greater time delay. It may be interesting to carry out further investigation of these trends, such as examining any existence of correlation between other variables.

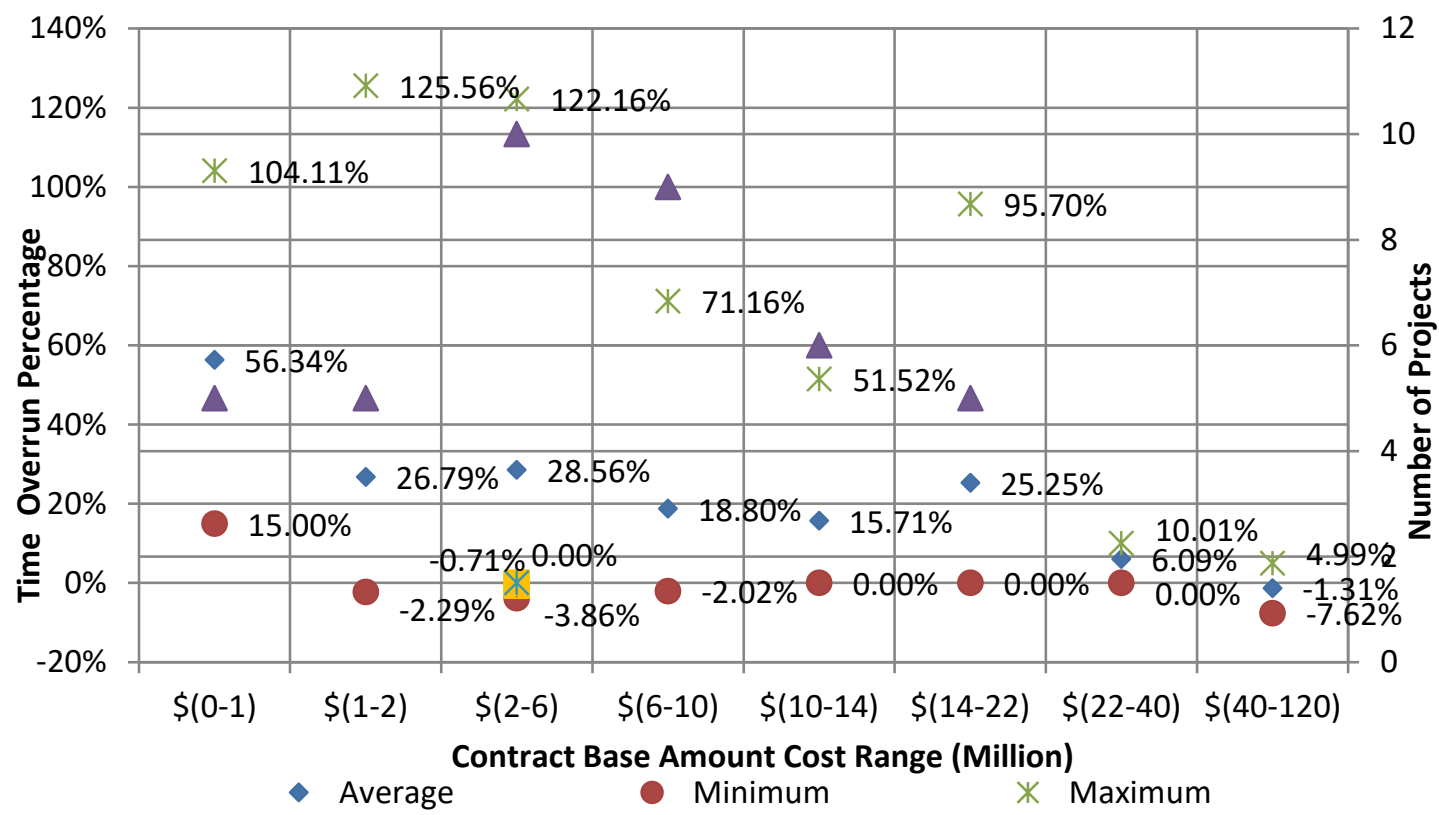

Figure 5-10: Time overrun percentages for specified contract base amount.

The overall average time overrun percentage for all the projects in the dataset was at $23.3 \%$. Figure 5-11 compares the time overrun average of all projects in the dataset to the time overrun percentage of the control projects. 


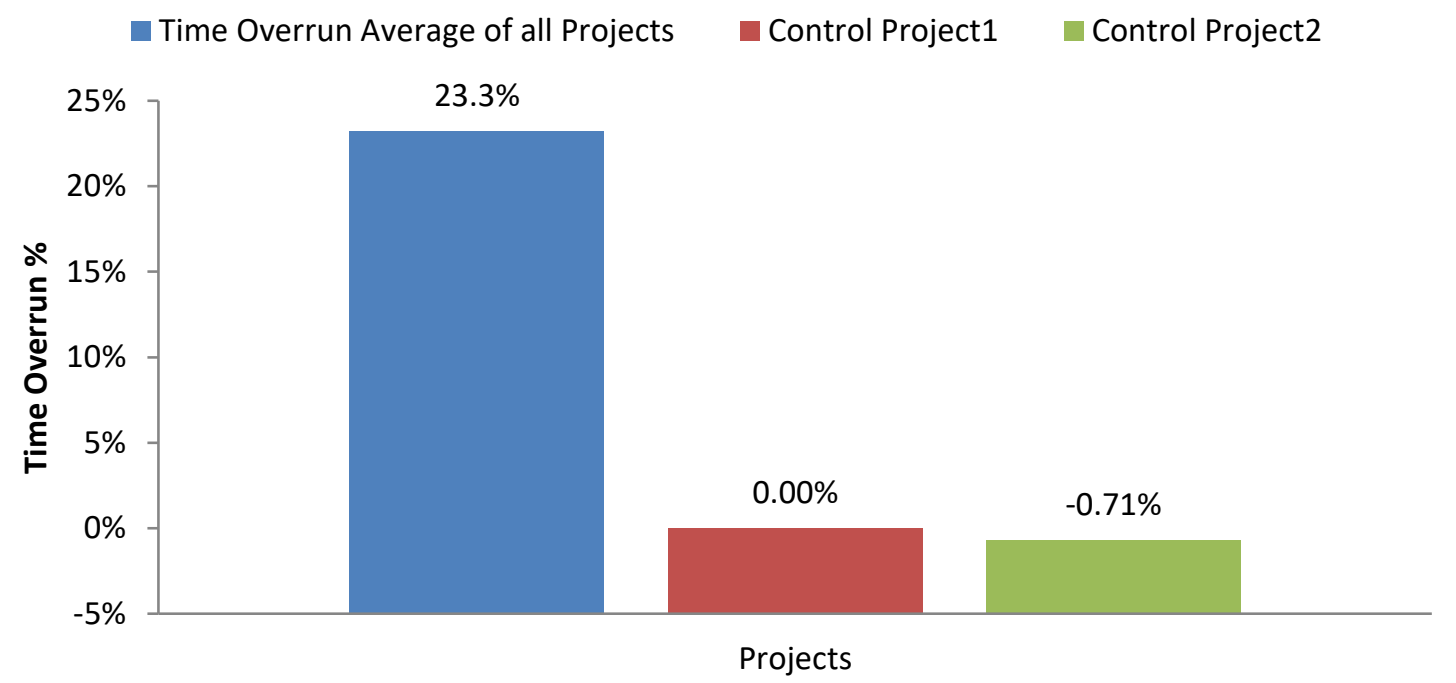

\section{Figure 5-11: Comparison of time overrun average of all projects to time overrun of control projects.}

Another time performance measure is the average time overrun, which measures the difference between the scheduled time and the actual completion time of the projects, divided by the number of projects, as was shown in Equation 5-4. For the traditional DBB projects of the dataset, the average time overrun was calculated to be at 104.63 days while the average time overrun for the control projects was calculated to be negative 2.0 days as shown in Figure 5-12. 


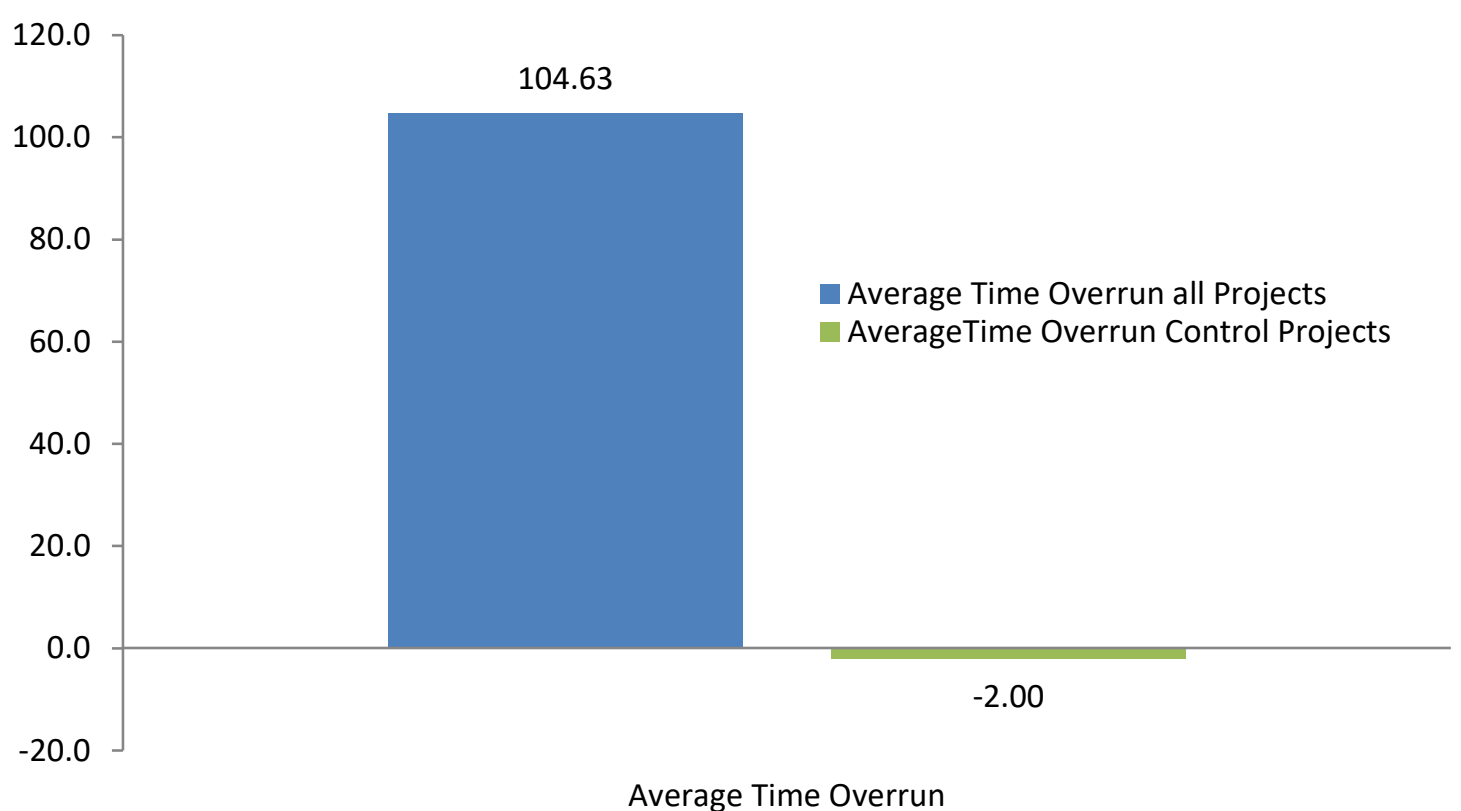

Figure 5-12: Comparison of average time overrun of all projects to control projects.

Table 5-7 shows the percentage of projects completed at different levels of time and cost overrun. For example, at $0 \%$ cost overrun (actual cost - base cost)/base cost, $2.44 \%$ of the projects were completed within the bid price. At $0 \%$ time overrun (actual duration - bid duration)/bid duration, $34.15 \%$ of the projects were completed on time. No trends can be observed from this table and it can be concluded that there exists no relationship between the cost overrun and the time overrun for a specific overrun percent. 
Table 5-7: Percentage of Projects at Different Levels of Time and Cost Overrun

\begin{tabular}{ccc}
\hline$\%$ Overrun & $\begin{array}{c}\text { \% of Projects at } \\
\text { Indicated \% of Cost } \\
\text { Overrun }\end{array}$ & $\begin{array}{c}\text { \% of Projects at } \\
\text { Indicated \% of Time } \\
\text { Overrun }\end{array}$ \\
\hline $0 \%$ & $2.44 \%$ & $34.15 \%$ \\
$5 \%$ & $34.15 \%$ & $7.32 \%$ \\
$10 \%$ & $39.02 \%$ & $9.76 \%$ \\
$15 \%$ & $17.07 \%$ & $17.07 \%$ \\
$20 \%$ & $4.88 \%$ & $4.88 \%$ \\
$25 \%$ & $0.00 \%$ & $4.88 \%$ \\
$30 \%$ & $0.00 \%$ & $2.44 \%$ \\
$35 \%$ & $0.00 \%$ & $2.44 \%$ \\
$40 \%$ & $2.44 \%$ & $0.000 \%$ \\
$55 \%$ & $0.00 \%$ & $2.44 \%$ \\
$75 \%$ & $0.00 \%$ & $2.44 \%$ \\
$85 \%$ & $0.00 \%$ & $2.44 \%$ \\
$100 \%$ & $0.00 \%$ & $2.44 \%$ \\
$105 \%$ & $0.00 \%$ & $2.44 \%$ \\
$125 \%$ & $0.00 \%$ & $2.44 \%$ \\
$135 \%$ & $0.00 \%$ & $2.44 \%$ \\
\hline
\end{tabular}

Figure 5-13 shows the number of projects completed at different levels of time and cost overrun. This graph is helpful to identify the projects with the same time and cost overrun at an indicated percentage. For example, there are six projects that have approximately the same percent of time and cost overrun. Five of these projects had a percent overrun range between $5 \%$ and $10 \%$, and one project fell in the $10 \%$ to $20 \%$ range. At $5 \%$ of both time and cost overrun, four projects, which is equivalent to $9.68 \%$ of the projects, experienced time and cost overruns. This figure is also significant to identify the projects with a certain successful limit of percent of both time and cost overrun. For example, if 5\% time and cost overrun was considered a successful limit, then, seven projects ( $16.2 \%$ of all projects) were considered to have been successfully completed. 


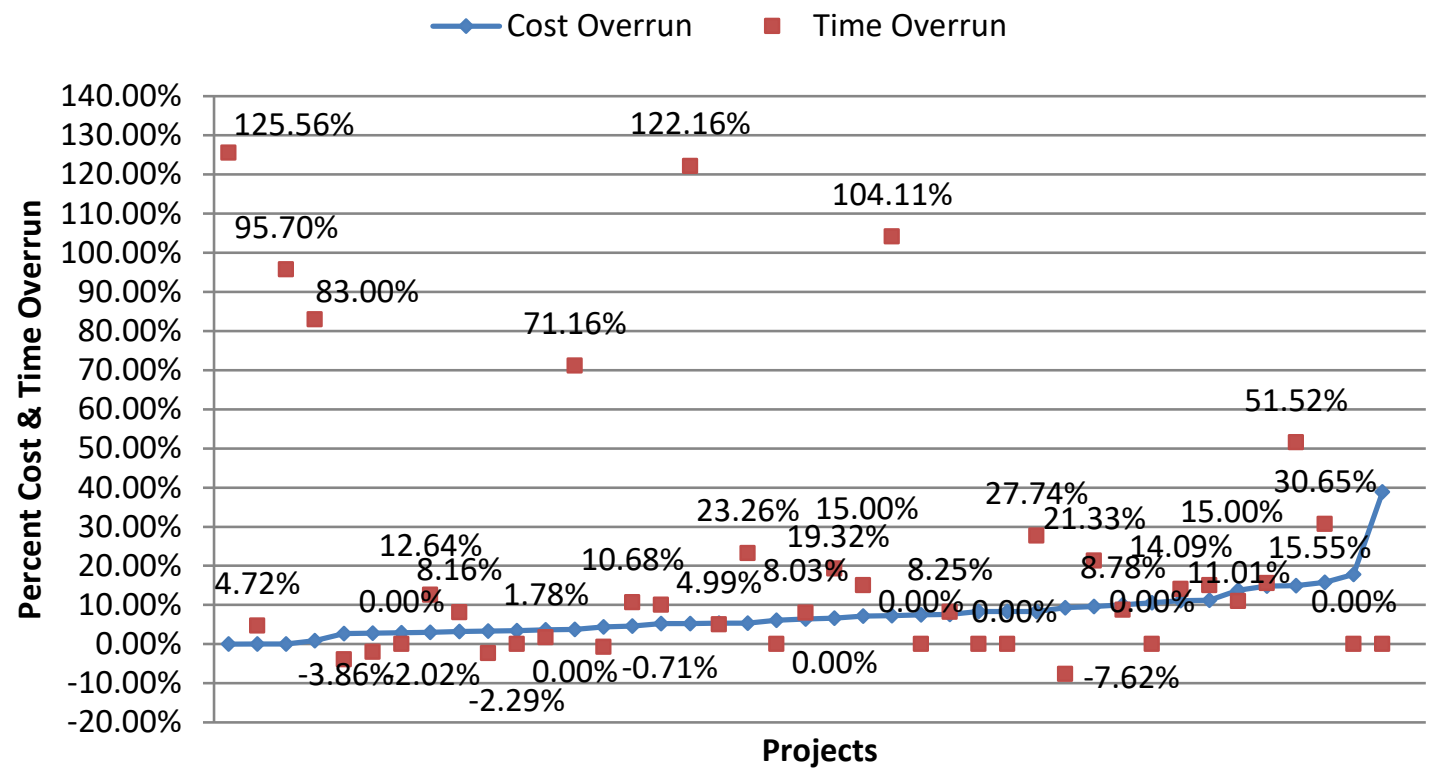

Figure 5-13: Comparison of percent time overrun to percent cost overrun per project.

\section{Performance Evaluation with Regard to Change Orders (CO)S}

Change orders (CO), commonly issued due to Request for Proposal (RFP), occur for many reasons on construction projects. These reasons share common characteristics and can be classified in common categories. In DBB projects, the causes of changes have been classified into five categories. According to the U.S. Army Corps of Engineers and the U.S. Navy (National Research Council 1986), the categories into which the primary causes for changes fall are:

- Design deficiencies (errors and omissions),

- Criteria changes,

- Unforeseen conditions,

- Owner requested changes, and

- Other categories. 
The number and percentage cost of COs obtained from the control projects were compared with the corresponding KPIs of the traditional DBB projects of the dataset. The control projects utilized CO Logs that were updated weekly by the researcher. A CO Log is shown in Appendix F. Equations 5-6, 5-7, and 5-8 were used to determine numerical values of the KPIs with regard to change orders.

Change Order Cost $\%=\frac{\sum \text { Cost of Change Orders }}{\text { Actual Total Project Cost }} x 100$

Percent of changes that are owner requested:

Owner's CO Cost $\%=\frac{\text { Total Cost of Owner's CO }}{\sum \text { Cost of Change Orders }} \times 100$

Percent of changes that are due to design errors and omissions:

Errors and Omissions CO Cost $\%=\frac{\sum \text { Cost of Errors and Omissions CO }}{\sum \text { Cost of Change Orders }} x 100$

Figure 5-14 illustrates how the percent of total $\mathrm{CO}$ cost of projects varies in relation to the contract base amount categories. The average coefficient of variation was significant at $102 \%$. In examining the categories of the base contract amount, the $\$ 2 \mathrm{M}-\$ 6 \mathrm{M}$ range category had a minimum and maximum $\mathrm{CO} \cos \mathrm{t}$ - as a percentage of the contract base amount - of $2.2 \%$ and $15.8 \%$, respectively. The CO percentage costs for the control projects were, in comparison, at 3.6 and $8.1 \%$. These values were respectively at the minimum and average percentage $\mathrm{CO}$ cost for the dataset projects in the same base contract value category.

Figure 5-14 does not show a uniform trend of the percent of $\mathrm{CO}$ cost versus the contract base amount. This is due to the fact that COs are based on many variables that change with different projects. The most significant interactions of cost variables are the following: 
1- Timing of the change order: Practically, the cost of change increases as the project moves toward completion (Chick, 1999); and

2- Reason for the Change: As previously mentioned, there are several reasons for the owner to issue a change order.

Contractors may need to underbid projects to secure work in a competitive bidding environment. COs may be used to make up losses inherent in the bids. The outlier project with $38.8 \%$ total CO cost was a water treatment plant upgrade in the City of Fort Lauderdale previously illustrated in the cost overrun in Figure 5-5. The cost overrun of this project was equal to the CO cost of $\$ 678,975.27$.

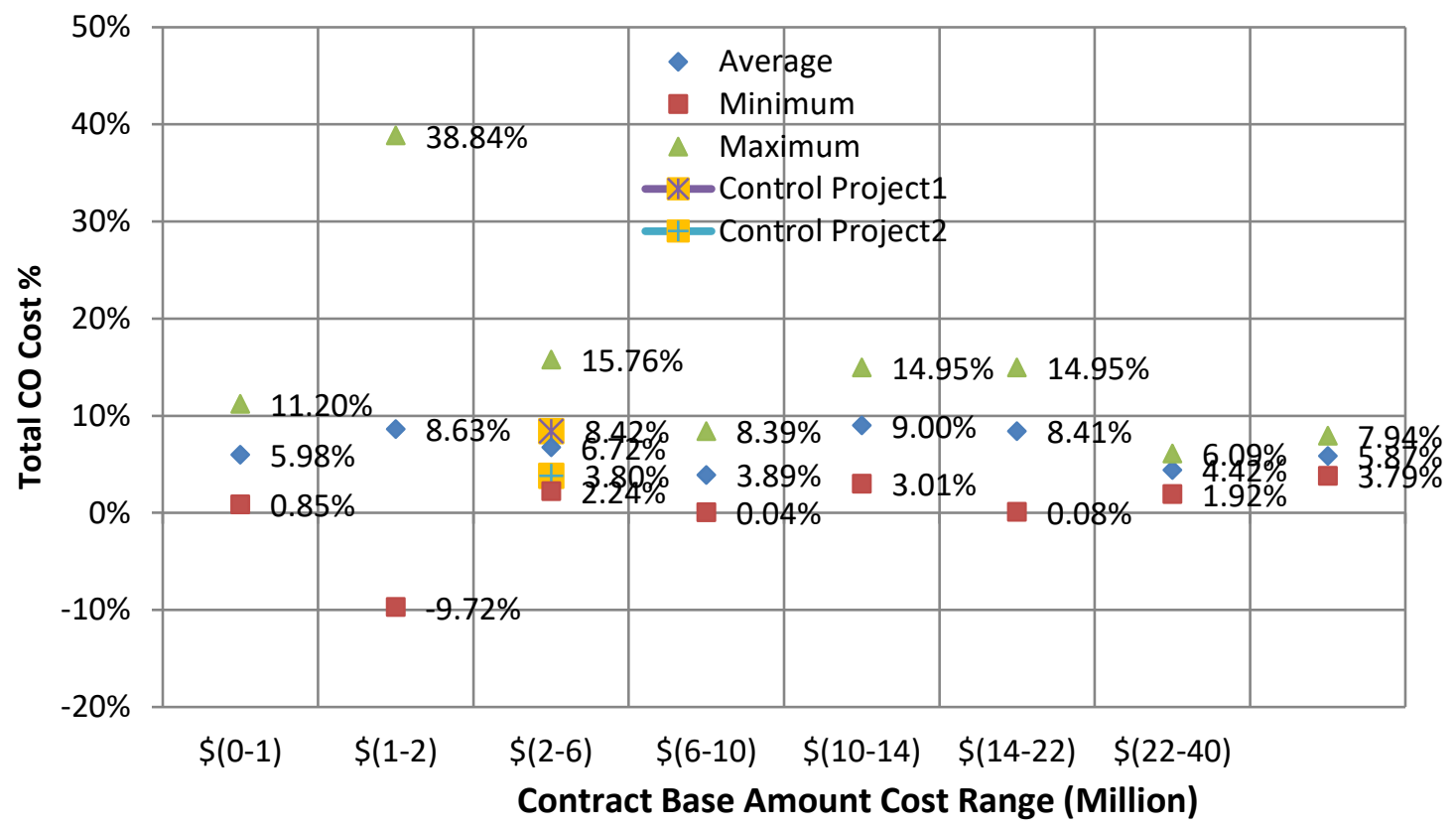

Figure 5-14: Total CO cost for specified contract base amount range.

Table 5-8 lists some basic information about the overall average of the RFP percentage cost. 
Table 5-8: Statistics of the CO Performance Measure

\begin{tabular}{cccccc}
\hline Measure & Average & $\begin{array}{c}\text { Standard } \\
\text { Deviation }\end{array}$ & $\begin{array}{c}\text { Coeff. of } \\
\text { Variation }\end{array}$ & Minimum & Maximum \\
\hline$\%$ Total CO & $6.57 \%$ & $6.75 \%$ & $102.6 \%$ & $0.0 \%$ & $38.8 \%$ \\
\hline
\end{tabular}

Rowland (1981) found that the amount of change orders increases with the increase in the contract size due to the complexity of larger projects. Rowland (1981) found that lack of effective communication channels in large projects, tend to increase the likelihood of a high number of change orders. In addition, the larger the gap between the low bid and the next low bid on a project, the greater the likelihood that a project will experience greater number of change orders. According to Rowland, when there is a low bid is significantly lower than the next low bid due to an error, the low bidder who has been awarded the project needs to take advantage of change orders to recover the losses.

From another perspective, because the risks are higher in largest cost ranges, (above $\$ 22 \mathrm{M}$ ), more care could be exercised during construction and planning phases, leading to a lower likelihood of cost overrun and time delays. Similarly, for the smallest cost ranges $(\$ 0 \mathrm{M}-\$ 1 \mathrm{M})$, because the projects are very simple in comparison to large complex projects, the $\mathrm{CO}$ cost percent tends to be lower.

Figure 5-15 shows how the owner requested $\mathrm{CO}$ cost of projects as a percentage of the base contract amount varies in relation to the contract base amount categories. In examining the category ranges of the base contract amount, the $\$ 2 \mathrm{M}-\$ 6 \mathrm{M}$ range had a minimum and maximum of $0.14 \%$ and $7.1 \%$ owner requested $\mathrm{CO}$ cost, respectively. The owner requested $\mathrm{CO}$ cost percentage for the control projects were at $4.5 \%$ and $1.9 \%$, which are close to the average and the minimum percentages for the dataset projects in 
the same base contract value category. Figure 5-15 shows that the highest owner requested change orders were in $\$ 1 \mathrm{M}$ - $\$ 2 \mathrm{M}$ range with an average of $7.5 \%$. The outlier project with $38.08 \%$ of owner requested CO cost was a water treatment plant upgrade in the City of Fort Lauderdale previously illustrated in the cost overrun in Figure 5-5 and Figure 5-14. Total change orders were $\$ 678,975.27$ of which $85 \%(\$ 578,158)$ were owner requested changes. As shown the average trend is not uniform across the contract base amount range due to the nature of variation of the conditions of each project. In water related projects, contracts that are less than $\$ 1$ million are either simple rehabilitation projects, site preparation projects, or small pipeline projects. In that $\$ 0 \mathrm{M}$ $\$ 1 \mathrm{M}$ range, projects are simple and straight forward such as coatings, making it limited for owners to implement additional scope of work. On the contrary, $\$ 1 \mathrm{M}$ - \$2M range has the highest average percent of owner requested CO cost. The $\$ 1 \mathrm{M}-\$ 2 \mathrm{M}$ range projects include rehabilitation and improvement projects to existing structures that are more complicated than the $\$ 0 \mathrm{M}$ - $\$ 1 \mathrm{M}$ range. In these types of projects, the onsite owner's operations personnel who have the hands-on experience of working in these facilities and who were not involved in the design and planning phase of the project generate wish lists of changes that they would like to replace or add to the facilities. This rarely is the case in larger projects composed mostly of new structures and in which the owner's wish list tends to be smaller and lean towards a smaller impact on the overall cost of the project. 


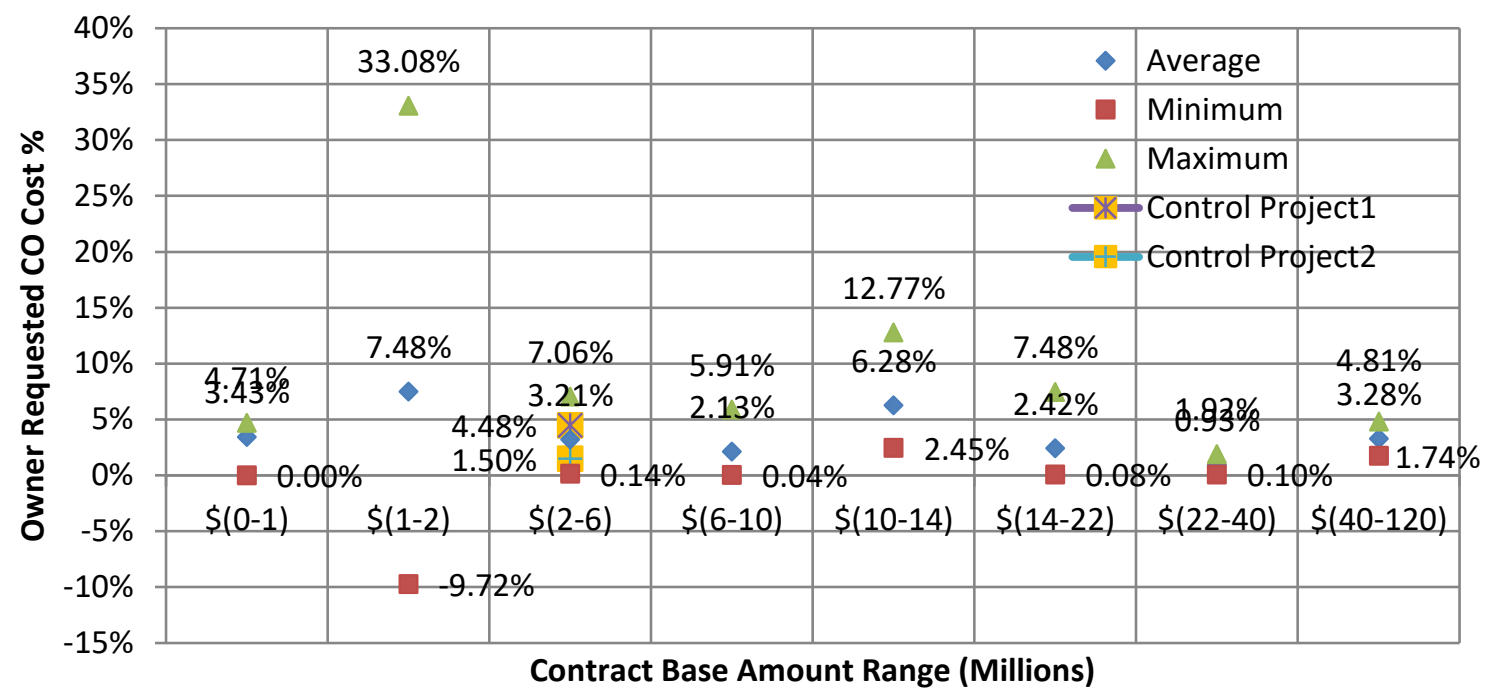

Figure 5-15: Owner requested $\mathrm{CO}$ cost for specified contract base amount range.

Figure 5-16 illustrates how the owner requested $\mathrm{CO}$ cost of projects as percentage of the total $\mathrm{CO}$ cost varies in relation to the actual expenditure cost. Both control projects fell close to the minimum. Figure 5-16 shows that the average owner requested $\mathrm{CO}$ cost of projects as a percentage of the total $\mathrm{CO}$ cost does vary greatly among the contract actual expenditure cost range. Figure 5-16 is similar to Figure 5-15; however, the trends are sharper. Figure 5-16 also shows that the most frequent owner requested change orders were in $\$ 1 \mathrm{M}$ - \$2M range with an average of $98.83 \%$. 


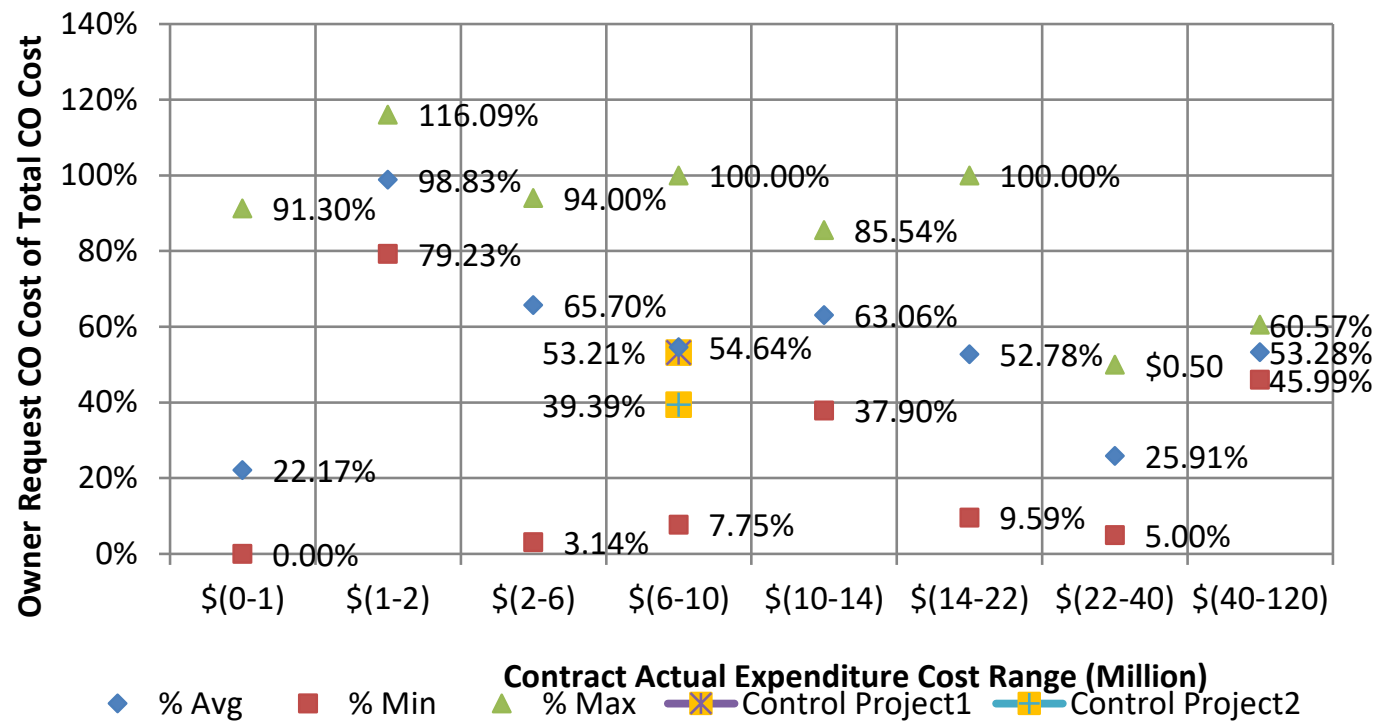

Figure 5-16: Owner requested CO cost for specified actual expenditure range.

The researcher reviewed the COs of the dataset projects and assessed the COs related to errors and omissions. Omissions usually add value to a project. Instead of being included at the time of contract award, the building improvement that was omitted from the design documents is picked up by a change order. Design errors, on the other hand, are mistakes made by the designer that, when corrected, do not add to the greater value of the project. Figure 5-17 shows how the errors and omissions CO cost percentage of projects varies in relation to the contract base amount. In examining the categories of the base contract amount, the $\$ 2 \mathrm{M}$ - $\$ 6 \mathrm{M}$ category had a minimum and a maximum of $0.35 \%$ and $3.20 \%$ of error and omission CO cost, respectively. In comparison, the error and omission $\mathrm{CO}$ cost percentage for the control projects were at $0.88 \%$ and $0.60 \%$, which are close to the average minimum for the dataset projects in the same base contract value category. Figure 5-17 is the opposite of Figure 5-15 where the least frequent error and omission change orders were in the $\$ 1 \mathrm{M}$ - $\$ 2 \mathrm{M}$ range with an average of $0.75 \%$. As 
previously mentioned, the $\$ 1 \mathrm{M}$ - $\$ 2 \mathrm{M}$ range projects includes rehabilitation and improvement projects where the errors and omissions are limited since the design of such projects is simpler than most of the other contract ranges. The narrow ranges of variation in the percent error and omission CO cost for projects in the $\$ 40 \mathrm{M}$ - $\$ 120 \mathrm{M}$ range, is because there were only two projects in that category, and both projects had close percent values.

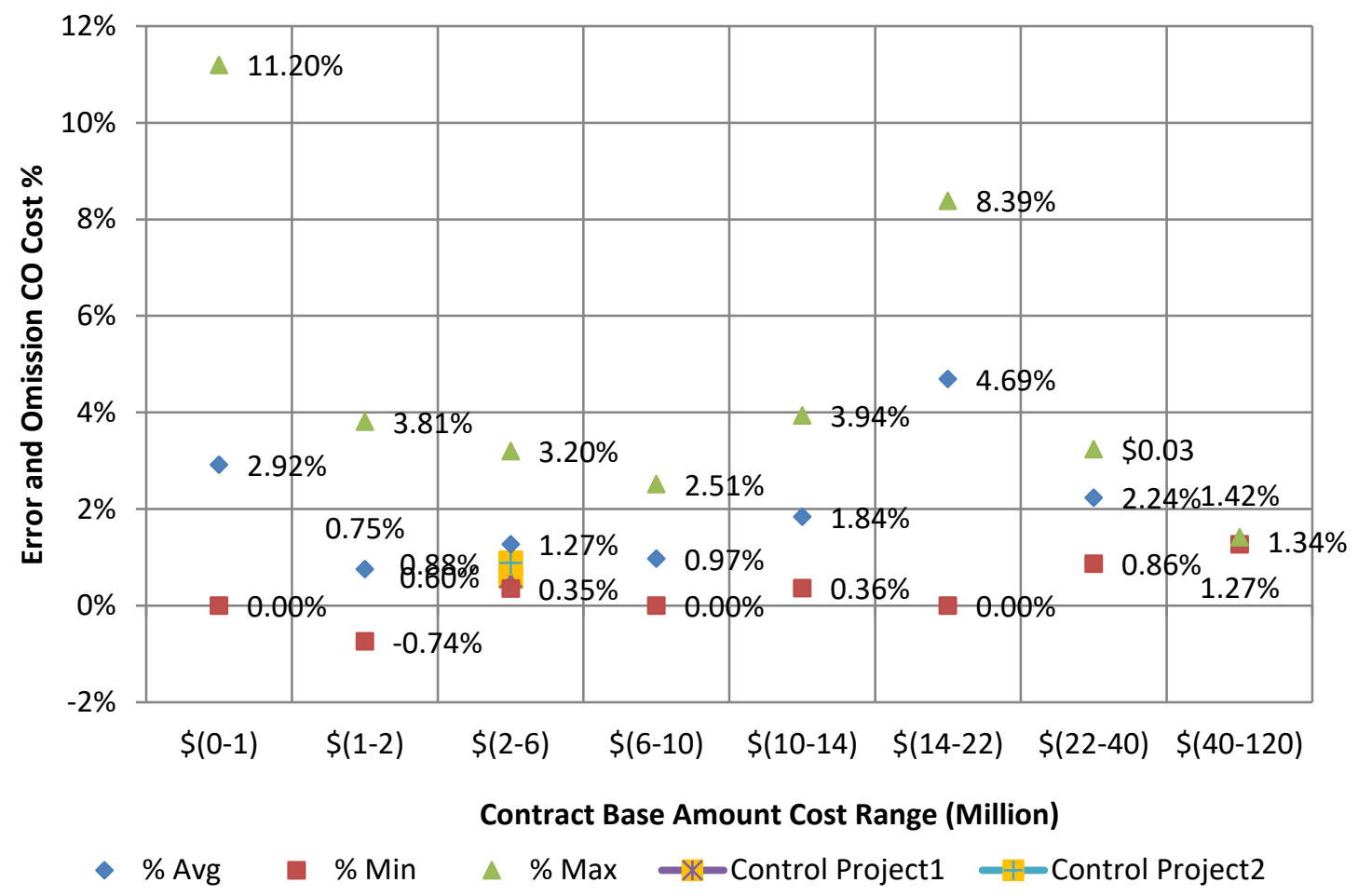

Figure 5-17: Error and omission $\mathrm{CO}$ cost for specified contract base amount range.

Similarly, Figure 5-18 shows how the percent of errors and omissions CO cost of projects varied in relation to the actual expenditure cost. One of the control projects fell above the average, while the other very close to the minimum. 


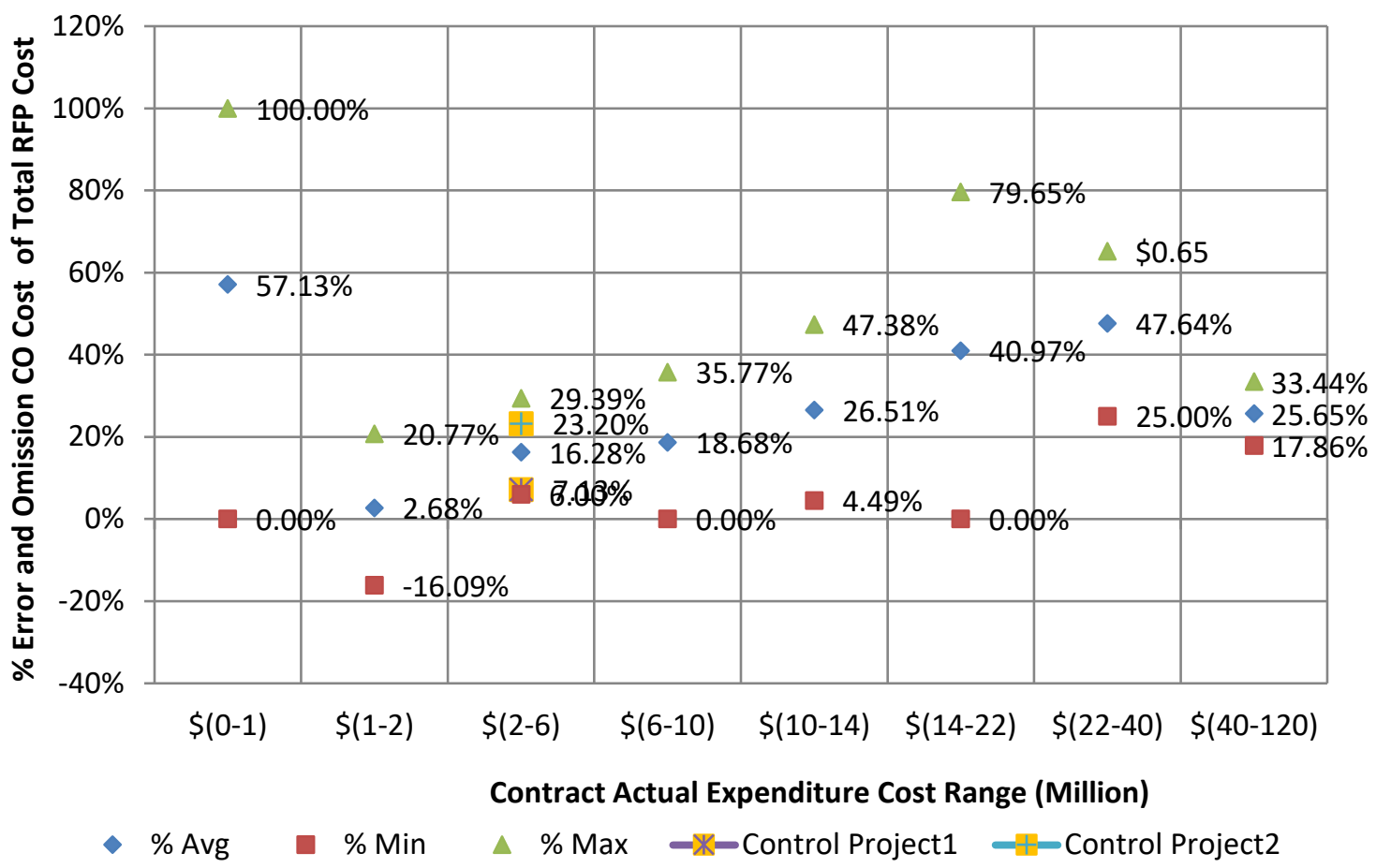

Figure 5-18: Error and omission $C O$ cost for specified actual expenditure cost range.

In Figure 5-19 the time overrun percentage is plotted against the total number of RFPs. Wide ranges of variation in time overrun percentages can also be observed when the time overrun percentage is plotted in relation to total number of RFPs, as was the case when plotted against the project base contract amount. When examining the ranges of the total number of RFPs, the time overrun percentage of the two control projects fell near the average minimum for projects in the dataset having the same range of RFPs.

In the case of time overrun, it is important to consider the large fluctuations, particularly in the categories of five to 10 and 10 to 15 RFPs. The first category represented five projects with $12.3 \%$, and the second category had four projects and represented more than $57 \%$ of average time overrun. Figure 5-19 does not show a particular trend of the 
number of RFPs versus time overrun. This is mostly due to the fact that RFPs are based on many variables that change with different projects such as:

1- Time extensions granted when RFPs are owner requested; and

2- Work stoppages, where it is not uncommon that the contractor has to stop the work when a change order is issued, thus increasing the time overrun.

Since the cases stated above do not occur in every RFP, this would not have to result in an increase in the time overrun. On large projects, group leaders may pay special attention to prevent time overrun from exceeding larger rates.

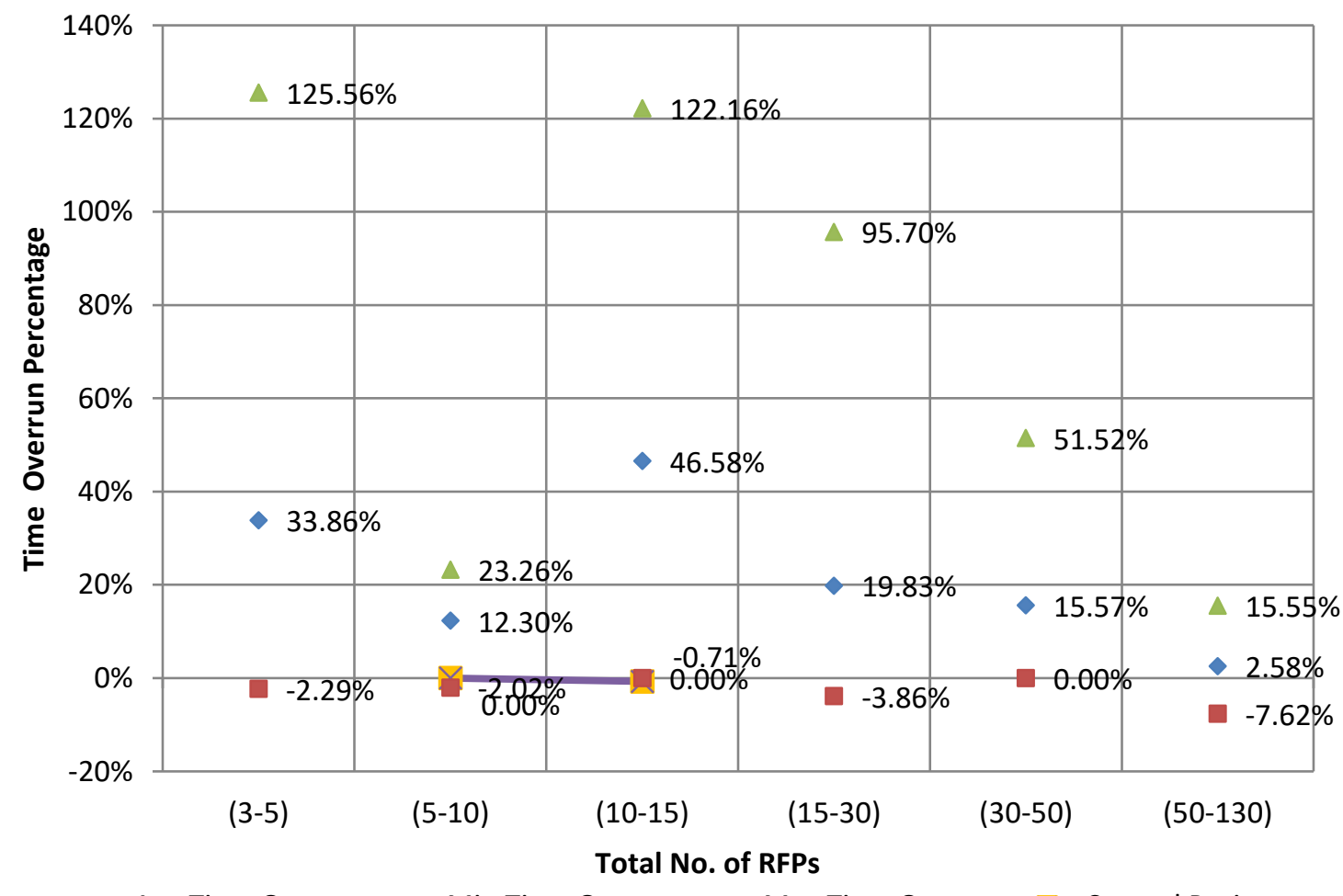

- Avg Time Overrun $\square$ Min Time Overrun $\triangle$ Max Time Overrun $-x-$ Control Projects

Figure 5-19: Time overrun for specified total number of RFPs.

Another way to evaluate the performance of a project with regards to the cost of RFPs is by plotting how the time overrun percentage varies with respect to the specified percent 
ranges of total CO cost to contract base amount. This evaluation is shown in Figure 5-20. It can be seen from Figure 5-20 that in evaluating this KPI, the control projects had time overrun percentages of negative $0.89 \%$ and $0 \%$, respectively. Both control projects thus have this KPI falling near or below the minimum average of the dataset projects in the same ranges.

Similarly, Figure 5-21 illustrates how the time overrun percentage varies in relation to the specified percent range of total $\mathrm{CO}$ cost to actual paid amount. The time overrun percentage for the control projects again shows to be at or very near to the minimum averages of the dataset projects. Projects with minimum percent range of total $\mathrm{CO}$ cost experienced the most time delay (an average of $53.15 \%$ ). This can be attributed to small size projects with tight schedules where a small percent of $\mathrm{CO}$ can lead to higher levels of delay in the contract execution. Projects with the largest percent range of total $\mathrm{CO}$ cost experienced the least time delays due to their large projects' size with long original projects durations. The zero time overrun value for projects with over $16 \%$ total CO cost was because there was only one project in that category, and that project did not experience any time delay. 


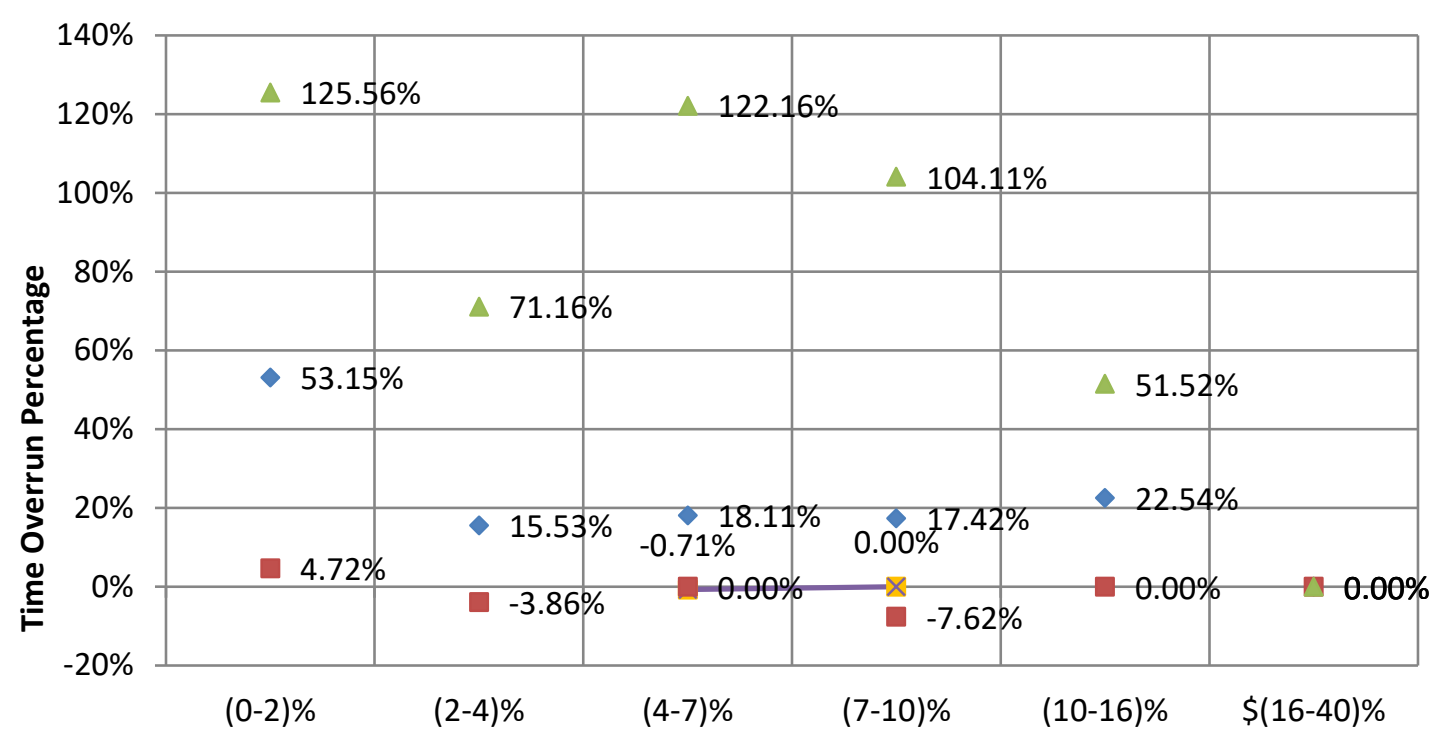

Percent Range of Total CO Cost to Contract Base Amount

$\checkmark$ Avg Time Overrun - Min Time Overrun $\triangle$ Max Time Overrun $-x-$ Control Projects

Figure 5-20: Time overrun for specified percent range of total RFP cost to contract base amount.

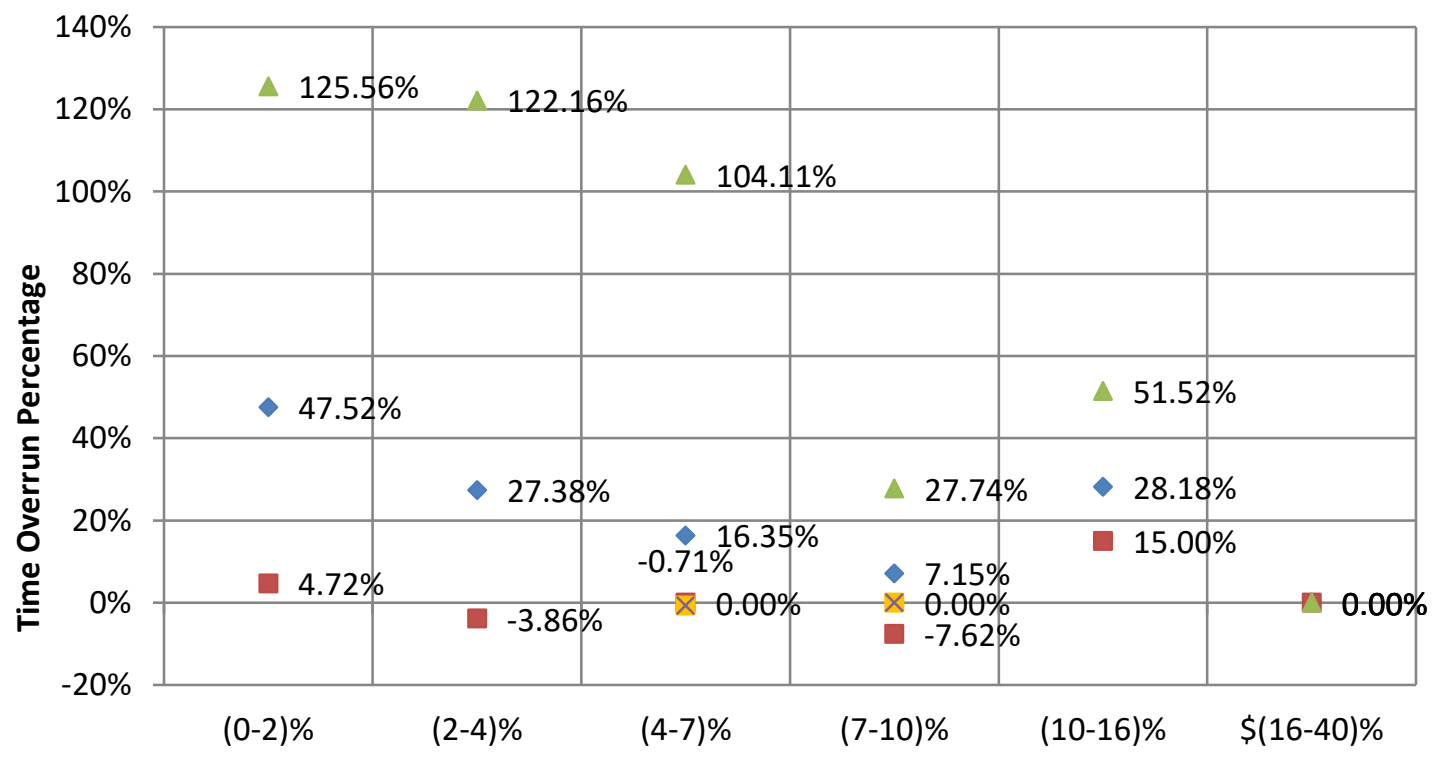

Percent Range of Total CO Cost to Actual Paid Amount

$\checkmark$ Avg Time Overrun $\square$ Min Time Overrun $\triangle$ Max Time Overrun $\quad x$ Control Projects

Figure 5-21: Time overrun to specified percent range of total CO cost to actual paid amount. 
Figure 5-22 illustrates how the cost overrun percentage varies in relation to the specified percent range of total CO cost to contract base amount. The cost overrun percentages for both control projects were near the minimum calculated average for the dataset projects. The relationship between cost overrun and percent range of total CO cost to contract base amount, in Figure 5-22, shows a strong direct correlation, where an increasing cost overrun percentage value is directly related to an increased percent range of total CO cost of projects. A similar pattern is shown in Figure 5-23, in which cost overrun percentage increases with an increase in the percent range of total $\mathrm{CO}$ cost to actual paid amount. This trend is logical and expected given that cost overrun is mostly due to additional cost coming from COs. It can be observed from previous figures that the higher percentage of $\mathrm{CO}$ costs does not occur in large projects and these projects tend to have lower cost overrun percentages. Figure 5-23 also shows that the cost overrun percentage for the control projects was at or below the average minimums of the corresponding dataset categories. 


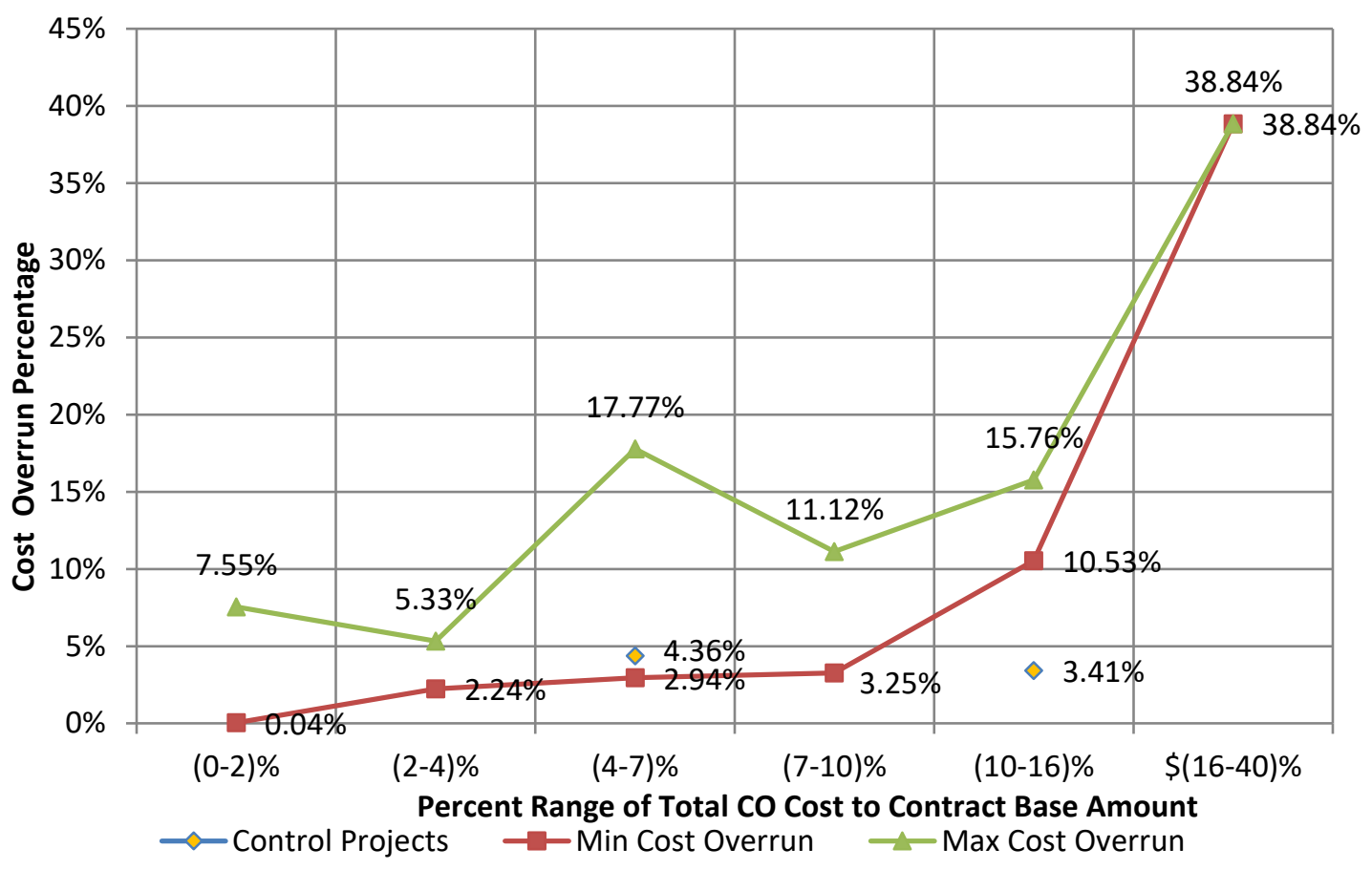

Figure 5-22: Cost overrun to specified percent range of total $\mathrm{CO}$ cost to contract base amount.

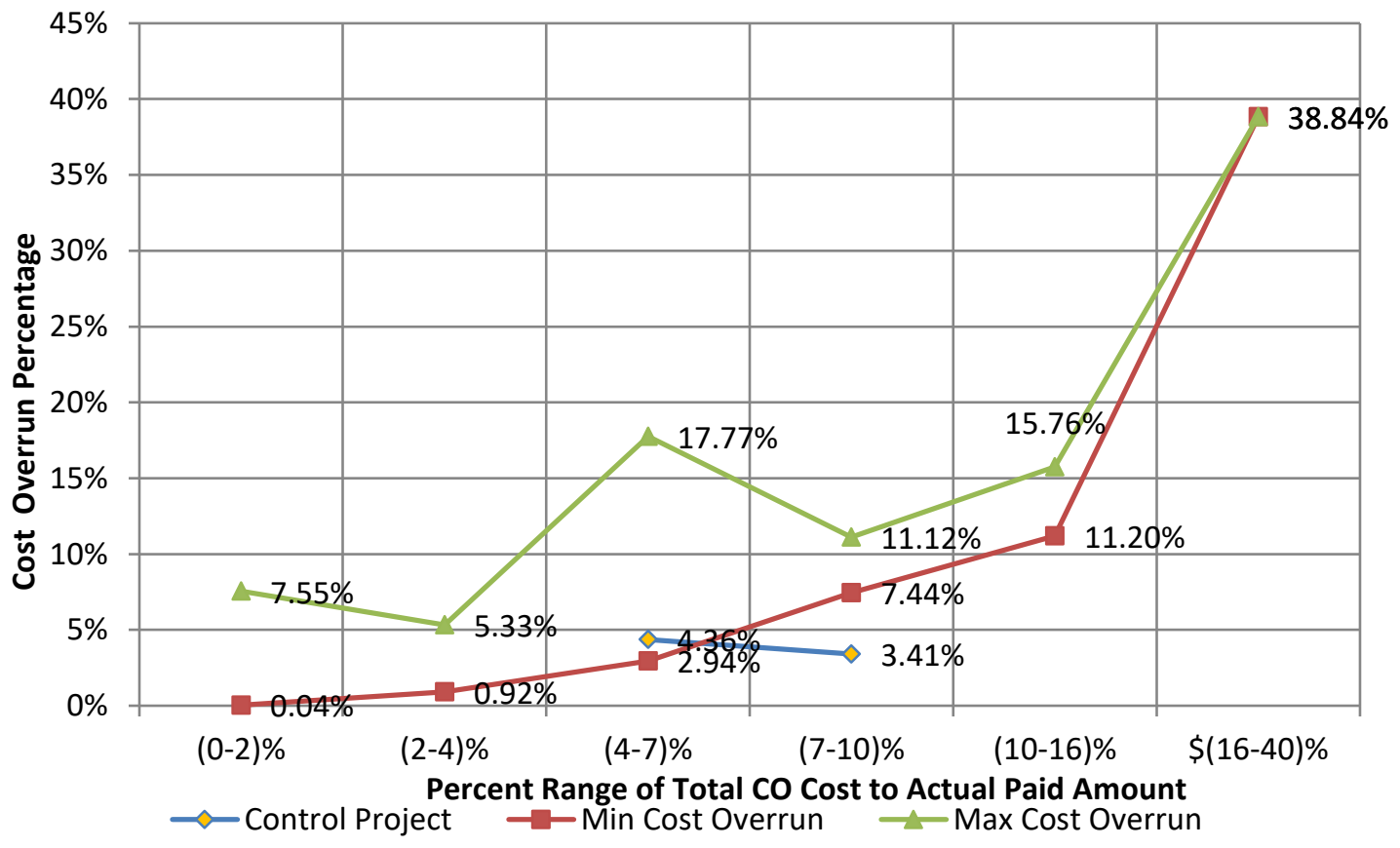

Figure 5-23: Cost overrun to specified percent range of total CO cost to actual paid amount. 
The overall average number of RFPs for all the dataset projects was 24.8 . Figure 5-24 compares the overall average number of RFPs for all the dataset projects of the dataset to the number of RFPs of the control projects. The plot shows that the values of eight and 10 total number of RFPs recorded for the control projects fall well below the overall average number of RFPs in the dataset projects.

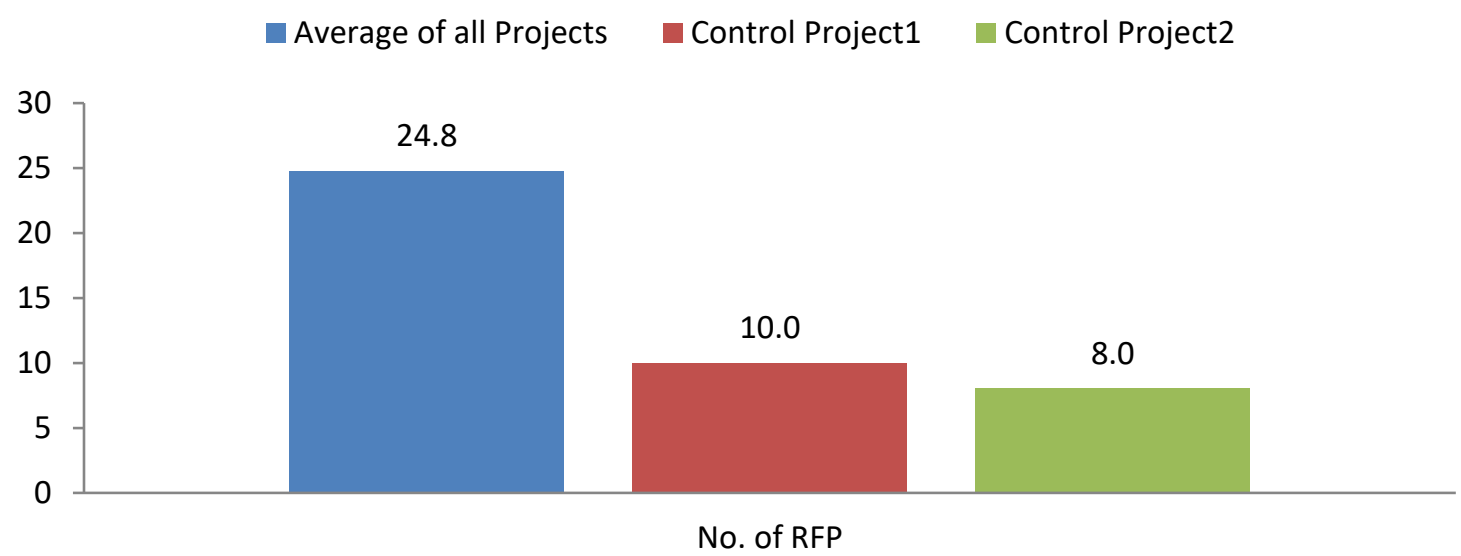

Figure 5-24: Comparison of average number of RFPs of all projects to control projects.

\section{$\underline{\text { Request for Information (RFI) Evaluation }}$}

In most Construction Documents, it is inevitable that the agreement, drawings, and specifications will not adequately address every single matter of the project. There may be gaps, conflicts, or ambiguities. The goal of the Request for Information (RFI) is to act as a partnering tool to resolve these gaps, conflicts, or ambiguities during the bidding process or early in the construction process, thus eliminating the need for costly corrective measures such as change orders. In many cases, the response to the RFI may lead to additional work during the construction process. The number of RFIs obtained 
from the control projects was compared to those of the dataset projects. The control projects utilized RFI Logs that were updated weekly by the researcher. An RFI Log is shown in Appendix G.

RFI performance measures include two components: (1) number of RFIs, and (2) average RFI response time. Equations 5-9 and 5-10 are used for performance evaluations with regard to RFIs.

RFI per Unit Price $=\frac{\text { Total Number of RFIS }}{\text { Actual Total Project Cost }}$

FI Response Time per Unit Price $=\frac{\text { Average RFI Response Time }}{\text { Actual Total Project Cost }}$

Figure 5-25 illustrates how the number of project RFIs varies in relation to the contract base amount. In examining the categories of the base contract amount, the $\$ 2 \mathrm{M}$ $\$ 6 \mathrm{M}$ range had a minimum of 10 and a maximum of 55 RFIs. The numbers of RFIs for the two control projects were 10 and 25 , respectively. In comparison, the numbers of RFIs of the control projects fall between the minimum and the average of the dataset projects in the same particular cost range.

It can be noted that the $\$ 10 \mathrm{M}-\$ 14 \mathrm{M}$ range experienced a greater number of RFIs than the other ranges, with an average of 159 RFIs. The relationship between contract base amount and total number of RFIs, in Figure 5-25, shows a strong direct correlation, where a contract base amount value is directly related to an increased number of RFIs. Contract base amount range of $\$ 10 \mathrm{M}$ - $\$ 14 \mathrm{M}$ includes an outlier value, which is difficult to explain due to lack of adequate data to determine the cause of the RFIs. 


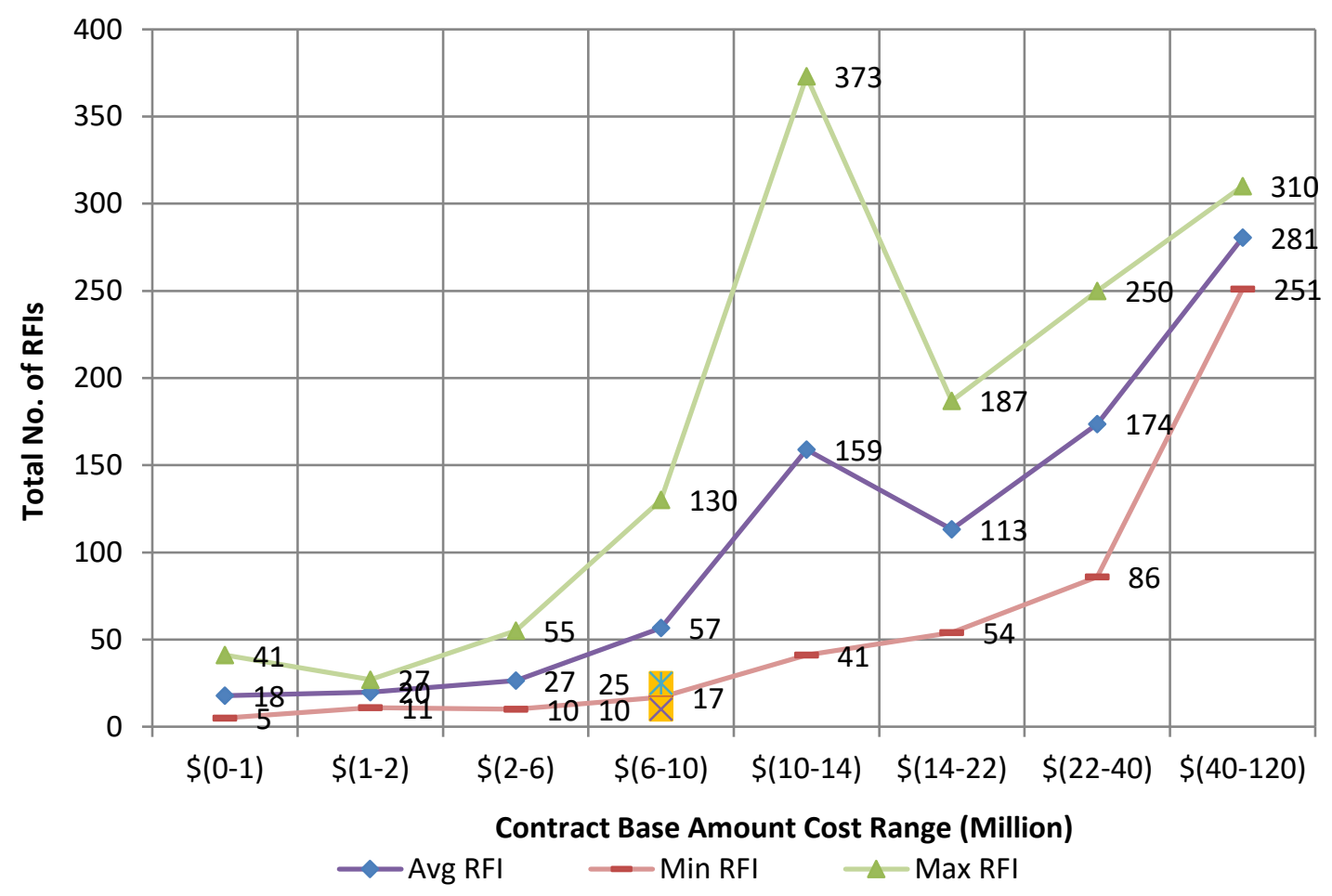

Figure 5-25: Total number of RFIs by specified contract base amount range.

The variation of the cost overrun percentage with respect to the number of RFIs is plotted in Figure 5-26. This plot is significant as it shows that the cost overrun percentage of any particular project has no apparent relation to the number of RFIs recorded for that same project. The cost overrun percentage for the control projects seem to fall somewhere midway between the average and the minimum trend lines of the dataset projects. The average cost overrun rate varies between approximately $5.8 \%$ and $8.3 \%$. 


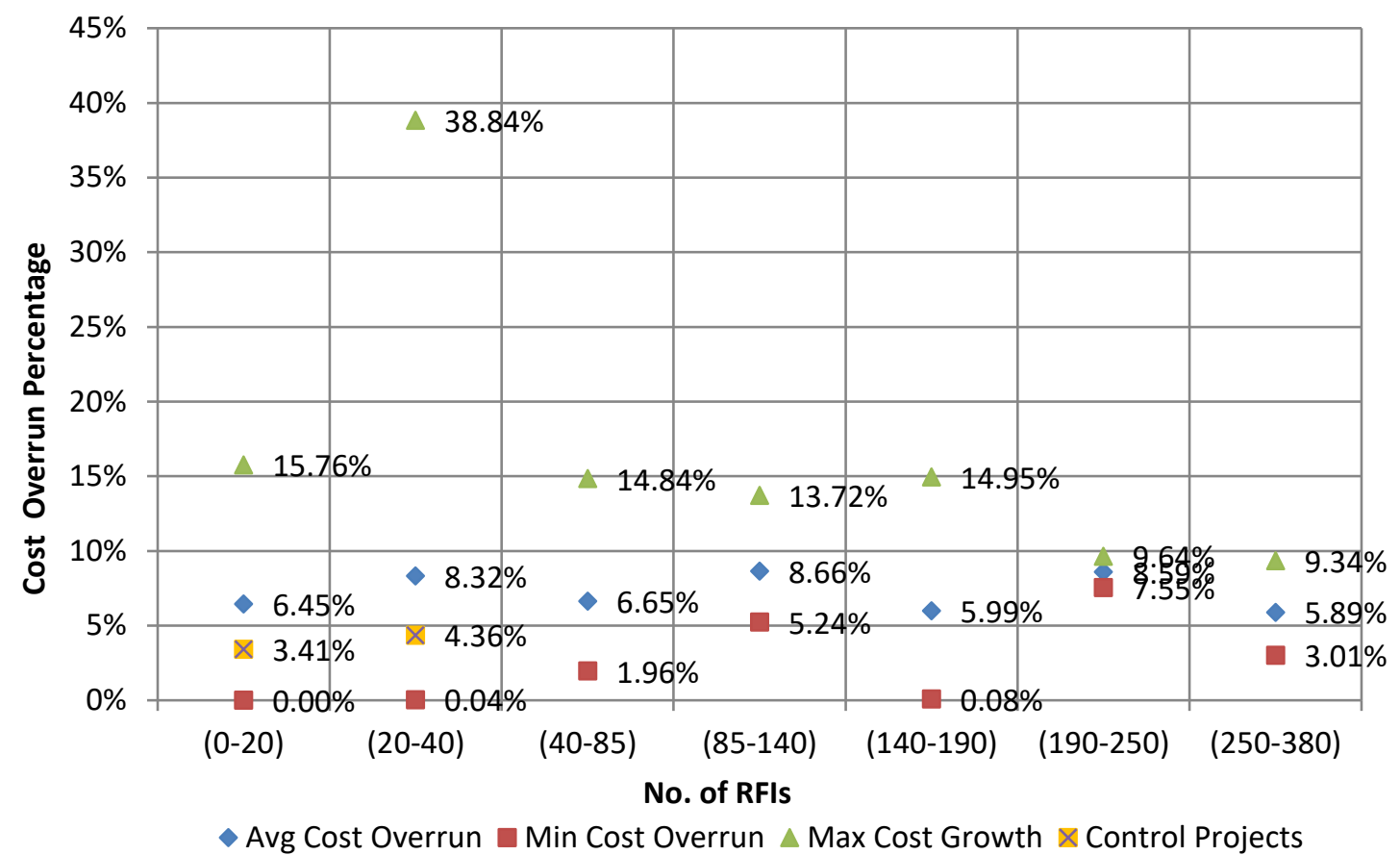

Figure 5-26: Cost overrun by specified total number of RFIs range.

In Figure 5-27, the time overrun percentage is plotted against the number of RFIs.

While wide ranges of variation in time overrun percentages can be observed when the overrun percentage is plotted in relation to number of RFIs, no direct correlation can be derived from this plot, and time overrun for a particular project does not seem to be the result of a large number of RFIs. It can be observed that the number of RFIs issued on any project is directly related to the size and the duration of a project. However, a large number of RFIs is insufficient to support time overrun where they fail to provide an identifiable design defect or set of design defects. Many RFIs issued by the contractors are due to needed clarifications, lack of project communications, submittals related questions, and other unjustifiable RFIs. The control projects seem to fare well in this KPI when compared to the dataset. The time overrun percentage for the control projects fell very close to the minimum values of the dataset projects' time overrun percentages. For 
example, in the 20 to 40 range, the time overrun percentage for the control project was at negative $0.89 \%$, compared to the $24.5 \%$ average value for dataset projects with a similar number of RFIs.

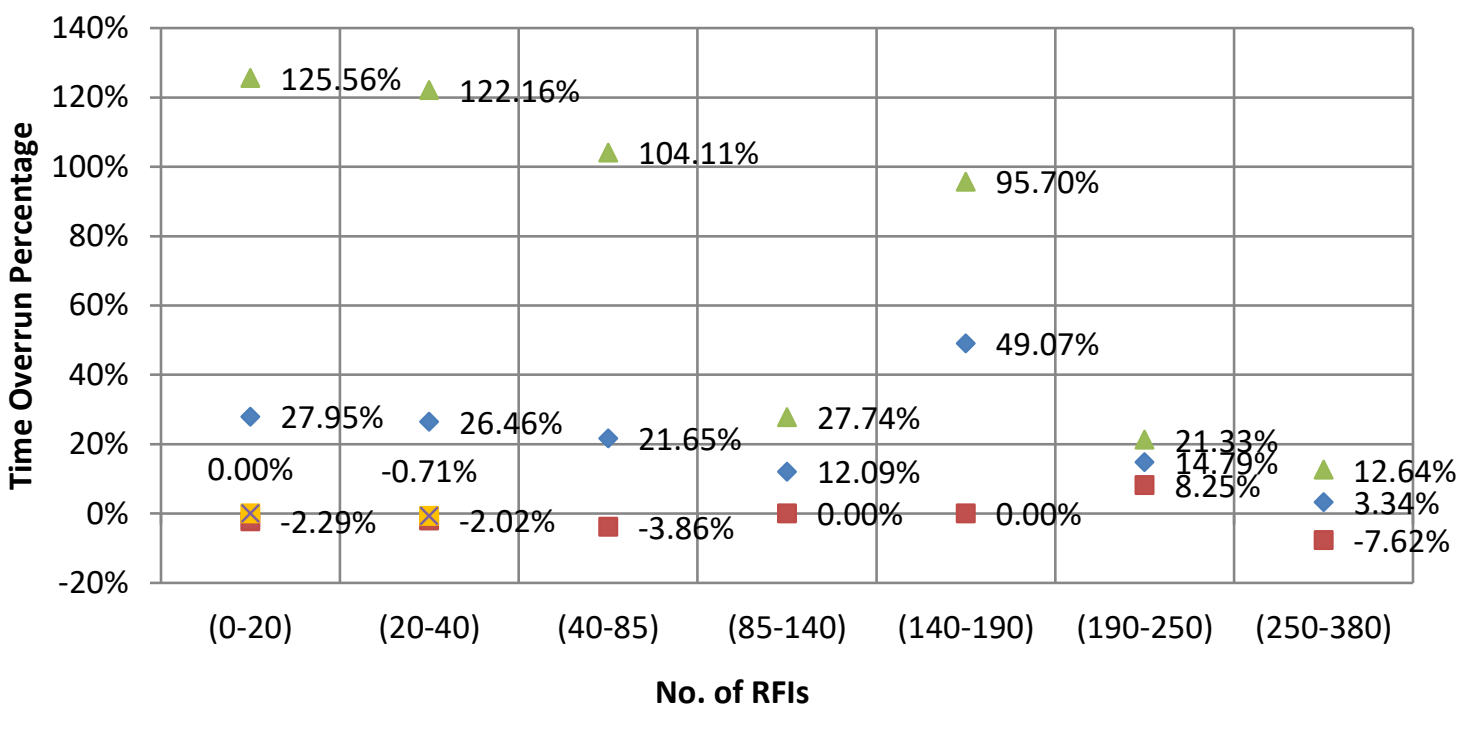

$\downarrow$ Avg Time Overrun $\square$ Min Time Overrun $\triangle$ Max Time Overrun $\times$ Control Projects

Figure 5-27: Time overrun specified total number of RFIs range.

Another KPI for construction projects is how the RFI response time per unit price varies in relation to the contract base amount. Relevant data was obtained from 33 projects where the RFI response time was available for this study. Figure 5-28 shows the RFI response time per unit price for the control projects and those of the dataset projects. The plot shows that the control projects fell below the average RFI response time per unit price value of the dataset. For example, in the $\$ 2 \mathrm{M}$ - $\$ 6 \mathrm{M}$ range category, the RFI response time per unit price for the control projects were at 2.12E-06 and 9.62E-07. Both values were below the average of 2.72E-06 and one control project value was below the minimum of $1.13 \mathrm{E}-06$. The relationship between RFI response time per unit price and 
contract base amount, in Figure 5-28, shows a strong direct correlation, where a contract base amount value is directly related to a decreased RFI response time per unit price. On large projects, managers expect a large number of RFIs and may make special efforts to better process the RFIs to avoid conflicts and delays.

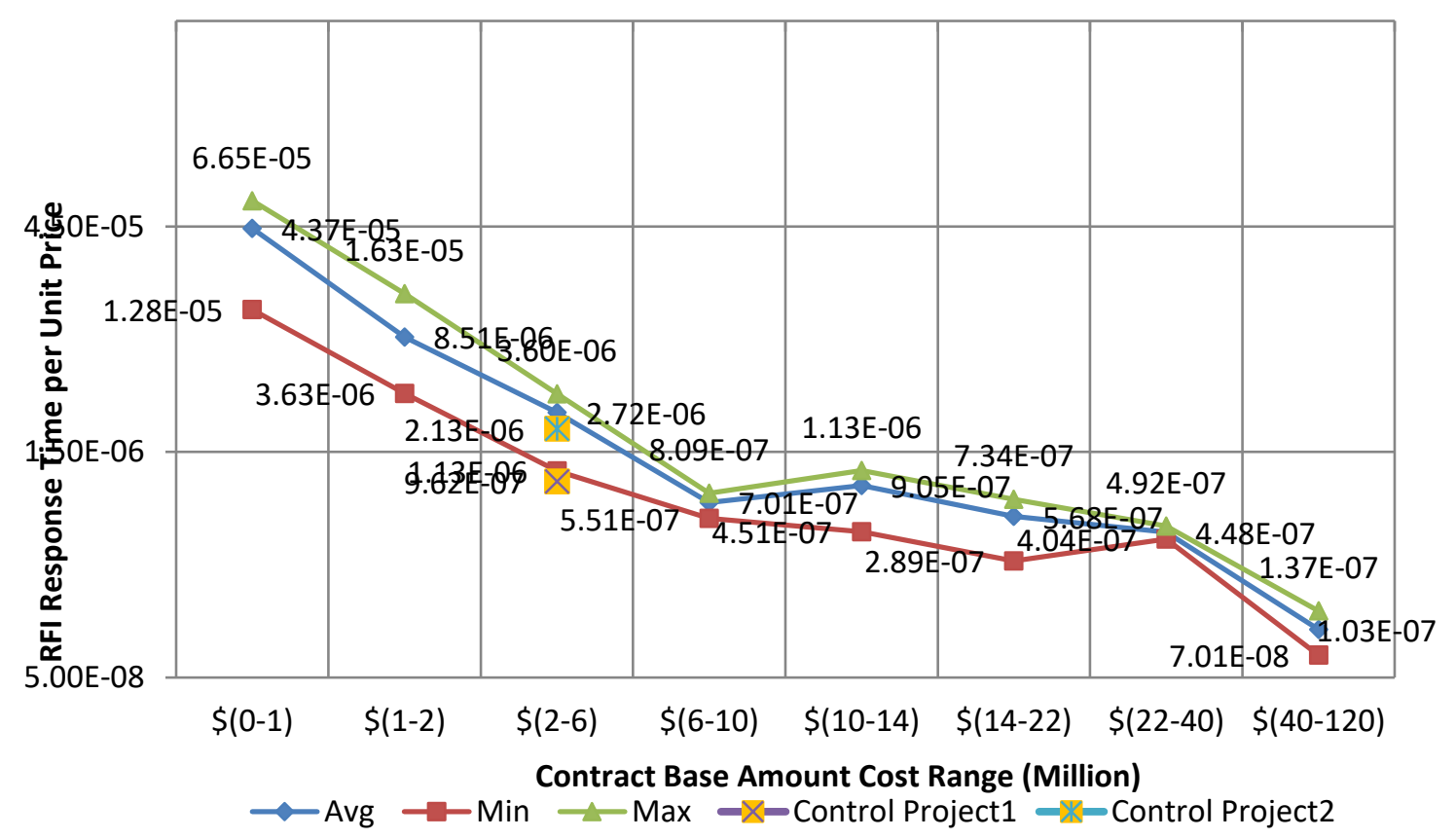

Figure 5-28: RFI response time per unit price by specified base amount cost range.

Figure 5-29 shows how the number of RFIs per unit price varies in relation to the contract base amount. The RFI per unit price for the control projects fell below the average value of the dataset projects in the same cost range. In the $\$ 2 \mathrm{M}-\$ 6 \mathrm{M}$ range category, the RFI per unit price for the control projects were at 4.93E-06 and 3.21E-06. Both values were below the average of $6.31 \mathrm{E}-06$, and one control value was below the minimum of 3.36E-06. The average values plotted in Figure 5-29 show a declining trend where the RFI per unit price decrease with the increased contract base amount with the exception of the outliers of $\$ 10 \mathrm{M}$ - $\$ 14 \mathrm{M}$ range. A possible explanation for this 
correlation is that projects become more complex as they become larger, so better management skills exist and more attention is paid. Larger projects have higher unit prices, and therefore the ratio of RFI/unit price would decrease according to the formula RFIs per Unit Price $=\frac{\text { Total Number of RFIs }}{\text { Actual Total Project Cost }}$

Even though more complex projects would be expected to have more RFIs, the ratio would decrease due to the greater actual project cost.

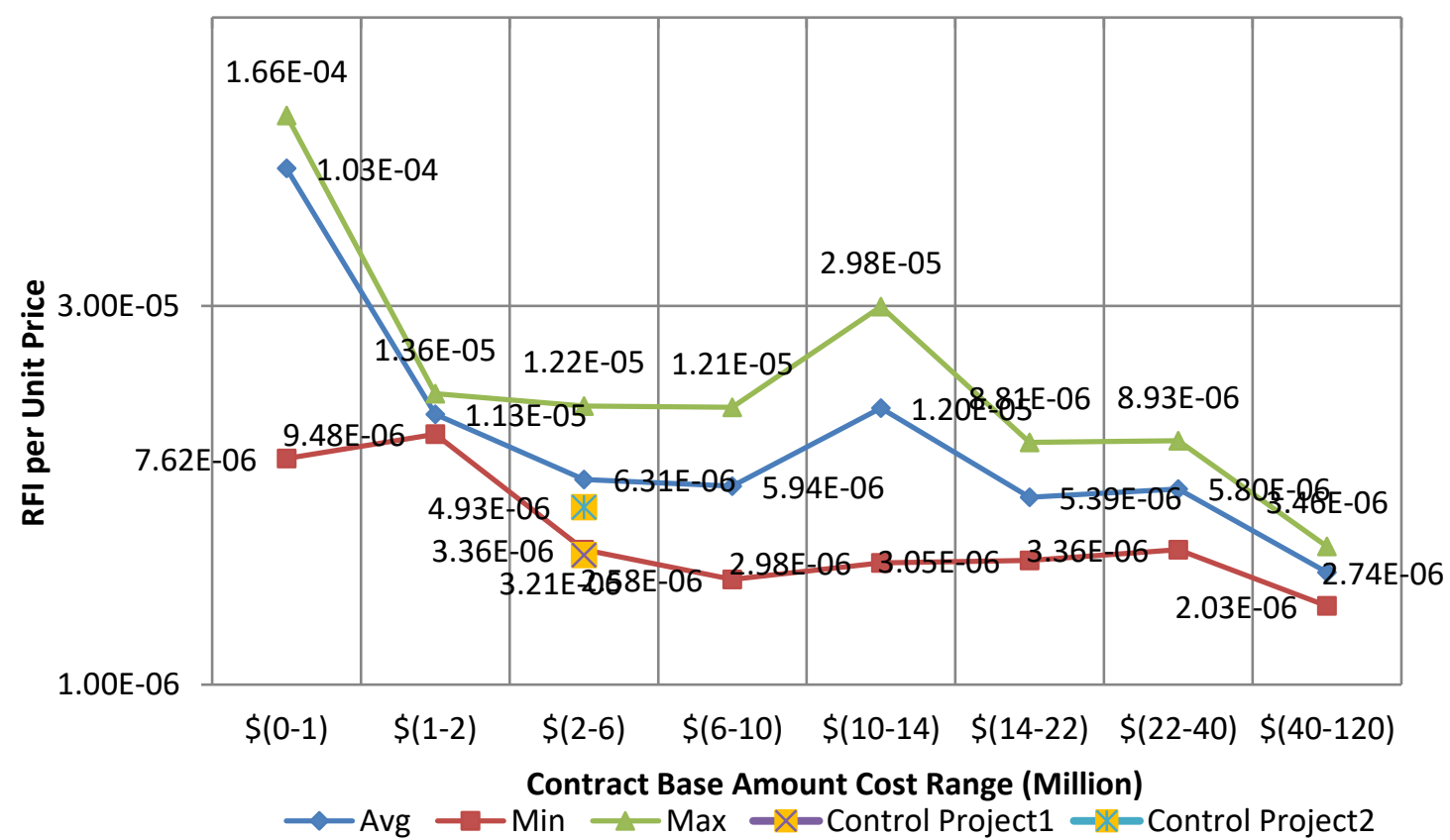

Figure 5-29: RFI per unit price to specified base amount cost range.

Figure 5-30 compares the values of the overall average RFI response time per unit price and the average number of RFIs per unit price for all dataset projects of the dataset to those of the control projects. In both comparisons, both control projects were far below the average values of the dataset projects, thus showing a superior performance when measured using these KPIs. 


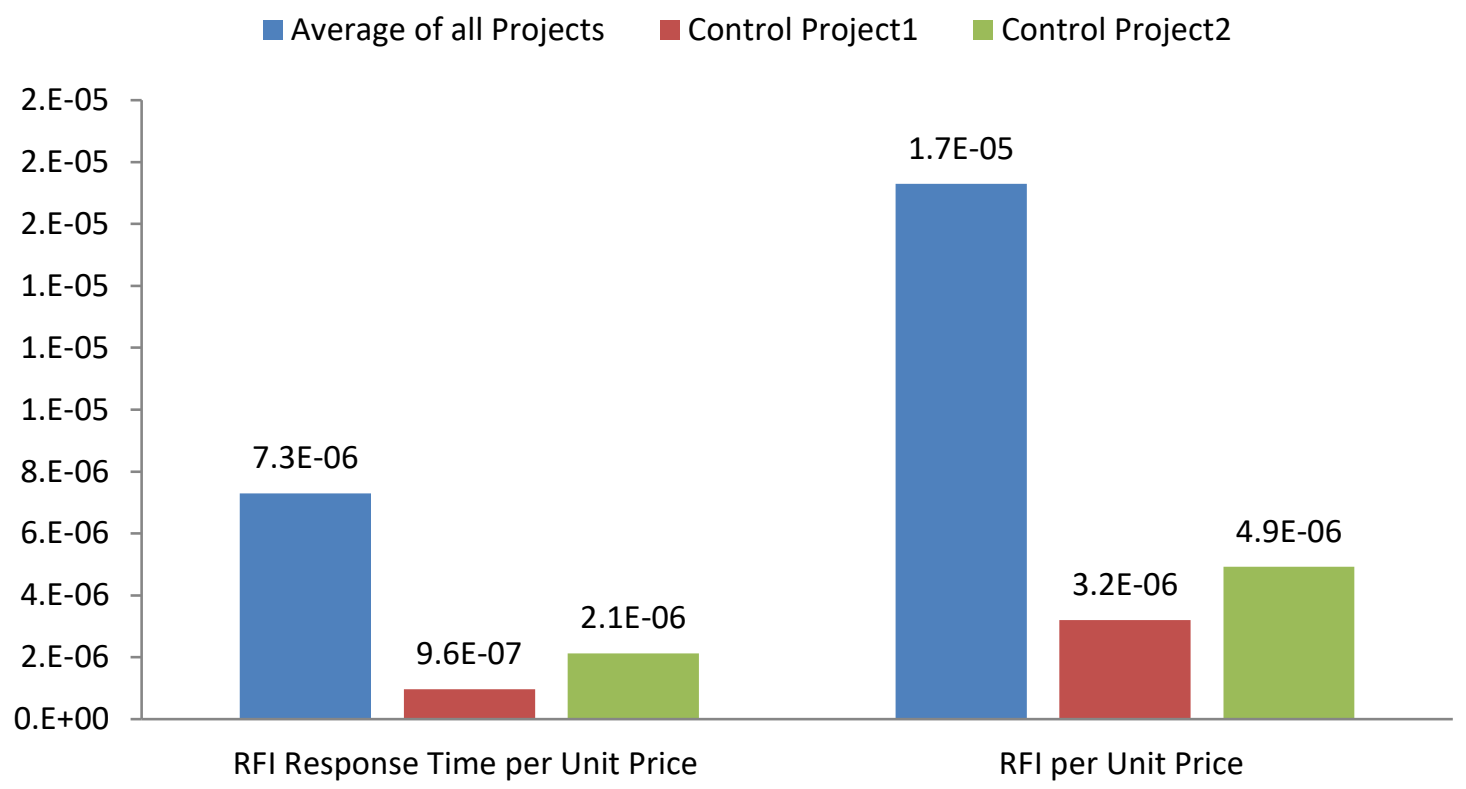

Figure 5-30: Comparison of average RFI response time per unit price and average RFI per unit price of all projects to control projects.

The overall average number of RFIs for all of the dataset projects of the dataset was 82. Figure 5-31 compares the overall average number of RFIs for all of the dataset projects to the number of RFIs of the control projects. The control projects were at 10 and 25 total RFIs, and were thus far below the average values of the dataset projects.

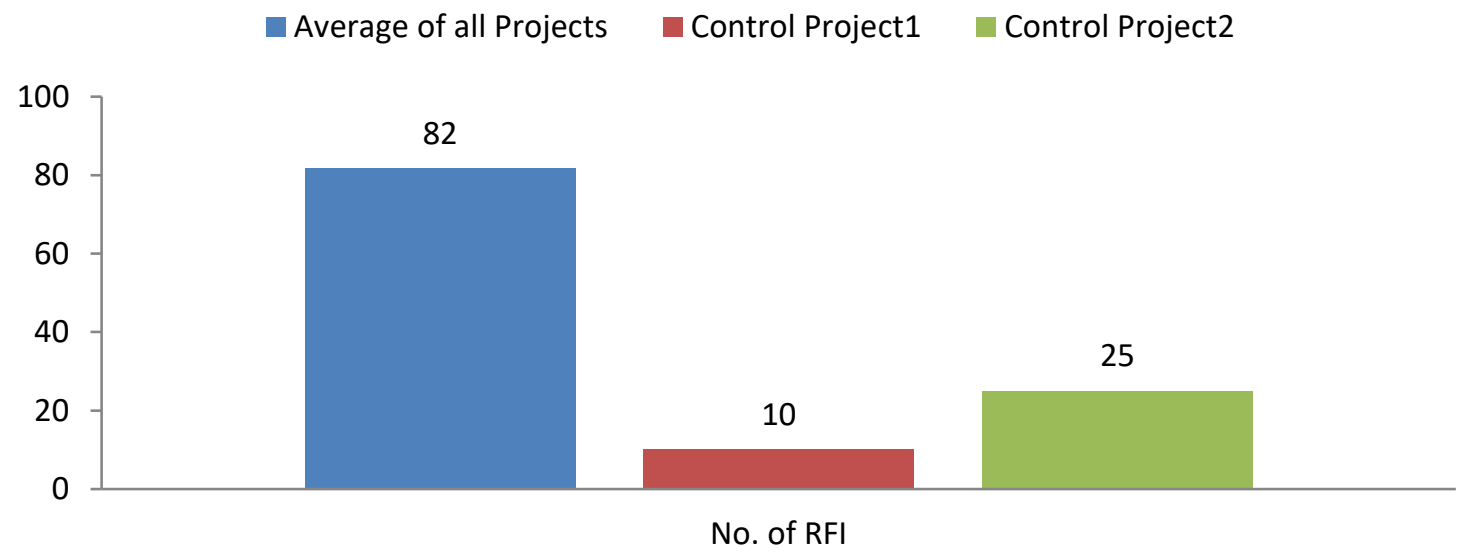

Figure 5-31: Comparison of average number of RFIs of all projects to control projects. 


\section{Construction Claims}

Disputes often arise between subcontractors, contractors, and owners regarding the performance of the project. Expectations of owners, contractors, subcontractors, architects, engineers, or suppliers may not be realized, and disputes may arise at any time. Disputes frequently occur over the scope, timing and quality of actual work performed, and materials delivered. Project claims cost is an economic measure of such disputes. The cost of claims obtained from the control projects was compared with those obtained from the dataset projects. The researcher used a Construction Claims Log for the control projects. A Construction Claims Log is shown in Appendix I.

Construction claims evaluation was measured based on cost of claims, which could be as a result of the following six components:

1- Cost escalation,

2- Time for completion and construction delays,

3- Changes in project scope,

4- Geotechnical and site-related problems,

5- Weather and force majeure conditions, and

6- Negligence in both design and construction.

Equation 5-12 was used for the evaluation of the cost of claims KPI.

Total Claims Cost $\%=\frac{\sum \text { Direct Cost of Claims }}{\text { Actual Total Project Cost }} \times 100$

Figures 5-32 and 5-33 show how the cost of claims — as a total dollar amount and as a percentage of project base contract amounts, respectively — varies in relation to the contract base amount. In the $\$ 1 \mathrm{M}$ - $\$ 7 \mathrm{M}$ range category, the cost of claims for the control 
projects were at $\$ 0.0$, which is at the minimum of all the dataset projects in the same size category.

The highest number of claims was in the $\$ 14 \mathrm{M}-\$ 22 \mathrm{M}$ range. The next highest was the $\$ 10 \mathrm{M}-\$ 14 \mathrm{M}$ range, and the third highest was the $\$ 22 \mathrm{M}-\$ 40 \mathrm{M}$ range. The irregularity of the trends suggests that claims are not necessarily endemic to water related projects across the industry, but rather depend on the management of these projects. This finding indicates the significant impact that management and planning strategies can have on reducing or eliminating claims.

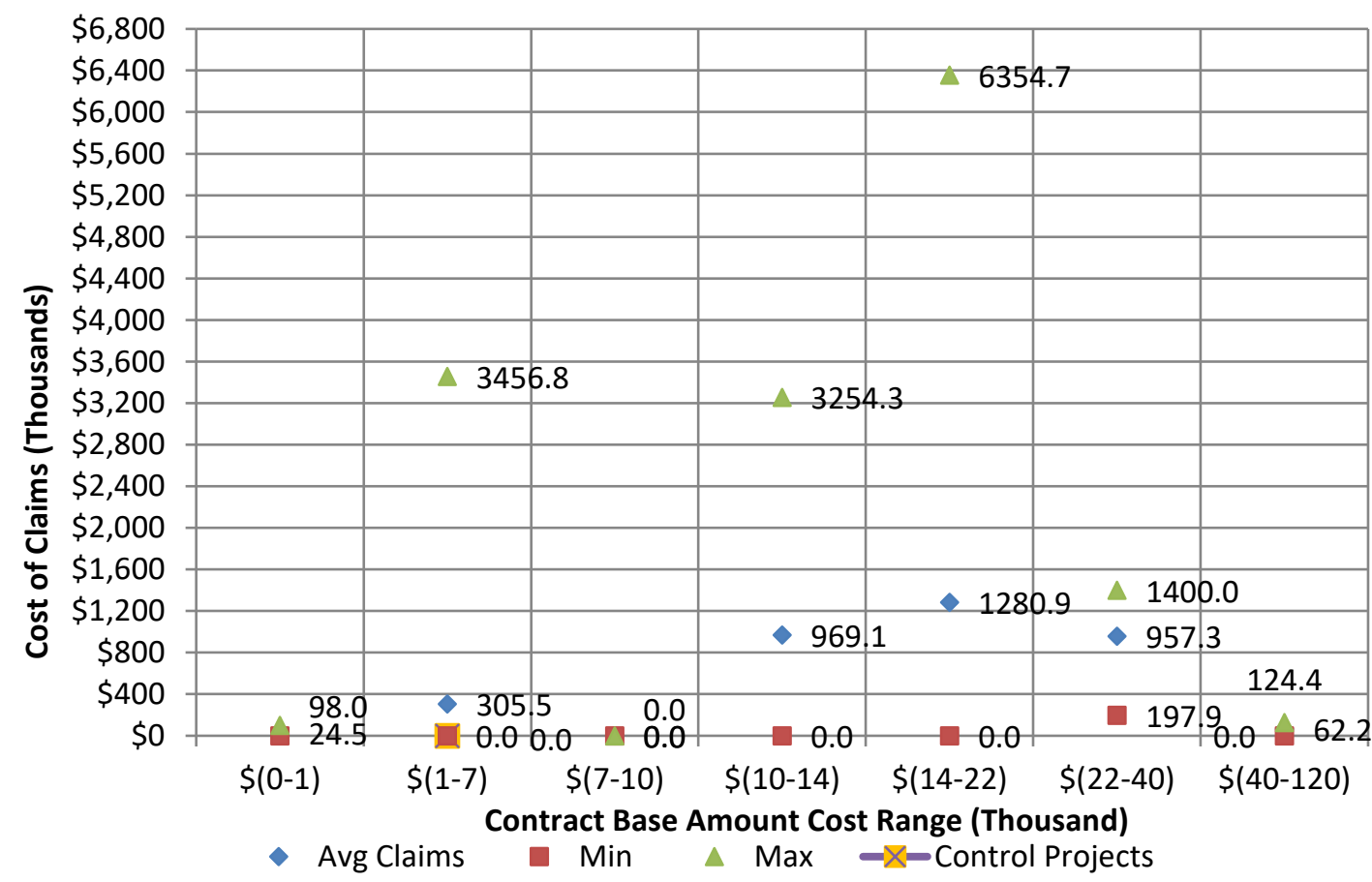

Figure 5-32: Cost of claims to specified contract base amount cost range. 


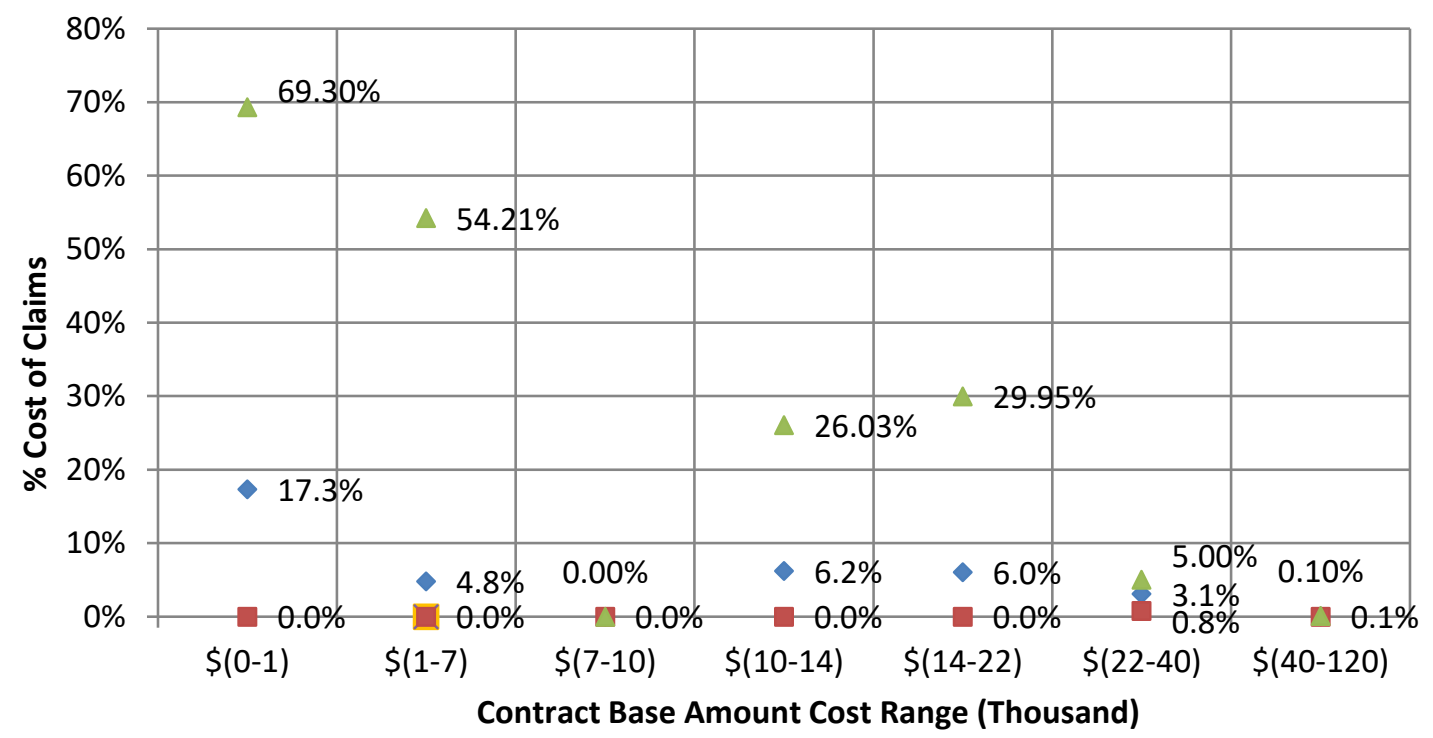

\% Avg. Claims $\%$ Min $\triangle$ Series3 $-x$-Control Projects

Figure 5-33: Comparison of percent of cost of claims to contract base amount cost range.

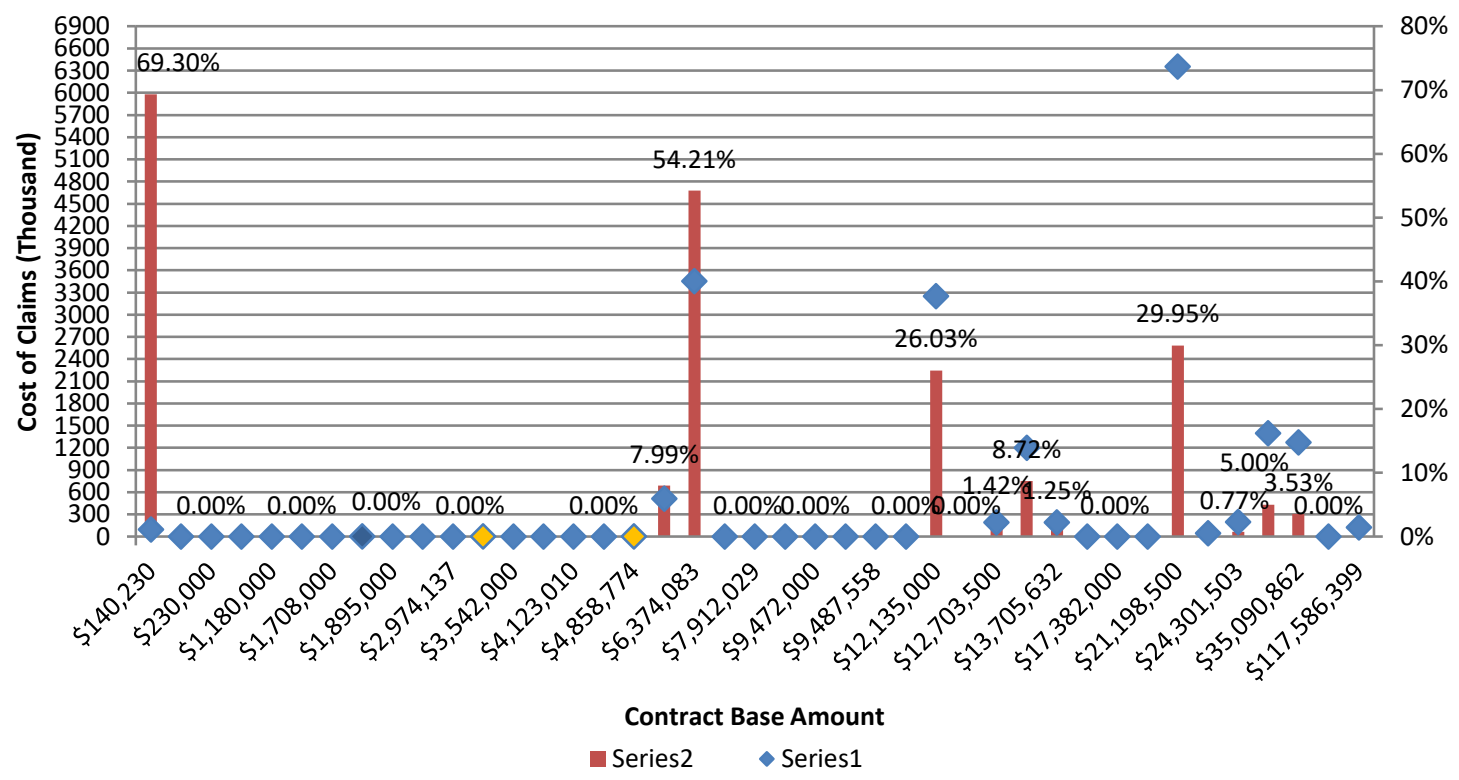

Figure 5-34: Comparison of cost of claims to contract base amount of projects.

\section{Summary of Findings}

Cost: The control projects had lower total cost overrun during construction than the traditional DBB projects of the dataset. The average cost overrun of the control 
projects was $3.9 \%$, while the average cost overrun of the dataset projects was almost double the amount (7.22\%). The average cost overrun of control projects was $\$ 157,407$. The average cost overrun of the dataset projects was a staggering $\$ 936,147$.

Time: The control projects also had a lower total time overrun during construction than the dataset projects. The average time overrun of the control projects was negative $0.35 \%$, while that of the dataset projects was $23.25 \%$. The average time overrun of the control projects was negative 2 days, compared to an average time overrun for the dataset projects of 104.63 days.

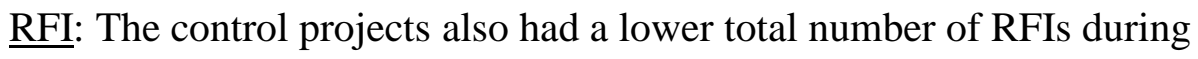
construction than the dataset projects. The average number of RFIs of the control projects was 17.5 RFIs per project, while that of traditional DBB projects of the dataset projects was 81.7 RFIs.

COs: The control projects also had better performance than the dataset projects in regard to total number of RFPs during construction. The average number of RFPs of the control projects was 9.0 per project, while the average number of RFPs of the dataset projects was 24.8 RFPs per project. However, the total normalized cost of COs was essentially the same. The delivery method does not therefore appear to affect the CO cost performance.

Claims: The control projects had a lower claims cost than the dataset projects. The average claims cost of the control projects was $0.0 \%$, while the average claims cost of the dataset projects was $4.9 \%$.

Figure 5-35 compares KPIs between the dataset and the control projects. 


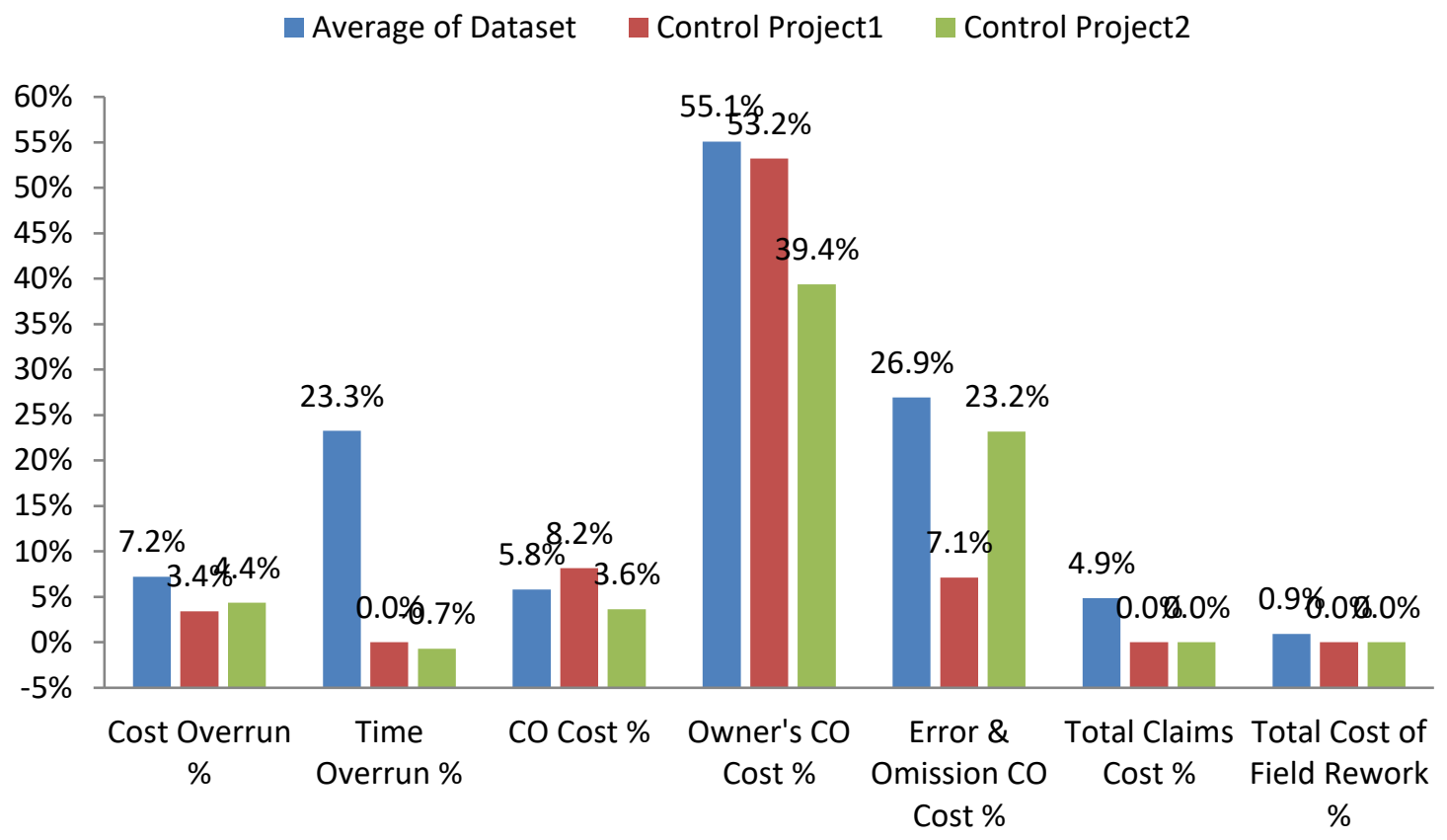

Figure 5-35: Comparison of KPIs between dataset and control projects.

\section{Obtaining Input from Project Participants}

The focus group conducted in this study included various stakeholders in the control projects in order to evaluate the validity of the comparison of the KPI results between the dataset and the control projects. The focus group was necessary to get more in-depth information and for gathering subjective perspectives from key stakeholders to validate the direct correlation made between the improved KPI results of the control projects and the implemented IPD principles. The focus group assisted in providing additional interpretations of the data and increased the validity of the findings using a variety of data collection techniques.

The study conducted a focus group session with control projects' personnel who were experienced participants in water utility construction projects. The focus group involved seven participants forming a set of different types of stakeholders such as 
owners, engineers, consultants, and contractors. Two main criteria were established for participants' selection: (1) influence and experience in construction projects at Miami Dade South District Wastewater Treatment Plant (MD-SDWWTP), and (2) involvement in the projects used for the control projects. A secondary criterion used was the years of professional industrial experience, which was set at a minimum of 10 years.

Two discussion topics were administered with the focus group:

1. Effect of the implemented IPD principles on the KPIs of the control projects, and

2. Ranking of said IPD principles in terms of their influence on the improvements. A questionnaire was designed and administered to the participants listing the IPD principles implemented in the control projects. The questionnaire included the following items:

1- Participants were asked to rank the implemented IPD principles from 1 to 5 (1 being the highest and 5 the lowest) based on their perception of how influential these principles were in improving the KPIs of the control projects.

2- Participants were asked to indicate their opinions regarding certain project outcomes based on their experience with MD-SDWWTP control projects. These outcomes were: client satisfaction, change order costs, number of construction defects, number of RFIs, and working experience.

3- Participants were asked to rank from 0 to 5 ( 0 being no effect and 5 being the most effect), the implemented IPD principles in the control projects according to their respective influence on each of the following aspects of the projects: open communication within the project team and ability to address issues, integrated 
and collaborative teams, lean principles, co-location of teams, performance evaluations, and mutual respect and trust.

The opinions and views of the participants were subsequently analyzed to draw conclusions.

\section{Focus Group Results}

\section{$\underline{\text { Ranking of KPIs }}$}

Table 5-9 shows the participants' ranking of the IPD principles from 1 to 5 based on which they felt was most influential in improving the KPIs of the control projects. The overall final ranking is based on a quotient that is obtained by multiplying the rank that each participant assigned to a KPI by the number of participants who gave that ranking, and then adding them up for that KPI. In this sense, the item that receives the lowest quotient is the highest-ranked.

Table 5-9: Ranking of the KPIs based on their Most Influence in Improving the Delivery Method.

\begin{tabular}{clc}
\hline Rank & \multicolumn{1}{c}{ KPIs } & Quotient \\
\hline 1 & Change Order Cost \% & 16 \\
2 & Total Claims Cost \% & 17 \\
3 & Time Overrun \% & 19 \\
4 & RFI Response Time per Unit Price & 23 \\
5 & RFIs per Unit Price & 25 \\
6 & Total Cost of Field Rework \% & 26 \\
\hline
\end{tabular}




\section{$\underline{\text { Ranking of the Implemented IPD Principles in the Control Projects }}$}

Figures 5-36 shows the ranking from 1 to 6 ( 1 being most effective and 6 being the least effective) ranking based on effectiveness in determining the success of a construction project.

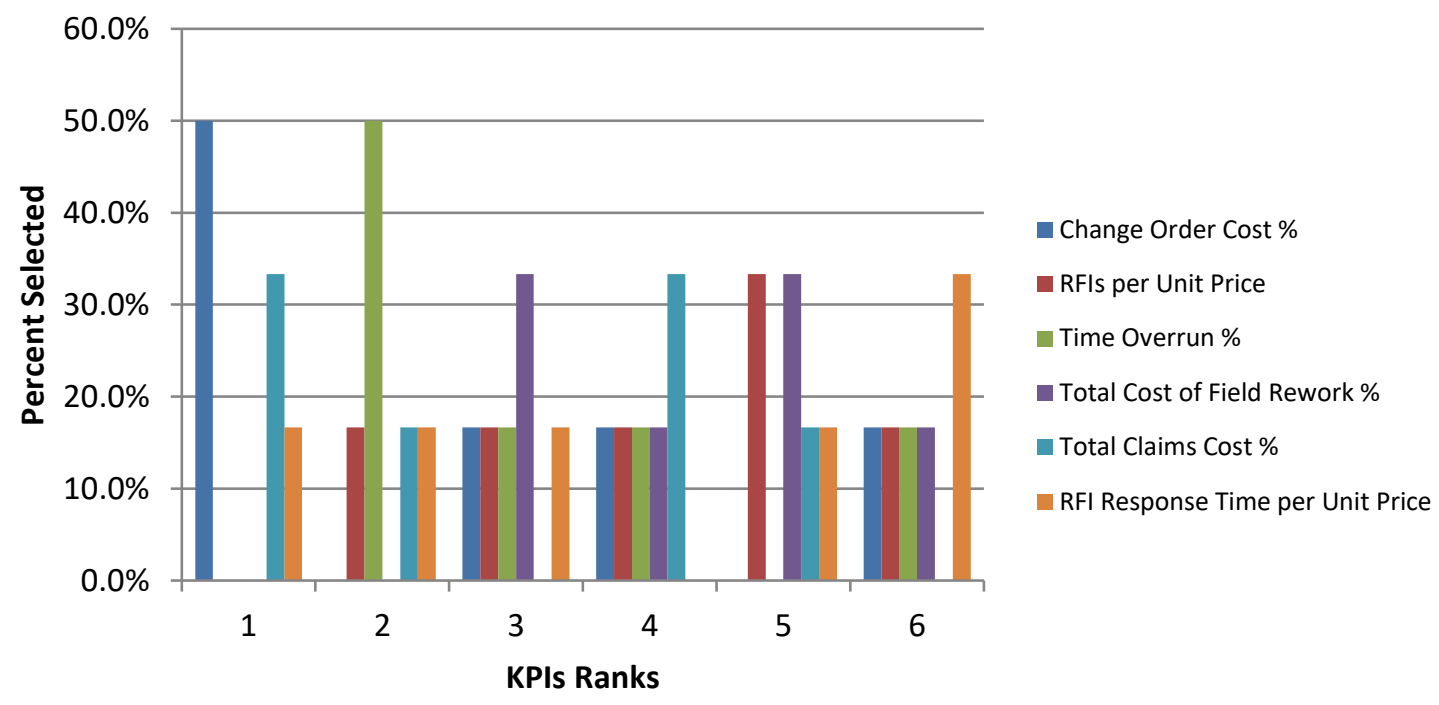

Figure 5-36: KPIs ranking based on effectiveness in determining the success of a construction project.

Figure 5-37 shows the control projects' characteristics based on the experience of the focus group participants with these projects.

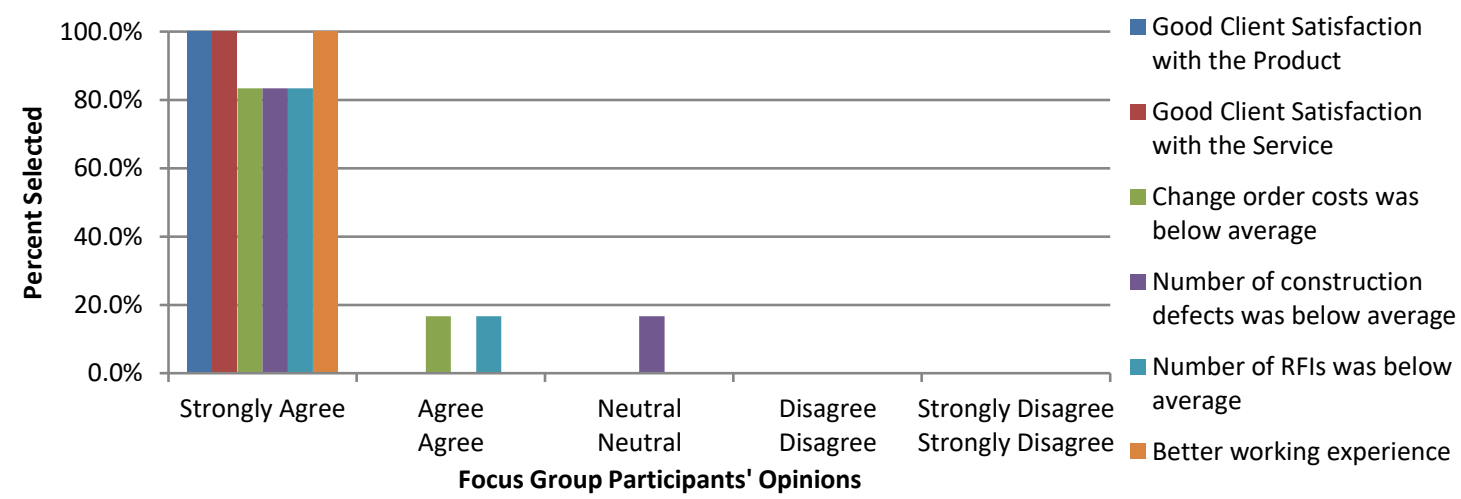

Figure 5-37: Characteristics based on experience with control projects. 


\section{$\underline{\text { Participants' Opinions Concerning Outcomes of MD-SDWWTP Control Projects }}$}

\section{including Client Satisfaction}

The concept of quality is closely related to customer satisfaction, which has gradually been elevated in importance in the construction industry. Customer satisfaction is commonly described as a comparison between the customer's pre-purchase expectations and their post-purchase perceptions. Hence, it involves the customer's final feelings about whether the outcome provided a satisfying or dissatisfying experience (Forsythe, 2007).

There are two main aspects of quality.

1- Quality of end product, which has to do with the users' satisfaction with the finished construction and is a critical success factor (Collins and Baccarini, 2004; Forsythe, 2007). It is also related to how the final product and its functions meet the contract specifications (Chan and Chan, 2004, Collins and Baccarini, 2004).

2- Service quality during the construction process, which reflects the client's perception of the process during which project participants interact to create the end product (Maloney, 2002, Forsythe, 2007).

As part of the evaluation process, the focus group conducted with the wastewater utility (owner) representatives measured KPIs related to their satisfaction with the product received and the services rendered. Notes on the focus group meeting were handwritten and audio taped. Satisfaction levels, change order costs, number of construction defects, number of RFIs, and working experience were rated using the following scale:

$$
\begin{aligned}
& \text { 1= Strongly Agree, } \\
& 2=\text { Agree, }
\end{aligned}
$$


$3=$ Neutral,

4= Disagree, or

$5=$ Strongly Disagree.

The opinions of project personnel regarding the traditional DBB delivery method are based on personal experience. The opinions and experiences of project participants, whether they are owners, engineers or contractors are important. These participants contributed valuable information that is essential to the management and success of a program. Table 5-10 shows the participants' responses. A total of six participants answered this question, and the values indicated represent the number of participants that selected that answer. For instance, all six participants strongly agreed that the implementation of IPD principles with DBB delivery method provided good client satisfaction with the product, good client satisfaction with the service, and better working experience. Only one participant rated the number of construction defects as Neutral.

Table 5-10: Participants' Opinions Concerning Characteristics of MD-SDWWTP Control Projects including Client Satisfaction

\begin{tabular}{|c|c|c|c|c|c|}
\hline Job Characteristics & $\begin{array}{c}(1) \\
\text { Strongly } \\
\text { Agree } \\
\end{array}$ & $\begin{array}{c}\text { (2) } \\
\text { Agree }\end{array}$ & $\begin{array}{c}\text { (3) } \\
\text { Neutral }\end{array}$ & $\begin{array}{c}(4) \\
\text { Disagree }\end{array}$ & $\begin{array}{c}\text { (5) } \\
\text { Strongly } \\
\text { Disagree }\end{array}$ \\
\hline $\begin{array}{l}\text { Good Client Satisfaction } \\
\text { with the Product }\end{array}$ & 6 & & & & \\
\hline $\begin{array}{l}\text { Good Client Satisfaction } \\
\text { with the Service }\end{array}$ & 6 & & & & \\
\hline $\begin{array}{l}\text { Change order costs were } \\
\text { below average }\end{array}$ & 5 & 1 & & & \\
\hline $\begin{array}{l}\text { Number of construction } \\
\text { defects was below average }\end{array}$ & 5 & & 1 & & \\
\hline $\begin{array}{l}\text { Number of RFIs was } \\
\text { below average }\end{array}$ & 5 & 1 & & & \\
\hline Better working experience & 6 & & & & \\
\hline
\end{tabular}




\section{CHAPTER 6}

\section{PROJECT PERFORMANCE RATING (PPR) MODEL AND CORRELATION BETWEEN IPD PRINCIPLES AND PROJECT KPI}

This chapter discusses the development and implementation of the Project Performance Rating (PPR) model. It also displays the correlation between the implemented IPD principles and the Key Performance Indicators (KPIs). The PPR is a comprehensive rating of performance for treatment plant projects and can be used to gauge the overall project performance. Program planning, training, and effective implementation of the right project delivery method - accompanied with effective contract and program management — are essential to the success of construction projects.

\section{PPR Purpose}

Water and wastewater construction projects do not have well-established overall performance rating models. Treatment facilities are unique, highly complex, and normally require several performance dimensions to be considered successful. Generally, it is not sufficient to deem that a given project is successful assuming it is completed on time and within budget. The same project could have suffered poor quality work and experienced major claims, which can ultimately affect the success rate. Project performance is a complex concept that cannot be measured by one performance factor. It involves several factors and sub factors that need to be accounted for, some of which are qualitative metrics that do not have standards and are more difficult to measure. An aggregate PPR plays an important role in combining the key performance factors of a 
project into one number, rating, or score, which represents the performance of a given project. In this way, PPR facilitates the comparison of projects and can be used to provide a basis for improving future projects.

This chapter introduces a PPR model that can be applied to treatment plant construction projects, regardless of the project delivery system used. To effectively implement this model, the PPR is developed as a linear function of the various key performance indicators. The overall project performance is determined through the combination of all the key performance indicators. In this sense, the PPR will be an effective tool that can be used to assist owners in scoring construction projects of treatment facilities. The owner of a project can assess several performance factors, which this model combines to compute the overall performance index or success rating of the project. A PPR model can be used in conjunction with a project rating scale, which can serve as a guide that owners can use to evaluate a project's overall performance. The flowchart in Figure 6-1 illustrates the model development process used in this study. 


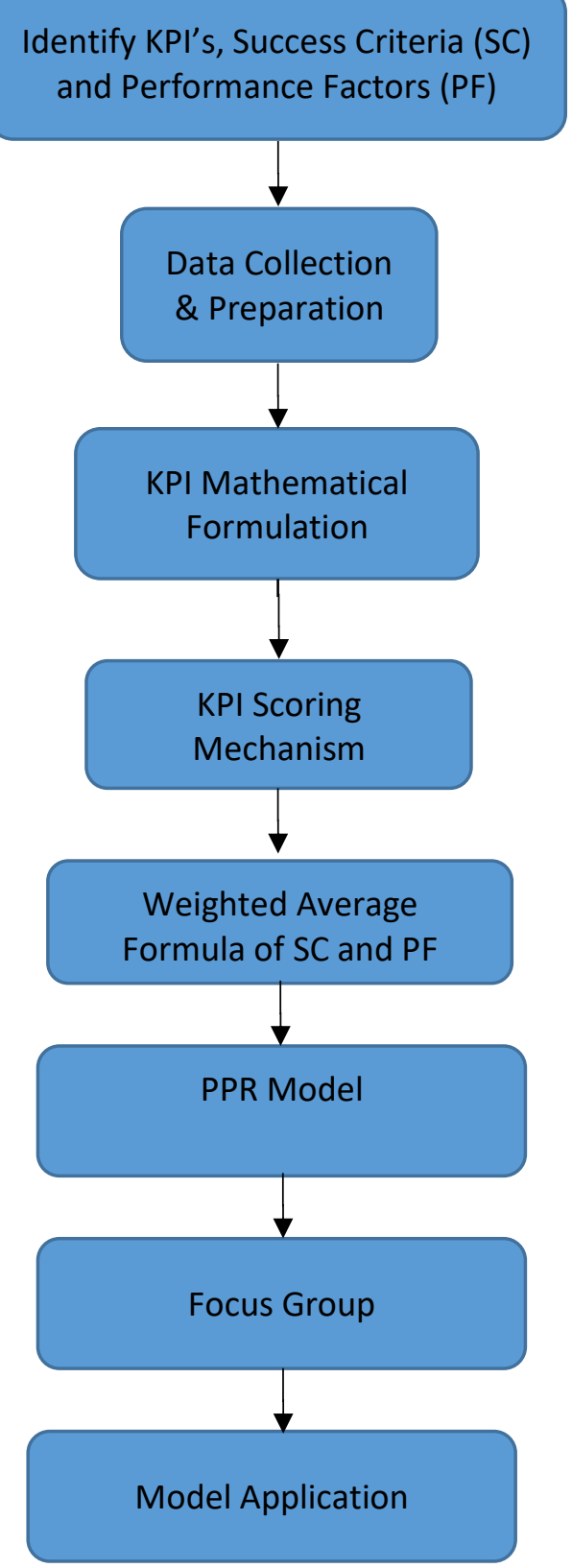

Figure 6-1: Flowchart of model development process.

\section{Success Criteria and Performance Factors}

The developed PPR model includes all the key factors and subfactors identified as being part of the performance rating. Success Criteria (SC) are selected, such as 
Customer Satisfaction, and Project Cost and supplemented by a number of Performance Factors describing significant evaluation elements.

The Performance Index is based on the success criteria with different weights assigned to each SC and PF. The model is designed in such a way as to allow the owner to use the weights of the SC and performance factors that reflect the level of importance of each SC and performance factor with respect to the specific facility being constructed. The PPR model is thus flexible in that it allows the respective weights of the SC and performance factor to be determined to fit the circumstances of each individual project and owner preferences.

The relative significance of specific performance factor may change as construction activities headway from one evaluation period into the next. A list of performance evaluation criteria and factors is shown in Figure 6-2. They illustrate the key performance factors selected as evaluation factors.

Figure 6-2 exhibits three levels:

1- PI is the top level,

2- SC is the second level that includes five criteria that the PPR combines, and

3- Performance factor (PF) represents all the individual performance factors listed under each of the five SCs. 


\section{PPR Model}

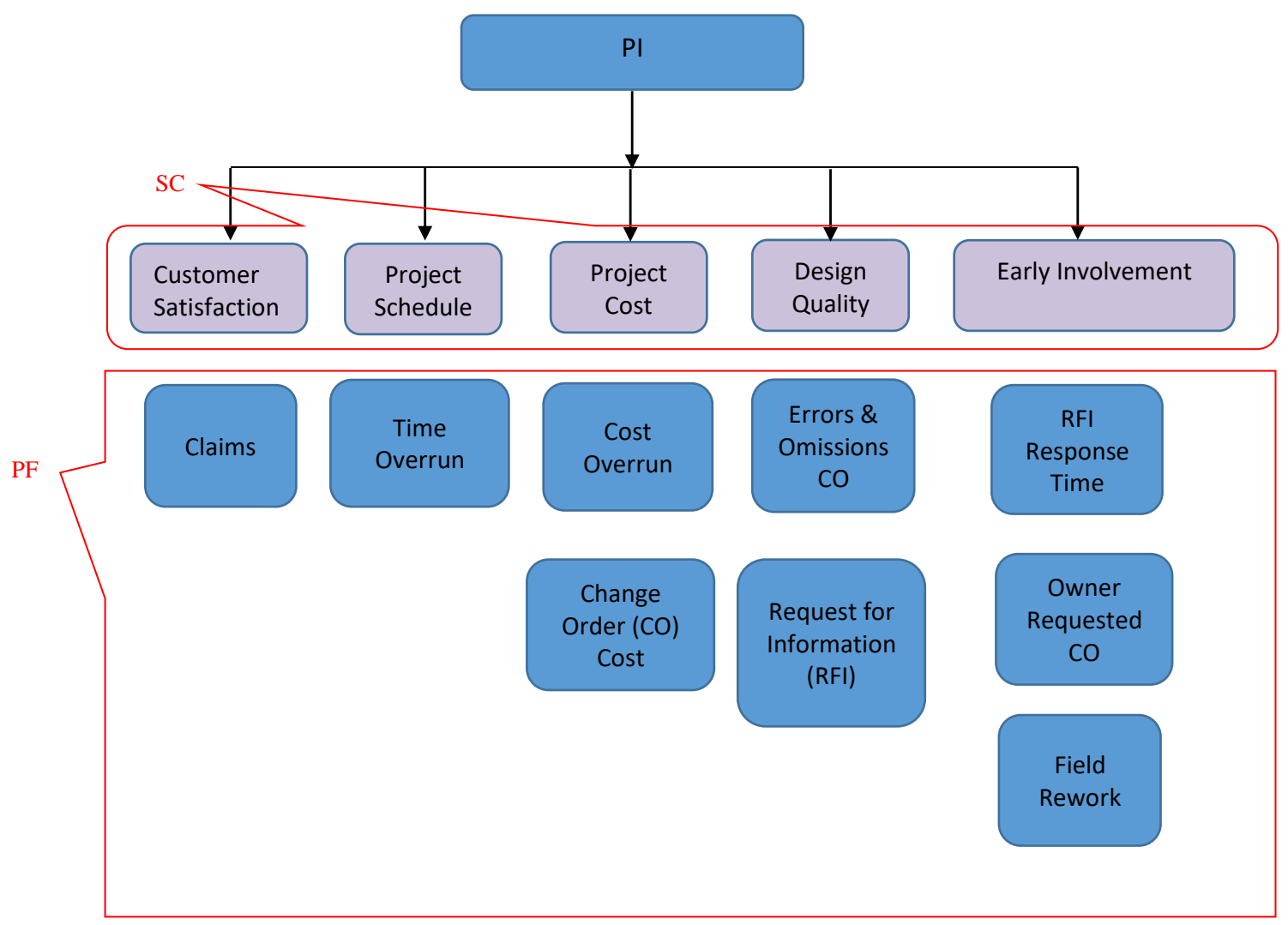

Figure 6-41: Flowchart of PPR model

\section{Customer Satisfaction}

A successfully managed and delivered project is one that results in customer satisfaction and repeat business. A project's performance with respect to owner satisfaction can be measured by the number of claims resulting from that particular project. Claims are thus used as a critical performance factor for customer satisfaction since an owner is not likely to hire the same contractor in the future if the current project resulted in claims. 


\section{Project Schedule}

Project Schedule reflects the timely and efficient preparation, implementation, and closeout of tasks; meeting project milestones and contractual delivery dates; recovery from delays; and appropriateness of response to changes. Ontime completion of a project is an indicator of many successful aspects of the project delivery, such as efficiency and proper project management. A project's performance with respect to schedule can be measured using time overrun as a critical performance factor.

\section{Project Cost}

A successfully managed and delivered project is one that gets completed on or under budget. The main consideration when evaluating project cost is the measurement of the contractor's performance against the bid cost of the contract. Change orders typically alter the original contract amount, and cost overrun tracks costs incurred in excess of the contract amounts. Cost overrun and change order costs are thus used as critical PFs for project cost.

\section{Design Quality}

A good quality design typically includes detailed approach in design concepts, analysis, and detailed execution procedures, thoroughness and accuracy. A large number of RFIs and high errors and omissions cost indicate low quality of the design and construction documents. Therefore, RFIs and error and omission costs are used as critical PFs for quality. 


\section{Early Involvement}

Early involvement of project participants — including the owner-promotes a well-developed relationship among project participants and is essential at all levels where decisions can be made and results achieved. Frequent and honest communication improves project efficiency through reduced RFI response time, improved labor relations, reduced owner requested change orders, and field rework through improved planning, organizing, and managing of all program elements. Early involvement helps to achieve and sustain a high level of communication and collaboration, thus resulting in recognizing critical problem areas and ensuring integrated operational efficiency. Error and omissions typically initiate change orders to pay for the correction needed due to poor design quality.

\section{Weighting of Success Criteria (SC) and Performance Factors (PF)}

In order to calculate the project performance index, the detailed performance evaluation structure of the PPR should indicate the relative priorities assigned to the various SC and PFs. Communicating relative priorities in this model is accomplished through the use of percentage weights. The SC are considered substantial factors and the weights designating the proper importance to the SC are assigned by the owner. All assigned weights for SC must total to $100 \%$.

The weights of the PFs are left as variables to be determined by the owner depending on the level of importance of each PF with respect to a specific facility. The relative importance of the factors as described by the weight of each PF should be designed to fit the needs of each owner. For example, the number of change orders is 
generally critical to the contract. However, if an owner anticipates a larger number of change orders from expected unforeseen conditions due to the lack of record drawings, then the weight of such a PF can be adjusted to have a lower weight. This way, the expected high number of change orders is not indicative of an unsuccessful project.

Conversely, change orders for another project, for the same or different owner, could be mostly unlikely and therefore, their PF weight is set higher by the owner. The total of the PF weights for each PF totals $100 \%$ of the assigned weight for that factor as shown in the example below in Table 6-1. The actual weights assigned to SC and PFs used in actual projects may be different from those shown in this example. 
Table 6-1: Weighing of SCs and Example PFs

Success Criteria (SC)
/Performance Factor (PF)

Customer Satisfaction

Claims

Project Schedule

Time Overrun

Project Cost

Cost Overrun
CO Cost

Design Quality

Error \& Omission CO

RFI

Early Involvement
Assigned Weight

$25 \%$

$100 \%$

$21 \%$

$100 \%$

$20 \%$

$50 \%$

$50 \%$

$18 \%$

$60 \%$

$40 \%$

$16 \%$

\begin{tabular}{ll} 
RFI Response Time & $20 \%$ \\
Owner Requested CO & $20 \%$ \\
Field Rework & $60 \%$ \\
\hline
\end{tabular}

\section{$\underline{\text { KPIs }}$}

Standards or criteria for PFs need to be developed for measuring performance, assessing effectiveness, and calculating the PI. Quantitative performance measurement standards, also known as objective performance standards, are based on well-defined parameters for measuring performance. KPIs are used whenever the given performance can be precisely or finitely measured and are not a substitute for judgment (Tufte, 1983). The KPIs used in this model that can be quantitatively measured are: 
- $\quad$ Total Claims Cost \%,

- Time Overrun,

- Cost Overrun \%,

- $\quad$ Change Order Cost \%,

- $\quad$ Errors and Omissions Cost \%,

- RFI per Unit Price,

- Owner Requested Changes \%,

- $\quad$ RFI Response Time per Price, and

- $\quad$ Total Cost of Field Rework \%.

The means and standard deviations of the dataset were then computed for each of the nine KPIs, as summarized in Table 6-2.

Table 6-2: KPI Mean and Standard Deviation of the Dataset

\begin{tabular}{lccc}
\hline KPI & Mean $\left(\mu_{j}\right)$ & $\begin{array}{c}\text { Standard } \\
\text { Deviation }\left(\sigma_{j}\right)\end{array}$ & Range \\
\hline Cost Overrun \% & 7.38 & 6.59 & 0.00 to 38.84 \\
Change Order Cost \% & 5.83 & 5.40 & -10.77 to 27.98 \\
Time Overrun \% & 23.25 & 34.51 & -7.62 to 125.56 \\
RFIs per Unit Price ${ }^{1}$ & 16.40 & 33.88 & 2.03 to 166.11 \\
Errors and Omissions Cost \% & 27.68 & 25.23 & 0.00 to 100.00 \\
Total Claims Cost \% & 4.85 & 14.21 & 0.00 to 69.30 \\
RFI Response Time per Unit Price $^{1}$ & 6.13 & 14.85 & 0.00 to 66.47 \\
Total Cost of Field Rework \% & 0.93 & 0.058 & 0.72 to 1.11 \\
Owner Requested Changes \% & 55.08 & 35.29 & 0.00 to 116.09 \\
\hline
\end{tabular}




\section{Scoring Mechanism}

For any given project, the developed PPR model combines five SC into one score for that project. These five SCs are:

- Customer Satisfaction,

- Project Schedule,

- Project Cost,

- Design Quality, and

- Early Involvement.

The computed PI is based on the scores of the five SC, along with the different weights assigned to each. The advantage of using a linear model lies in its simplicity and the fact that it allows for the easy modifications of the PFs. The project performance rating does not depend on the IPD principles; it depends on the SC in this model, which are calculated as the weighted averages of their respective PFs. The SC scores are combined and normalized before they are introduced to the weighted average equation.

The score for each of the five SC also include many PFs, for instance, Project Cost includes the Cost Overrun and the Change Order Cost as shown in Figure 6-2. Since the KPIs used in this study have various units, values for different factors cannot be simply added together, such as cost and time.

\section{$\underline{\text { KPIs Mathematical Formulation and Normalization }}$}

For KPIs, a standardization method is used that can transform any set of numbers to their equivalent values on the standard normal distribution. The standardization proposed by Kreyszig (1979) is used in this study. This method uses the expression shown in 
Equation 6-1 to transform a number $\mathrm{X}$ of a population into its equivalent standardized value $\mathrm{Z}$ by subtracting the mean and dividing by the standard deviation of the population (Kreyszig, 1979).

$$
Z=\frac{X-\text { Mean }}{\text { St.Deviation }}
$$

Where $\mathrm{X}$ is a KPI value.

One main advantage of such standardization is that a $Z$ value calculated as shown in Equation 6-1 is centered around zero. Positive values indicate above average performance and negative values indicate below average performance, while zero indicates the average project performance regarding the specific KPI. Therefore, the measurement units of the standardized values are the number of standard deviations $(N)$ above or below the average. For instance, a $Z$ value of 3 for a specific KPI of a project means that the project was three standard deviations above the average project performance for that specific KPI. Using the standardized value $Z$ of a KPI, a performance score equation was developed in this study to calculate the performance score for that particular KPI using the expression developed in Equation 6-2.

$$
\text { Performance Score }=\frac{10(-Z+N)}{2 N} \text { and }-N \leq Z \leq N
$$

A performance score of zero is assigned to a $\mathrm{PF}$ whose $Z$ value is greater than or equal to $N$; a performance score of 10 over 10 is assigned to a PF whose standardized $\mathrm{Z}$ value is less than or equal to the negative number of standard deviations $(-N)$. Table 6-3 summarizes the performance scoring mechanism for the PFs. It is important to note that above average performance score value for these PFs is an indication of bad project. This includes the following factors: Cost Overrun, Time Overrun, Change Order Cost, Owner 
Requested CO, Errors and Omissions CO, Claims, Field Rework, RFI, and RFI Response Time. For example, an above average value for cost should result in a low performance score. Hence, the performance score values are obtained in Equation 6-2 by multiplying $Z$ by -1 to reflect the correct score of the factors.

Table 6-3: KPI Standardization

\begin{tabular}{|c|c|}
\hline $\begin{array}{c}\text { KPI Standardized } \\
Z \text { Score }(Z)\end{array}$ & Performance Score \\
\hline$Z>N$ & 0 \\
\hline$Z<-N$ & 10 \\
\hline$-N \leq Z \leq N$ & $10 \times \frac{(-Z+N)}{(2 N)}$ \\
\hline
\end{tabular}

$* N$ is the number of standard deviations

In this study, the KPI values for the entire construction sector under consideration are assumed to follow a normal distribution. The normal distribution has $99.7 \%$ of the area under curve falls within a distance of $= \pm 3$ standard deviations (SD) from the mean. In other words, $99.7 \%$ of values are less than three standard deviations (3SD) away from the mean. $95.4 \%$ of the area under the curve falls within a distance of $= \pm 2$ SD from the mean and $68.2 \%$ of values are less than one standard deviation $( \pm 1)$ away from the mean value. This is illustrated in Figure 6-3. 


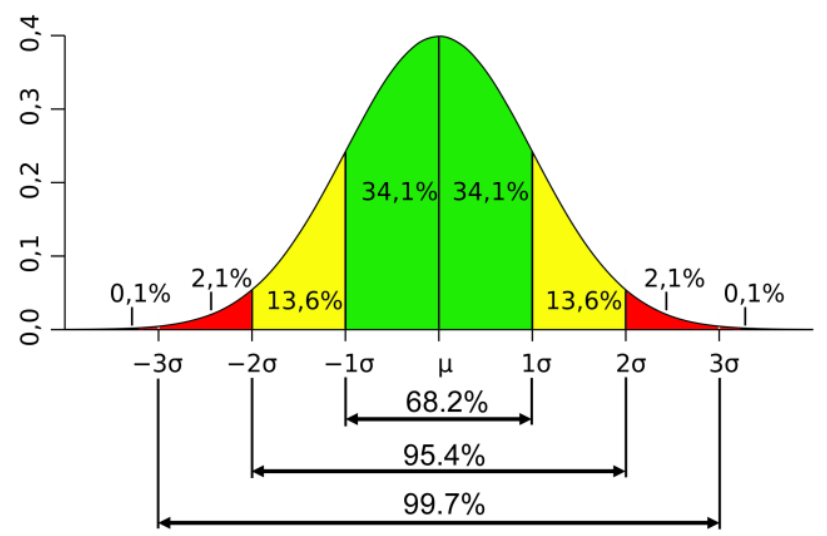

Figure 6-3: Normal distribution density curve.

These percentages of the area of the normal density curve correspond to confidence levels, with $95 \%$ being the most commonly used confidence level in research and applied practice. A 90\% confidence level means one time in 10 an outlier will be found. Since the number of standard deviation and the $Z$ value were defined as $N$ and $Z$, respectively, the range of $Z$ would be $-N \leq Z \leq N$. Table 6-4 shows the confidence levels for typical values of $N$.

Table 6-4: Confidence Level

\begin{tabular}{|c|c|}
\hline $\boldsymbol{N}$ & $\begin{array}{c}\text { Confidence Level } \\
\text { (Area of normal density curve) }\end{array}$ \\
\hline 1 & $68.2 \%$ \\
\hline 1.28 & $80.0 \%$ \\
\hline 1.645 & $90.0 \%$ \\
\hline 1.96 & $95.0 \%$ \\
\hline 2 & $95.4 \%$ \\
\hline 2.58 & $99.0 \%$ \\
\hline 3 & $99.7 \%$ \\
\hline
\end{tabular}

A higher $N$ value increases the performance score of the PF for a positive value of $Z$ and decreases the performance score of the PF for a negative value of $Z$. For example, consider a project where the claims $\mathrm{PF}$ is to be calculated. In the case where $N=1$ and 
$\mathrm{Z}=-0.26$, it yields a $\mathrm{PF}$ performance score $=6.3$. For the same project, when $N=2$ and $\mathrm{Z}=-0.26$, the calculated PF performance score is 5.7. Also for the same project, and when $N=3$ and $\mathrm{Z}=-0.26$, it yields $\mathrm{PF}$ performance score of 5.4. Since the $Z$ value in this example was negative, the performance score decreased as the value of $N$ increased. Since some of the PFs have positive $Z$ value and some have negative $Z$ value, changing the $N$ value has no major effect on the overall performance rating of a project. Choosing a value for $N$ is thus subjective and should be determined by the owner depending on the project. For example, an owner might choose a value of $N=2$ for projects exceeding $\$ 10$ $\mathrm{M}$ and $N=3$ for projects equals to or less than $\$ 10 \mathrm{M}$. Other owners might choose a value of $N=2$ for complex projects and $N=3$ for simple projects, such as rehabilitation projects. However, for PPR purposes, the value of $N$ does not significantly affect the final rating score. A value of $N=2$, corresponding to the commonly used $95.4 \%$ confidence interval, is a typical value that is therefore used for the PI formula.

The following example demonstrates how the performance score is calculated using Equation 6-2. Suppose two standard deviations will be used for a certain project, then $N=2$. 


\section{Table 6-5: KPI Standardization with 3 Standard Deviations}

\begin{tabular}{|c|c|}
\hline $\begin{array}{c}\text { KPI Standardized } Z \text { Score } \\
(Z)\end{array}$ & Performance Score \\
\hline$Z>2$ & 0 \\
\hline$Z<-2$ & 10 \\
\hline$-2 \leq Z \leq 2$ & $10 \times \frac{(-Z+2)}{(4)}$ \\
\hline
\end{tabular}

The Performance Score is evaluated based on a variable scale from 0 to 10 ; zero being a low performance score, 5 being average, and 10 being good. Table 6-6 shows the various cases of the $\mathrm{Z}$ value. Figure 6-4 shows the linear relationship that exists between the Performance Score and $Z$ for different values of $N$. For different values of $N$ Figure 6-4 shows that $Z$ is constrained in an interval between $+N$ and $-N$. For example, selecting $N=1$ for PF resulted in $Z$ values which vary from +1 to -1 for the same PF. Figure 6-4 also shows that a higher $N$ value increases the Performance Score of the PF for a positive value of $Z$ and decreases the performance score of the PF for a negative value of $Z$. For example, consider $N=2$ and $Z=-1.1$ for a $P F$, the Performance $S$ core for that same $P F=7.8$. For $N=3$ and $Z=-1.1$, the Performance Score $=6.9$. 


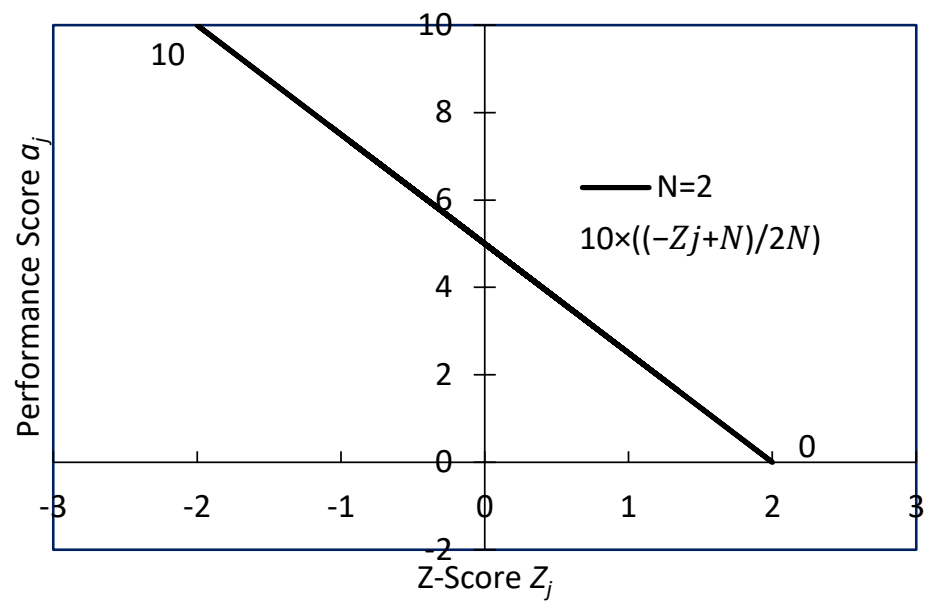

Figure 6-4: Comparison of Performance Score of $Z$.

The KPIs were then computed, followed by the standardized value, Z, for each KPI, and the PF scores based on a value of $N=2$, as summarized in Table 6-6.

Table 6-6: Control Projects KPIs and PFs Scores

\begin{tabular}{llrrrrrr}
\hline & & \multicolumn{3}{c}{ Final Site Work } & \multicolumn{3}{c}{ Screening System } \\
\hline $\mathrm{j}$ & PF & KPI & $\mathbf{Z}$ & Score & KPI & $\mathbf{Z}$ & Score \\
1 & Cost Overrun & $3.41 \%$ & -0.60 & 6.51 & $4.36 \%$ & -0.46 & 6.11 \\
2 & Change Order Cost & $8.15 \%$ & 0.43 & 3.93 & $3.64 \%$ & -0.40 & 6.01 \\
3 & Time Overrun & $0.00 \%$ & -0.67 & 6.68 & $-0.7 \%$ & -0.69 & 6.68 \\
4 & RFIs & 3.21 & -0.39 & 5.97 & 4.93 & -0.34 & 5.85 \\
5 & Errors and Omissions CO & $7.13 \%$ & -0.81 & 7.04 & $23.20 \%$ & -0.18 & 5.44 \\
6 & Claims & $0.00 \%$ & -0.34 & 5.85 & $0.00 \%$ & -0.34 & 5.85 \\
7 & RFI Response Time & 0.96 & -0.35 & 5.87 & 2.13 & -0.27 & 5.67 \\
8 & Field Rework & $0.00 \%$ & -16.03 & 10.00 & $0.00 \%$ & -16.0 & 10.00 \\
9 & Owner's CO & $53.21 \%$ & -0.05 & 5.13 & $39.39 \%$ & -0.44 & 6.11 \\
\hline
\end{tabular}

*Based on a value of $N=2$ 


\section{Scoring Computation of KPIs and SC for PPR}

The dataset of 43 projects was used to compute the means and standard deviations of the KPIs. Forty-three projects of the dataset were analyzed for key performance indicators and the normalized means and standard deviations of the nine KPIs were computed. The remaining two projects are control projects with IPD principles implemented in their project delivery. For all nine PFs for each project of the dataset, the standardized $Z$ values and the performance scores were computed using Equations 6-1 and 6-2, respectively. The scoring computation for each of the five SC is illustrated in the following subsections.

\section{SC No. 1: Customer Satisfaction}

For the purpose of the PPR development, one KPI is used for quantifying Customer Satisfaction related to a specific project. This KPI is total claims cost as a percentage of the total project cost. This is a very important KPI for Customer Satisfaction since an owner is not likely to hire the same company in the future if the current project resulted in claims. Based on the level of importance for assessing Customer Satisfaction, the weight for Claims PF is a variable that is selected by the owner depending on the project's needs.

For the used dataset, the normalized mean value for Claims cost is $4.85 \%$ of the total project cost, and the standard deviation is 14.21 . The Total Claims Cost \% KPI is standardized to obtain its respective $Z$ value. After this standardization, a performance score is computed using Equation 6-2.

The equation for the performance score of Customer Satisfaction SC is thus expressed as shown in Equation 6-3: 
Customer Satisfaction $=\omega_{\mathrm{i}} \times \frac{10 \times\left[-\frac{(\text { Total Claims Cost } \%-4.85)}{14.21}+\mathrm{N}\right]}{2 \times \mathrm{N}}$

$\omega_{\mathrm{i}}$ is the user-assigned weight for the Claims PF

\section{SC No. 2: Project Schedule}

The performance score for the Project Schedule SC is based on Time Overrun Percentage. This selected KPI reflects timely and efficient preparation, implementation, and closeout of tasks, meeting key program milestones and contractual delivery dates, recovery from delays, and appropriateness of response to changes. For the dataset used, the normalized mean for Time Overrun is $23.25 \%$ and the standard deviation is 34.51 . Time Overrun is standardized as shown in Equation 6-4.

The equation for the performance score of PS is expressed in Equation 6-4.

Project Schedule $=\omega_{\mathrm{i}} \times \frac{10 \times\left[-\frac{(\text { Time Overrun\%-23.25) }}{34.51}+\mathrm{N}\right]}{2 \times \mathrm{N}}$

where

$\omega_{\mathrm{i}}$ is the user-assigned weight for Time Overrun

Equation 6-4 is essentially used to calculate the performance score of a project with respect to its schedule.

\section{SC No. 3: Project Cost}

Project Cost includes the ability to control and adjust the project contract costs and cost reductions through value engineering and process methods. The main consideration when evaluating Project Cost is the measurement of the contractor's performance against the bid cost of the contract. Construction cost performance is relatively easy to track 
because project teams keep useful records of several cost items for different project phases. Two KPIs are used to quantify the cost performance score:

1- Cost Overrun Percentage, and

2- Change Order Cost Percentage of total cost.

The normalized mean for Cost Overrun is $7.38 \%$ and the standard deviation is 6.59 . The normalized mean for Change Order Cost is $5.83 \%$ and the standard deviation is 5.40. The standardized $Z$ value for each of the two PFs is formulated separately in the expression for the performance score of the Project Cost SC shown in Equation 6-5.

Project Cost $=\omega_{\mathrm{i}} \times \frac{10 \times\left[-\left(\frac{\text { Cost Overrun\%-7.38 }}{6.59}\right)+\mathrm{N}\right]}{2 \mathrm{~N}}+\omega_{\mathrm{j}} \times \frac{10 \times\left[-\left(\frac{\text { Change Order Cost } \%-5.83}{5.40}\right)+\mathrm{N}\right]}{2 \mathrm{~N}}$

where $\omega_{\mathrm{i}}$ is the user-assigned weight for Cost Overrun and $\omega_{\mathrm{j}}$ is the user-assigned weight for Change Order Cost. Equation 6-5 is used to calculate a project's performance score with respect to its cost.

\section{SC No. 4: Design Quality}

A good design typically includes detailed approach in design concepts, analysis, and detailed execution procedures, thoroughness and accuracy. A good design is also based on meeting technical requirements for design, performance and processing, reliability, and adequate design reviews. Two KPIs are used to quantify the design quality performance score. The two-project quality KPIs used are:

1- Errors and Omissions Cost Percentage, and

2- Number of RFI per Unit Price. 
Error and Omission cost amounts are measured based on cost percentages relative to total construction costs. The normalized mean for Errors and Omissions Cost Percentage is $27.68 \%$ and the standard deviation is 25.23 . The normalized mean for Number of RFI per Unit Price is 16.40 per million dollars and the standard deviation is 33.88 per million dollars. The standardized $Z$ value for each of these KPIs is formulated separately in the expression for the performance score of the design quality SC shown in Equation 6-6.

$$
\begin{aligned}
\text { Design Quality } & =\omega_{\mathrm{i}} \times \frac{10 \times\left[-\left(\frac{\text { Errors \& Omissions Cost } \%-27.68}{25.23}\right) \mp N\right]}{2 N} \\
& +\omega_{\mathrm{j}} \times \frac{10 \times\left[-\left(\frac{\text { RFI per Unit Price }-16.40}{33.88}\right) \mp N\right]}{2 N}
\end{aligned}
$$

where

$\omega_{\mathrm{i}}$ is the user-assigned weight for Errors and Omissions Cost

$\omega_{\mathrm{j}}$ is the user-assigned weight for RFI

The Number of RFI per Unit Price is in RFI per million dollars.

\section{SC No. 5: Early Involvement}

Effective communications among project participants is essential at all levels where decisions can be made and results achieved. Frequent and honest communication improves labor relations, planning, organizing, and managing all program elements. Management actions are needed to achieve and sustain a high level of early involvement. Collaboration and communication help to recognize critical problem areas and ensure integrated operation efficiency.

The Early Involvement performance score comprises three KPIs:

1- RFI Response Time per Price, 
2- Owner Requested Change Cost Percentage, and

3- Total Cost of Field Rework Percentage.

The normalized mean for RFI Response Time per Price is 6.13 days per million dollars and the standard deviation is 14.85 . The normalized mean for Owner Requested Change Cost Percentage is $55.08 \%$ and the standard deviation is 35.29 . The normalized mean for Field Rework Percentage is $0.93 \%$ and the standard deviation is 0.058 . The performance score for Early Involvement is expressed in Equation 6-7.

Communication and Collaboration

$$
\begin{aligned}
& =\omega_{i} \times \frac{10 \times\left[-\left(\frac{R F I \text { Response Time per Price }-6.13}{14.85}\right)+N\right]}{2 N} \\
& +w_{j} \times \frac{10 \times\left[-\left(\frac{\text { Owner Requested Change Cost } \%-55.08}{35.29}\right)\right]}{2 N} \\
& +w_{k} \times \frac{10 \times\left[-\left(\frac{\text { Field Rework } \%-0.93}{0.058}\right)\right]}{2 N}
\end{aligned}
$$

where $\quad \omega_{\mathrm{i}}$ is the user-assigned weight for RFI Response Time

$\omega_{\mathrm{j}}$ is the user-assigned weight for Owner Requested Change Cost

$\omega_{\mathrm{k}}$ is the user-assigned weight for Field Rework

\section{Performance Index (PI) Formula}

The PI is a linear weighted sum of the five SCs. Owners can apply the PPR model to their water and wastewater construction projects, and the project's performance can be rated relative to the 43-project dataset compiled for this study. There are also no restrictions on the use of data values outside the range of the dataset collected to build 
this model. For instance, in the dataset, the range of Total Claims Cost Percent is 0\%$69 \%$, however a value of $75 \%$, which is outside the dataset range, can still be used in the PPR model.

After obtaining the weights and the performance scores of all the SCs, weighted scores can be calculated. The weighted scores for the five SCs are then combined into the PPR model using Equation 6-8.

$$
\begin{aligned}
& P I=\left(\omega_{1} \times \text { Return Business }\right)+\left(\omega_{2} \times \text { Schedule }\right)+\left(\omega_{3} \times \text { Cost Control }\right)+ \\
& \left(\omega_{4} \times \text { Design Quality }\right)+\left(\omega_{5} \times \text { Communication\& Collaboration }\right) \\
& \omega_{1} \text { is the user-assigned weight for Customer Satisfaction } \\
& \omega_{2} \text { is the user-assigned weight for Project Schedule } \\
& \omega_{3} \text { is the user-assigned weight for Project Cost } \\
& \omega_{4} \text { is the user-assigned weight for Design Quality } \\
& \omega_{5} \text { is the user-assigned weight for Early Involvement }
\end{aligned}
$$

Tables 6-7 and 6-8 present a numerical example showing how the SC performance scores and the PI are calculated for a sample project. 
Table 6-7: Weighted PF Score Computation

\begin{tabular}{|c|c|c|c|}
\hline $\begin{array}{l}\text { Performance } \\
\text { Factor (PF) }\end{array}$ & $\begin{array}{c}\text { (a) } \\
\text { PF Score }\end{array}$ & \begin{tabular}{l}
\multicolumn{1}{c}{ (b) } \\
PF Assigned \\
Weights \\
\end{tabular} & $\begin{array}{l}\text { (c) } \\
\text { Weighted PF Score } \\
\text { (a)x(b) }\end{array}$ \\
\hline \multirow[t]{2}{*}{ Claims } & $\begin{array}{c}10 \\
\text { (Excellent) }\end{array}$ & 1.0 & 10 \\
\hline & & $\begin{array}{l}\text { Total for Customer } \\
\text { Satisfaction }\end{array}$ & 10 \\
\hline Time Overrun & 7.5 & $\begin{array}{c}1.0 \\
\text { Total for Project Schedule }\end{array}$ & $\begin{array}{l}7.5 \\
7.5\end{array}$ \\
\hline Cost Overrun & 5.0 & .80 & 4 \\
\hline CO Cost & 2.5 & $\begin{array}{c}.20 \\
\text { Total for Project Cost }\end{array}$ & $\begin{array}{l}0.5 \\
4.5\end{array}$ \\
\hline $\begin{array}{l}\text { Error \& Omission } \\
\text { Cost }\end{array}$ & 5.0 & .60 & 3 \\
\hline RFI & 2.5 & $\begin{array}{c}.40 \\
\text { Total for Design Quality }\end{array}$ & $\begin{array}{l}1.0 \\
4.0\end{array}$ \\
\hline RFI Response Time & 2.5 & .20 & 0.5 \\
\hline $\begin{array}{l}\text { Owner Requested } \\
\text { Changes }\end{array}$ & 5.0 & .20 & 1.0 \\
\hline Field Rework & 5.0 & $\begin{array}{c}0.6 \\
\text { Total for Early } \\
\text { Involvement }\end{array}$ & $\begin{array}{l}3.0 \\
4.5\end{array}$ \\
\hline
\end{tabular}

*Weighted PF Scores are calculated as follows: [PF Score $\mathrm{x}$ Assigned Factor Weight $]=$ Weighted PF Scores. For example, for Claims: $[10$ x .50] $=5$.

Table 6-8: Total Weighted Success Criteria Score Computation

\begin{tabular}{|c|c|c|c|c|c|}
\hline $\begin{array}{l}\text { Weighted } \\
\text { Factor }\end{array}$ & SC Score & $\mathrm{x}$ & $\begin{array}{l}\text { SC Assigned } \\
\text { Weight }\end{array}$ & & $\begin{array}{l}\text { Total Weighted } \\
\text { SC Score }\end{array}$ \\
\hline $\begin{array}{l}\text { Customer } \\
\text { Satisfaction }\end{array}$ & 10 & $\mathrm{x}$ & .24 & $=$ & 2.4 \\
\hline Project Schedule & 7.5 & $\mathrm{x}$ & .22 & $=$ & 1.65 \\
\hline Project Cost & 4.5 & $\mathrm{x}$ & .20 & $=$ & 0.9 \\
\hline Design Quality & 4.0 & $\mathrm{x}$ & .18 & $=$ & 0.72 \\
\hline $\begin{array}{l}\text { Early } \\
\text { Involvement }\end{array}$ & 3.75 & $\mathrm{x}$ & .16 & - & 0.6 \\
\hline
\end{tabular}




\section{$\underline{\text { PPR Model Application }}$}

The PPR Model application can be achieved by running several model simulations and comparing the results amongst each other values of various simulations with having generalized knowledge about these projects. Model application is described in the following section.

\section{Control Project Model Simulation}

The PPR Model will be assessed to be valid if its output matches the "real" output within some specified range of accuracy. Two wastewater construction projects are used as control projects for implementing the model and verifying its output as compared with the actual results. The first control project (CP1) is Final Site Work and the second control project (CP2) is Screening System Improvements at Miami Dade Water and Sewer Department. The control projects are described in Chapter 4 of this study.

It is important to note that the control projects were completed, and the SC and PF scores were calculated per the equations described in this PPR Model. The PPR Model simulation is run for 10,000 trials on each control project in order to obtain a mean rating value for each of the control projects. The PPR Model simulation is also run for 10,000 trials on the 43 projects of the dataset to get a mean rating value for the entire dataset. In each simulation run, various values of the user defined weights of the SCs and PFs are randomly selected using Monte Carlo simulation in excel in order to simulate different owner preferences. Tables 6-9 to 6-13 show a sample of the PI calculations of CP1 for five simulation runs with the weights chosen for each SC and PF in each run. 
Table 6-9: PPR Simulation No. 1

\begin{tabular}{|c|c|c|c|c|c|c|c|c|}
\hline \multirow[b]{2}{*}{ SC } & \multirow[b]{2}{*}{ PF } & \multicolumn{3}{|c|}{ PF } & \multicolumn{3}{|c|}{ SC } & \multirow[b]{2}{*}{$\begin{array}{c}\text { (g) } \\
\text { PI } \\
\sum(\mathbf{f})\end{array}$} \\
\hline & & $\begin{array}{c}\text { (a) } \\
\text { Weight }\end{array}$ & $\begin{array}{c}\text { (b) } \\
\text { Score }\end{array}$ & $\begin{array}{c}\text { (c) } \\
\text { Weighted } \\
\text { Score } \\
\text { (a)x(b) }\end{array}$ & $\begin{array}{c}\text { (d) } \\
\text { Score } \\
\sum(\mathbf{c})\end{array}$ & $\begin{array}{c}\text { (e) } \\
\text { Weight }\end{array}$ & $\begin{array}{c}\text { (f) } \\
\text { Weighted } \\
\text { Score } \\
\text { (d)x(e) }\end{array}$ & \\
\hline $\begin{array}{c}\text { Customer } \\
\text { Satisfaction }\end{array}$ & Claims & 1.0 & 5.57 & 5.57 & 5.57 & 0.24 & 1.34 & \multirow{9}{*}{6.46} \\
\hline $\begin{array}{c}\text { Project } \\
\text { Schedule }\end{array}$ & Time Overrun & 1.0 & 6.12 & 6.12 & 6.12 & 0.21 & 1.29 & \\
\hline \multirow{2}{*}{ Project Cost } & Cost Overrun & 0.9 & 6.00 & 5.40 & \multirow{2}{*}{5.83} & \multirow{2}{*}{0.20} & \multirow{2}{*}{1.17} & \\
\hline & CO Cost & 0.1 & 4.28 & 0.43 & & & & \\
\hline \multirow{2}{*}{ Design Quality } & Errors \& Omissions Cost & 0.9 & 6.36 & 5.72 & \multirow{2}{*}{6.29} & \multirow{2}{*}{0.18} & \multirow{2}{*}{1.13} & \\
\hline & RFI per Unit Price & 0.1 & 5.65 & 0.56 & & & & \\
\hline \multirow{3}{*}{$\begin{array}{c}\text { Early } \\
\text { Involvement }\end{array}$} & $\begin{array}{c}\text { RFI Response Time per Unit } \\
\text { Price }\end{array}$ & 0.1 & 5.58 & 0.56 & \multirow{3}{*}{9.07} & \multirow{3}{*}{0.17} & \multirow{3}{*}{1.54} & \\
\hline & Owner Requested Changes & 0.1 & 5.09 & 0.51 & & & & \\
\hline & $\begin{array}{c}\text { Field Rework } \\
\text { Find }\end{array}$ & 0.8 & 10.00 & $\begin{array}{l}-ー- \\
8.00\end{array}$ & & & & \\
\hline
\end{tabular}

Table 6-10: PPR Simulation No. 2

\begin{tabular}{|c|c|c|c|c|c|c|c|c|}
\hline \multirow[b]{2}{*}{ SC } & \multirow[b]{2}{*}{ PF } & \multicolumn{3}{|c|}{ PSF } & \multicolumn{3}{|c|}{ PF } & \multirow[b]{2}{*}{$\begin{array}{l}\text { (g) } \\
\text { PPR } \\
\sum(f)\end{array}$} \\
\hline & & $\begin{array}{c}\text { (a) } \\
\text { Weight }\end{array}$ & $\begin{array}{c}\text { (b) } \\
\text { Score }\end{array}$ & $\begin{array}{c}\text { (c) } \\
\text { Weighted } \\
\text { Score } \\
\text { (a)x(b) }\end{array}$ & $\begin{array}{c}\text { (d) } \\
\text { Score } \\
\sum(\mathbf{c})\end{array}$ & $\begin{array}{c}\text { (e) } \\
\text { Weight }\end{array}$ & $\begin{array}{c}\text { (f) } \\
\text { Weighted } \\
\text { Score } \\
(\text { d)x(e) } \\
\end{array}$ & \\
\hline $\begin{array}{c}\text { Customer } \\
\text { Satisfaction }\end{array}$ & $\begin{array}{l}\text { Claims } \\
----------\end{array}$ & $100 \%$ & 5.57 & $\begin{array}{c}5.57 \\
-ー-ー\end{array}$ & $\begin{array}{r}5.57 \\
-----\end{array}$ & $15 \%$ & 0.84 & \multirow{9}{*}{6.98} \\
\hline $\begin{array}{c}\text { Project } \\
\text { Schedule }\end{array}$ & Time Overrun & $100 \%$ & 6.12 & 6.12 & 6.12 & $15 \%$ & 0.92 & \\
\hline \multirow{2}{*}{ Project Cost } & Cost Overrun & $90 \%$ & 6.00 & $\overline{5.40}$ & \multirow{2}{*}{5.83} & \multirow{2}{*}{$17 \%$} & \multirow{2}{*}{0.99} & \\
\hline & CO Cost & $10 \%$ & 4.28 & $\underline{0.43}$ & & & & \\
\hline \multirow{2}{*}{ Design Quality } & Errors \& Omissions Cost & $90 \%$ & 6.36 & 5.72 & \multirow{2}{*}{6.29} & \multirow{2}{*}{$26 \%$} & \multirow{2}{*}{1.63} & \\
\hline & RFI per Unit Price & $10 \%$ & 5.65 & 0.56 & & & & \\
\hline \multirow{3}{*}{$\begin{array}{c}\text { Early } \\
\text { Involvement }\end{array}$} & $\begin{array}{c}\text { RFI Response Time per Unit } \\
\text { Price }\end{array}$ & $20 \%$ & $\begin{array}{r}-ே \\
5.58\end{array}$ & 1.12 & \multirow{3}{*}{8.13} & \multirow{3}{*}{$32 \%$} & \multirow{3}{*}{2.60} & \\
\hline & Owner Requested Changes & $20 \%$ & 5.09 & 1.02 & & & & \\
\hline & Field Rework & $60 \%$ & 10.00 & $\begin{array}{l}-ー- \\
6.00\end{array}$ & & & & \\
\hline
\end{tabular}


Table 6-11: PPR Simulation No. 3

\begin{tabular}{|c|c|c|c|c|c|c|c|c|}
\hline \multirow[b]{2}{*}{ SC } & \multirow[b]{2}{*}{ PF } & \multicolumn{3}{|c|}{ PSF } & \multicolumn{3}{|c|}{ PF } & \multirow[b]{2}{*}{$\begin{array}{c}\text { (g) } \\
\text { PPR } \\
\sum(\mathbf{f})\end{array}$} \\
\hline & & $\begin{array}{c}\text { (a) } \\
\text { Weight }\end{array}$ & $\begin{array}{c}\text { (b) } \\
\text { Score }\end{array}$ & $\begin{array}{c}\text { (c) } \\
\text { Weighted } \\
\text { Score } \\
\text { (a)x(b) }\end{array}$ & $\begin{array}{c}\text { (d) } \\
\text { Score } \\
\sum(\mathbf{c})\end{array}$ & $\begin{array}{c}\text { (e) } \\
\text { Weight }\end{array}$ & $\begin{array}{c}\text { (f) } \\
\text { Weighted } \\
\text { Score } \\
\text { (d)x(e) }\end{array}$ & \\
\hline $\begin{array}{c}\text { Customer } \\
\text { Satisfaction }\end{array}$ & Claims & $100 \%$ & 5.57 & 5.57 & 5.57 & $18 \%$ & 1.00 & \multirow{9}{*}{6.59} \\
\hline $\begin{array}{c}\text { Project } \\
\text { Schedule }\end{array}$ & Time Overrun & $100 \%$ & 6.12 & 6.12 & 6.12 & $21 \%$ & 1.29 & \\
\hline \multirow{2}{*}{ Project Cost } & Cost Overrun & $90 \%$ & 6.00 & 5.40 & \multirow{2}{*}{5.83} & \multirow{2}{*}{$20 \%$} & \multirow{2}{*}{1.17} & \\
\hline & CO Cost & $10 \%$ & 4.28 & 0.43 & & & & \\
\hline \multirow{2}{*}{ Design Quality } & Errors \& Omissions Cost & $90 \%$ & 6.36 & 5.72 & \multirow{2}{*}{6.29} & \multirow{2}{*}{$17 \%$} & \multirow{2}{*}{1.07} & \\
\hline & RFI per Unit Price & $10 \%$ & 5.65 & 0.56 & & & & \\
\hline \multirow{3}{*}{$\begin{array}{c}\text { Early } \\
\text { Involvement }\end{array}$} & $\begin{array}{c}\text { RFI Response Time per Unit } \\
\text { Price }\end{array}$ & $15 \%$ & 5.58 & 0.84 & \multirow{3}{*}{8.60} & \multirow{3}{*}{$24 \%$} & \multirow{3}{*}{2.06} & \\
\hline & Owner Requested Changes & $15 \%$ & 5.09 & 0.76 & & & & \\
\hline & $\begin{array}{r}\text { Field Rework } \\
\text { Fien }\end{array}$ & $70 \%$ & 10.00 & $\begin{array}{l}-\bullet- \\
7.00\end{array}$ & & & & \\
\hline
\end{tabular}

Table 6-12: PPR Simulation No. 4

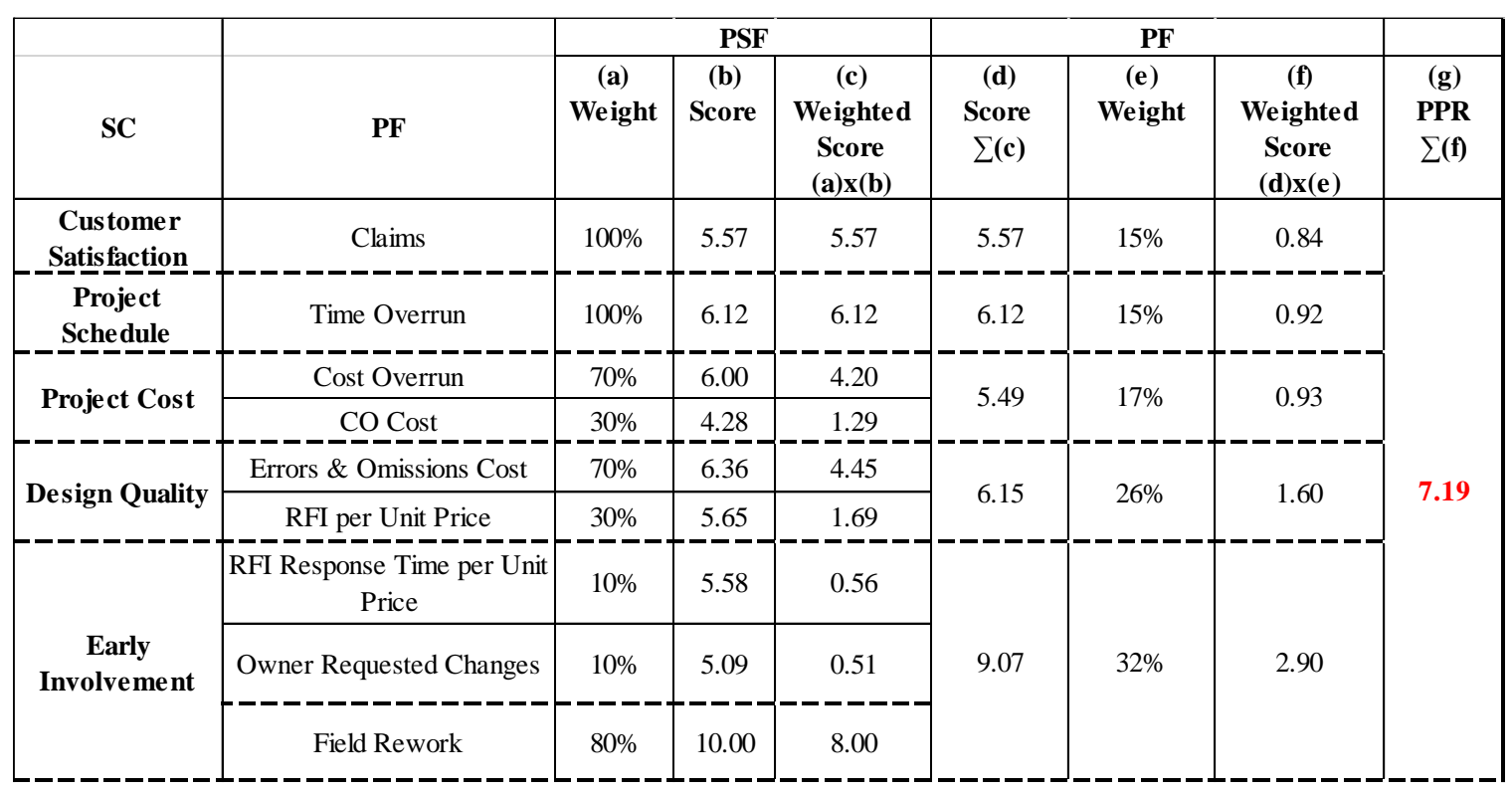


Table 6-13: PPR Simulation No. 5

\begin{tabular}{|c|c|c|c|c|c|c|c|c|}
\hline \multirow[b]{2}{*}{ SC } & \multirow[b]{2}{*}{ PF } & \multicolumn{3}{|c|}{ PSF } & \multicolumn{3}{|c|}{ PF } & \multirow[b]{2}{*}{$\begin{array}{c}\text { (g) } \\
\text { PPR } \\
\sum(f)\end{array}$} \\
\hline & & $\begin{array}{c}\text { (a) } \\
\text { Weight }\end{array}$ & $\begin{array}{c}\text { (b) } \\
\text { Score }\end{array}$ & $\begin{array}{c}\text { (c) } \\
\text { Weighted } \\
\text { Score } \\
\text { (a)x(b) }\end{array}$ & $\begin{array}{c}\text { (d) } \\
\text { Score } \\
\sum(\mathbf{c})\end{array}$ & $\begin{array}{c}\text { (e) } \\
\text { Weight }\end{array}$ & $\begin{array}{c}\text { (f) } \\
\text { Weighted } \\
\text { Score } \\
\text { (d)x(e) }\end{array}$ & \\
\hline $\begin{array}{c}\text { Customer } \\
\text { Satis faction. }\end{array}$ & Claims & $100 \%$ & 5.57 & $\begin{array}{c}5.57 \\
---\end{array}$ & 5.57 & $13 \%$ & 0.72 & \multirow{9}{*}{6.83} \\
\hline $\begin{array}{l}\text { Project } \\
\text { Schedule }\end{array}$ & Time Overrun & $100 \%$ & 6.12 & 6.12 & 6.12 & $12 \%$ & 0.73 & \\
\hline \multirow{2}{*}{ Project Cost } & Cost Overrun & $70 \%$ & 6.00 & 4.20 & \multirow{2}{*}{5.49} & \multirow{2}{*}{$16 \%$} & \multirow{2}{*}{0.88} & \\
\hline & CO Cost & $30 \%$ & 4.28 & 1.29 & & & & \\
\hline \multirow{2}{*}{ Design Quality } & Errors \& Omissions Cost & $90 \%$ & 6.36 & 5.72 & \multirow{2}{*}{6.29} & \multirow{2}{*}{$25 \%$} & \multirow{2}{*}{1.57} & \\
\hline & RFI per Unit Price & $10 \%$ & 5.65 & 0.56 & & & & \\
\hline \multirow{3}{*}{$\begin{array}{c}\text { Early } \\
\text { Involvement }\end{array}$} & $\begin{array}{c}\text { RFI Response Time per Unit } \\
\text { Price }\end{array}$ & $15 \%$ & 5.58 & 0.84 & \multirow{3}{*}{8.60} & \multirow{3}{*}{$34 \%$} & \multirow{3}{*}{2.92} & \\
\hline & Owner Requested Changes & $15 \%$ & 5.09 & 0.76 & & & & \\
\hline & $\begin{array}{r}\text { Field Rework }\end{array}$ & $70 \%$ & 10.00 & 7.00 & & & & \\
\hline
\end{tabular}

The average PI of the 10,000 simulation runs for each control project and the dataset using the PPR model are summarized in Table 6-14.

Table 6-14: PPR Simulation Output Summary

\begin{tabular}{cccc}
\hline & $\mathrm{CP} 1$ & $\mathrm{CP} 2$ & Dataset \\
\hline Average PI & 5.95 & 6.00 & 5.04 \\
\hline
\end{tabular}

Figure 6-5 is a graphical representation of the results of 100 simulation runs. 


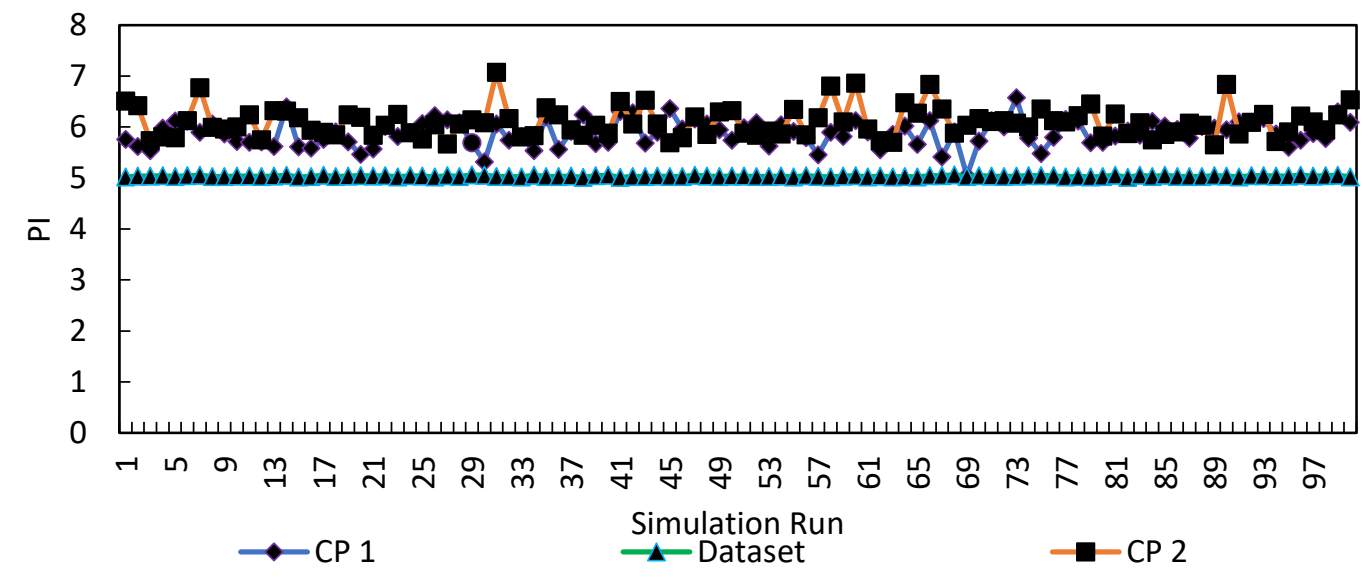

Figure 6-5: Average PI for 100 simulation runs.

\section{Model Simulation Results and Conclusions}

The average PPR Model results of the two control projects $(\mathrm{CP} 1=5.95$ and $\mathrm{CP} 2$ $=6.00)$ are higher than the average PPR results of the dataset (Dataset $=5.04)$ by $18 \%$ and 19\%, respectively. This implies that the two control projects performed better than the average of the dataset projects, and it can therefore be concluded that the use of certain applicable IPD principles in the DBB delivery method leads to noticeable improvement in the performance of water and wastewater treatment plant projects compared to the traditional DBB delivery method. This improvement is also reflected in the KPIs comparison between the control projects and the dataset in Chapter 5, which also showed that implementing certain applicable IPD principles can be highly beneficial to DBB delivery method in water related public projects. The study also demonstrated through the focus group that implementing selective IPD principles improves project performance indicators such as cost, schedule, disputes, and owner's satisfaction.

The average PI of the dataset is equal to 5.04. This score is consistent with the literature, which has shown the traditional DBB approach to have several shortcomings 
and pertinent issues, and in need of improvement in order to keep up with the water utility owners' demands and expectations.

The focus group participants strongly agreed that the use of certain IPD principles in the traditional DBB method improved client satisfaction with the product and client satisfaction with the service and improved the working experience. The focus group participants also attributed most KPI improvements to the implemented IPD principles.

The two control projects scored close on their performance ratings: 5.95 for CP1 and 6.600 for CP2. This can be attributed to two main reasons: (1) the fact that both projects were executed for the same owner, were managed by the same consultant, and followed the same principles; and (2) the standardization process of the KPIs in which the standard deviation of the KPI dataset used has an inverse effect on the range of performance scores for different projects. In other words, the higher the standard deviation of the population used, the narrower the range of performance scores output of the model.

Figure 6-6 shows the KPI values of the control projects and the dataset. For each KPI, the values of the two control projects are different yet close. This can be attributed to the standardization process, which depends on the standard deviation value of the dataset. For instance, owner's CO \% KPI has values of $53.2 \%$ for CP1 and $39.4 \%$ for $\mathrm{CP} 2$, resulting in a range of $13.8 \%$. This $13.8 \%$ difference constitutes a small percentage of roughly $11 \%$ of the dataset range, which is $116 \%$. This results in the performance scores of the two control projects to be close (5.1 for $\mathrm{CP} 1$ and 5.7 for $\mathrm{CP} 2$ ) as shown in Figure 6-7. 


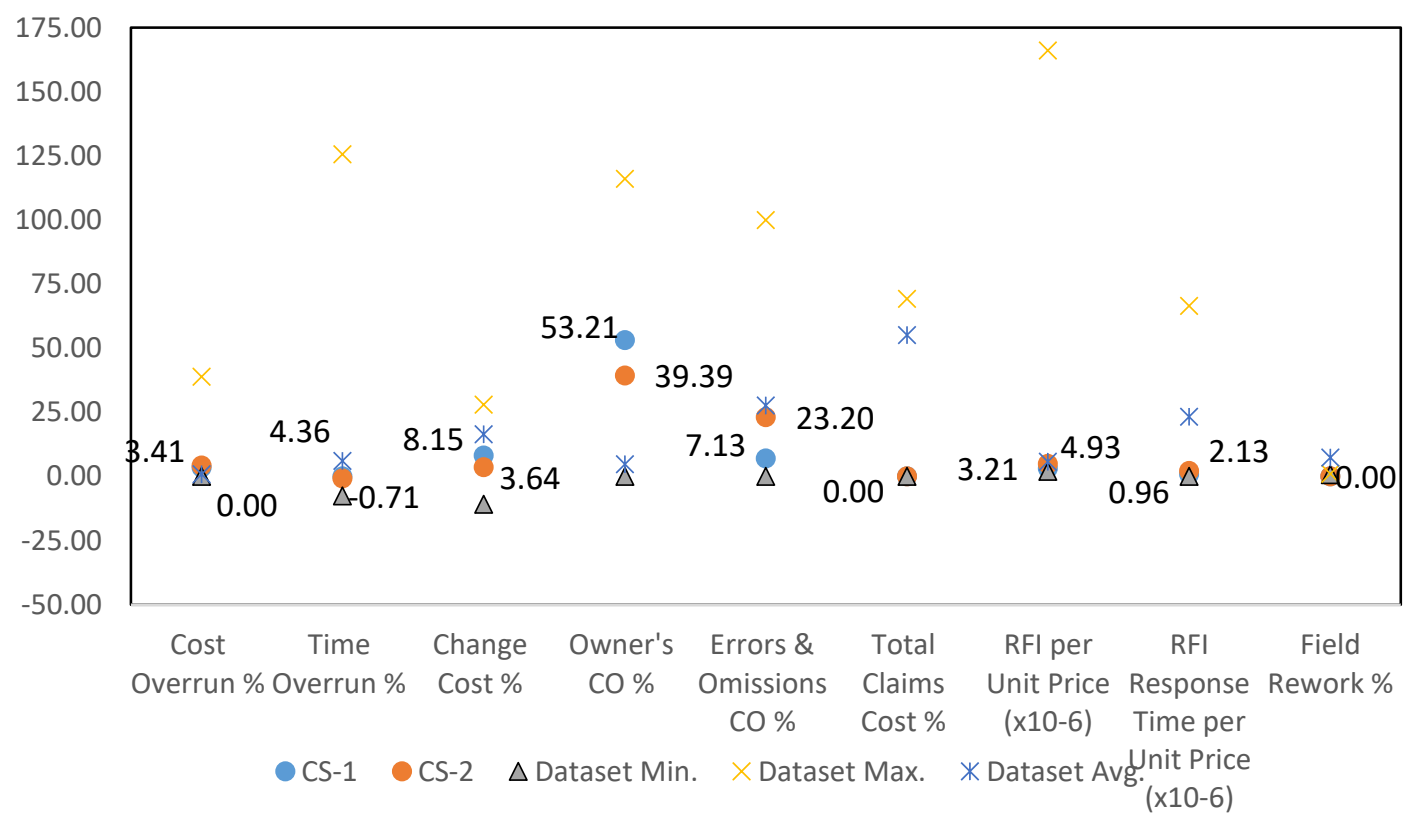

Figure 6-6: Comparison between KPI values of control projects and dataset.

On the contrary, Change Cost $\%$ PF score of the control projects $(8.2 \%$ for $\mathrm{CP} 1$ and $3.7 \%$ for $\mathrm{CP} 2$ ) differ by only $4.5 \%$ and yet resulted in a high score difference of (4.3 for CP1 and minus 5.7 for CP2) 1.4 due to the small dataset KPI values range of $38.7 \%$. It can thus be stated that a large difference in the KPI values does not necessarily lead to a large difference in PF scores of projects using the PPR model. The variation in scores is inversely related to the standard deviation of the dataset KPI values. For the control projects, since the KPI values differ only by a small margin compared to the dataset range, the corresponding PF scores thus came out to be close. 


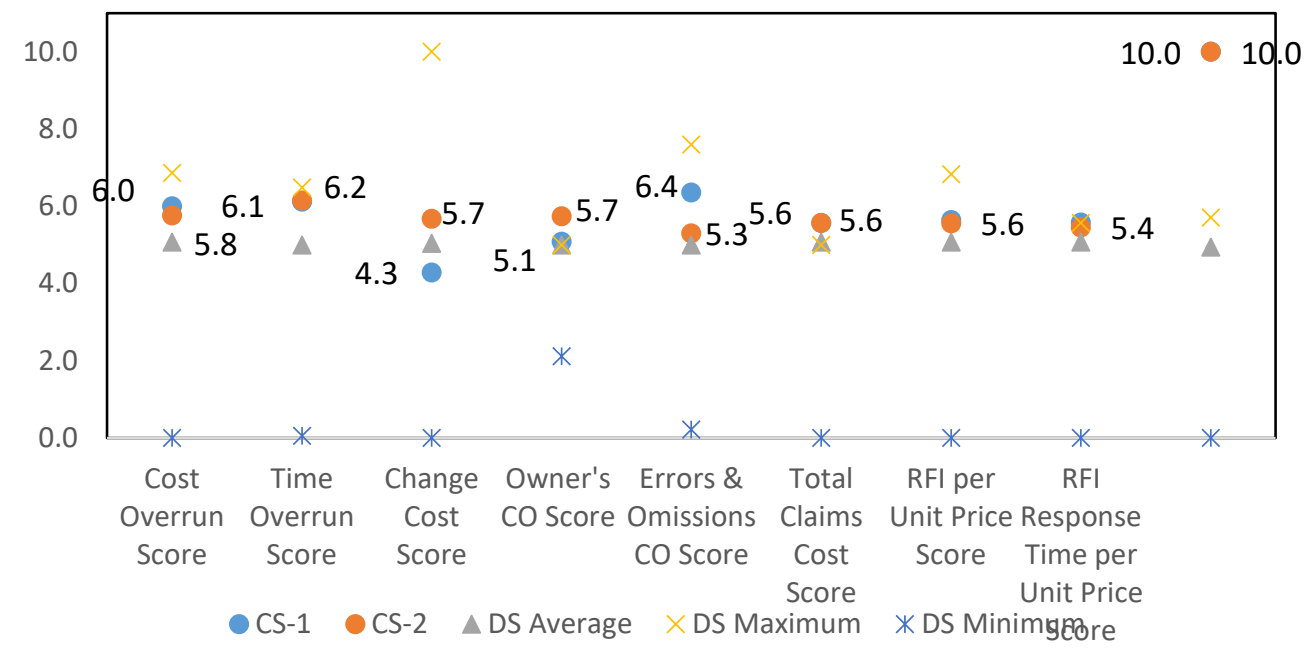

Figure 6-7: Comparison between PF scores of control projects and dataset.

Given the uniformity in project size distribution and large number of randomly selected projects included in the dataset, it can be considered to be representative of the entire water and wastewater construction market, and the resulting PPR model can be readily implemented to water and wastewater construction projects anywhere in the United States.

\section{Correlation between IPD Principles and KPIs}

The study demonstrated that implementing IPD principles to projects delivered using DBB delivery method improves the performance score of such projects. The IPD principles were not included in the PPR model because the IPD principles have a direct relationship with the KPIs. In other words, the performance score of KPI is indirectly dependent on the score of the IPD. In order to predict how improving the implementation of certain IPD principles can impact the performance score of a project, the links between IPD and KPIs are investigated as part of this study. 


\section{Integrated Project Delivery (IPD) Principles}

IPD principles are qualitative or subjective performance standards, which rely on the evaluator's opinions and impressions of performance quality, but not depend on personal bias or intuitive feeling (Platoon, 1990). The IPD principles used in this study are:

1- Mutual Respect and Trust,

2- Lean Principles,

3- Integrated and Collaborative Teams,

4- Collaborative Decision Making,

5- Co-location of Teams,

6- Jointly Developed Project Target Criteria,

7- Open Communication with the Project Team and Ability to Address Issues, and

8- Project's Staff Performance Evaluations.

\section{IPD Principles Scoring Mechanism}

A measuring scale that was developed by Azhar (2014) and that varies from zero to 10 is used for each of the selected IPP principles. In this scale a zero means that the IPD principle was not implemented in a project and a ten means it is fully implemented. Following are tables illustrating the scores for each of the IPD principles. (Azhar, 2014) 
Table 6-15: Scoring Mechanism for Open Communication

\begin{tabular}{|c|c|c|c|c|}
\hline \multicolumn{5}{|c|}{ Score for Open Communication } \\
\hline 10 & 7.5 & 5 & 2.5 & 0 \\
\hline $\begin{array}{l}\text { Communicatio } \\
\mathrm{n} \text { flow is } \\
\text { formally open } \\
\text { and direct, } \\
\text { frequency of } \\
\text { meetings is } \\
\text { high }\end{array}$ & $\begin{array}{l}\text { Communicatio } \\
\mathrm{n} \\
\text { flow is } \\
\text { informally } \\
\text { open, } \\
\text { frequency } \\
\text { of meetings is } \\
\text { high }\end{array}$ & $\begin{array}{l}\text { Communicatio } \\
\mathrm{n} \\
\text { flow is } \\
\text { formally } \\
\text { open and } \\
\text { direct, } \\
\text { frequency of } \\
\text { meetings is low }\end{array}$ & $\begin{array}{l}\text { Communicatio } \\
\mathrm{n} \\
\text { flow is } \\
\text { restrictive } \\
\text { and routes } \\
\text { through long } \\
\text { transmission } \\
\text { chain, } \\
\text { frequency } \\
\text { of meetings is } \\
\text { high }\end{array}$ & $\begin{array}{l}\text { Communicatio } \\
\mathrm{n} \\
\text { flow is } \\
\text { restrictive } \\
\text { and routes } \\
\text { through long } \\
\text { transmission } \\
\text { chain, } \\
\text { frequency } \\
\text { of meetings }\end{array}$ \\
\hline
\end{tabular}

Table 6-16: Scoring Mechanism for Integrated and Collaborative Teams

\begin{tabular}{|c|c|c|c|c|}
\hline \multicolumn{5}{|c|}{ Score for Integrated and Collaborative Teams } \\
\hline 10 & 7.5 & 5 & 2.5 & 0 \\
\hline $\begin{array}{l}\text { Goals are } \\
\text { aligned } \\
\text { and interaction } \\
\text { between the } \\
\text { participants is } \\
\text { open }\end{array}$ & $\begin{array}{l}\text { Goals are } \\
\text { aligned } \\
\text { but interaction } \\
\text { between the } \\
\text { participants is } \\
\text { partially open }\end{array}$ & $\begin{array}{l}\text { Goals are not } \\
\text { aligned but the } \\
\text { interaction } \\
\text { between the } \\
\text { participants is } \\
\text { open }\end{array}$ & $\begin{array}{l}\text { Goals are not } \\
\text { aligned but the } \\
\text { interaction } \\
\text { between the } \\
\text { participants is } \\
\text { partially open }\end{array}$ & $\begin{array}{l}\text { Goals are not } \\
\text { aligned and } \\
\text { there } \\
\text { is a physical } \\
\text { disconnect } \\
\text { between the } \\
\text { participants }\end{array}$ \\
\hline
\end{tabular}


Table 6-17 Scoring Mechanism for Mutual Respect and Trust

\begin{tabular}{|c|c|c|c|c|}
\hline \multicolumn{5}{|c|}{ Score for Mutual Respect and Trust } \\
\hline 10 & 7.5 & 5 & 2.5 & 0 \\
\hline $\begin{array}{l}\text { Trust-building } \\
\text { workshops } \\
\text { were } \\
\text { conducted } \\
\text { during } \\
\text { the project } \\
\text { phases, team } \\
\text { has } \\
\text { high prior } \\
\text { working } \\
\text { experience and } \\
\text { trust } \\
\text { competence } \\
\text { was considered } \\
\text { as } \\
\text { selection } \\
\text { criteria }\end{array}$ & $\begin{array}{l}\text { Trust-building } \\
\text { workshops } \\
\text { were } \\
\text { conducted } \\
\text { during } \\
\text { the project } \\
\text { phases, team } \\
\text { has } \\
\text { high prior } \\
\text { working } \\
\text { experience and } \\
\text { trust } \\
\text { competence } \\
\text { was not } \\
\text { considered as } \\
\text { selection } \\
\text { criteria }\end{array}$ & $\begin{array}{l}\text { Trust-building } \\
\text { workshops } \\
\text { were } \\
\text { not conducted } \\
\text { during the } \\
\text { project } \\
\text { phases, team } \\
\text { has } \\
\text { medium prior } \\
\text { working } \\
\text { experience and } \\
\text { trust } \\
\text { competence } \\
\text { was considered } \\
\text { as } \\
\text { selection } \\
\text { criteria }\end{array}$ & $\begin{array}{l}\text { Trust-building } \\
\text { workshops } \\
\text { were } \\
\text { not conducted } \\
\text { during the } \\
\text { project } \\
\text { phases, team } \\
\text { has } \\
\text { medium prior } \\
\text { working } \\
\text { experience and } \\
\text { trust } \\
\text { competence } \\
\text { was not } \\
\text { considered as } \\
\text { selection } \\
\text { criteria }\end{array}$ & $\begin{array}{l}\text { Trust-building } \\
\text { workshops } \\
\text { were } \\
\text { not conducted } \\
\text { during the } \\
\text { project } \\
\text { phases, team } \\
\text { has } \\
\text { no working } \\
\text { experience and } \\
\text { trust } \\
\text { competence } \\
\text { was not } \\
\text { considered as } \\
\text { selection } \\
\text { criteria }\end{array}$ \\
\hline
\end{tabular}

Table 6-18: Scoring Mechanism for Jointly Developed Project Target Criteria

\begin{tabular}{|c|c|c|c|c|}
\hline \multicolumn{5}{|c|}{ Score for Jointly Developed Project Target Criteria } \\
\hline 10 & 7.5 & 5 & 2.5 & 0 \\
\hline $\begin{array}{l}\text { When input is } \\
\text { taken from all } \\
\text { key } \\
\text { participants, } \\
\text { and also all } \\
\text { participants are } \\
\text { involved in } \\
\text { devising } \\
\text { project } \\
\text { target criteria }\end{array}$ & $\begin{array}{l}\text { All key } \\
\text { participants } \\
\text { provide input } \\
\text { while final } \\
\text { project } \\
\text { target criteria } \\
\text { are developed } \\
\text { by owners, } \\
\text { A/E, and } \\
\text { contractor }\end{array}$ & $\begin{array}{l}\text { When input is } \\
\text { taken from } \\
\text { owners, } \mathrm{A} / \mathrm{E} \text {, } \\
\text { and } \\
\text { contractor, and } \\
\text { also same } \\
\text { participants } \\
\text { develops } \\
\text { project } \\
\text { target criteria }\end{array}$ & $\begin{array}{l}\text { When input is } \\
\text { taken from } \\
\text { owners, A/E, } \\
\text { and contractor } \\
\text { while project } \\
\text { target criteria } \\
\text { are set by } \\
\text { only owners } \\
\text { and/or A/E }\end{array}$ & $\begin{array}{l}\text { Project target } \\
\text { criteria are } \\
\text { based } \\
\text { on inputs of } \\
\text { owners and/or } \\
\text { A/E, without } \\
\text { consulting } \\
\text { from } \\
\text { other project } \\
\text { participants }\end{array}$ \\
\hline
\end{tabular}


Table 6-19: Scoring Mechanism for Collaborative Decision Making

\begin{tabular}{|c|c|c|c|c|}
\hline \multicolumn{5}{|c|}{ Score for Collaborative Decision Making } \\
\hline 10 & 7.5 & 5 & 2.5 & 0 \\
\hline $\begin{array}{l}\text { When input is } \\
\text { taken from all } \\
\text { key } \\
\text { participants, } \\
\text { and } \\
\text { also all } \\
\text { participants are } \\
\text { involved in } \\
\text { decision } \\
\text { making }\end{array}$ & $\begin{array}{l}\text { When all key } \\
\text { participants } \\
\text { provide input } \\
\text { while final } \\
\text { decision } \\
\text { makers } \\
\text { are owners, } \\
\text { A/E, } \\
\text { and contractor }\end{array}$ & $\begin{array}{l}\text { When input is } \\
\text { taken from } \\
\text { owners, } \mathrm{A} / \mathrm{E} \text {, } \\
\text { and } \\
\text { contractor, and } \\
\text { also same } \\
\text { participants are } \\
\text { involved in } \\
\text { decision } \\
\text { making }\end{array}$ & $\begin{array}{l}\text { When input is } \\
\text { taken from } \\
\text { owners, } \mathrm{A} / \mathrm{E} \text {, } \\
\text { and } \\
\text { contractor } \\
\text { while } \\
\text { decision } \\
\text { makers } \\
\text { are either only } \\
\text { owner/A/E or } \\
\text { contractor }\end{array}$ & $\begin{array}{l}\text { When major } \\
\text { decisions are } \\
\text { made on sole } \\
\text { discretion of } \\
\text { either } \\
\text { owners/A/E } \\
\text { or contractor, } \\
\text { without input } \\
\text { from other } \\
\text { project } \\
\text { participants }\end{array}$ \\
\hline
\end{tabular}

Table 6-20: Scoring Mechanism for Lean Principles

\begin{tabular}{|c|c|c|c|c|}
\hline \multicolumn{5}{|c|}{ Score for Lean Principles } \\
\hline 10 & 7.5 & 5 & 2.5 & 0 \\
\hline $\begin{array}{l}\text { Project } \\
\text { includes Lean } \\
\text { Construction } \\
\text { Design (value } \\
\text { engineering to } \\
\text { reduce cost), } \\
\text { Lean } \\
\text { Production } \\
\text { Management } \\
\text { (stable } \\
\text { schedule with } 6 \\
\text { week look } \\
\text { ahead and } \\
\text { constraints } \\
\text { ) and Lean } \\
\text { Construction } \\
\text { Supply } \\
\text { (reliable } \\
\text { material } \\
\text { deliveries and } \\
\text { reliable } \\
\text { workforce) }\end{array}$ & $\begin{array}{l}\text { Project } \\
\text { includes lean } \\
\text { construction } \\
\text { design (value } \\
\text { engineering to } \\
\text { reduce cost) } \\
\text { and Lean } \\
\text { Production } \\
\text { Management } \\
\text { (stable } \\
\text { schedule with } 6 \\
\text { week look } \\
\text { ahead and } \\
\text { constraints) }\end{array}$ & $\begin{array}{l}\text { Project } \\
\text { includes lean } \\
\text { construction } \\
\text { design (value } \\
\text { engineering to } \\
\text { reduce cost), } \\
\text { and Lean } \\
\text { Construction } \\
\text { Supply } \\
\text { (reliable } \\
\text { material } \\
\text { deliveries and } \\
\text { reliable } \\
\text { workforce) }\end{array}$ & $\begin{array}{l}\text { Project } \\
\text { includes one of } \\
\text { the three lean } \\
\text { principles: } \\
\text { Lean } \\
\text { construction } \\
\text { design, or Lean } \\
\text { Production } \\
\text { Management } \\
\text { or Lean } \\
\text { Construction } \\
\text { Supply }\end{array}$ & $\begin{array}{l}\text { Project does } \\
\text { not include } \\
\text { lean } \\
\text { construction } \\
\text { techniques and } \\
\text { principles }\end{array}$ \\
\hline
\end{tabular}


Table 6-21: Scoring Mechanism for Co-location of Teams

\begin{tabular}{|l|l|l|l|l|}
\hline \multicolumn{5}{|c|}{ Score for Co-location of Teams } \\
\hline \multicolumn{1}{|c|}{10} & \multicolumn{1}{|c|}{7.5} & \multicolumn{1}{c|}{5} & \multicolumn{1}{c|}{2.5} & \multicolumn{1}{c|}{0} \\
\hline $\begin{array}{l}\text { When all key } \\
\text { participants are } \\
\text { located onsite } \\
\text { and also all key } \\
\text { participants are } \\
\text { dedicated full } \\
\text { time }\end{array}$ & $\begin{array}{l}\text { When all key } \\
\text { participants are } \\
\text { located onsite } \\
\text { and also all key } \\
\text { participants are } \\
\text { not dedicated } \\
\text { full time }\end{array}$ & $\begin{array}{l}\text { When owner, } \\
\text { engineer, and } \\
\text { contractor are } \\
\text { located onsite } \\
\text { and are } \\
\text { dedicated full } \\
\text { time }\end{array}$ & $\begin{array}{l}\text { When owner, } \\
\text { engineer, and } \\
\text { contractor are } \\
\text { located onsite } \\
\text { and are not } \\
\text { dedicated full } \\
\text { time }\end{array}$ & $\begin{array}{l}\text { When } \\
\text { contractor is } \\
\text { located onsite } \\
\text { and is } \\
\text { dedicated full } \\
\text { time while } \\
\text { owner or } \\
\text { engineer are } \\
\text { not located } \\
\text { onsite }\end{array}$ \\
\hline
\end{tabular}

Table 6-22: Scoring Mechanism for Performance Evaluations

\begin{tabular}{|l|l|l|l|l|}
\hline \multicolumn{5}{|c|}{ Score for Performance Evaluations } \\
\hline \multicolumn{1}{|c|}{10} & \multicolumn{1}{|c|}{7.5} & \multicolumn{1}{c|}{5} & \multicolumn{1}{c|}{2.5} & \multicolumn{1}{c|}{0} \\
\hline When all key & When owner & When owner & When owner & No evaluations \\
participants are & evaluates all & evaluates & evaluates \\
evaluated, and & key & Engineer and \\
contractor only & & \\
the owner & participants, & contractor only & & \\
receives & and owner is & & & \\
evaluation & not evaluated & & & \\
\hline
\end{tabular}

In this section, the links connecting IPD principles to KPIs are discussed and identified. The major findings from the focus group helped in developing the links between IPD and KPI.

\section{Inputs from Focus Group}

The focus group, mentioned earlier, for this research was utilized at different stages during the model development. The second meeting with the focus group helped bridge the knowledge gap with regard to identifying the individual links between the IPD principles and the KPIs. 
Figures 6-8 through 6-16 show the ranking from 0 to 5 ( 0 being no effect and 5 being the most effect) of the IPD principles as per their respective influence on each KPI. Based on the results, it is clear that individual KPI improvements can be attributed to various IPD principles.
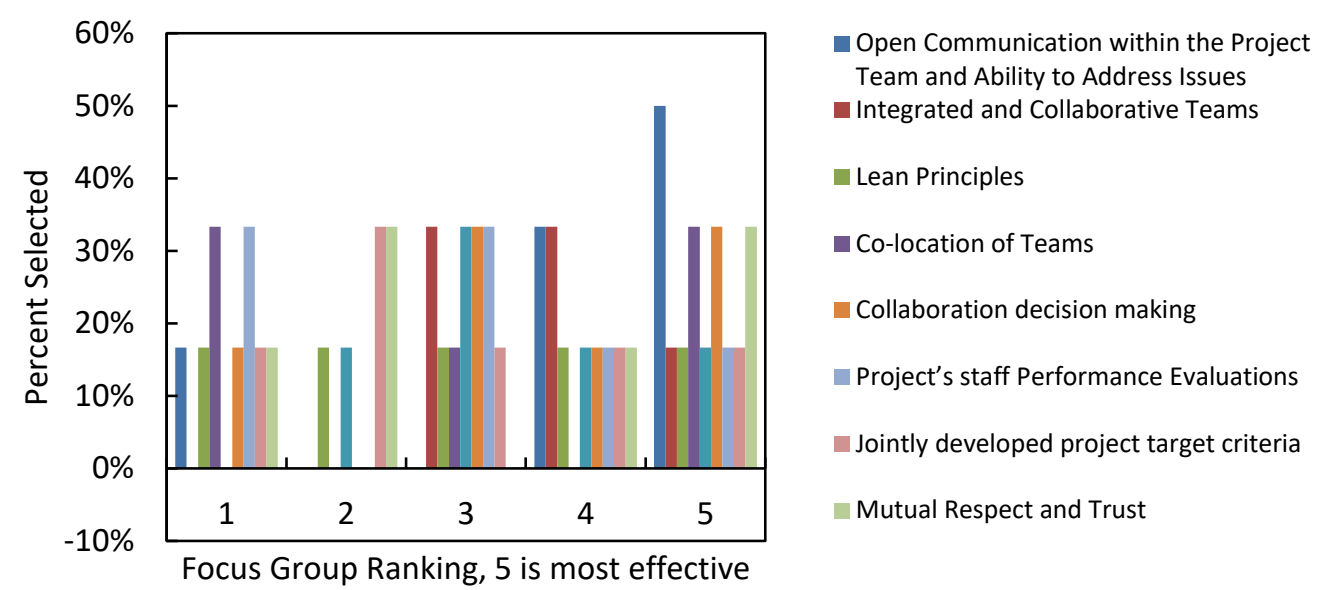

Figure 6-8: Effect of IPD principles on reduced percentage cost overrun.

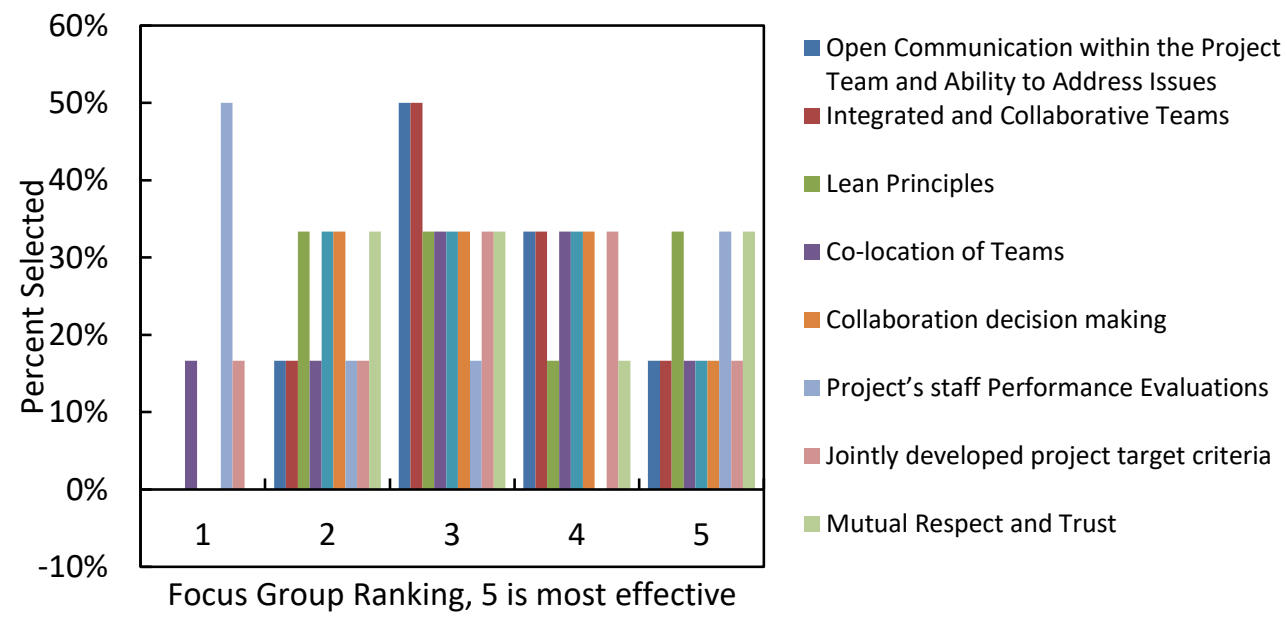

Figure 6-9: Effect of IPD principles on reduced percentage time overrun. 


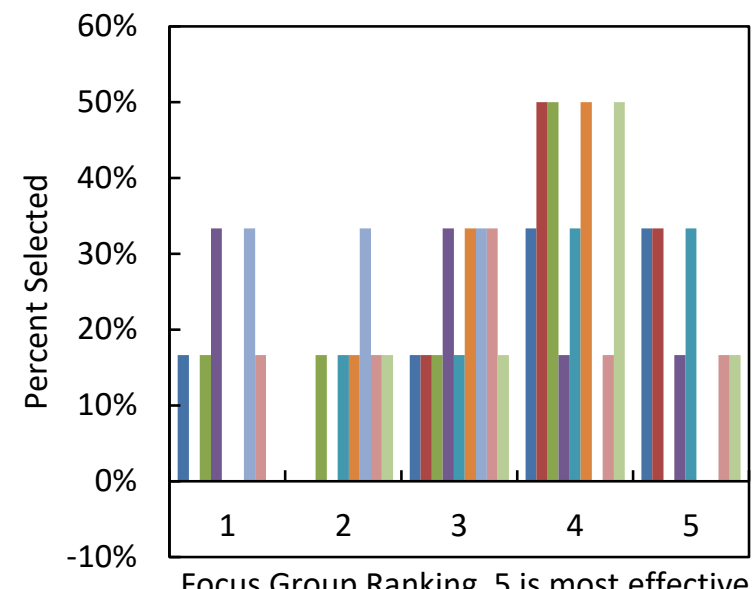

Open Communication within the Project

Team and Ability to Address Issues

- Integrated and Collaborative Teams

Lean Principles

Co-location of Teams

- Collaboration decision making

- Project's staff Performance Evaluations

Jointly developed project target criteria

Mutual Respect and Trust

Focus Group Ranking, 5 is most effective

Figure 6-10: Effect of IPD principles on reduced percentage cost of CO.

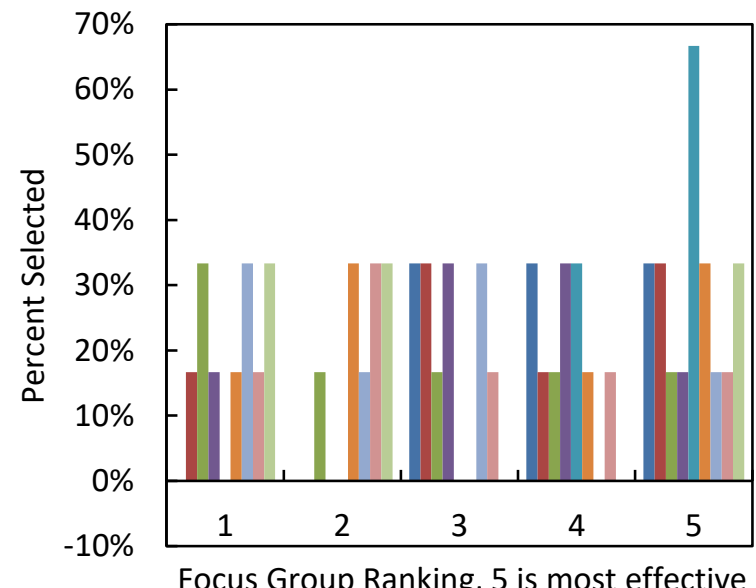

- Open Communication within the Project Team and Ability to Address Issues

- Integrated and Collaborative Teams

Lean Principles

Co-location of Teams

Collaboration decision making

- Project's staff Performance Evaluations

- Jointly developed project target criteria

Mutual Respect and Trust

Figure 6-11: Effect of IPD principles on reduced percentage cost of error and omissions. 


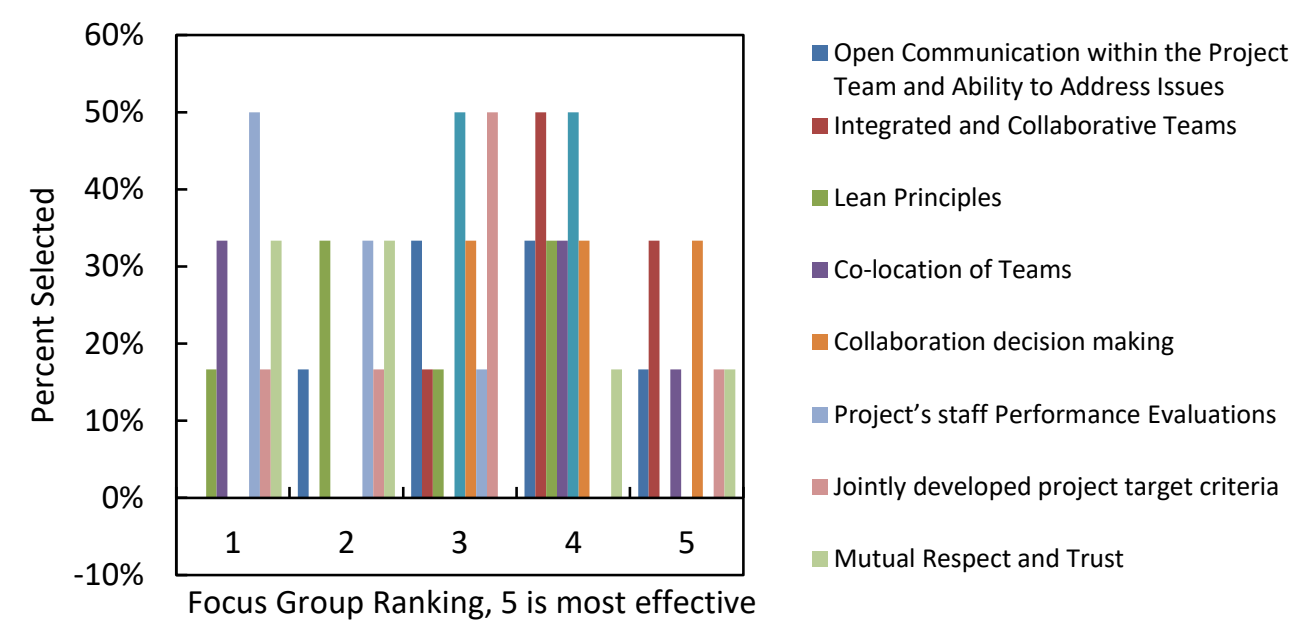

Figure 6-12: Effect of IPD principles on reduced percentage cost of owner's CO.

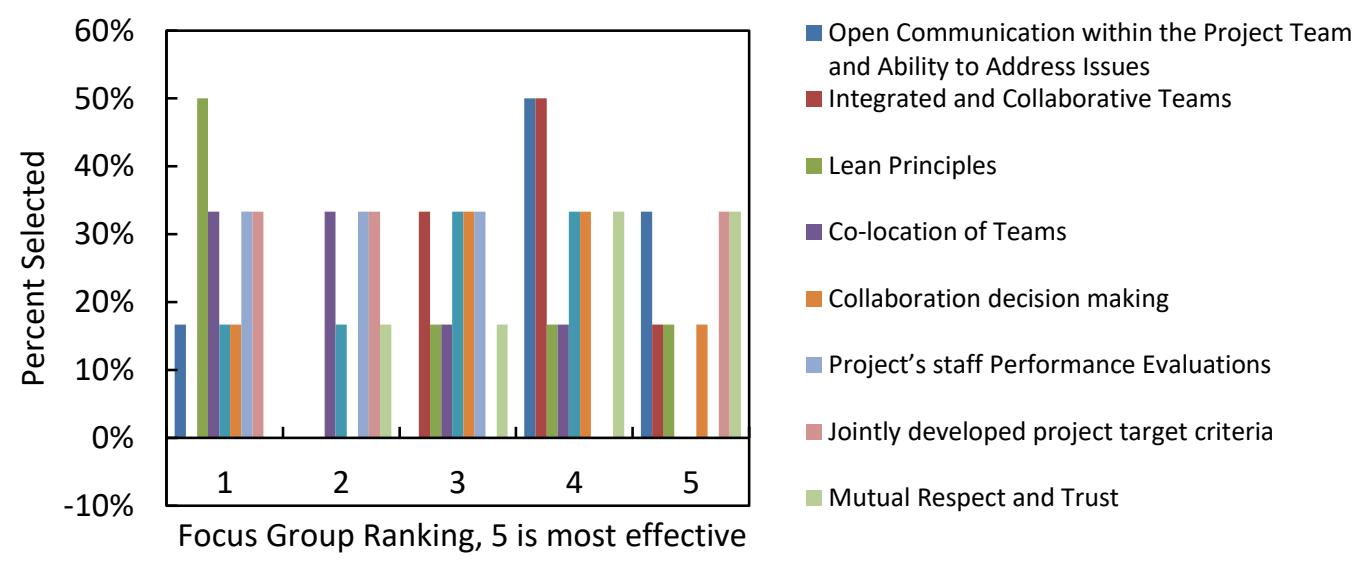

Figure 6-13: Effect of IPD principles on reduced number of claims. 


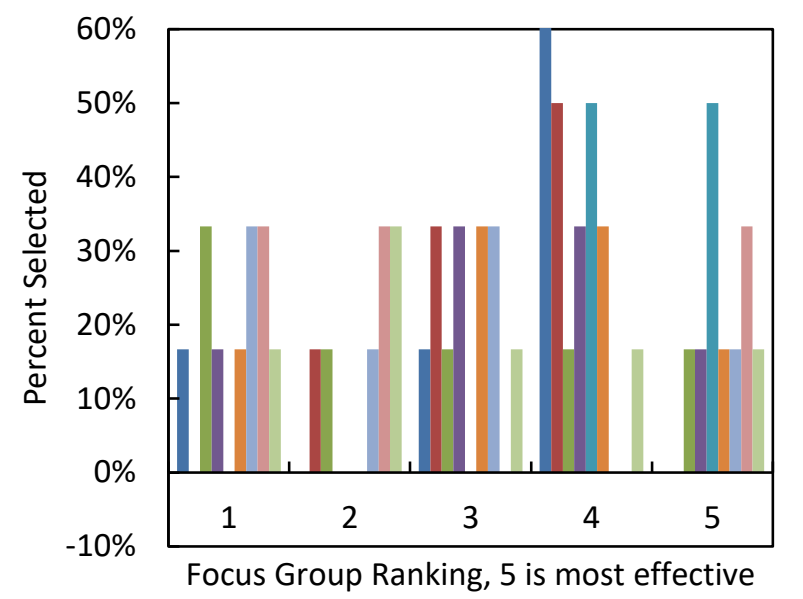

- Open Communication within the Project Team and Ability to Address Issues

- Integrated and Collaborative Teams

Lean Principles

Co-location of Teams

Collaboration decision making

- Project's staff Performance Evaluations

Jointly developed project target criteria

Mutual Respect and Trust

Figure 6-14: Effect of IPD principles on reduced number of RFIs.

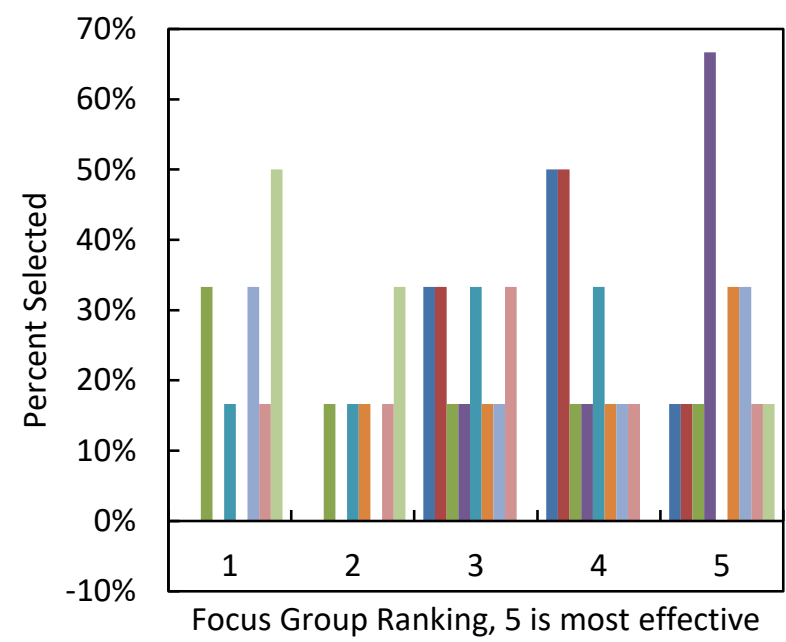

Open Communication within the Project Team and Ability to Address Issues

- Integrated and Collaborative Teams

- Lean Principles

Co-location of Teams

Collaboration decision making

- Project's staff Performance Evaluations

- Jointly developed project target criteria

Mutual Respect and Trust

Figure 6-15: Effect of IPD principles on reduced time to respond to RFIs. 


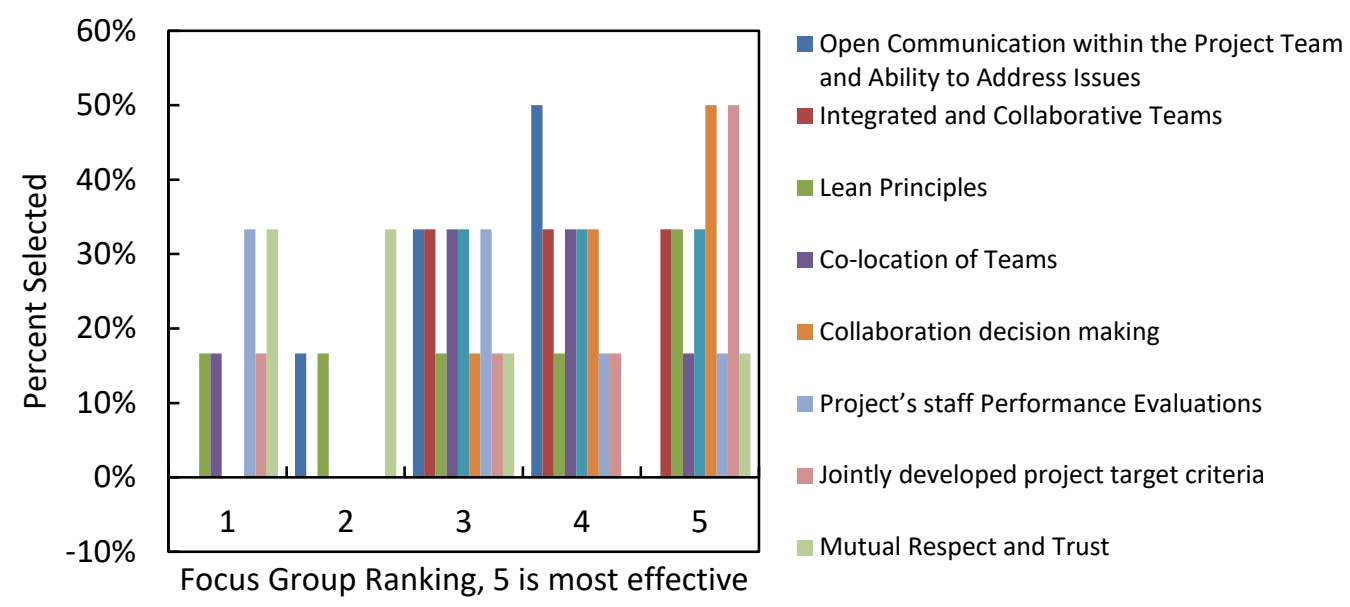

Figure 6-16: Effect of IPD principles on reduced amount of field rework.

In Figure 6-8, the highest percentage selected with scores 4 and 5 is Open Communication within the Project Team and Ability to Address Issues, with a score of $83.3 \%$. This means that $83.3 \%$ of the focus group participants indicated that the reduced percentage of cost overrun is attributed to Open Communication within the Project Team and Ability to Address Issues.

In Figure 6-9, the improvement in the KPI related to time overrun has been justifiably related to most of the IPDs. This means that the focus group participants could not narrow down the IPD principles that can reduce the percentage of cost overrun. The improvement related to cost of change orders is justifiably related to Integrated and Collaborative Teams, as shown in Figure 6-10, where 83.3\% of the focus group participants selected scores 4 and 5 .

As shown in Figure 6-12, 83.3\% of the focus group participants related Reduced Percentage Cost of Owner's CO to Integrated and Collaborative Teams. In Figure 6-13, 83.3\% of the focus group participants indicated that reduced number of claims is 
attributed to Open Communication within the Project Team and Ability to Address Issues.

The improvement related to reduced time to respond to RFIs is attributed to CoLocation of Teams, as can be seen from Figure 6-15. In Figure 6-16, the highest percentage selected with scores 4 and 5 for reduced amount of field rework is attributed to Collaborative Decision Making with a score of $83.3 \%$.

Figure 6-17 summarizes the links between the IPD principles and the KPIs based on the focus group findings. 


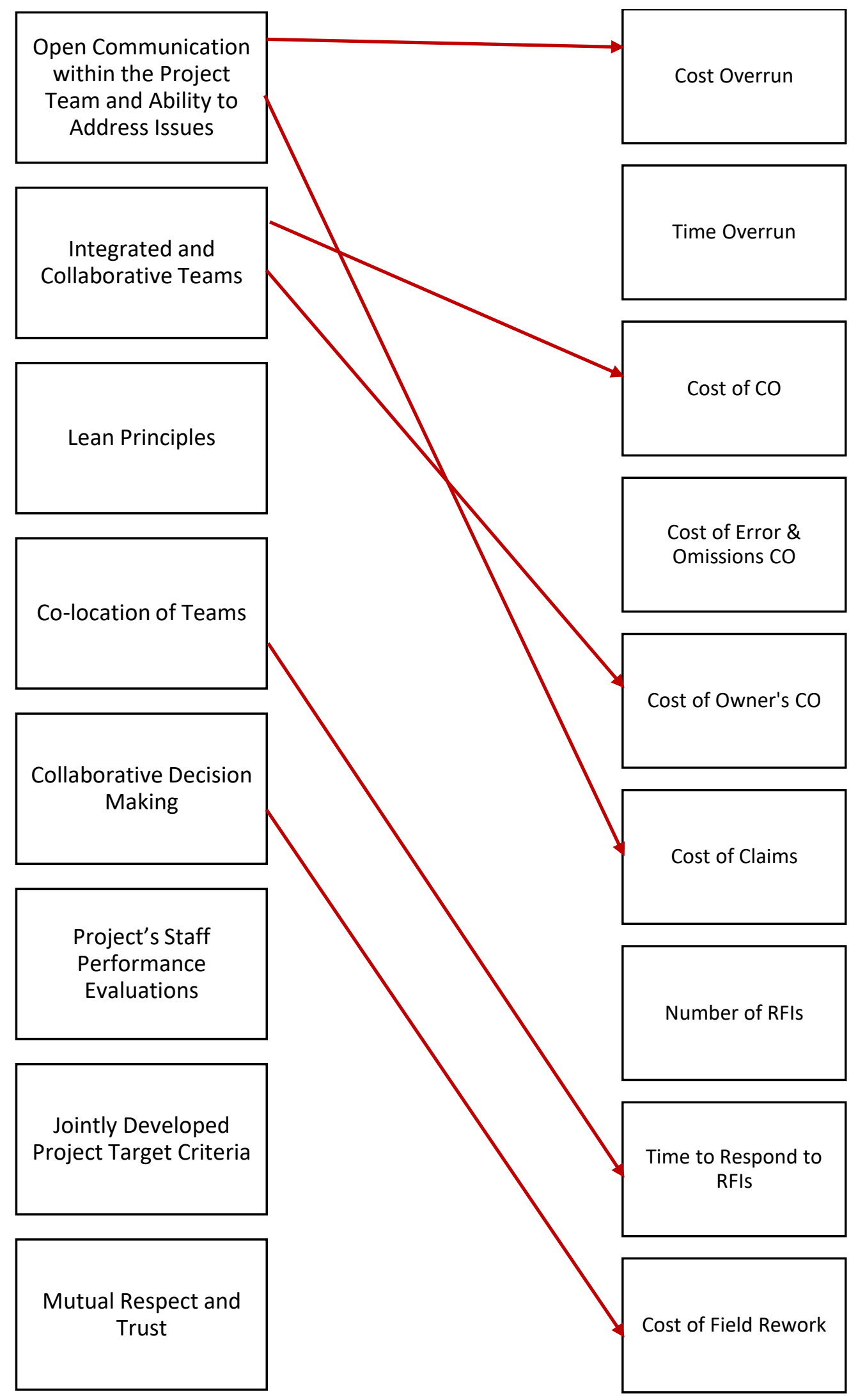

Figure 6-17: Links between IPD principles and KPIs identified by focus group. 


\section{Regression Analysis}

Regression analysis was applied on the variables of KPIs and IPDs that are linked per Figure 6-17 to try to develop a prediction model that can predict certain KPI scores from their related IPD principles. The regression model is developed to help owners predict how improving the implementation of certain IPD principles can impact the performance score of their related KPIs. The regression analysis of the links as identified by the focus group revealed interesting results and thus regression analysis was applied to all the possible links between the KPIs and IPDs to show for each KPI which IPD principles will affect it and at what level. This will be a worthwhile tool for owners to have and to help them determine which IPD principles to implement to improve a specific KPI. The means of the dataset were then computed for each of the nine IPD principles, as summarized in Table 6-23. The IPD scores for the control projects are summarized in Table 6-24.

\section{Table 6-23: IPD Principles Score Means of the Dataset}

\begin{tabular}{lc}
\hline IPD Principles & Mean Score \\
\hline $\begin{array}{l}\text { Open Communication within Project Team \& Ability to Address } \\
\text { Issues }\end{array}$ & 3.69 \\
Integrated and Collaborative Teams & 0.34 \\
Lean Principles & 1.48 \\
Co-Location of Teams & 4.49 \\
Project's Staff Performance Evaluations & 1.92 \\
Mutual Respect and Trust & 1.82 \\
Jointly Developed Project Target Criteria & 0.51 \\
\hline
\end{tabular}


Table 6-24: Control Projects IPD Principles Scores

\begin{tabular}{lcc}
\hline IPD Principles & \multicolumn{2}{c}{ IPD Score } \\
\cline { 2 - 3 } & $\begin{array}{c}\text { Control } \\
\text { Project 1 }\end{array}$ & $\begin{array}{c}\text { Control } \\
\text { Project 2 }\end{array}$ \\
\hline Open Communication within Project Team & 7.5 & 7.5 \\
Integrated and Collaborative Teams & 7.5 & 7.5 \\
Lean Principles & 7.5 & 5.0 \\
Co-Location of Team & 7.5 & 5.0 \\
Project's Staff Performance Evaluations & 5.0 & 5.0 \\
Mutual Respect and Trust & 5.0 & 5.0 \\
Jointly Developed Project Target Criteria & 7.5 & 7.5 \\
Collaborative Decision Making & 7.5 & 7.5 \\
\hline
\end{tabular}

\section{Variable Sensitivity}

Regression analysis provides the correlation of determination $\left(\mathrm{R}^{2}\right)$ that represents how accurately the regression model represents the existing data. $\mathrm{R}^{2}$ determines the proportion of the variation in the response variable explained by changes in the independent, categorical variable.

The p-value is used to identify the level of significance of the variables; small pvalues indicate the statistically significant variables. 


\section{$\underline{\text { Variable Correlations }}$}

For numerical variables, correlation coefficients indicate the degree of association between variables. Correlation coefficients can range from -1 to +1 . Larger coefficient values, either positive or negative, indicate a stronger linear association between variables. Coefficient values of zero indicate no association between variables. Positive coefficients indicate that the independent variable and response variable vary in the same direction (positive sloped line); negative coefficients indicate the independent variable and response variable vary in opposite directions (negative sloped line).

\section{Correlation between Cost Overrun and Open Communication with the Project Team and Ability to Address Issues}

The resulting regression equation is a polynomial $3^{\text {rd }}$ degree and is displayed in Equation 6-18.

$$
y=0.0023 x^{3}-0.0819 x^{2}+0.9882 x+2.6966
$$

Where $x$ is the score of Open Communication with the Project Team and Ability to Address Issues (Independent variable) $y$ is the score of Cost Overrun (Dependent variable)

Figure 6-18 shows the polynomial regression curve between Cost Overrun and Open Communication with the Project Team and Ability to Address Issues. 


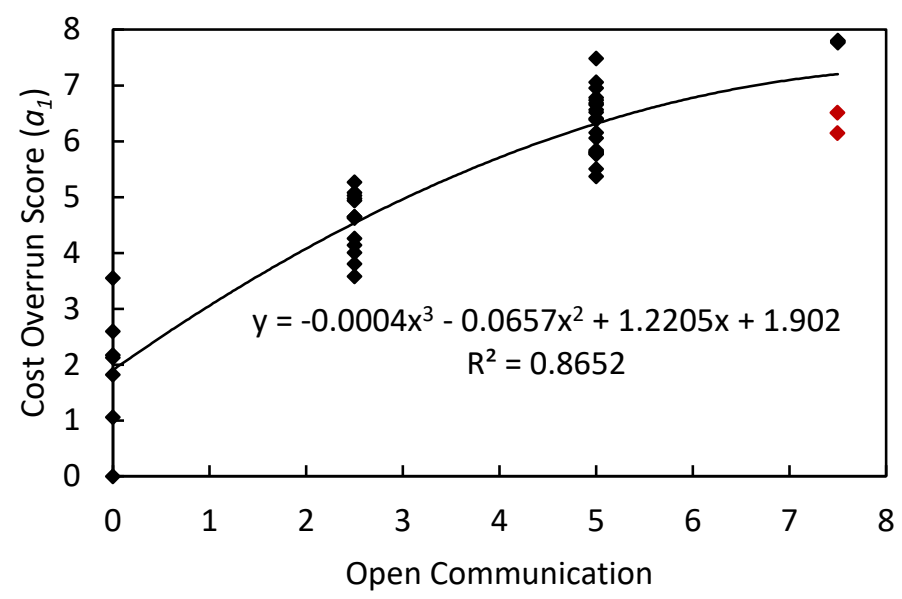

Figure 6-18: Polynomial regression curve between cost overrun and open communication with the project team and ability to address issues.

The two red data points in Figure 6-18 represent the two control projects and the black data points represent the dataset.

Based on the results of one-way analysis of variance (ANOVA), the predictor variable shows a high level of significance because the $p$-value is 0.000 . The $R^{2}$ value provides an explanation of the proportion of variation in the dependent variable due to a change in the independent variable. The $\mathrm{R}^{2}$ value of 0.8652 is high and it indicates that $86.5 \%$ of the variation in the dependent variable is predictable from the independent variable. The regression analysis reports the Pearson correlation coefficient, $\mathrm{R}$, for the numerical variable to be 0.930 . This indicates a strong association with the response variable. Based on the results of this analysis, it is observed that the independent variable, Open Communication with the Project Team and Ability to Address Issues, displays a statistically significant effect on the prediction of Cost Overrun. The result of the polynomial regression equation can be used by water utilities to predict Cost Overrun score in a rather simple but yet accurate way. 
The resulting regression analysis, equations, and correlations between the IPDs and KPIs are shown in Tables 6-25 through 6-38.

Table 6-25: Polynomial Regression Curves between Open Communication with the Project Team and Ability to Address Issues and KPIs

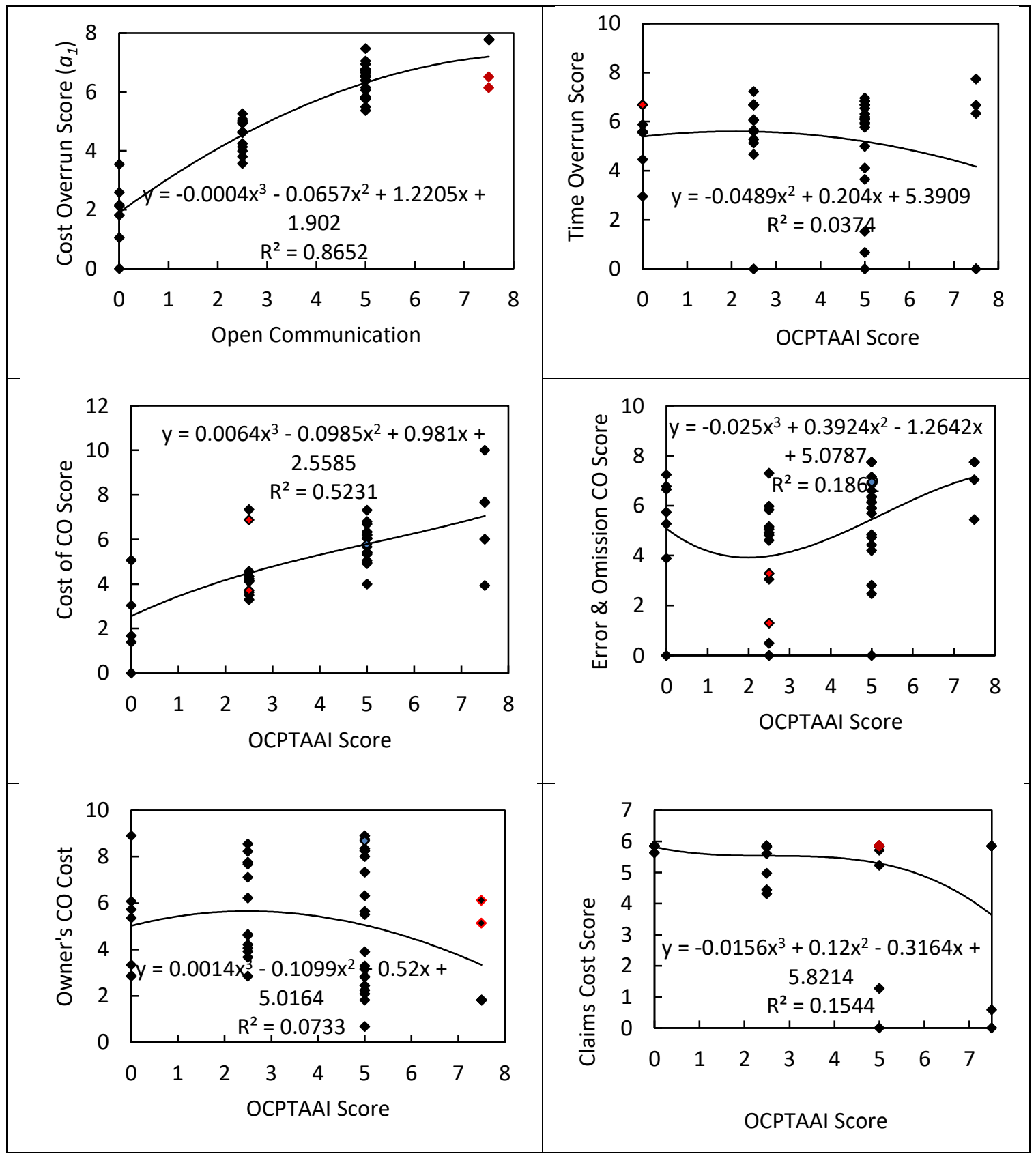




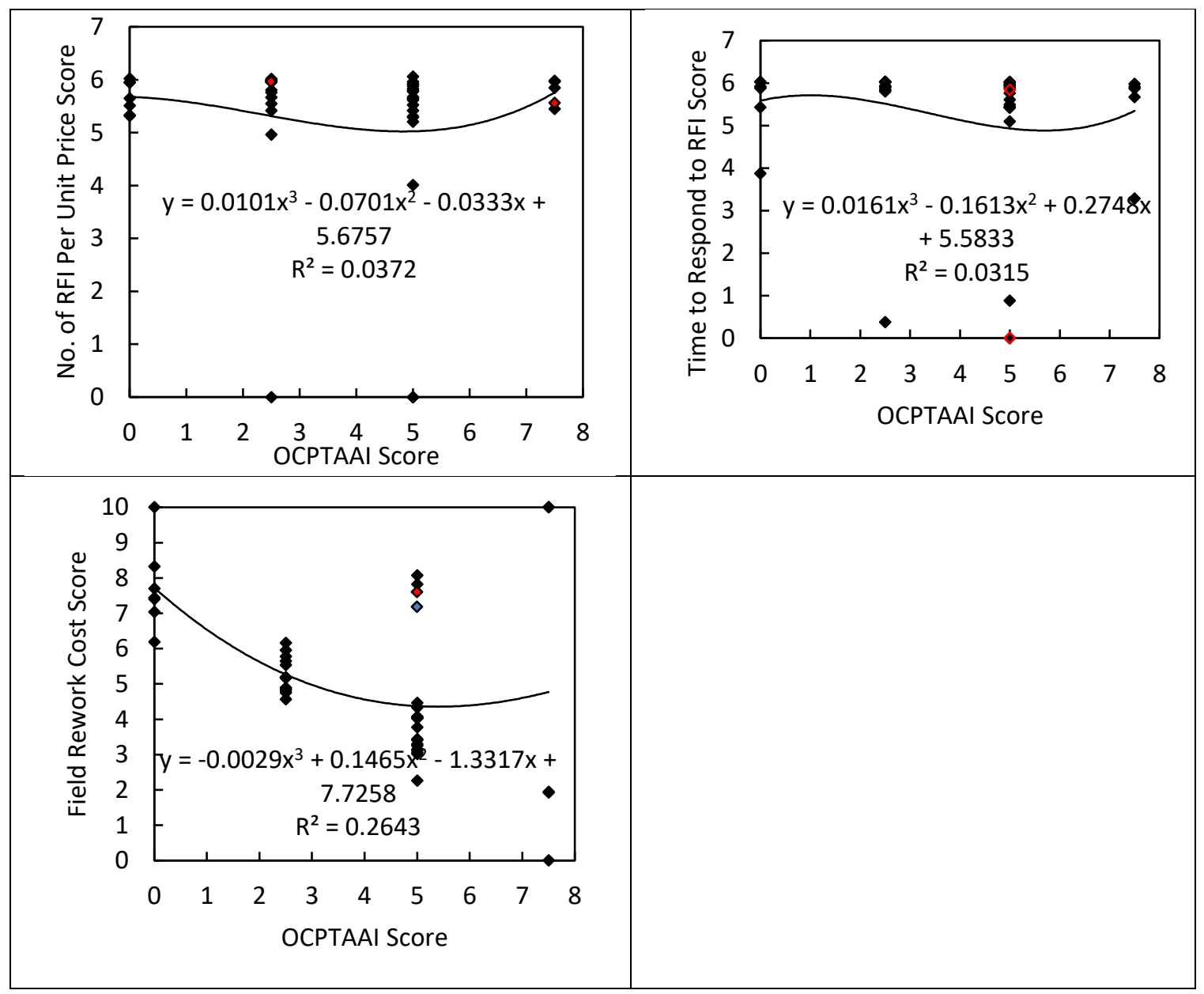

Table 6-26: Correlation between Open Communication with the Project Team and Ability to Address Issues and KPIs

\begin{tabular}{|c|c|c|l|}
\hline KPIs & $\mathbf{R}^{\mathbf{2}}$ & Effect & \multicolumn{1}{c|}{ Analysis } \\
\hline Cost Overrun & 0.865 & Strong & $\begin{array}{l}\text { Regular status meetings typically include } \\
\text { reviewing project cost reports and detailing } \\
\text { project cost estimates to help overcome major } \\
\text { cost obstacles. This explains the strong effect } \\
\text { of Communication and Ability to Address } \\
\text { Issues on Cost Overrun. }\end{array}$ \\
\hline Cost of CO & 0.523 & Weak & $\begin{array}{l}\text { Regular status meetings include detailed review } \\
\text { of CO cost reports, which help in reducing the } \\
\text { CO costs when reviewed by stakeholders of } \\
\text { different backgrounds. This effect is moderate }\end{array}$ \\
\hline
\end{tabular}




\begin{tabular}{|c|c|c|c|}
\hline & & & $\begin{array}{l}\text { because changes in the scope, especially when } \\
\text { they are related to unforeseen conditions or } \\
\text { design deficiencies, cannot be avoided. }\end{array}$ \\
\hline $\begin{array}{l}\text { Cost of Field } \\
\text { Rework }\end{array}$ & 0.264 & No & $\begin{array}{l}\text { Field Rework is typically caused by inadequate } \\
\text { project supervision, inadequate design } \\
\text { specifications, lack of proper inspection by the } \\
\text { designer, and other factors. Open } \\
\text { Communication and Ability to Address Issues } \\
\text { is expected to have an effect on this KPI, } \\
\text { however the dataset shows no effect. }\end{array}$ \\
\hline $\begin{array}{l}\text { Cost of Error } \\
\& \text { Omissions } \\
\mathrm{CO}\end{array}$ & 0.186 & No & $\begin{array}{l}\text { Since Open Communication and Ability to } \\
\text { Address Issues was not implemented during the } \\
\text { design phase, it had no effect on Cost of Error } \\
\& \text { Omissions CO. }\end{array}$ \\
\hline $\begin{array}{l}\text { Cost of } \\
\text { Claims }\end{array}$ & 0.154 & No & $\begin{array}{l}\text { No correlation exists because Open } \\
\text { Communication and Ability to Address Issues } \\
\text { does not provide the ability to resolve disputes } \\
\text { at a large scale }\end{array}$ \\
\hline $\begin{array}{l}\text { Cost of } \\
\text { Owner's CO }\end{array}$ & 0.073 & No & $\begin{array}{l}\text { No correlation exists because Open } \\
\text { Communication and Ability to Address Issues } \\
\text { does not limit the owner from issuing change } \\
\text { orders due to their preferences during } \\
\text { construction. }\end{array}$ \\
\hline Time Overrun & 0.037 & No & $\begin{array}{l}\text { Open Communication and Ability to Address } \\
\text { Issues cannot eliminate the main factors of time } \\
\text { overrun such as design errors and omissions, } \\
\text { environmental and site conditions, resources } \\
\text { availability, severe weather conditions, or } \\
\text { client driven delays. }\end{array}$ \\
\hline $\begin{array}{l}\text { Number of } \\
\text { RFIs }\end{array}$ & 0.037 & No & $\begin{array}{l}\text { Since Open Communication and Ability to } \\
\text { Address Issues was not implemented during the } \\
\text { design phase, contract documents can be } \\
\text { incomplete, conflicting, or erroneous, thereby } \\
\text { requiring revisions and clarifications to be } \\
\text { provided by the designers. }\end{array}$ \\
\hline
\end{tabular}


Table 6-27: Polynomial Regression Curves between Lean Principles and KPIs

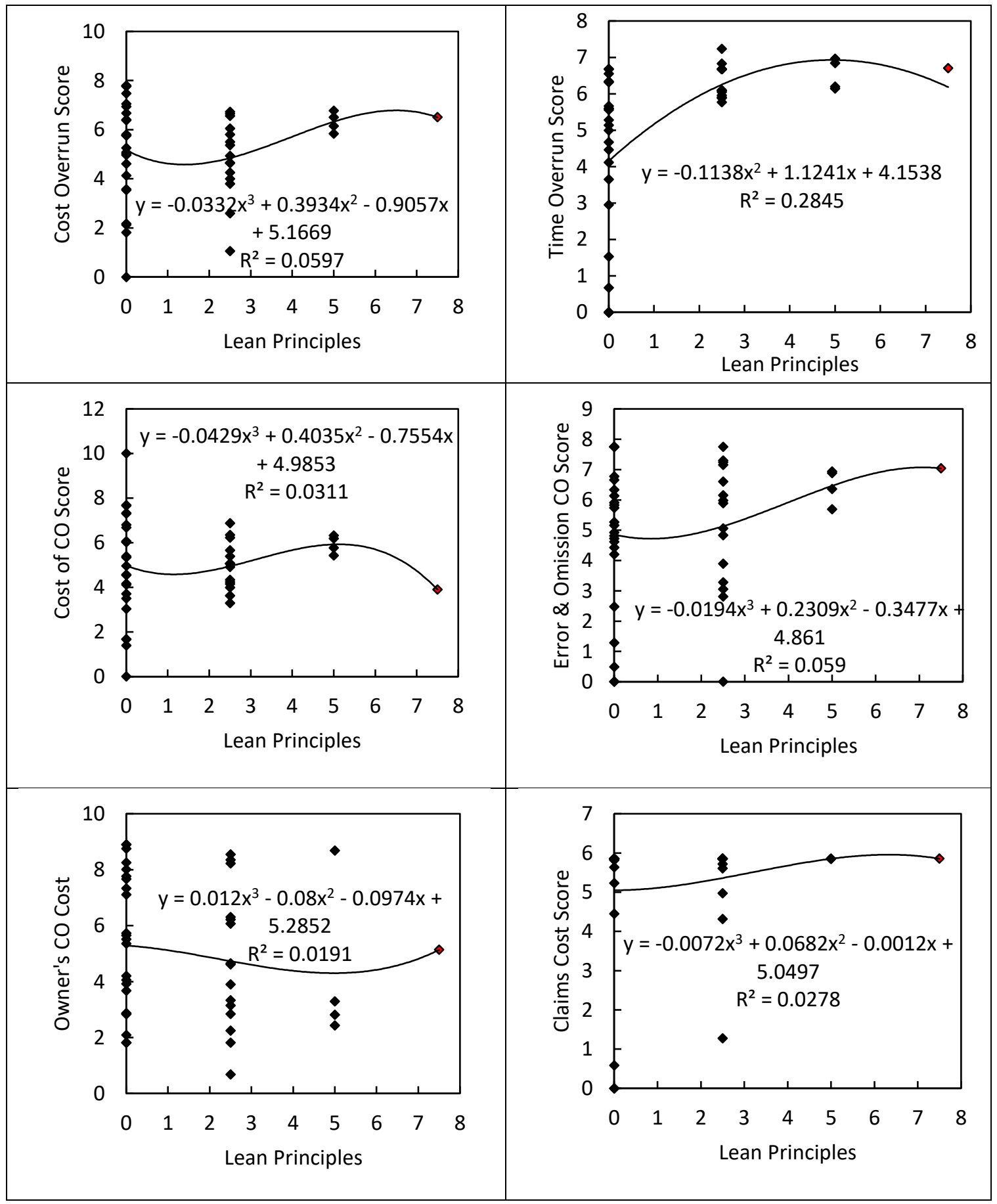




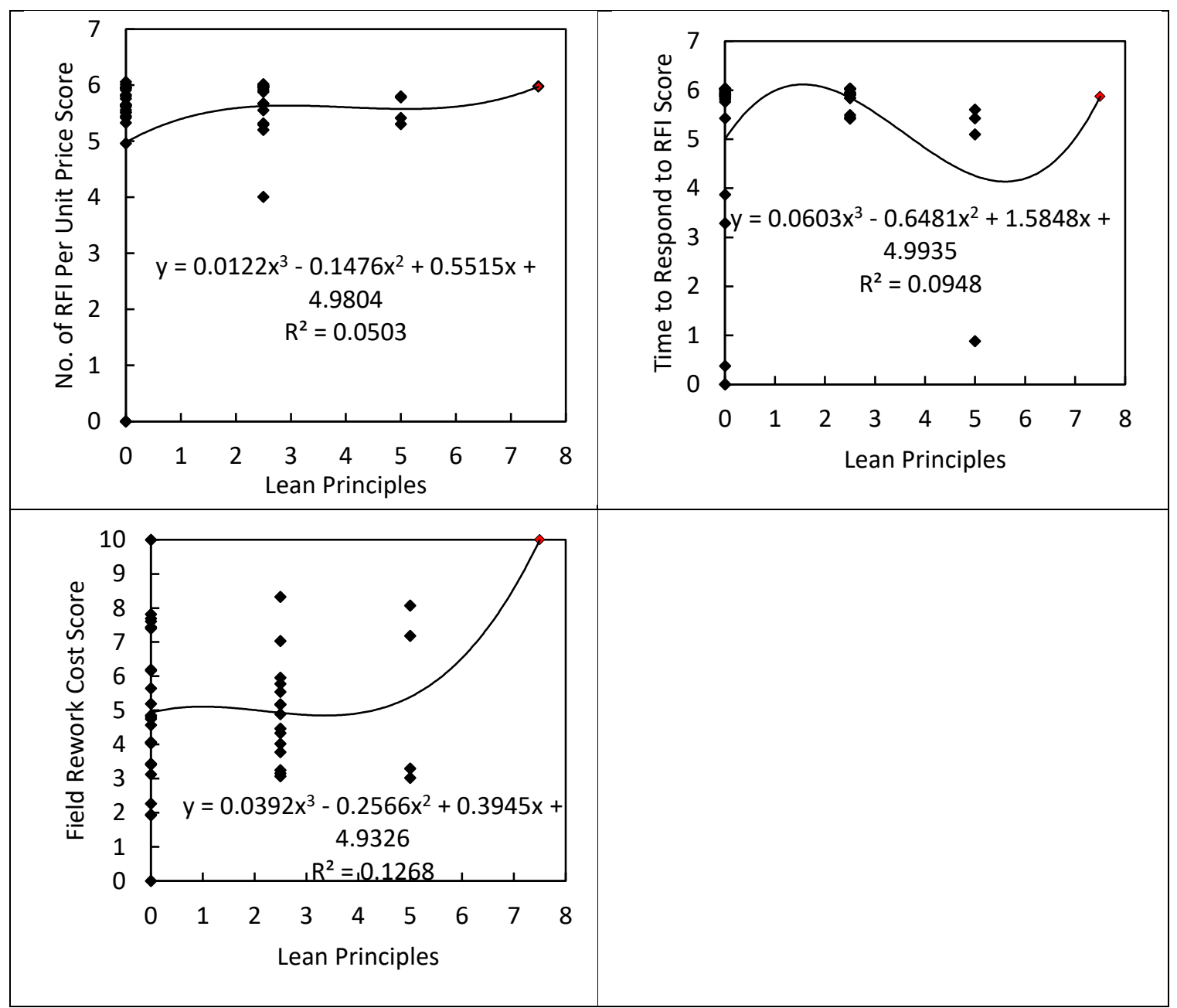

Table 6-28: Correlation between Lean Principles and KPIs

\begin{tabular}{|c|c|c|l|}
\hline KPIs & $\mathbf{R}^{\mathbf{2}}$ & Effect & \multicolumn{1}{c|}{ Analysis } \\
\hline Time Overrun & 0.284 & Weak & $\begin{array}{l}\text { Lean Principles focus on adhering to the } \\
\text { construction project schedule. Monthly } \\
\text { progress schedule updates result in a more } \\
\text { detailed schedule that clearly show all schedule } \\
\text { activities and contribute in reducing Time } \\
\text { Overrun. The effect is weak because Lean } \\
\text { Principles cannot eliminate the other factors of } \\
\text { Time Overrun such as design errors and } \\
\text { omissions, environmental and site conditions, } \\
\text { severe weather conditions, or client driven } \\
\text { delays. }\end{array}$ \\
\hline
\end{tabular}




\begin{tabular}{|c|c|c|c|}
\hline $\begin{array}{l}\text { Cost of Field } \\
\text { Rework }\end{array}$ & 0.126 & No & $\begin{array}{l}\text { Monthly progress schedule updates result in a } \\
\text { detailed schedule that clearly shows all the } \\
\text { activities that must occur during that specific } \\
\text { time frame. This detailed look ahead schedule } \\
\text { assists in reducing Cost of Field Rework. } \\
\text { However, the relationship is weak because } \\
\text { Field Rework is caused by other factors such as } \\
\text { inadequate project supervision, inadequate } \\
\text { design specifications, and lack of proper } \\
\text { inspection by the designer. }\end{array}$ \\
\hline $\begin{array}{l}\text { Time to } \\
\text { Respond to } \\
\text { RFIs }\end{array}$ & 0.094 & No & $\begin{array}{l}\text { Lean Principles focus on adhering to the } \\
\text { construction project schedule to maximize value } \\
\text { and eliminate waste. Therefore, Lean } \\
\text { Principles have no effect on Time to Respond } \\
\text { to RFIs. }\end{array}$ \\
\hline Cost Overrun & 0.059 & No & $\begin{array}{l}\text { Lean Principles are not expected to have no } \\
\text { effect on Cost Overrun. }\end{array}$ \\
\hline $\begin{array}{l}\text { Cost of Error } \\
\& \text { Omissions } \\
\text { CO }\end{array}$ & 0.059 & No & $\begin{array}{l}\text { Lean Principles focus on maximizing value and } \\
\text { eliminating waste. They are not expected to } \\
\text { have effect on Cost of Error \& Omissions CO. }\end{array}$ \\
\hline $\begin{array}{l}\text { Number of } \\
\text { RFIs }\end{array}$ & 0.050 & No & $\begin{array}{l}\text { Lean Principles focus on maximizing value and } \\
\text { eliminating waste. They are not expected to } \\
\text { have effect on Number of RFIs. }\end{array}$ \\
\hline Cost of $\mathrm{CO}$ & 0.031 & No & $\begin{array}{l}\text { Lean Principles focus on maximizing value and } \\
\text { eliminating waste. They are not expected to } \\
\text { have effect on Cost of CO. }\end{array}$ \\
\hline $\begin{array}{l}\text { Cost of } \\
\text { Claims }\end{array}$ & 0.028 & No & $\begin{array}{l}\text { Lean Principles focus on maximizing value and } \\
\text { eliminating waste. They are not expected to } \\
\text { have effect on Cost of Claims. }\end{array}$ \\
\hline $\begin{array}{l}\text { Cost of } \\
\text { Owner's CO }\end{array}$ & 0.019 & No & $\begin{array}{l}\text { Lean Principles focus on maximizing value and } \\
\text { eliminating waste. They are not expected to } \\
\text { have effect on Cost of Owner's CO. }\end{array}$ \\
\hline
\end{tabular}


Table 6-29: Polynomial Regression Curves between Co-Location of Teams and KPIs

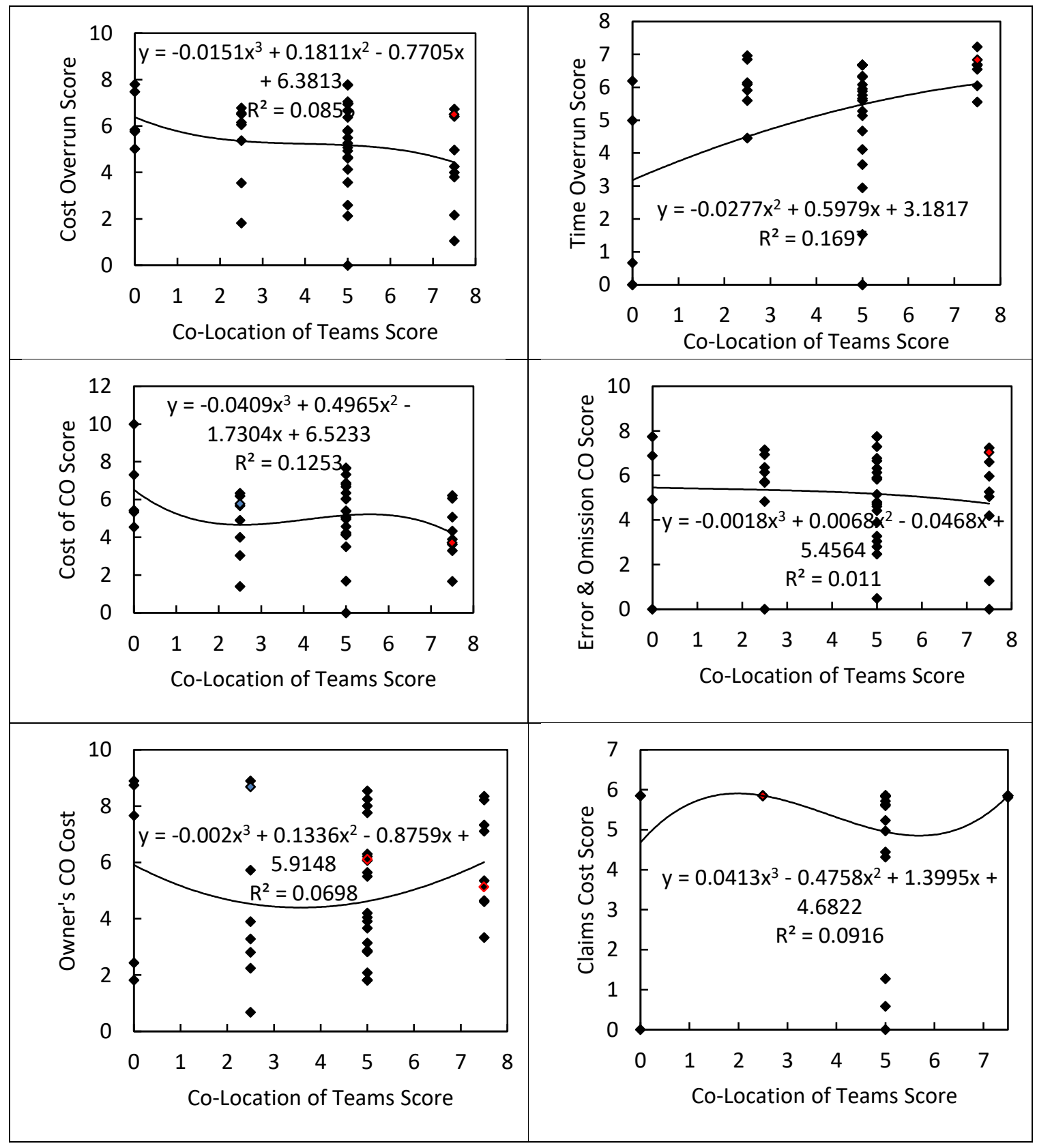




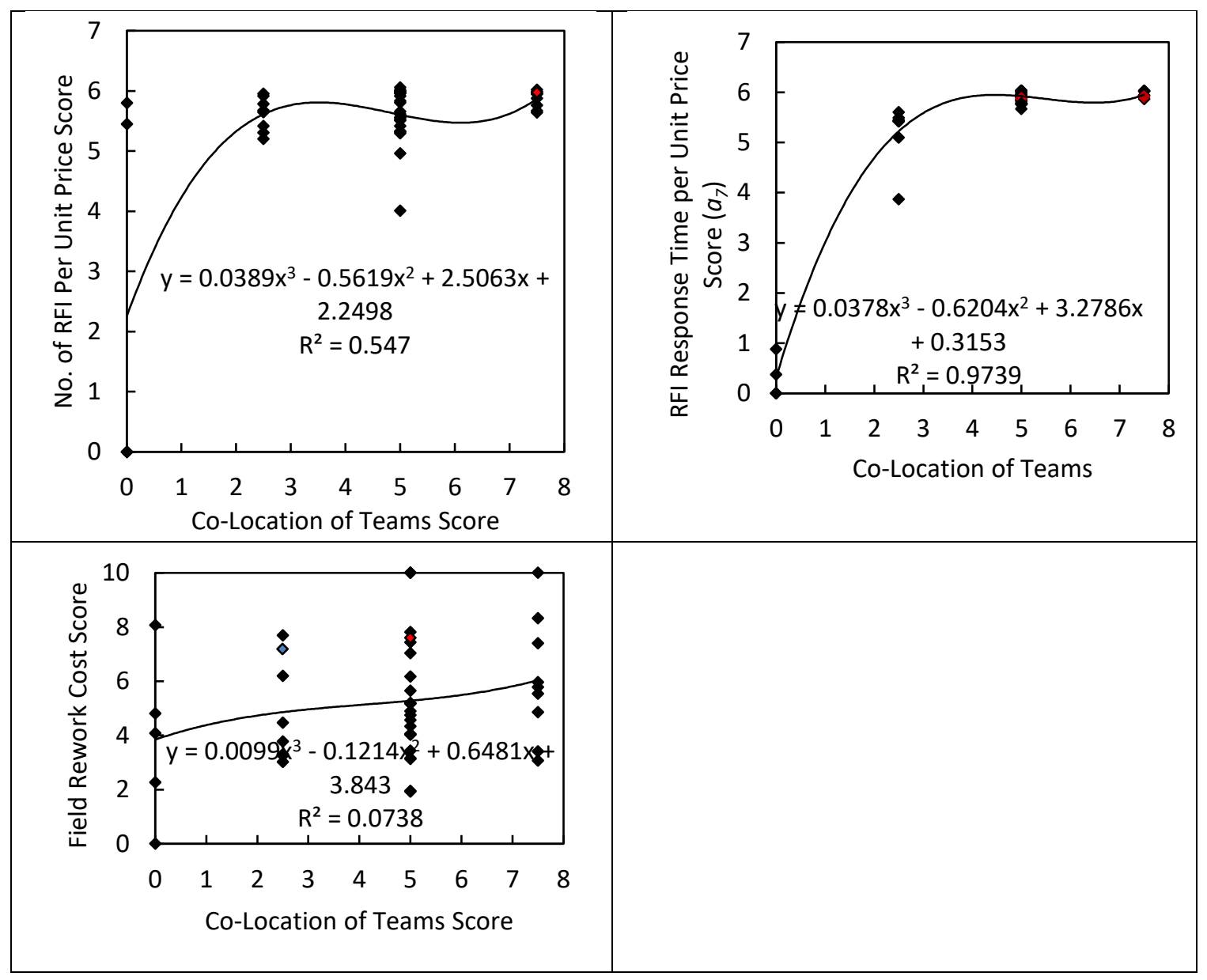

Table 6-30: Correlation between Co-Location of Teams and KPIs

\begin{tabular}{|l|l|l|l|}
\hline \multicolumn{1}{|c|}{ KPIs } & \multicolumn{1}{|c|}{$\mathbf{R}^{\mathbf{2}}$} & Effect & \multicolumn{1}{c|}{ Analysis } \\
\hline $\begin{array}{l}\text { Time to } \\
\text { Respond to } \\
\text { RFIs }\end{array}$ & 0.974 & Strong & $\begin{array}{l}\text { Co-location of Teams is a strategic approach to } \\
\text { using the benefits of face-to-face interactions } \\
\text { to build team relationships, improve } \\
\text { communications, and resolve issues. Since the } \\
\text { team members are present onsite, they can } \\
\text { respond to RFIs and provide information more } \\
\text { efficiently. }\end{array}$ \\
\hline $\begin{array}{l}\text { Number of } \\
\text { RFIs }\end{array}$ & 0.548 & Weak & $\begin{array}{l}\text { Contract documents can be incomplete, } \\
\text { conflicting, or erroneous, thereby requiring } \\
\text { revisions and clarifications to be provided by } \\
\text { the designers. Due to Co-Location of Teams, } \\
\text { face-to-face interactions some clarifications } \\
\text { can be provided on the spot without the need to }\end{array}$ \\
\hline
\end{tabular}




\begin{tabular}{|l|l|l|l|}
\hline & & $\begin{array}{l}\text { submit RFIs. The effect is moderate because } \\
\text { some clarifications will have to be documented } \\
\text { in RFIs. Co-Location of Teams might have a } \\
\text { strong effect on this KPI if it was implemented } \\
\text { during design. }\end{array}$ \\
\hline Time Overrun & 0.172 & No & $\begin{array}{l}\text { Co-location of Teams is expected to increase } \\
\text { productivity and therefore reduce Time } \\
\text { Overrun. However, it cannot eliminate other } \\
\text { factors of time overrun such as design errors } \\
\text { and omissions, environmental and site } \\
\text { conditions, resources availability, severe } \\
\text { weather conditions, or client driven delays. }\end{array}$ \\
\hline Cost of CO & 0.126 & No & $\begin{array}{l}\text { Changes in the scope, especially when they are } \\
\text { related to unforeseen conditions or design } \\
\text { deficiencies, cannot be avoided. Co-location of } \\
\text { Teams is not expected to have an effect on this } \\
\text { KPI. }\end{array}$ \\
\hline $\begin{array}{l}\text { Cost of } \\
\text { Claims }\end{array}$ & 0.092 & No & $\begin{array}{l}\text { A low number of claims on a project reflects } \\
\text { good team approach to project gains and } \\
\text { losses, and effective communication lines. Co- } \\
\text { location of Teams would not necessarily } \\
\text { provide insight into the team's ability to } \\
\text { resolve disputes before escalating to claims. } \\
\text { Poor communication lines exist within poorly } \\
\text { managed co-located teams. }\end{array}$ \\
\hline $\begin{array}{l}\text { Cost of } \\
\text { Owner's CO }\end{array}$ & 0.074 & No & $\begin{array}{l}\text { Co-location of Teams does not necessarily } \\
\text { promote regular status meetings for reviewing } \\
\text { project cost reports and detailing project cost } \\
\text { estimates to help overcome major cost } \\
\text { obstacles. }\end{array}$ \\
\hline No & 0.081 & $\begin{array}{l}\text { Field Rework is typically caused by inadequate } \\
\text { project supervision, inadequate design } \\
\text { specifications, lack of proper inspection by the } \\
\text { designer, and others. Co-location of Teams is } \\
\text { not expected to have an effect on this KPI. } \\
\text { change orders due to their preferences during } \\
\text { construction. Co-Location of Teams might }\end{array}$ \\
\hline Nong
\end{tabular}




\begin{tabular}{|l|l|l|l|}
\hline & & $\begin{array}{l}\text { have an effect on this KPI if it was } \\
\text { implemented during design. }\end{array}$ \\
\hline $\begin{array}{l}\text { Cost of Error } \\
\text { \&Omissions }\end{array}$ & 0.011 & No & $\begin{array}{l}\text { Co-location of Teams was not implemented } \\
\text { during design; therefore, it has no effect on } \\
\text { Cost of Error \& Omissions CO. }\end{array}$ \\
\hline
\end{tabular}

Table 6-31: Polynomial Regression Curves between Collaborative Decision Making and KPIs

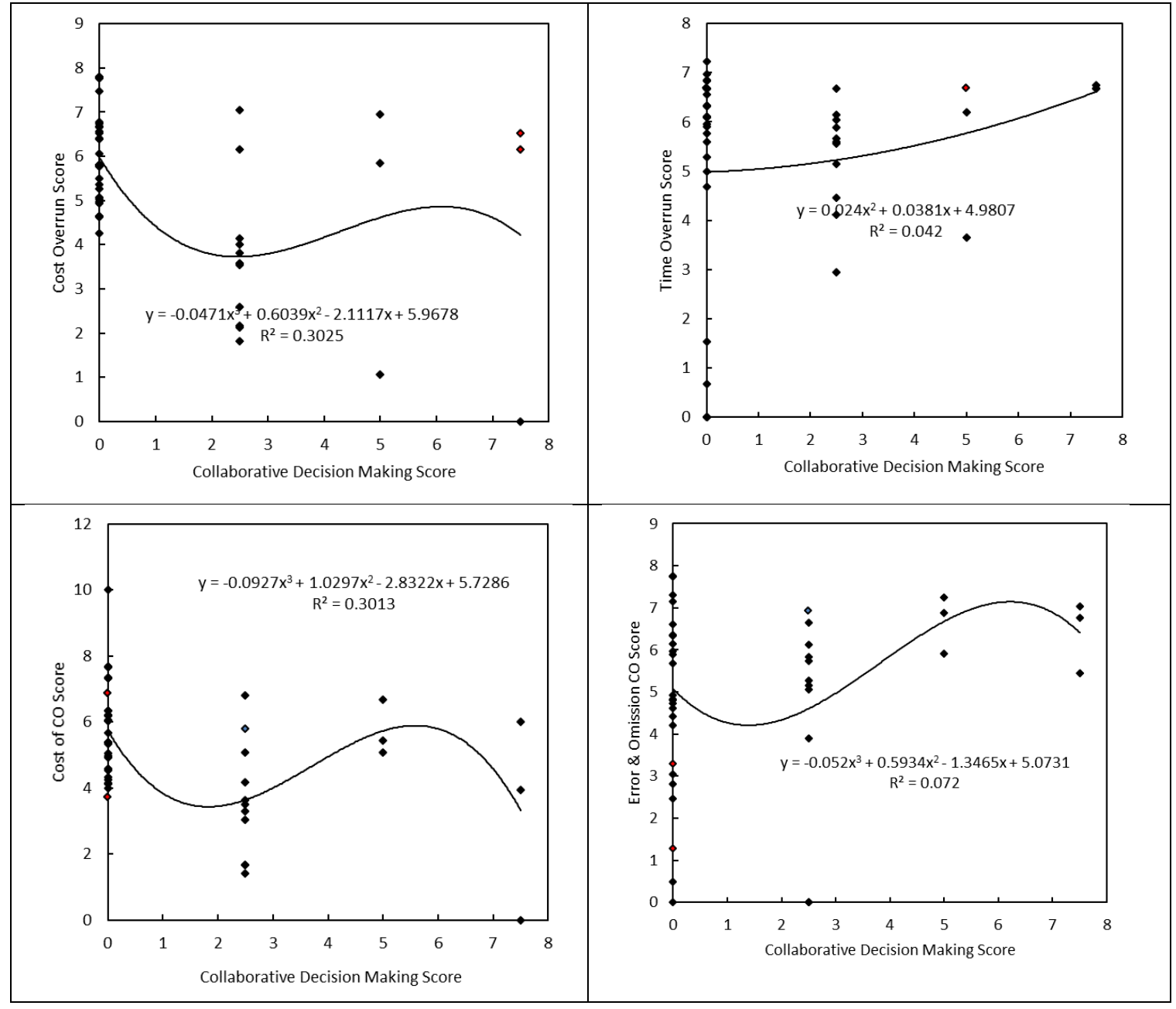




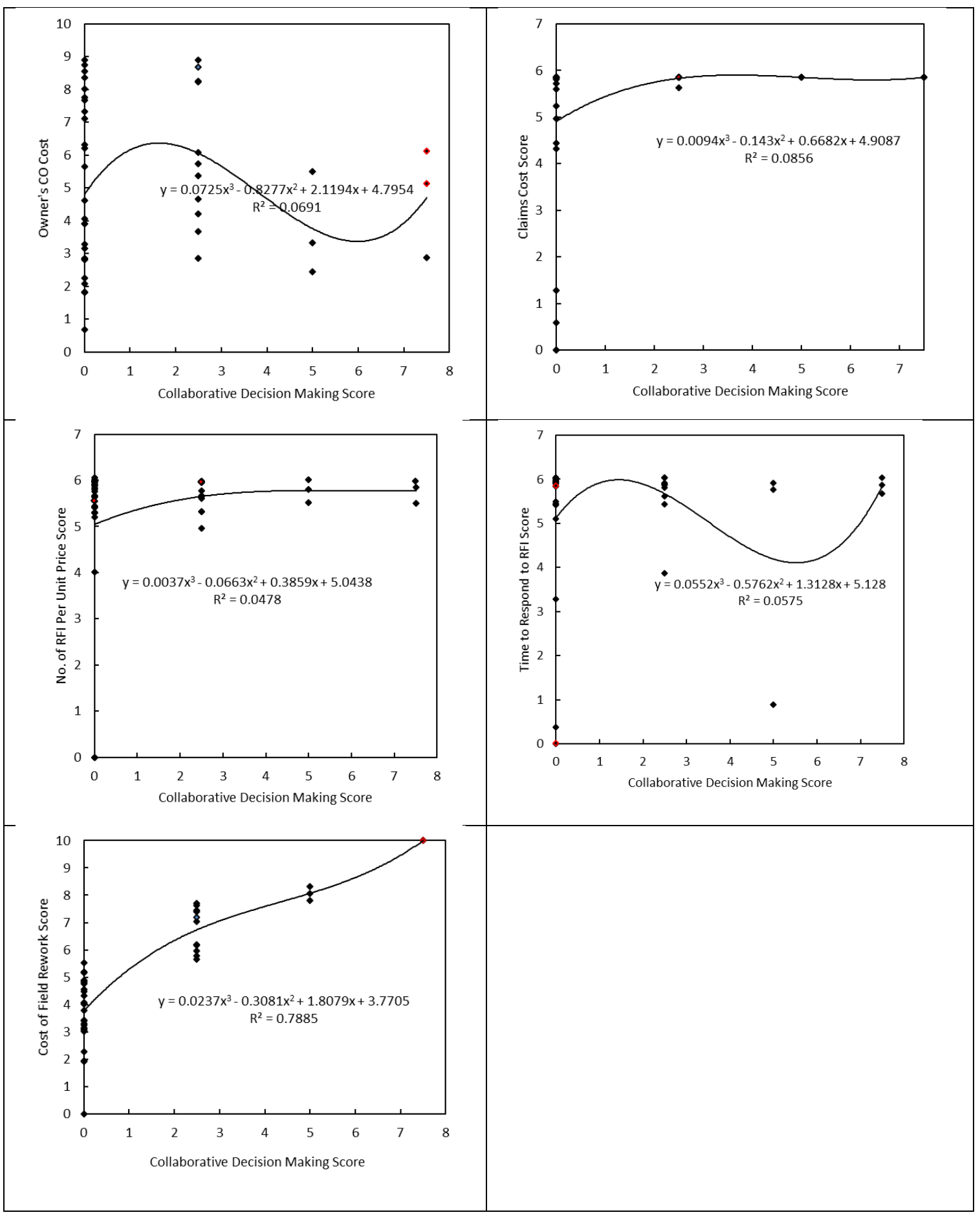


Table 6-32: Correlation between Collaborative Decision Making and KPIs

\begin{tabular}{|c|c|c|c|}
\hline KPIs & $\mathbf{R}^{2}$ & Effect & Analysis \\
\hline $\begin{array}{l}\text { Cost of Field } \\
\text { Rework }\end{array}$ & 0.788 & Strong & $\begin{array}{l}\text { The influence of several different stakeholders } \\
\text { helps to ensure that the decisions made are ones } \\
\text { that consider the input of all the stakeholders } \\
\text { present around the table. This eliminates the } \\
\text { activities that have to be done more than once } \\
\text { in the field and creates a strong effect on this } \\
\text { KPI. }\end{array}$ \\
\hline Cost Overrun & 0.302 & Weak & $\begin{array}{l}\text { Stakeholders are able to leverage the } \\
\text { experience of all the parties represented and } \\
\text { have the potential to reduce Cost Overrun. }\end{array}$ \\
\hline Cost of $\mathrm{CO}$ & 0.301 & Weak & $\begin{array}{l}\text { Stakeholders are able to leverage the } \\
\text { experience of all the parties represented and } \\
\text { have the potential to reduce CO costs. } \\
\text { However, changes in the scope, especially } \\
\text { when they are related to unforeseen conditions } \\
\text { or design deficiencies, cannot be avoided. }\end{array}$ \\
\hline $\begin{array}{l}\text { Cost of } \\
\text { Claims }\end{array}$ & 0.086 & No & $\begin{array}{l}\text { When team members are constantly at } \\
\text { crossroads over key points, they would not be } \\
\text { able to resolve disputes before escalating to } \\
\text { claims. A low number of claims on a project } \\
\text { reflects good team approach to project gains } \\
\text { and losses, and effective communication lines. }\end{array}$ \\
\hline $\begin{array}{l}\text { Cost of Error } \\
\& \text { Omissions } \\
\text { CO }\end{array}$ & 0.072 & No & $\begin{array}{l}\text { Since Collaborative Decision Making was not } \\
\text { implemented during the design phase, it had no } \\
\text { effect on Cost of Error \& Omissions CO. }\end{array}$ \\
\hline $\begin{array}{l}\text { Cost of } \\
\text { Owner's CO }\end{array}$ & 0.069 & No & $\begin{array}{l}\text { No correlation exists because Collaborative } \\
\text { Decision Making does not limit the owner from } \\
\text { issuing change orders due to their preferences } \\
\text { during construction. }\end{array}$ \\
\hline $\begin{array}{l}\text { Time to } \\
\text { Respond to } \\
\text { RFIs }\end{array}$ & 0.057 & No & $\begin{array}{l}\text { When more people need to be consulted before } \\
\text { a decision can be made, Time to Respond to } \\
\text { RFIs is extended. Collaborative Decision } \\
\text { Making does not reduce Time to Respond to } \\
\text { RFIs, yet it might increase it. }\end{array}$ \\
\hline $\begin{array}{l}\text { Number of } \\
\text { RFIs }\end{array}$ & 0.048 & No & $\begin{array}{l}\text { Since Collaborative Decision Making was not } \\
\text { implemented during the design phase, contract }\end{array}$ \\
\hline
\end{tabular}




\begin{tabular}{|l|l|l|l|}
\hline & & $\begin{array}{l}\text { documents can be incomplete, conflicting or } \\
\text { erroneous, thereby requiring revisions and } \\
\text { clarifications to be provided by the designers. }\end{array}$ \\
\hline Time Overrun & 0.042 & No & $\begin{array}{l}\text { When more people need to be consulted before } \\
\text { a decision can be made, the project lead times } \\
\text { are extended to facilitate this extra consultation. } \\
\text { Collaborative Decision Making does not reduce } \\
\text { Time Overrun yet it might increase it. }\end{array}$ \\
\hline
\end{tabular}

Table 6-33: Polynomial Regression Curves between Project's Staff Performance Evaluation and KPIs

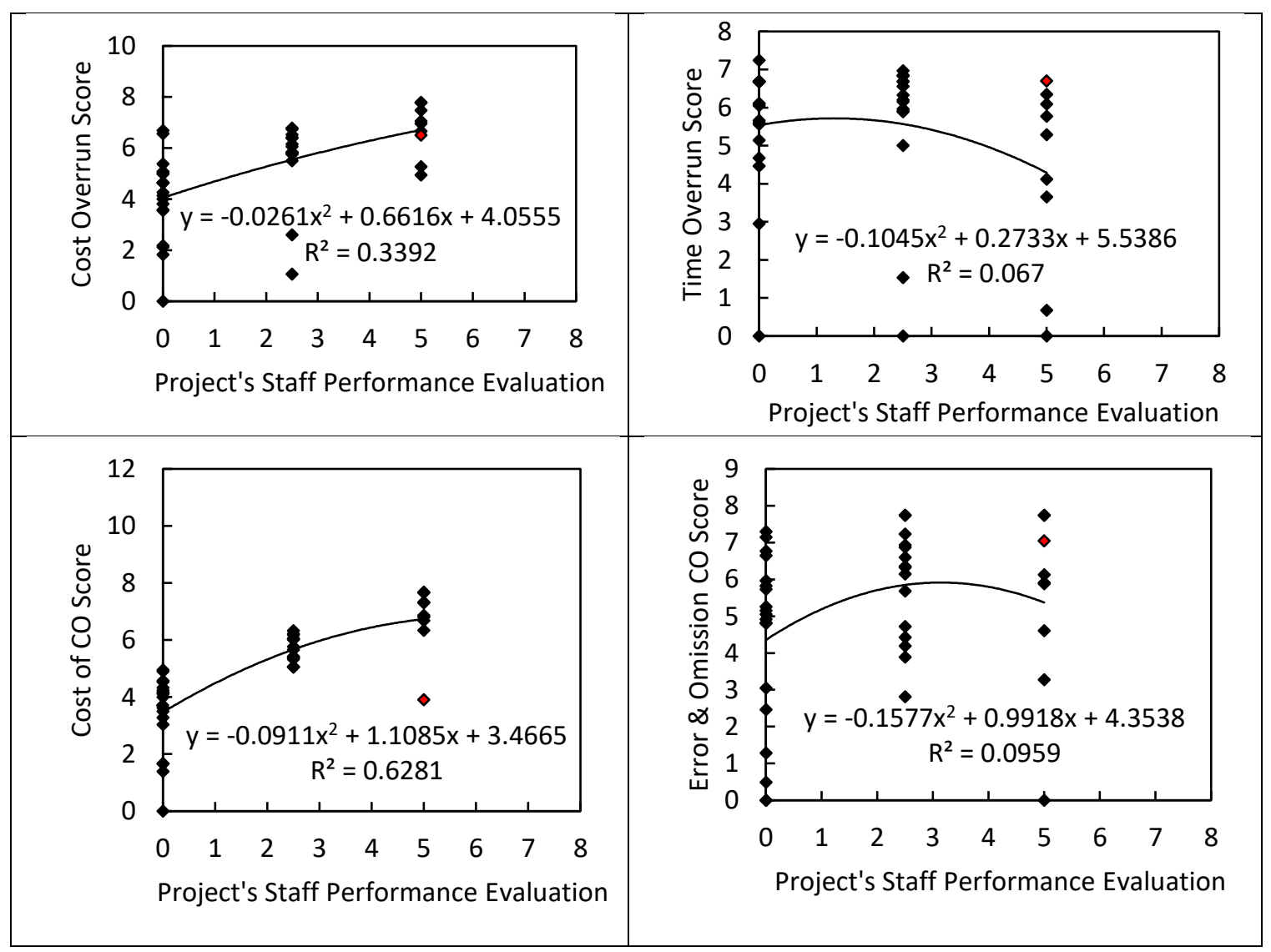




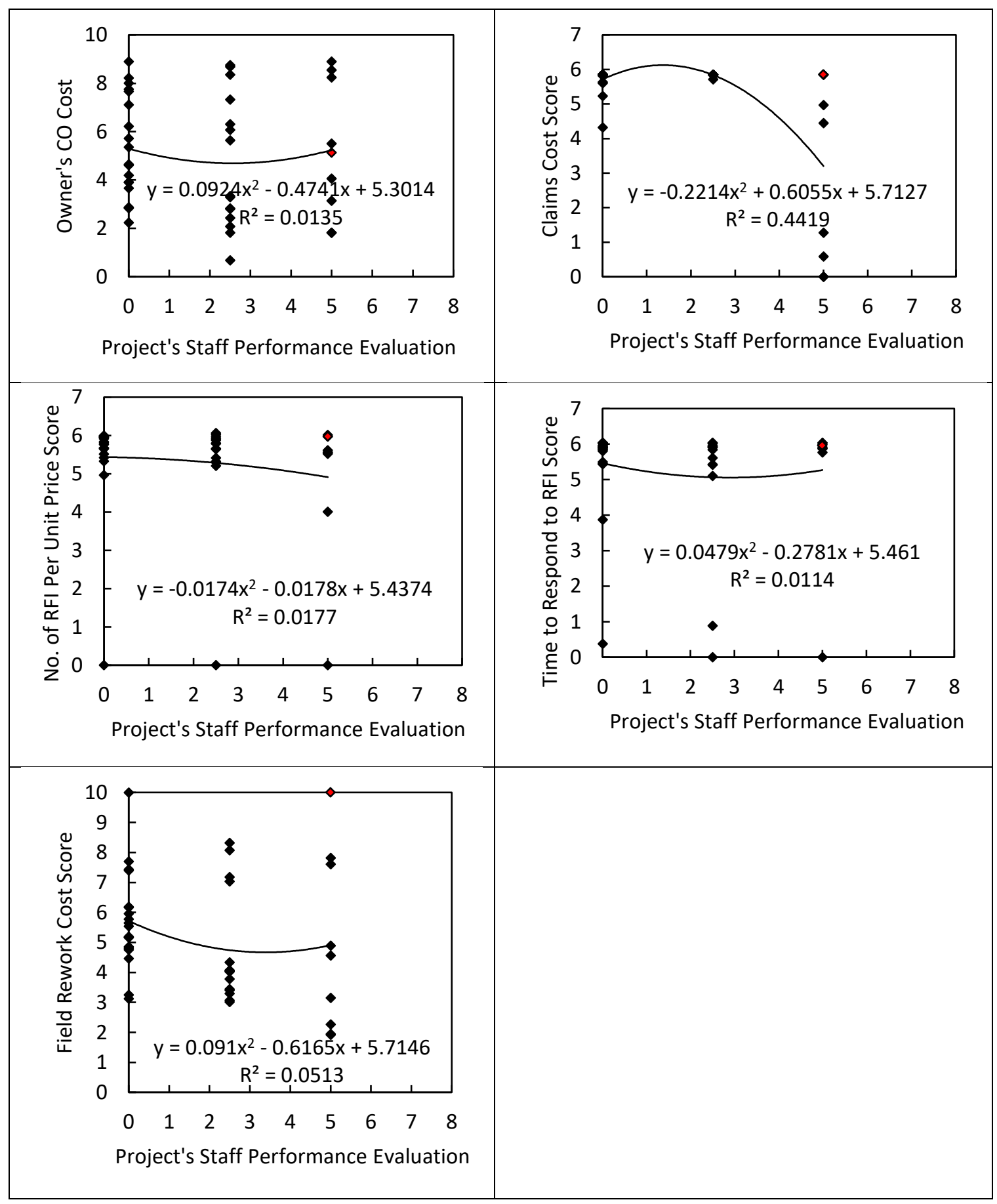


Table 6-34: Correlation between Project's Staff Performance Evaluations and KPIs

\begin{tabular}{|l|l|l|l|}
\hline \multicolumn{1}{|c|}{ KPIs } & \multicolumn{1}{|c|}{$\mathbf{R}^{2}$} & Effect & \multicolumn{1}{c|}{ Analysis } \\
\hline Cost of CO & 0.628 & Weak & $\begin{array}{l}\text { Project's Staff Performance Evaluations } \\
\text { includes ratings for cost effectiveness and } \\
\text { efficiency and budget compliance, which give } \\
\text { contractors a push to reduce the CO, costs. } \\
\text { However, changes in the scope, especially } \\
\text { when they are related to unforeseen } \\
\text { conditions or design deficiencies, cannot be } \\
\text { avoided. }\end{array}$ \\
\hline Cost of Claims & 0.441 & Weak & $\begin{array}{l}\text { This correlation exists because Project's Staff } \\
\text { Performance Evaluations includes ratings for } \\
\text { cooperation, teamwork, and relationships. } \\
\text { The effect is weak due to other factors such } \\
\text { as lack of effective communication lines. }\end{array}$ \\
\hline Cost Overrun & 0.339 & Weak & $\begin{array}{l}\text { Project's Staff Performance Evaluations } \\
\text { includes ratings for cost effectiveness, } \\
\text { efficiency, and budget compliance, which } \\
\text { give contractors a push to reduce the Cost } \\
\text { Overrun. }\end{array}$ \\
\hline $\begin{array}{l}\text { Cost of Error } \\
\text { \& Omissions } \\
\text { CO }\end{array}$ & 0.095 & No & $\begin{array}{l}\text { Since Project's Staff Performance } \\
\text { Evaluations was not implemented during the } \\
\text { design phase, it has no effect on Cost of Error } \\
\text { \& Omissions CO. }\end{array}$ \\
\hline Rework & 0.067 & No & $\begin{array}{l}\text { Project's Staff Performance Evaluations } \\
\text { includes ratings for adherence to schedule, } \\
\text { which expects to have an effect on this KPI. } \\
\text { Since Project's Staff Performance } \\
\text { Evaluations was not implemented during } \\
\text { design, it cannot eliminate design errors and } \\
\text { omissions, or client driven delays, therefore } \\
\text { no effect is derived. }\end{array}$ \\
\hline & 0.051 & $\begin{array}{l}\text { Field Rework is typically caused by } \\
\text { inadequate project supervision, inadequate } \\
\text { design specifications, lack of proper } \\
\text { inspection by the designer, and other factors. } \\
\text { Project's Staff Performance Evaluations is } \\
\text { expected to have an effect on this KPI, but the } \\
\text { dataset does not show it. }\end{array}$ \\
\hline
\end{tabular}




\begin{tabular}{|l|l|l|l|}
\hline $\begin{array}{l}\text { Number of } \\
\text { RFIs }\end{array}$ & 0.017 & No & $\begin{array}{l}\text { Since Project's Staff Performance Evaluations } \\
\text { was not implemented during the design phase } \\
\text { it does not have an effect on the Number of } \\
\text { RFIs. }\end{array}$ \\
\hline $\begin{array}{l}\text { Cost of } \\
\text { Owner's CO }\end{array}$ & 0.013 & No & $\begin{array}{l}\text { No correlation exists because Open } \\
\text { Communication and Ability to Address Issues } \\
\text { because it does not limit the owner from } \\
\text { issuing change orders due to their preferences } \\
\text { during construction. }\end{array}$ \\
\hline $\begin{array}{l}\text { Time to } \\
\text { Respond to } \\
\text { RFIs }\end{array}$ & 0.011 & No & $\begin{array}{l}\text { Project's Staff Performance Evaluations is } \\
\text { not expected to expedite the Time to Respond } \\
\text { to RFIs because it is not typical for Time to } \\
\text { Respond to RFIs to be a factor of the } \\
\text { Project's Staff Performance Evaluations. }\end{array}$ \\
\hline
\end{tabular}

Table 6-35: Polynomial Regression Curves between Jointly Developed Project Target Criteria and KPIs

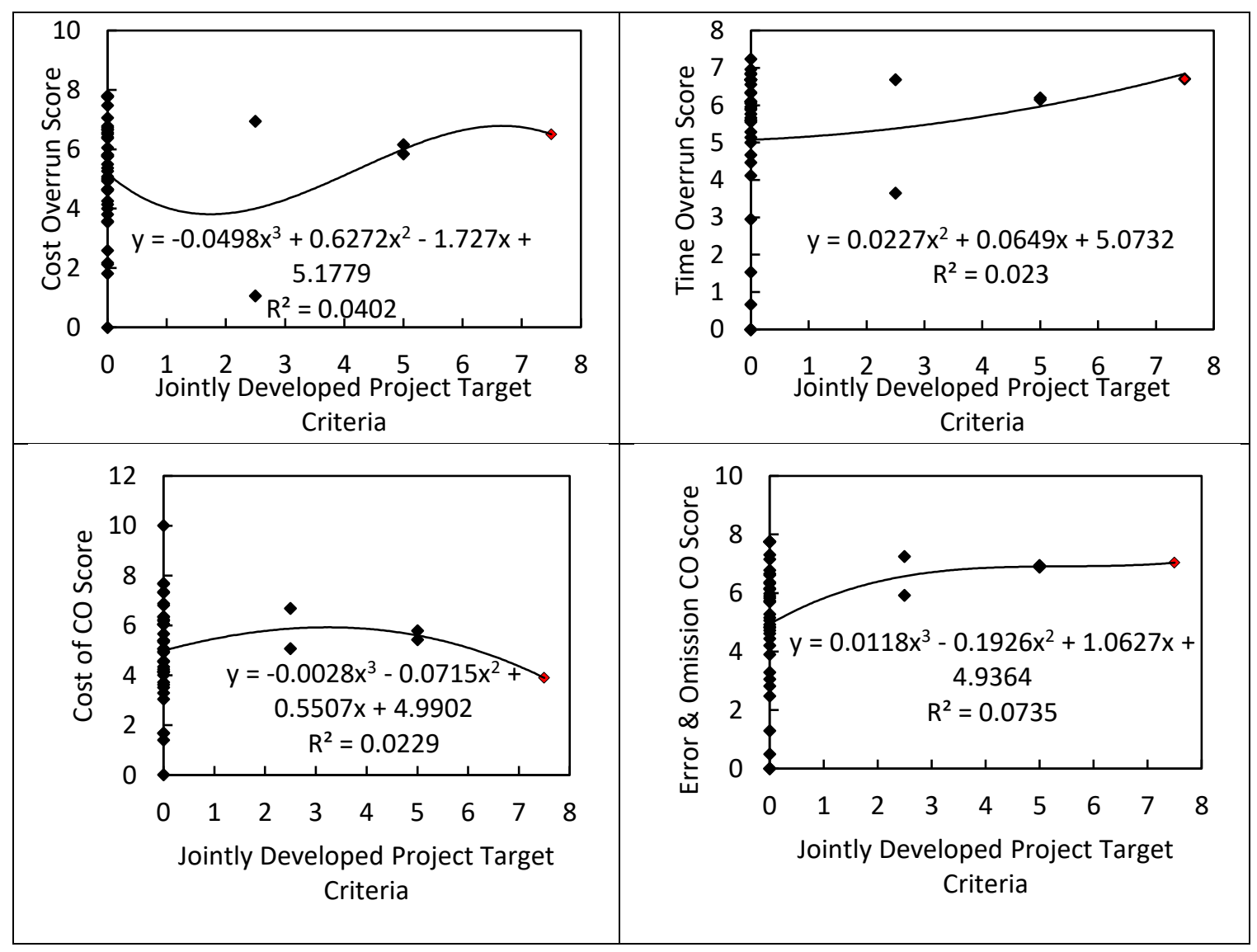




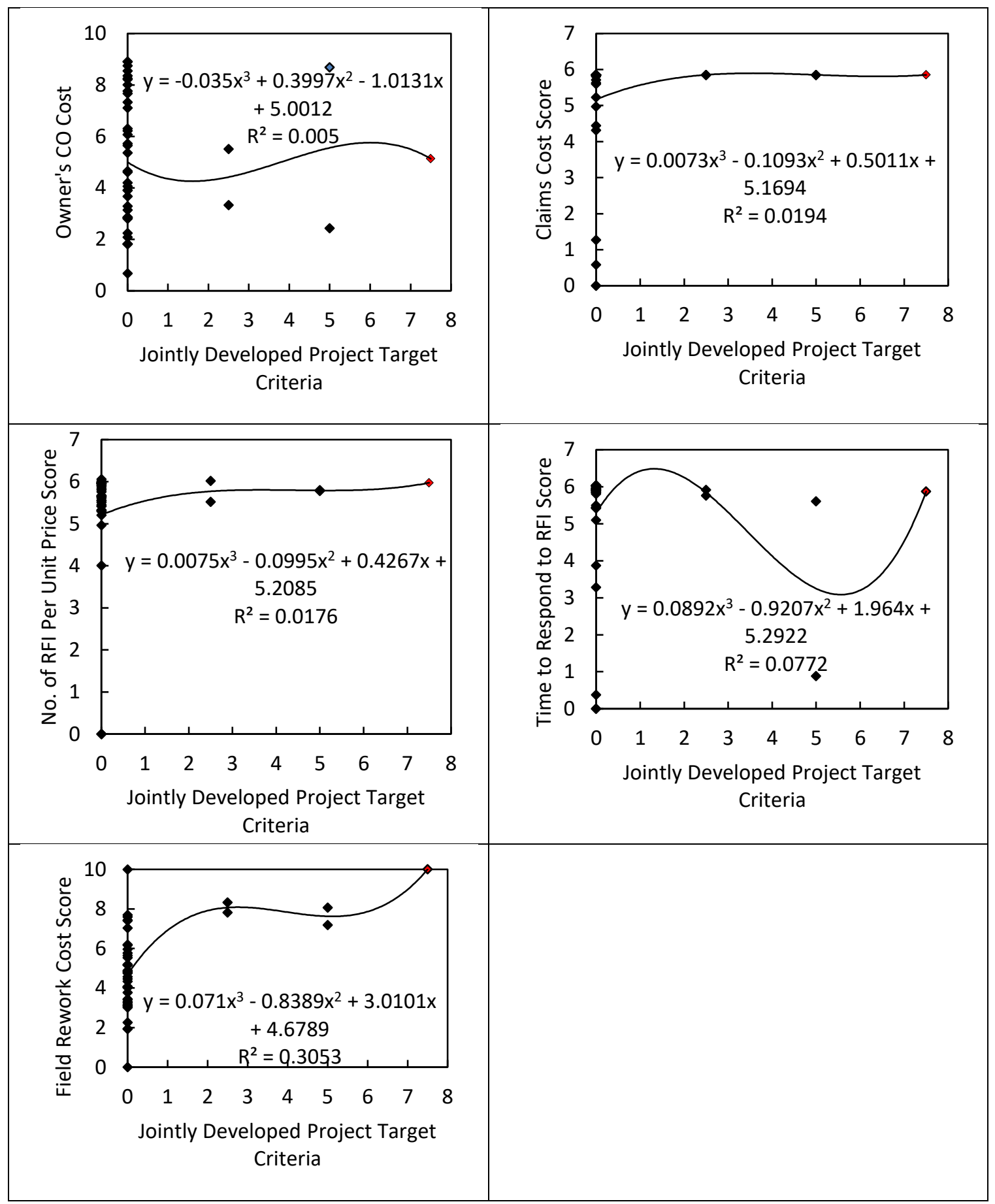


Table 6-36: Correlation between Jointly Developed Project Target Criteria and KPIs

\begin{tabular}{|c|c|c|c|}
\hline KPIs & $\mathbf{R}^{2}$ & Effect & Analysis \\
\hline $\begin{array}{l}\text { Cost of Field } \\
\text { Rework }\end{array}$ & 0.305 & Weak & $\begin{array}{l}\text { Field Rework is typically caused by inadequate } \\
\text { project supervision, inadequate design } \\
\text { specifications, lack of proper inspection by the } \\
\text { designer, and others. Jointly Developed Project } \\
\text { Target Criteria is not expected to have an effect } \\
\text { on this KPI, however the dataset shows a weak } \\
\text { effect. There is no enough data for Jointly } \\
\text { Developed Project Target Criteria to analyze } \\
\text { this effect. }\end{array}$ \\
\hline $\begin{array}{l}\text { Time to } \\
\text { Respond to } \\
\text { RFIs }\end{array}$ & 0.077 & No & \multirow{8}{*}{$\begin{array}{l}\text { There is not enough data for Jointly Developed } \\
\text { Project Target Criteria to analyze these effects. }\end{array}$} \\
\hline $\begin{array}{l}\text { Cost of Error } \\
\& \text { Omissions } \\
\mathrm{CO}\end{array}$ & 0.073 & No & \\
\hline Cost Overrun & 0.040 & No & \\
\hline Time Overrun & 0.023 & No & \\
\hline Cost of $\mathrm{CO}$ & 0.022 & No & \\
\hline $\begin{array}{l}\text { Cost of } \\
\text { Claims }\end{array}$ & 0.019 & No & \\
\hline $\begin{array}{l}\text { Number of } \\
\text { RFIs }\end{array}$ & 0.017 & No & \\
\hline $\begin{array}{l}\text { Cost of } \\
\text { Owner's CO }\end{array}$ & 0.005 & No & \\
\hline
\end{tabular}


Table 6-37: Polynomial Regression Curves between Mutual Respect and Trust and KPIs

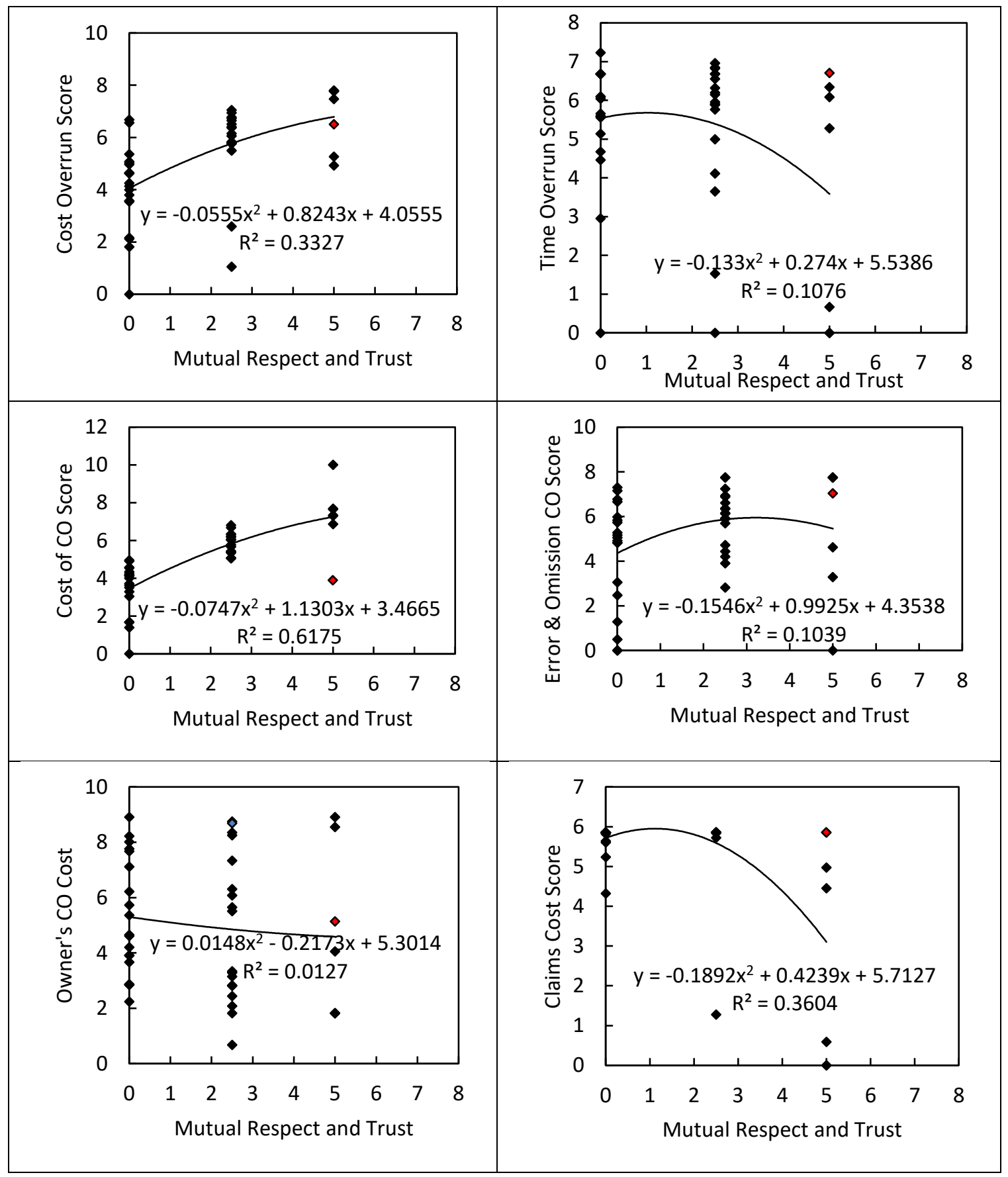




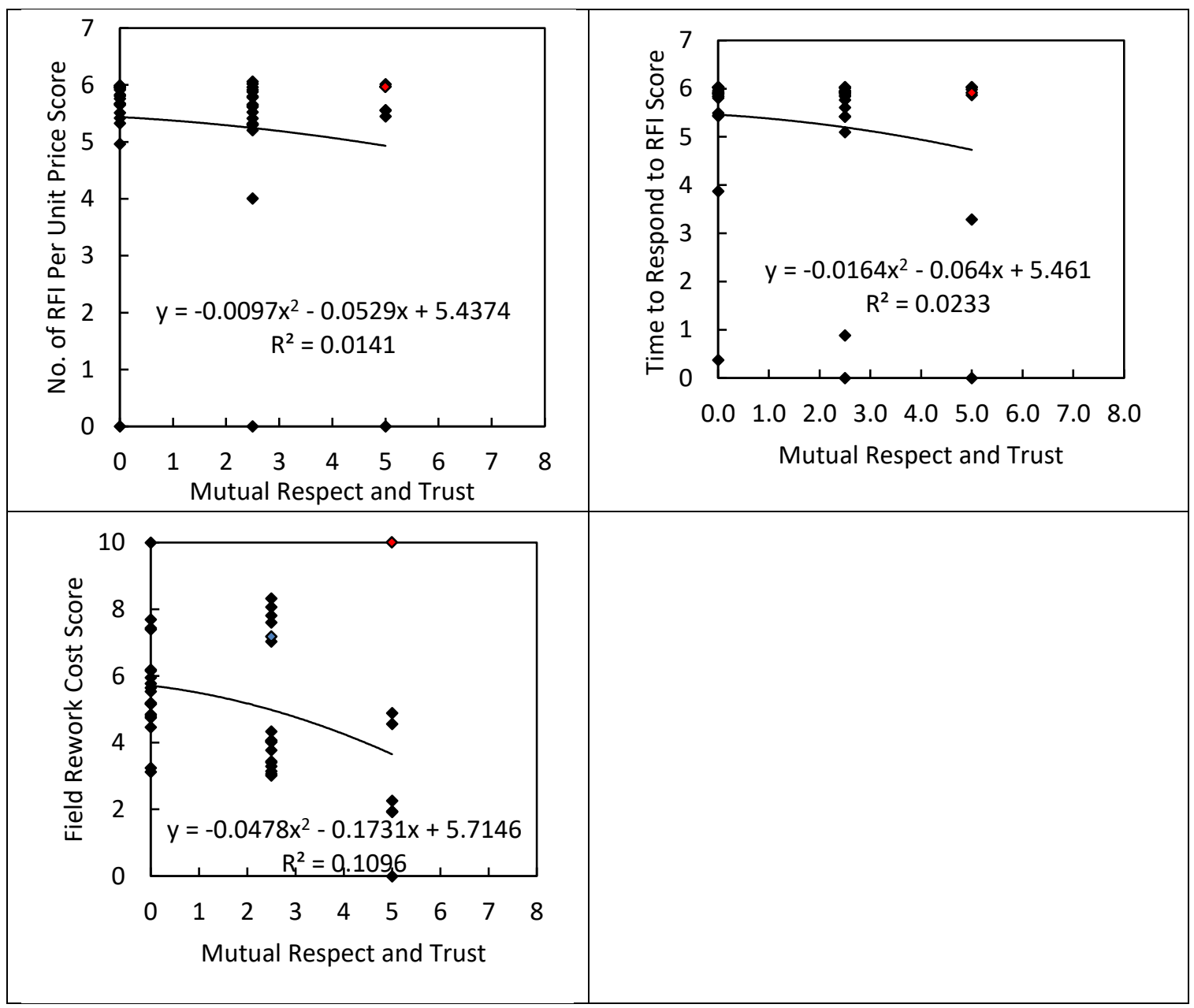


Table 6-38: Correlation between Mutual Respect and Trust and KPIs

\begin{tabular}{|l|l|l|l|}
\hline \multicolumn{1}{|c|}{ KPIs } & \multicolumn{1}{|c|}{$\mathbf{R}^{\mathbf{2}}$} & Effect & \multicolumn{1}{c|}{ Analysis } \\
\hline Cost of CO & 0.617 & Weak & $\begin{array}{l}\text { Mutual Respect and Trust promote openness, } \\
\text { honesty, shared values, and ethics, which can } \\
\text { help in reducing the cost of CO. However, the } \\
\text { effect is moderate because in some projects, } \\
\text { the number of changes that are related to } \\
\text { unforeseen conditions or design deficiencies is } \\
\text { high and could not be avoided. }\end{array}$ \\
\hline $\begin{array}{l}\text { Cost of } \\
\text { Claims }\end{array}$ & 0.360 & Weak & $\begin{array}{l}\text { This relationship exists because Mutual } \\
\text { Respect and Trust promotes honesty, } \\
\text { openness, flexibility, and problem solving. } \\
\text { Absence of trust incurs dysfunctional } \\
\text { environment and toxic culture and militant } \\
\text { stakeholders. }\end{array}$ \\
\hline Cost Overrun & 0.332 & Weak & $\begin{array}{l}\text { Mutual Respect and Trust promote openness, } \\
\text { honesty, shared values, and ethics, which can } \\
\text { help in reducing the Cost Overrun. However, } \\
\text { the effect is weak because Mutual Respect and } \\
\text { Trust cannot overcome the major cost } \\
\text { obstacles that are related to unforeseen } \\
\text { conditions or design deficiencies. }\end{array}$ \\
\hline $\begin{array}{l}\text { Time } \\
\text { Overrun } \\
\text { Respond to } \\
\text { RFIs }\end{array}$ & 0.023 & No Field \\
\hline Rework
\end{tabular}




\begin{tabular}{|l|c|c|l|}
\hline $\begin{array}{l}\text { Cost of } \\
\text { Owner's CO }\end{array}$ & 0.012 & No & $\begin{array}{l}\text { No correlation exists because Mutual Respect } \\
\text { and Trust does not limit the owner from } \\
\text { issuing change orders due to their preferences } \\
\text { during construction. }\end{array}$ \\
\hline $\begin{array}{l}\text { Cost of Error } \\
\text { \& Omissions } \\
\text { CO }\end{array}$ & 0.010 & No & $\begin{array}{l}\text { Mutual Respect and Trust is not expected to } \\
\text { have an effect on Cost of Error \& Omissions } \\
\text { CO that are due to design deficiencies and } \\
\text { errors. }\end{array}$ \\
\hline
\end{tabular}

\section{Results and Conclusions}

The regression analysis reaffirmed the findings by directly correlating the improvements in the KPIs of the control projects to the implemented IPD principles. The regression results identified the individual links between the IPD principles and the KPIs that they affected. The regression results indicated that most KPI improvements have been attributed to various individual IPD principles. The improvement in the KPI related to time overrun has been justifiably related to most of the IPDs.

Regression analysis applied on the KPIs and IPDs resulted in a KPI score prediction model that uses as input the IPD implementation score of a project. The correlation is classified in two categories: (1) Strong Effect with $R^{2}$ values greater than 0.70, and (2) Low Effect with $\mathrm{R}^{2}$ values less than 0.70. The applied regression analysis results demonstrated the following:

1. Open Communication with the Project Team and Ability to Address Issues displays a statistically significant effect on the prediction of Cost Overrun. The resulting regression equation is $y=0.0004 x^{3}-0.0657 x^{2}+1.2205 x+1.902$. 
Where $x$ is the score of Open Communication with the Project Team and Ability to Address Issues and $y$ is the score of Cost Overrun.

2. Co-Location of Teams displays a statistically significant effect on the prediction of Time to Respond to RFIs. The resulting regression equation is $y=$ $0.0378 x^{3}-0.6204 x^{2}+3.2786 x+0.3153$. Where $x$ is the score of CoLocation of Teams and $y$ is the score of Time to Respond to RFIs.

3. Collaborative Decision Making displays a statistically significant effect on the prediction of Field Rework Cost. The resulting regression equation is $y=$ $0.0237 x^{3}-0.3081 x^{2}+1.8079 x+3.7705$. Where $x$ is the score of Collaborative Decision Making and $y$ is the score of Field Rework Cost.

4. Since only four out of 45 projects implemented Integrated and Collaborative Teams, no sufficient data is available to form the regression. Therefore, the effect of Integrated and Collaborative Teams could not be determined on any KPI. The regression model developed can help owners predict how improving the implementation of certain IPD principles can impact the performance score of their related KPIs. The model shows that implementing certain IPD principles improves the performance score of a DBB project.

Figure 6-19 displays the links between IPD Principles and KPIs as identified by the regression analysis results. 


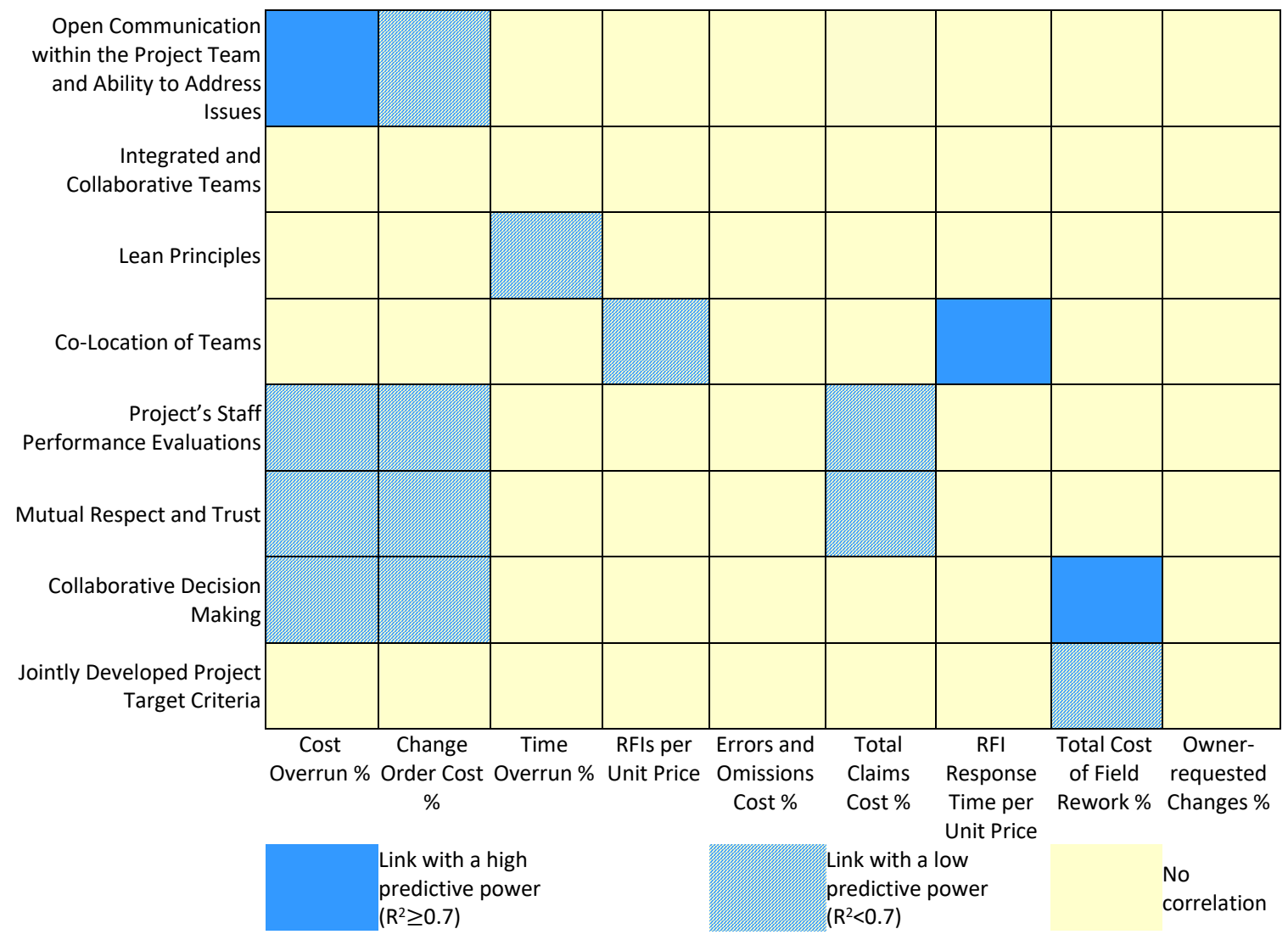

Figure 6-19: Links between IPD Principles and KPIs identified by regression analysis.

\section{Input from Focus Group}

The focus group, mentioned earlier, was also utilized at the final stages during the model development. The last meeting with the focus group helped in acknowledging the individual links between the IPD principles and the KPIs displayed in Figure 6-19. The focus group noted that the established links have common sense. The focus group participants were generally in agreement with the findings that were obtained through the regression analysis. 


\section{Guideline Metric}

A guideline metric was developed as a tool to assist owners and contractors who are willing to improve particular KPIs of their treatment plant projects. This tool, shown in Figure 6-20, allows the user to choose which IPD principle to implement in a project in order to improve the score of a particular KPI. This tool also demonstrates the different levels of IPD implementation and their corresponding pre-desired percentage of improvement in the score of a particular KPI. The level of improvement designated in this metric is measured with respect to the average KPI score of the dataset. The optimal combination of implementation levels for the IPD principles are:

Open Communication - Level 3,

Co-location of Teams - Level 4, and

Collaborative Decision Making - Level 3.

This combination will achieve the most cost-efficient improvement in Cost Overrun, RFI Response Time, and Cost of Field Rework KPIs. 


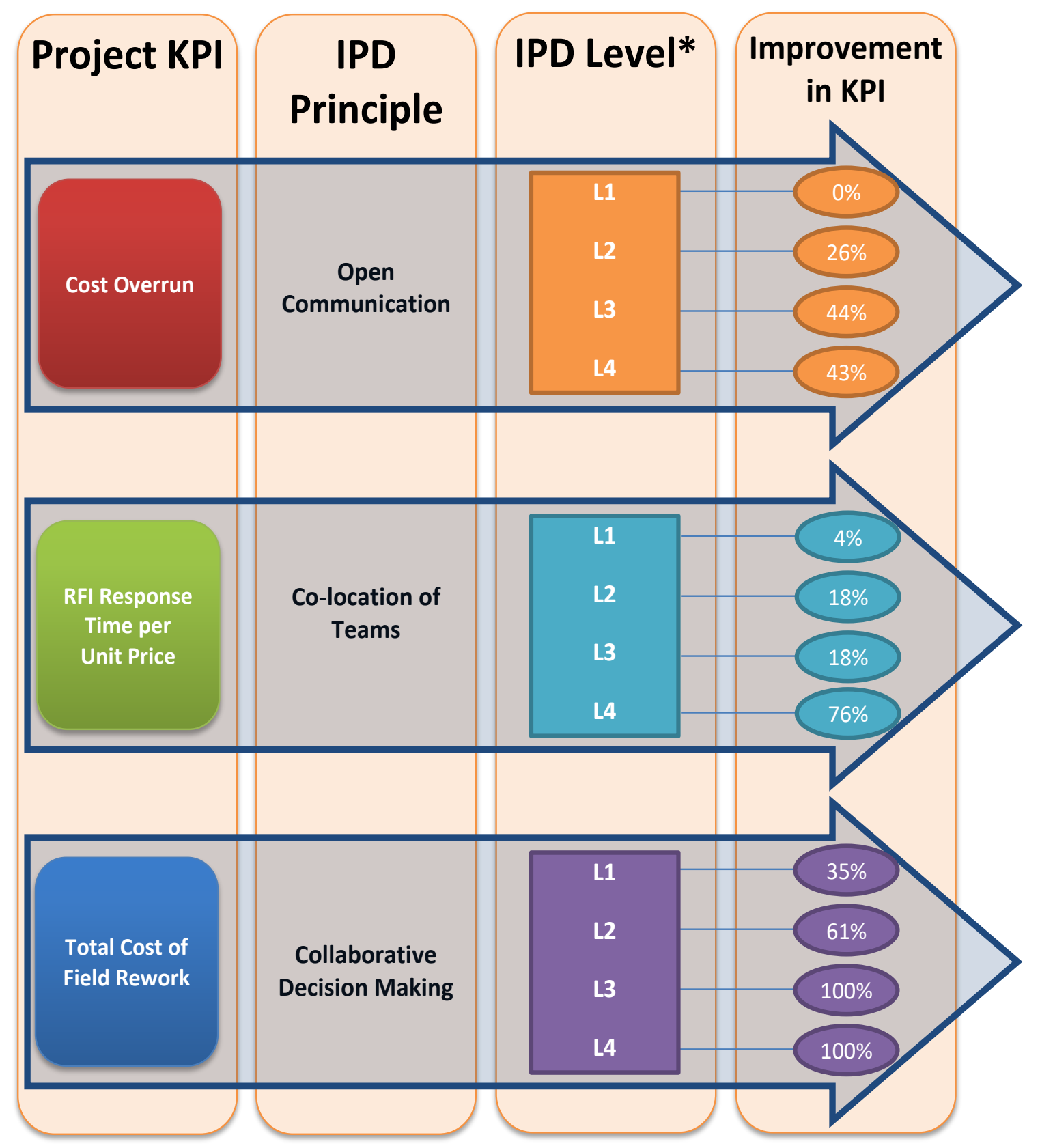

*IPD implementation level L1 corresponds to a measuring scale of 2.5 as defined by Azhar (2014) IPD implementation level L2 corresponds to a measuring scale 5 as defined by Azhar (2014) IPD implementation level L3 corresponds to a measuring scale 7.5 as defined by Azhar (2014) IPD implementation level L4 corresponds to a measuring scale 10 as defined by Azhar (2014)

Figure 6-20: IPD Implementation guideline metric. 
Regression analysis between the various IPD scores and the PI scores was performed to determine which IPD principle is most influential on the PI of a project. All results showed similar R-square values and the highest was for Lean Principles with Rsquare value of 0.1767 a shown in Figure 6-21.

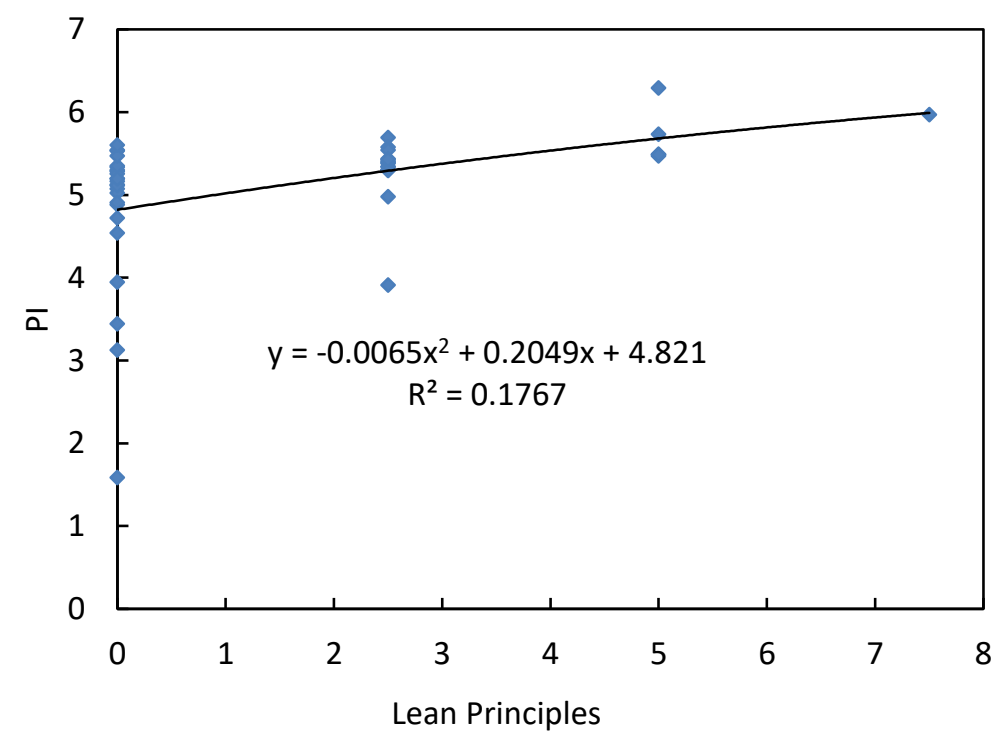

Figure 6-21: Regression analysis between PI and Lean Principles scores. 


\section{CHAPTER 7}

\section{CONCLUSIONS AND RECOMMENDATIONS}

\section{Conclusions}

As the world strives to achieve more development, the construction industry is becoming more and more an important and large sector of the world economy. The performance of the construction industry is affected by clients, contractors, consultants, stakeholders, regulators, national economies, and others. This research aimed at assessing how incorporating certain IPD principles in the commonly used DBB delivery method for water utilities major capital projects can improve the performance rating of the project. The study implemented applicable IPD principles to control projects at the Miami Dade Water and Sewer Department and collected relevant data. The research used comprehensive project data from several water utility facilities relevant to the current project delivery and procurement process of actual construction projects. The study showed, by the use of two control projects, that implementing some IPD principles can be highly beneficial to DBB delivery method in water related public projects. The study also demonstrated that a strong relationship exists between implementing selective IPD principles and project KPIs.

Eight IPD principles were implemented in the two control wastewater projects, and KPIs of these projects were measured and compared to KPIs of a dataset comprised of 43 completed projects in the same geographic region of South Florida. These specific IPD principles were selected because they do not require any design or preconstruction 
aspects to be set prior to construction. They can be implemented during construction after all parties meet each other and after all roles are assigned.

Results comparison for the various KPIs yielded the following conclusions:

1- Performance Evaluation with Regard to Cost

The control projects had lower average percent cost overrun during construction than the dataset projects. The average cost overrun of the control projects was $\$ 157,407$ (3.9\%). The average cost overrun of the dataset projects was $\$ 1,021,650(7.5 \%)$.

\section{2- Performance Evaluation with Regard to Time}

The control projects had a lower average time overrun percentage during construction than the dataset projects. The average time overrun of the control projects was $-0.06(-0.45 \%)$, compared with 101.77 (21.9\%) average time overrun for the dataset projects.

\section{3- Performance Evaluation with Regard to COs}

The number and cost of COs obtained from the control projects were compared with those of $\mathrm{DBB}$ projects as a percentage value of the total project cost. The control projects had a lower total number of RFPs during construction than the dataset projects. The average number of RFPs of the control projects was 9.0. The average number of RFPs of the dataset projects was 25.1. However, the total percentage cost of COs was essentially the same. The delivery method did not appear to affect $\mathrm{CO}$ cost performance.

\section{4- Request for Information (RFI) Evaluation}

The number of RFIs obtained from the control projects was compared to those of past projects delivered using DBB. The control projects had a lower total number of RFIs during construction than the dataset projects of similar size and nature. The average 
number of RFIs of the control projects was 17.5, while the average number of RFIs of dataset projects was 106.1 .

\section{5- Construction Claims}

The control projects had a lower claims cost as a percentage of contract amount than the dataset projects. The average claims cost of the control projects was $0.0 \%$, compared to an average claims cost of $5.1 \%$ for the dataset projects.

A focus group session that was conducted with the control projects personnel, who were experienced participants in water utility construction projects, reaffirmed the findings by directly correlating the improvements in the KPIs of the control projects to the implemented IPD principles.

\section{PPR Development}

A comprehensive Project Performance Rating (PPR) model was developed and implemented, combining key performance indicators identified by the study. The PPR model was developed in order to integrate key performance indicators and to highlight improvements on overall project performance of DBB projects by incorporating IPD principles. The PPR model allowed for the comparison of overall performance of projects delivered using DBB project delivery methods. The model showed projects delivered using the IPD principles with DBB method to have a significant increase in performance.

The performance of the control projects was superior when compared to that of

the dataset projects based on nine different performance factors (PF) categorized in five success criteria: Customer Satisfaction, Project Schedule, Project Cost, Design Quality, 
and Early Involvement. A number of KPIs were developed to quantify those PFs based on critical project performance data. Using a dataset comprised of 43 actual water and wastewater projects delivered using $\mathrm{DBB}$, an algorithm was developed and presented for computing a single-number performance index for a project. The algorithm leaves room for users to customize the model in a way to satisfy their specific preferences with regard to the relative importance of each success factor and success criterion. Two control projects - managed by the research team and delivered by infusing a number of IPD principles into the traditional DBB delivery method-were used to demonstrate the use of the PPR model. The PPR Model rated the two control projects to have better performance than the dataset projects by a factor of 1.19. The PPR Model therefore shows that implementation of IPD principles to improve the delivery of the control projects.

The average PI of the dataset correlated to traditional DBB approach as shown in literature review where it has a few shortcomings and pertinent issues. This study provides owners and contractors of treatment facilities with a simple-to-use model for assessing the success of a project relative to database of past projects delivered using the traditional DBB delivery method. The implementation of IPD principles in the delivery of the project resulted in performance improvement in all success factors, with the exception change order cost which had a decline in its performance score. While the performance index varied with the choice of different user-assigned weights, all five simulation runs of the PPR model showed the implemented IPD principles to have a positive effect on the project performance. While the model was developed based on a dataset limited to a specific geographical region, the uniformity in project size 
distribution and large number of selected projects included in the dataset renders the PPR model applicable to water and wastewater construction projects at large.

\section{Correlation between IPD and KPI}

Although the construction industry has a generally positive perception of IPD, the correlation between IPD and project KPIs has been overlooked thus far. This study investigates the correlation links between various IPD principles and performance indicators through a statistical regression analysis of a large dataset representing actual water-related public projects. A two-way ANOVA test was conducted on the KPIs and IPD scores and results revealed significant correlations between only some IPD principles and certain project KPIs. The regression equations developed provide an easy way to predict the performance score of various project KPIs given different IPD implementation levels. Cost Overrun score of DBB projects can be predicted using Open Communication with the Project Team and Ability to Address Issues (OCPTAAI) score, Time to Respond to RFIs score can be predicted using Co-Location of Teams (CLT) score, and Cost of Field Rework score can be predicted using Collaborative Decision Making (CDM) score. The control projects performed noticeably better than average, despite the major limitations that prevented the implementation of the full array of IPD principles, during the design and construction phases. The major regression results summary indicates the following:

1- Open Communication with the Project Team and Ability to Address Issues displays a statistically significant effect on the prediction of Cost Overrun. The resulting regression equation is $y=0.0004 x^{3}-0.0657 x^{2}+1.2205 x+$ 
1.902 ; with $\mathrm{R}^{2}=0.8652$. Where $x$ is the score of Open Communication with the Project Team and Ability to Address Issues and $y$ is the score of Cost Overrun.

2- Co-Location of Teams displays a statistically significant effect on the prediction of Time to Respond to RFIs. The resulting regression equation is $y=$ $0.0378 x^{3}-0.6204 x^{2}+3.2786 x+0.3153$; with $\mathrm{R}^{2}=0.9739$. Where $x$ is the score of Co-Location of Teams and $y$ is the score of Time to Respond to RFIs.

3- Collaborative Decision Making displays a statistically significant effect on the prediction of Field Rework Cost. The resulting regression equation is $y=$ $0.0237 x^{3}-0.3081 x^{2}+1.8079 x+3.7705 ; \mathrm{R}^{2}=0.7885$. Where $x$ is the score of Collaborative Decision Making and $y$ is the score of Field Rework Cost.

The regression equations developed provide an easy way to predict the performance score of various project PFs given different IPD implementation levels.

The developed guideline metric provides an easy method for owners to predict the performance score of various projects KPIs given different IPD principles implementation levels, as well as the ability to identify which IPD tools to implement in their project delivery in order to improve certain aspects of the project performance. It is important to note that the implementation of Open Communication and Collaborative Decision Making requires a simple effort and planning compared to Co-Location of Teams. Co-Location of Teams will be efficient only on large size projects due to the preplanning and large costs associated with it. 


\section{Recommendations}

While this study has achieved its aim and research objectives, several issues remain to be addressed in future studies. The following issues are recommendations related to obtained results.

\section{1- Training Programs}

It is recommended that human resources be developed in the water related construction industry through proper and continuous training programs that address the performance of construction projects. These programs can be implemented by offering effective and efficient training courses in DBB delivery method that leads to the success of construction projects. Water utilities shall establish a continuous IPD learning plan for training purposes by using internal and external resources. Training shall ensure that all team members are comfortable with the methodology and with their commitment to the project. These courses shall focus on training on IPD principles and making the projects' personnel aware of the benefits of implementing IPD principles in the overall success of the water related projects from all aspects.

\section{2- Owners}

Achieving successful transitioning to DBB delivery method with the implementation of selective IPD principles is crucial. A successful transition requires efforts from owners to have the procurement ability and the right personnel to implement IPD.

All managerial levels should be equipped with effective decision-making capabilities. Owners shall emphasize continuous coordination and good relationships 
between project participants, which are required through the project's life cycle in order to solve problems and improve project performance. Owners shall have the authority to replace an entity, a group, or individuals who are not cooperating and do not fit as part of the construction group. Owners pose the most influence on the degree of collaboration they receive on their projects. This influence comes early in projects in the form of their procurement and contracting process. The owners have to be involved for the IPD principles implementation with DBB delivery method to be successful, rather than shifting the risks to the other project stakeholders. Project participants need to build confidence in each other in order to overcome the cultural barriers through the help of the owners. In IPD projects, the elements of trust must be taken to a higher level for the delivery to be a success.

\section{3- Engineers and Contractors}

Contractors and engineers are recommended to minimize waste rate through project implementation in order to improve cost performance. They should be more interested in collaborating with the owners and to have a good relationship in order to solve problems and improve project performance.

\section{4- Future Research}

Further research should be conducted regarding implementing more IPD principles to traditional DBB project delivery in public projects. Public projects should implement more IPD principles for more improvements in KPIs, and governments should find ways to incorporate certain IPD principles through legislation. More research is needed to investigate how to best allow the early involvement of all parties in public 
projects in order to achieve the desired outcomes. Furthermore, additional research is needed to study the ways pain and gain cost sharing can be implemented in public projects and how non-owner participants can place their costs at risk.

Further research should also be conducted to verify the following:

- The relationship between IPD adoption and construction cost,

- The effect of IPD adoption on labor productivity,

- The effect of IPD adoption on the workload of employees,

- The effect of IPD adoption on contractor profits,

- Public law modifications requirements, and

- Contractual risk and insurance allocation terms.

Further research is also needed to better understand the relationships among IPD principles and KPIs in public and private projects. Research including the implementation of IPD principles during the design phase is essential to reveal additional useful links with the KPIs. This will be worthwhile in order for owners to know the important explanatory variables to which they must pay close attention in order for their projects to be completed to their acceptable level of quality and satisfaction. Owners will be able to decide to what level they should use IPD procurement method in order to obtain the desired results.

\section{4- Limitations}

While the PPR model is well structured and includes a wide array of performance variables, it however does not account for the effects of certain factors which are external to the projects themselves, and are of a different nature than the performance measures 
that are being assessed. Such factors include recession, inflation, weather conditions, and complexity level of projects. 


\section{REFERENCES}

Abdirad, H., and Pishdad-Bozorgi, P. (2014). Developing a Framework of Metrics to Assess Collaboration in Integrated Project Delivery. Proceedings of the 50th Annual International Conference of the Associated Schools of Construction, Virginia Polytechnic Institute and State University, VA, U.S.

Abdul Aziz, A., Memon, H., Abdul Rahman, I., and Abd Karim, A. (2012). Controlling Cost Overrun Factors in Construction Projects in Malaysia. Research Journal of Applied Sciences, Engineering and Technology 5 (8):2621-2629.

Acocella, I. (2012). The Focus Groups in Social Research: Advantages and Disadvantages. Springer Quality and Quantity, 46 (4):1125-1136.

AIA California Council (2007). Integrated project delivery: A working definition. Retrieved from http://ipdca.net/images/Integrated\%20Project\%20Delivery\%20Definition.pdf

American Institute of Architects, AIA Minnesota, School of Architecture, University of Minnesota (2011). IPD Case Studies. Retrieved from http://www.aia.org/aiaucmp/groups/aia/documents/pdf/aiab093703.pdf

AIA California Council (2010). Integrated Project Delivery: Case Studies. Retrieved from http://hga.com/sites/default/files/downloads/resources/ipd_casestudies_aiacc_final_0104 10_0.pdf.

Alarcon, L. F. and Ashley, D. B. (1996). Modeling Project Performance for Decision Making. Journal of Construction Engineering and Management, September 1996;pp. 265273.

American Institute of Architects and AIA California Council (2007). Integrated Project Delivery: A Guide. Retrieved on May 1, 2011 from http://www.aia.org/contractdocs/AIAS077630

Aldrich, R. S. (2011). A Whole Systems Approach. ProQuest Library Journal, 136 (15):pp. 30.

Associated General Contractors (2004). Project Delivery Systems for Construction. Associated General Contractors of America.

Azhar, N. (2014). Integrated Construction Project Delivery System in the U.S. Public Sector: An Information Modeling Framework. Florida International University. 
Azhar, N., Kang, Y., and Ahmad, I. (2014). Factors Influencing Integrated Project Delivery In Publicly Owned Construction Projects: An Information Modeling Perspective. Procedia Engineering 77. pp. 213 - 221.

Baiden, B. and Price, A. (2011). The Effect of Integration on Project Delivery Team Effectiveness. International Journal of Project Management, 29:129-136.

Barlas Y. (1996). Formal aspects of model validity and validation in system dynamics. System Dynamics Review, 12, 183-210.

Barry, M-L., Steyn, H., Brent, A. (2009). The Use of Focus Group Technique in Management Research: The Example of Renewable Technology Selection in Africa. Retrieved from http://repository.up.ac.za/handle/2263/13460

Beard, J., Loulakis, M., and Wundram, E. (2001). Design-Build: Planning Through Development. RR Donnelley and Sons Company.

Benedict, D. I. and David J. K. (2011). Building Information Modeling and Integrated Project Delivery in the Commercial Construction Industry: A Conceptual Study. Journal of Engineering, Project, and Production Management, 2 (1):23-36.

Bennett, T. (2012). Financing our Water's Future with PPPs and 3D. WaterWorld. Blackburn, R. (2012).

Breaking down the barriers: Using Focus Groups to Research Small and Medium-Sized Enterprises. International Small Business Journal, 19 (1):44-63.

Bryde, D., Broquetas, M., and Marc, V. J. (2013). The project benefits of Building Information Modelling (BIM). International Journal of Project Management, 31 (7):971980 .

Carbasho, T., (2008). Integrated Project Delivery Improves Efficiency, Streamlines Construction, Lean Management Approach Eliminates Waste and Enhances Project Outcome. Tradeline Inc., ISSN: 1096-4894.

Chan, A. and Chan, A. (2004). Key Performance Indicators for Measuring Construction Success. Benchmarking: An International Journal, 11 (2):203-221.

Chan, A., Ho, D., and Tam, C.M. (2001). Design and Build Project Success Factors: Multivariate Analysis. Journal of Construction Engineering \& Management. 2001, 127 (2), pp. 93.

Cha, H. and Kim, C. (2011). Quantitative approach for project performance measurement on building construction in South Korea. KSCE Journal of Civil Engineering, 10.1007/s12205-011-1323-5, 1319-1328. 
Chan, I., Leung, M., and Yu, S. (2012). Managing the Stress of Hong Kong Expatriate Construction Professionals in Mainland China: Focus Group Study Exploring Individual Coping Strategies and Organizational Support. Journal of Construction Engineering and Management, 138 (10):1150-1160.

Chan, A. P. C., Scott, D., and Lam, E. W. M. (2002). Framework of Success Criteria for Design-Build Projects. Journal of Management in Engineering, 18 (3):120-128.

Chen Wei, T. and Chen, T. (2007). Critical success factors for construction partnering in Taiwan. International Journal of Project Management, 25 (5):475-484.

Chick, David (1999). The Time Value of Project Change. Journal of Cost Engineering, Vol.41/No. 6 .

Cho, S. and Ballard, G. (2011). Last Planner and Integrated Project Delivery. Lean Construction Journal, pp. 67-78.

Construction Industry Institute (CII) (2001). The Field Rework Index: Early Warning for Field Rework and Cost Growth. Research summary, Construction Industry Institute, University of Texas at Austin, Austin, TX, pp. 153-161.

Collins, A. and Baccarini, D. (2004). Project Success - A Survey. Journal of Construction Research, 5 (2):211-231.

CURT, The Construction Users Roundtable (2004). Collaboration, Integrated Information, and the Project Lifecycle in Building Design, Construction and Operation. Retrieved from http://www.curt.org/Training-WP1202-Collaboration-IntegratedInformation-and-the-Project-Life-Cycle-in-Building-Design.aspx

Darrington, J. (2011). Using a Design-Build Contract for Lean Integrated Project Delivery. Lean Construction Journal, pp. 85-91.

Dainty, A. R. J., Cheng, M., and Moore, D. R. (2003). Redefining Performance Measures for Construction Project Managers: An Empirical Evaluation. Construction Management and Economics 21:209-218.

El Asmar, M. (2012). Modeling and benchmarking performance for the integrated project delivery (IPD) system. University of Wisconsin-Madison. Retrieved from http://depot.library.wisc.edu/repository/fedora/1711.dl:AKMLTWGBWZFB78A/datastre ams/REF/content.

El Asmar, M., and Hanna, A. S. (2012). Quantifying Performance for the Integrated Project Delivery (IPD) System. Journal of Construction Engineering and Management, 139(11), 04013012. 
El Asmar, M., and Hanna, A. S. (2016). Evaluating Integrated Project Delivery Using the Project Quarterback Rating. Journal of Construction Engineering and Management, 142(1): 04015046.

El-Gohary, N. and El-Diraby, T. (2010). Dynamic Knowledge-Based Process Integration Portal for Collaborative Construction. Journal of Construction Engineering and Management, 136 (3):316-328.

Ellis. R., Pyeon, J., Herbsman, Z., Minchin, E., Molenaar, K. (2007). Evaluation of Alternative Contracting Techniques on FDOT Construction Projects. Transportation Research Board. Retrieved from http://www.dot.state.fl.us/researchcenter/Completed_Proj/Summary_CN/FDOT_BDC51_rpt.pdf

Elyamany, A., Basha, I. and Zayed, T. (2007), Performance evaluation model for construction Companies. Journal of Construction Engineering and Management, Vol. 133 No. 8, pp. 574-581.

FMI/CMAA Sixth Annual Survey of Owners. (2005). Retrieved from http://www.cmaafoundation.org/files/surveys/2005-survey.pdf

Focus Groups When and Why to Use. University of Wisconsin-Madison (1999). Retrieved from http://www.virginia.edu/processsimplification/resources/WiscFocusGroups.pdf

Forbes, L. H., and Syed, M. A. (2011). Modern construction: Lean project delivery and integrated practices, CRC Press, Boca Raton, FL.

Forsythe, P. (2007). A Conceptual Framework for Studying Customer Satisfaction in Residential Construction. Construction Management and Economics, 25 (2):171182.

Francom,T., El Asmar, M., and Ariaratnam, S.T. (2016). Performance Analysis of Construction Manager at Risk on Pipeline Engineering and Construction Projects. J. Manage. Eng., 32(6).

Furst, P. G. (2010). Constructing integrated project delivery. Industrial Management, 52 (4):19.

Ghassemi, R., and Becerick-Gerber, B. (2011). Transitioning to Integrated Project Delivery: Potential Barriers and Lessons Learned. Lean Construction Journal, pp. 35-52.

Gibbs, A. (1997). Focus groups. Social Research Update. On-line, Issue Nineteen. University of Surrey. Retrieved from http://sru.soc.surrey.ac.uk/SRU19.html. 
Gibson, E. G., Jr., Migliaccio, G. C., and O’Connor, J. T. (2008). Changing Project Delivery Strategy:An Implementation Framework. Public Works Management and Policy, 12 (3):483-502.

Gordon, C. M. (1994). Choosing Appropriate Construction Contracting Method. Journal of Construction Engineering and Management, ASCE, 120 (1):196-210.

Hanna, A., Lotfallah, W., Aoun, D., and Asmar, M. (2014). Mathematical Formulation of the Project Quarterback Rating: New Framework to Assess Construction Project Performance. J. Constr. Eng. Manage., 140(8), 04014033.

Hobbs, J. (2008). Integrated Project Delivery pulls together people, systems, business structures and practices. Daily Commercial News. Retrieved from http://www.dailycommercialnews.com/article/id26787

Haponava, T., and Al-Jibouri, S. (2012). Proposed system for measuring project performance using process-based key performance indicators. J. Manage. Eng., 10.1061/(ASCE)ME.19forty three-5479.0000078, pp. 140-149.

Hatem, D. J. (2008). Design Responsibility in Integrated Project Delivery: Looking Back and Moving Forward. Retrieved from http://donavanhatem.com/wp/wpcontent/uploads/2012/09/design-professional-whitepaper-design-responsibility-jan2008.pdf.

Heller, B. G. (2008). If architects do not take the leadership role on integrated practice, they will cede this turf. Design Intelligence. Retrieved from http://www.worlddesignforum.com.

Hoover, S. (2013). Innovation in Water/Wastewater Market. Constructech Magazine, Retrieved from http://www.constructech.com/news/articles/article.aspx ?article_id=8447.

Hutt, R.W. (1979). The Focus Group Interview: A Technique for Counseling Small Business Clients. Journal of Small Business Management, 17 (1):15-18.

Ilozor, B. and Kelly, D. (2011). Building Information Modeling and Integrated Project Delivery in the Commercial Construction Industry: A Conceptual Study. Journal of Engineering, Project, and Production Management, 2 (1):23-36.

Kangari, R., Farid, F., and Elgharib, M. H. (1992). Financial Performance Analysis for Construction Industry. J. of Construction Engineering and Management, Vol. 118, No. 2, June, pp. 349-361.

Kent, D. C., and Becerik-Gerber, B. (2010). Understanding Construction Industry Experience and Attitudes toward Integrated Project Delivery. Journal of Construction Engineering and Management, 136 (8):815-825. 
Kessler, F., Nossaman, Guthner, Knox and Elliot LLP (2007). Managing Your Money: Project Delivery Methods. Retrieved from http://www.nossaman.com/db30/cgibin/ news/FWK_MassTransit_04.05.pdf.

Kim, Y.and Dossick C. S. (2011). What makes Delivery of a Project Integrated? A Case study of Children's Hospital, Belleveue, WA. Lean Construction Journal, pp. 53-55.

Kim, D.Y., Han, S.H., Kim, H. and Park, H. (2009). Structuring the Prediction Model of Project Performance for International Construction Projects: A Comparative Analysis. Expert Systems with Applications, 36(2), 1961-71.

Konchar, M. and Sanvido, V. (1998). Comparison of U.S. Project Delivery Systems. Journal of Construction Engineering and Management, ASCE, 124 (6):435-444.

Kreyszig, E. (1979). Advanced Engineering Mathematics. Wiley, New York, pp. 880 eq(5).

Krueger, R.A. and Casey, M.A. (2008) Focus groups: A practical guide for applied research. 4th edition. New York: SAGE.

Lancaster, F. D., and Tobin, J. (2010). Integrated Project Delivery: Next-Generation BIM for Structural Engineering. Structures Congress, ASCE.

Leung, M. and Chan, I. (2012). Exploring Stressors of Hong Kong Expatriate Construction Professionals in Mainland China: Focus Group Study. Journal of Construction Engineering and Management, 138 (1):78-88.

Leung, M., Yu, J., and Chan, Y. (2014). Focus Group Study to Explore Critical Factors of Public Engagement Process for Mega Development Projects. Journal of Construction Engineering and Management, 140 (3), 04013061.

Ling, F. Y. Y., Chan, S. L., Chong, E., and Ee, L. (2004). Predicting Performance of Design-Build and Design-Bid-Build Projects. Journal of Construction Engineering and Management, 130 (1):75-83.

Liu, J., Love, P., Davis, P., Smith, J., and Regan, M. (2014). Conceptual Framework for the Performance Measurement of Public-Private Partnerships. Journal of Infrastructure Systems, 10.1061/(ASCE)IS.19forty three-555X.0000210, 04014023.

Mahdi, I.M., Al-Reshaid, K. (2005). Decision Support System for Selecting the Proper Project Delivery Method Using Analytical Hierarchy Process. International Journal of Project Management, 23 (7):564-572. 
Maloney, W. (2002). Construction Product/Service and Customer Satisfaction. Journal of Construction Engineering and Management, 128 (6):522-529.

Matthews, O., and Howell, G. A. (2005). "Integrated Project Delivery an Example of Relational Contracting.” Lean Construction Journal, 2(1), pp. 46-61.

Mohamed, S. (2003). Performance in international construction joint ventures: Modeling perspective. Journal of Construction Engineering and Management, 129(6), pp. 619-626.

Molenaar, K., Gransberg, D., Korkmaz, S., and Horman, M. (2009). High Performance Projects and Project Delivery Methods. A State-of-Practice Report. Retrieved from http://www.dbia.org/NR/rdonlyres/AA033026-60BF-495B-9C9C51353F744C71/0/Sep2009ReportPankowDBIA.pdf.

NASFA, COAA, APPA, AGC and AIA (2010). Integrated Project Delivery for Public and Private Owner. Retrieved from http://www.aia.org/aiaucmp/groups/aia/documents/pdf/aiab085586.pdf

National Research Council, Building Research Board, C. o. C. C. O. (1986). Construction Contract Modifications - Comparing the Experiences of Federal Agencies with Other Owners. Washington D.C.

Odeh, A. M., \& Battaineh, H. T. (2002). Causes of construction delay: traditional contracts. International Journal of Project Management, 20(1), pp. 67-73.

O'Toole, T. (2001). National Aeronautics and Space Administration (NASA) Award Fee Contracting Guide. Retrieved from http://www.hq.nasa.gov/office/procurement/regs/afguidee.html

Ouimet, J., Bunnage, J., Carini, R., Kuh, G., Kennedy, J. (2014). Using Focus Groups, Expert Advice, and Cognitive Interviews to Establish the Validity of a College Student Survey. Research in Higher Education, 45 (3):233-250.

Patton, M.Q. (1990). Qualitative Evaluation and Research Method, 2nd Ed. Newbury Park, CA: Sage.

Post, N. M. (2009). Market Study Finds Engineers Get Lowest Return From BIM. ENR: Engineering News-Record, 263 (11): pp. 12.

Pressman, A. (2007). Integrated practice in perspective: A new model for the architectural profession. Architectural Record.

Rennekamp, R. A. and Nall, M. A. (2011). Using Focus Groups in Program Development and Evaluation, Lexington: University of Kentucky - College of Agriculture. Retrieved from http://www2.ca.uky.edu/agpsd/focus.pdf. 
Riley, D., Diller, B., Ken, D. (2005). Effects of Delivery Systems on Change Order Size and Frequency in Mechanical Construction. Journal of Construction Engineering and Management, ASCE, 131 (9):953-962.

Rowland, M. (1981). The causes and effects of change orders on the construction process. Master's thesis, Georgia Institute of Technology, Atlanta.

Singleton, M. S. and Hamzeh, F. (2011). Implementing Integrated Project Delivery on Department of the Navy Construction Projects. Lean Construction Journal, pp. 17-31.

Smithson, J. (2000). Using and Analysing Focus Groups: Limitations and Possibilities. International Journal of Social Research Methodology, 3 (2):103-119.

Stitt, B. (2011). Building Information Modeling Streamlines Facility Design. Water World.

Swan, W. and Khalfan, M. (2007). Mutual Objective Setting for Partnering Projects in the Public Sector. Engineering, Construction and Architectural Management, 14 (2):119130.

Tadt, E., Hanna, A., Whited, G. (2012). Best Practices from WisDOT Mega and ARRA Projects - Request for Information: Benchmarks and Metrics. Retrieved from http://ntl.bts.gov/lib/44000/44400/44459/BP-

RFI_Benchmarks_and_Metrics_Final_March_2012.pdf.

The Construction Users Round Table, CURT (2004). Collaboration, Integrated Information, and the Project Lifecycle in Building Design, Construction and Operation. Retrieved from http://www.gnycuc.org/media/curt.pdf.

Thomsen, C., Darrington, J., Dunne, D., Lichtig, W. (2009). Managing Integrated Project Delivery. Construction Management Association of America. Retrieved from http://cmaa.com/files/shared/IPD_White_Paper_1.pdf.

Touran, Ali, Gransberg, D. D., Molenaar, K. R., Bakhshi, P., Ghavamifar, K. (2009). Evaluation and Selection of Airport Capital Project Delivery Methods. Retrieved from http://onlinepubs.trb.org/onlinepubs/acrp/acrp_webdoc_006.pdf.

Tufte, E.R. (1983). The visual display of quantitative information Cheshire, Connecticut, Graphics Press.

Turner, R.J. (1993). The Handbook of Project-Based Management. London: McGrawHill Companies. 
Water Design-Build Council (WDBC) 2013. 'Design-build' and 'design-bid-build' project compared. Retrieved from http://www.waterdesignbuild.com.

Yang, H., Yeung, J., Chan, A., Chiang, Y., and Chan, D. (2010). A critical review of performance measurement in construction. Journal of Facilities Management, 10.1108/14725961011078981, pp. 269-284.

Yahya, A. (2009). Evaluation of Ways to Recover Late Construction Projects. University of Maryland. Retrieved from

http://drum.lib.umd.edu/bitstream/1903/9349/1/Aliabadizadeh_umd_0117N_10397.pdf.

Yu, I.; Kim, K., Jung, Y., and Chin, S. (2007). Comparable Performance Measurement System for Construction Companies. Journal of Management in Engineering. 23(3), pp. 131-139. 
APPENDICES 
APPENDIX A

Three-Week Look Ahead Schedule

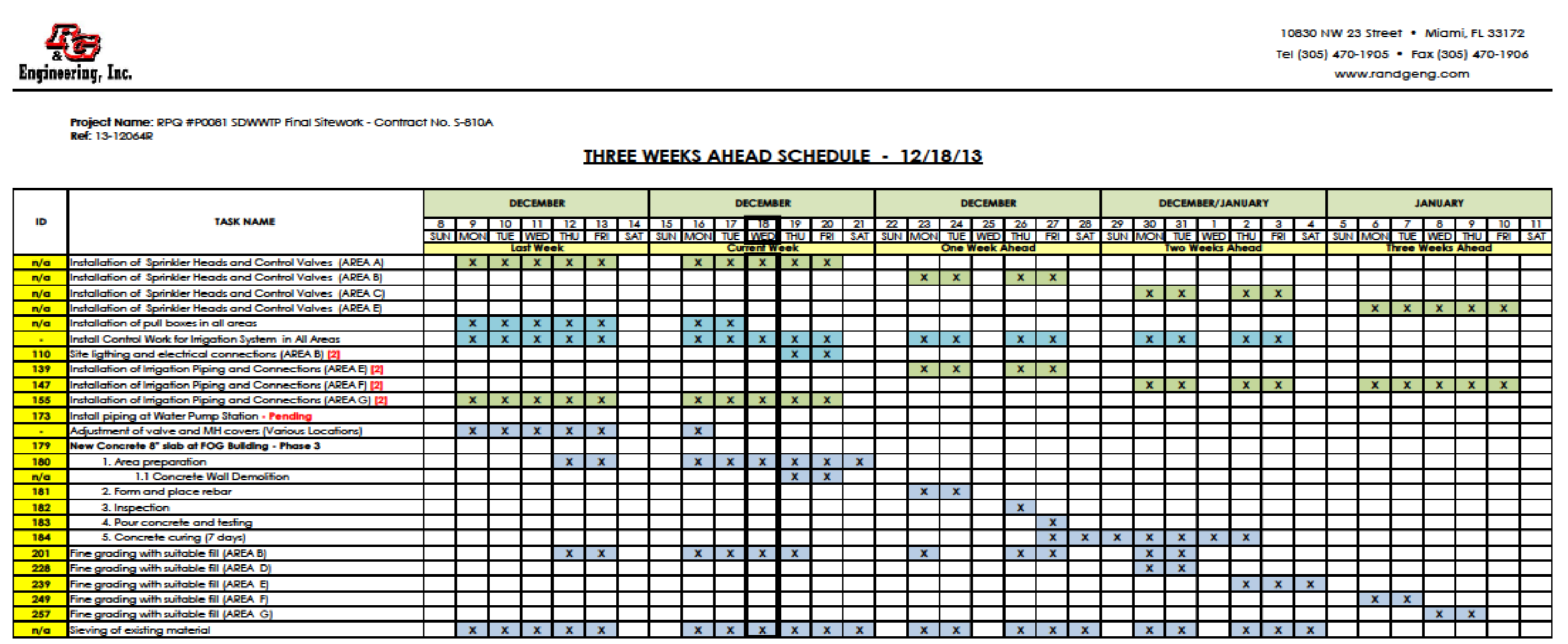

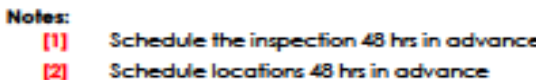

[2] Schedice locafiors $48 \mathrm{hrs}$ in advar

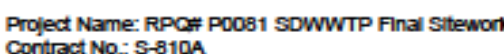

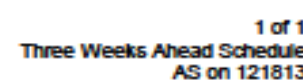




\section{APPENDIX B}

Waste Elimination Log

Project Name: Screens Systems Improvements Job No. S-863

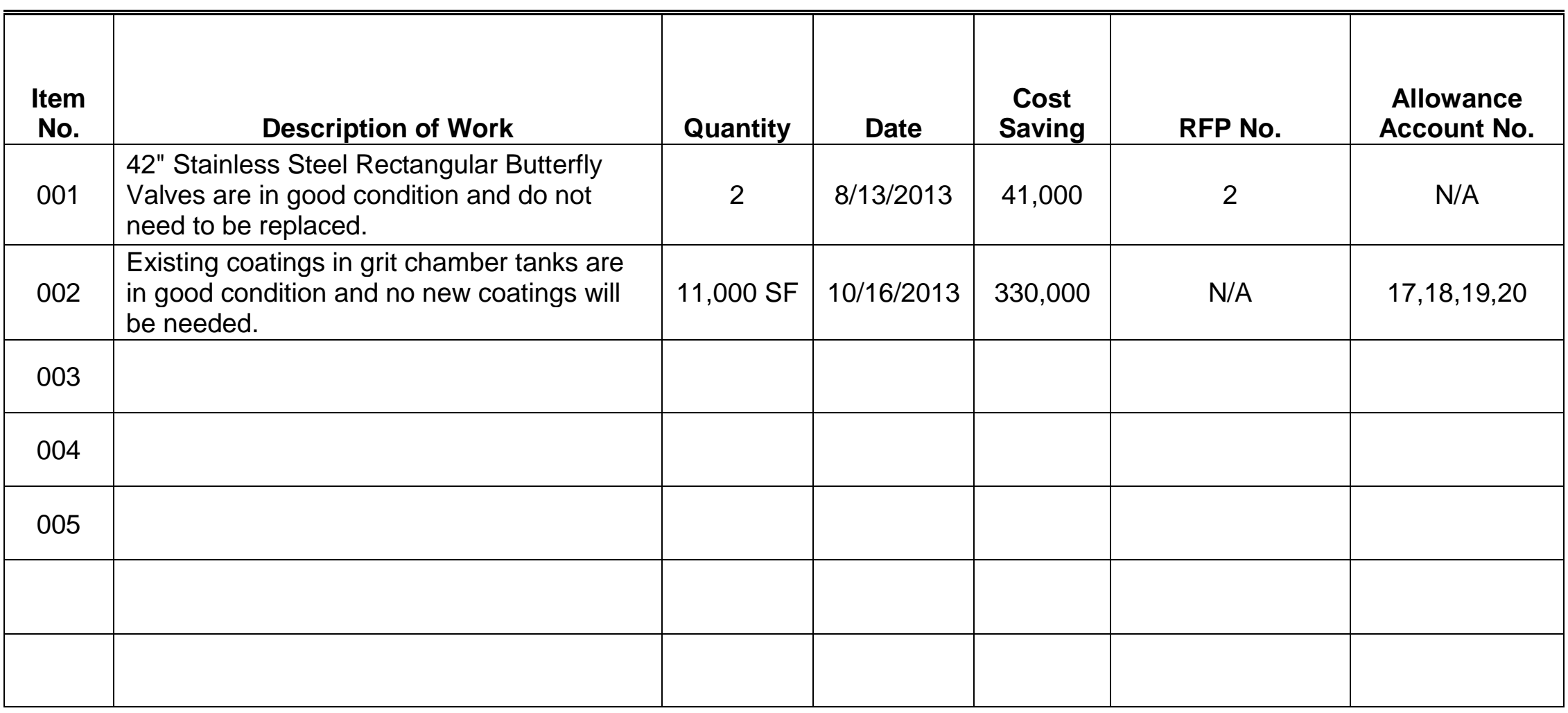


APPENDIX C

Pre-Engineered Office Building

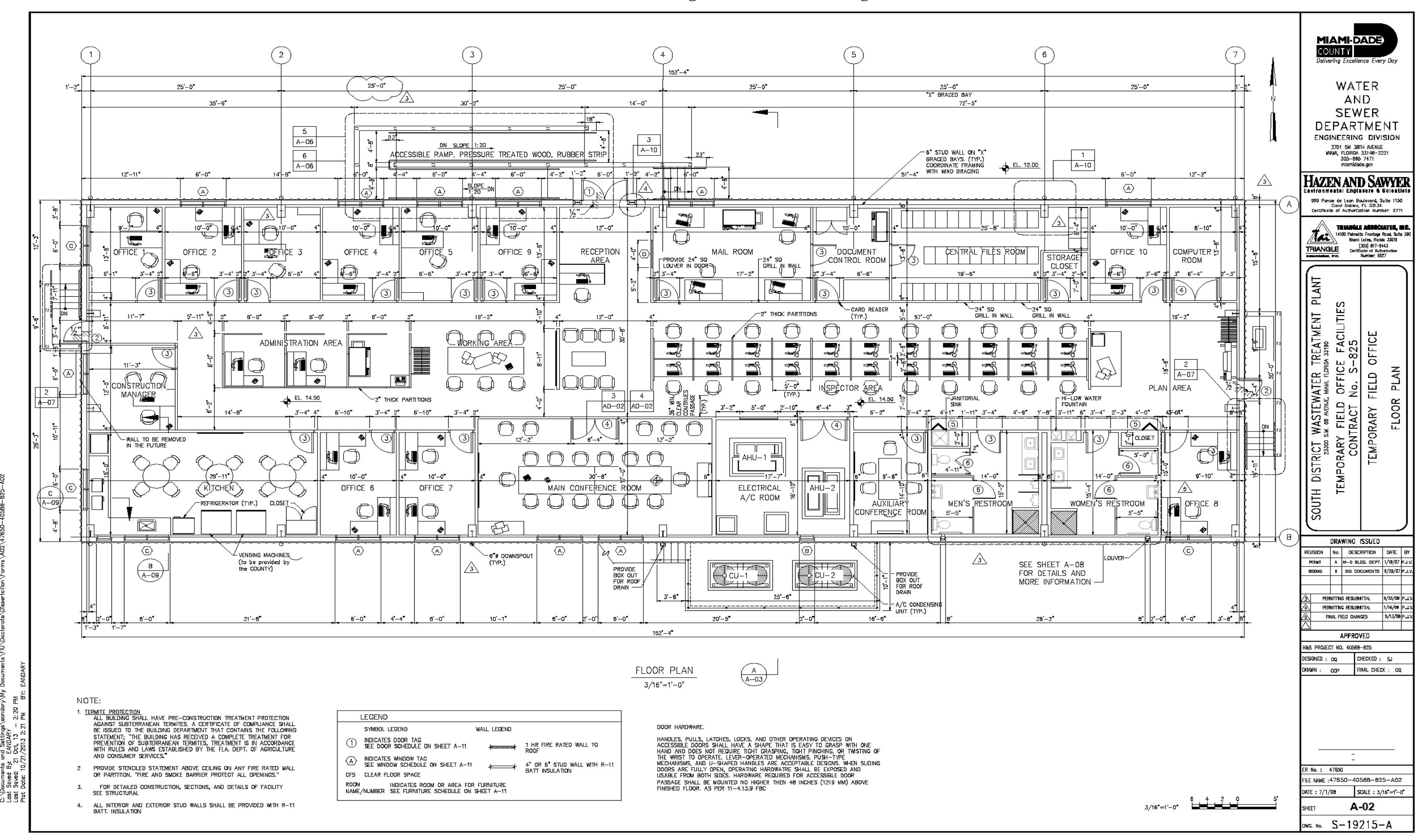


Site Layout

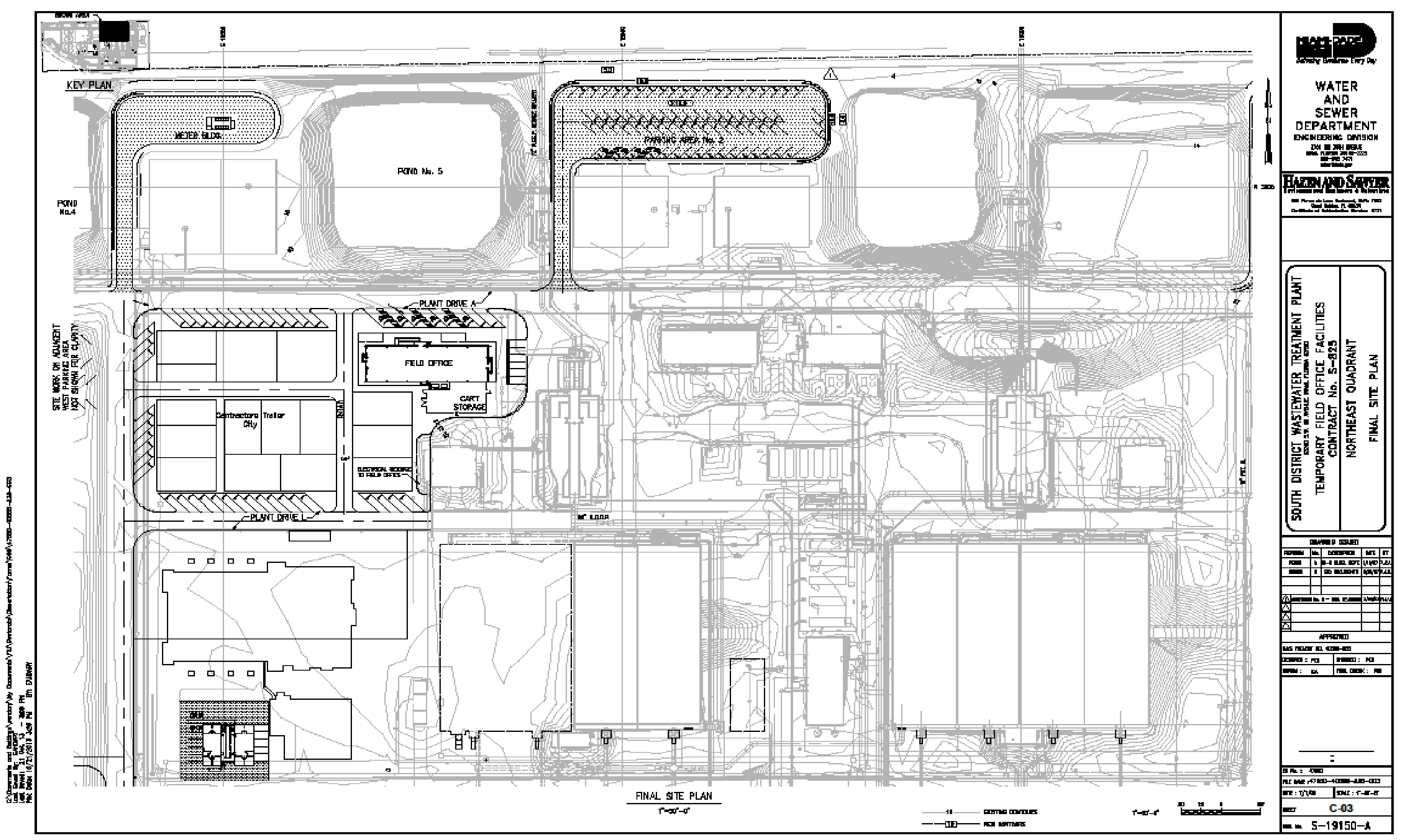




\section{APPENDIX D \\ Employee Performance Evaluation}

Employee Performance Evaluation

INSTRUCTIONS: Use this form to evaluate classified or exempt employees in non-professional, non-supervisory positions.

\begin{tabular}{|l|l|l|l|}
\hline \multicolumn{2}{|l|}{ EMPLOYEE INFORMATION First } & \multicolumn{1}{c|}{ M.I. } & Employee ID Number \\
\hline Name: Last & Status & Prob. End Date (If applicable) \\
\hline $\begin{array}{c}\text { Classification } \\
\text { Department }\end{array}$ & Unit & $\begin{array}{l}\text { Period Covered } \\
\text { From: }\end{array}$ & To: \\
\hline $\begin{array}{c}\text { Reason for Review } \\
\text { Merit Raise } \Gamma \text { Status Range } \quad \Gamma \quad \text { Annual Review }\end{array}$ Other (Explain) \\
\hline
\end{tabular}

RATERS: It is understood that the importance of each category will vary with job classification and department. Explain your rating in terms of performance in each category. Mark the appropriate box. Use additional sheets if necessary.

1. QUANTITY OF WORK: Includes amount of work performed.

\begin{tabular}{llll}
\cline { 2 - 3 } RATING: & $\Gamma$ & $\Gamma$ Satisfactory & $\Gamma$ Above Satisfactory \\
\hline
\end{tabular}

EXPLAIN REASON FOR A RATING:

2. QUALITY OF WORK: Includes accuracy, achievement of objectiveness, initiative and resourcefulness and neatness of work product.

RATING: ГJnsatisfactory

ГNeeds

Гiatisfactory ГAbove Satisfactory $\Gamma$

EXPLAIN REASON FOR A RATING:

Employee Performance Evaluation 


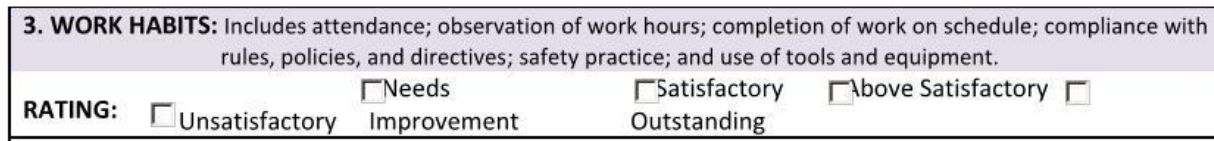

EXPLAIN REASON FOR A RATING:

4. INTERPERSONAL SKILLS: Includes participation and teamwork; contribution to unit morale; working cooperatively with the public, peers, and subordinates; and accepting advice and counseling from superiors. $\Gamma$

RATING: ГUnsatisfactory Needs Г $\Gamma$ Satisfactory Above Satisfactory EXPLAIN REASON FOR A RATING:

RATER'S OVERALL EVALUATION

$\Gamma$ UNSATISFACTORY Performance is inadequate and must be corrected.

$\Gamma$ NEEDS IMPROVEMENT

Performance is inadequate and must be corrected.

Г SATISFACTORY

Г ABOVE SATISFACTORY

$\Gamma$ OUTSTANDING

Employee is performing as required and expected in an entirely satisfactory manner. Performance surpasses job requirements.

Consistently conspicuous, distinguished performance. Employee displays initiative and creativity.

Employee has substantially enhanced departmental efficiency and/or effectiveness.

Check one of the following if the employee is eligible for a Merit Increase:_Granted,_Deferred,_re-evaluated in months.

If an employee is eligible for permanent status, please check one of the following:

$\lceil$ Granted $\Gamma$ Denied $\Gamma$ Extended for _ months with employee's written permission (attached) (Note: Probationary may not extend beyond one year) 
WAYS THE EMPLOYEE CAN OR MUST IMPROVE PERFORMANCE: If overall rating is Needs Improvement or

Unsatisfactory, a written plan of action for improvement must be included in this section. Optional if Satisfactory or better.

RATER: This report based on my observations, knowledge of employee's performance, and review of applicable information. It represents my best judgment of the employee's performance.

Rater's Signature:

Date:

Print Name: $\quad$ Title:

REVIEWER: I have received this report and discussed it with the rater. It represents an accurate appraisal of the employee's performance in accordance with Administrative Order. I concur in the recommendation, if any, as to merit raise or permanent status.

Reviewer's

Signature:

Date:

Print Name:

Title:

EMPLOYEE: I acknowledge that I have received a copy of this evaluation. I have had an opportunity to discuss it with my supervisor. In signing this evaluation, I do not necessarily agree with the conclusions. I understand that I may write my comments on another sheet of paper or below.

A permanent employee who has received an overall evaluation of "Unsatisfactory" or "Needs Improvement," must first request a review of the performance Evaluation by the Department Director within ten (10) calendar days. If the decision of the Director is not acceptable to the employee, the employee may continue the appeal within ten (10) calendar days after receipt of the Director's decision by making a request in writing to the Human Resource Department Director.

I have read and understand the above appeal process.

EMPLOYEE COMMENTS 


\section{MIAMI-DADE COUNTY, FLORIDA Capital Improvements Information System Miami-Dade Water and Sewer Department Contractor/Consultant Evaluation}

Contract:

Contract Name

Award Amount

Contract Type

Contractor/Consultant:

Evaluator ID:

Date:

Period:

\begin{tabular}{|c|c|c|c|c|c|c|}
\hline \multicolumn{6}{|c|}{ Rating* } & \\
\hline & 4 & 3 & 2 & 1 & N/A & Criteria \\
\hline 1- & & & & & & $\begin{array}{l}\text { Schedule - Quality of schedule and adherence to schedule } \\
\text { resulting in timeliness and minimizing delay to the owner and } \\
\text { community }\end{array}$ \\
\hline $2-$ & & & & & & $\begin{array}{l}\text { Cost effectiveness and efficiency - Budget compliance and } \\
\text { value of work }\end{array}$ \\
\hline 3- & & & & & & Vision - Design - Concepts or adhere to criteria. \\
\hline 4- & & & & & & $\begin{array}{l}\text { Cooperation - Teamwork and relationship with owner, subs } \\
\text { and suppliers. }\end{array}$ \\
\hline $5-$ & & & & & & $\begin{array}{l}\text { Coordination - Ability to organize, schedule and complete } \\
\text { tanks in adherence to the schedule. }\end{array}$ \\
\hline $6-$ & & & & & & $\begin{array}{l}\text { Accuracy and Technical Skills - Cost estimating, scheduling, } \\
\text { shop and other drawings, plans, manuals, project } \\
\text { documentation and conflict resolution. }\end{array}$ \\
\hline 7- & & & & & & $\begin{array}{l}\text { Completeness - Compliance with contract documents, } \\
\text { permits, Codes and standards }\end{array}$ \\
\hline 8- & & & & & & $\begin{array}{l}\text { Responsiveness - Timely, clear and concise responses to } \\
\text { owner comments and correspondence }\end{array}$ \\
\hline 9- & & & & & & $\begin{array}{l}\text { Commitment - Intangibles and contribution to project } \\
\text { success }\end{array}$ \\
\hline $10-$ & & & & & & Personnel - Quality and dedication of project staff \\
\hline $11-$ & & & & & & Management - Leadership ability \\
\hline $12-$ & & & & & & Quality - Work performed correctly the first time \\
\hline
\end{tabular}

Overall Performance Average:

Documentation that supports this evaluation and Contractor's/Consultant's comments can be obtained by contacting:

Evaluation Reviewed by: $\lceil$ Supervisor $\Gamma$ Division Chief $\square$ Assistant Director $\Gamma$ Director

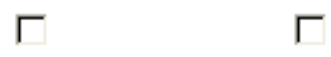


The method of delivery of this evaluation to Contractor/Consultant: Certified Mail Hand $\Gamma$ Email Г Fax

(Unresponsive Performance by contractor/consultant requires 2 delivery methods, one MUST be Certified Mail.)

Evaluation delivered to

\section{$\underline{* \text { Rating Key }}$}

4 Superior performance - Exemplary quality, no intervention required - project completed on time or early at or below budget with no change orders or amendments other than owner requested changes.

3 Satisfactory performance - Minor errors noted, addressed with timely corrective action.

2 Guarded performance - Errors and Omissions documented in writing with timely corrective action.

1 Unresponsive performance documented in writing without timely corrective action. N/A. No Information. 


\section{APPENDIX E}

Cost Summary

Miami-Dade Water and Sewer Department

\begin{tabular}{|c|c|c|c|}
\hline \multicolumn{4}{|c|}{ S-810 Payment Application Summary } \\
\hline $\begin{array}{l}\text { Total Contract } \\
\text { Amount: }\end{array}$ & $\$ 3,651,280.00$ & \multirow[b]{2}{*}{ Paid to Date } & \multirow[b]{2}{*}{ Total Remaining } \\
\hline & & & \\
\hline $\begin{array}{l}\text { Contingency } \\
\text { Allowance }\end{array}$ & $\$ 301,700.00$ & 0.00 & $301,700.00$ \\
\hline $\begin{array}{l}\text { Dedicated } \\
\text { Allowance } \\
\end{array}$ & $\$ 332,580.00$ & 0.00 & $332,580.00$ \\
\hline General & $\$ 582,421.00$ & 143117.50 & $43,303.50$ \\
\hline Area A & $\$ 371,421.00$ & $7,900.00$ & $363,521.00$ \\
\hline Area B & $\$ 495,189.00$ & $26,000.00$ & $469,189.00$ \\
\hline Area C & $\$ 563,723.00$ & $58,000.00$ & $505,723.00$ \\
\hline Area D & $\$ 286,823.00$ & 0.00 & $286,823.00$ \\
\hline Area $\mathrm{E}$ & $\$ 313,187.00$ & 0.00 & $313,187.00$ \\
\hline Area $\mathrm{F}$ & $\$ 202,118.00$ & 0.00 & $202,118.00$ \\
\hline Area $\mathbf{G}$ & $\$ 202,118.00$ & 0.00 & $202,118.00$ \\
\hline Total & $\$ 3,651,280.00$ & $235,017.50$ & $3,416,262.50$ \\
\hline
\end{tabular}




\section{APPENDIX $\mathbf{F}$}

CO Log

Miami-Dade Water and Sewer Department

Project Name: Screens Improvement

Job No. S-863

Status: $\mathrm{O}=$ Open, $\mathrm{C}=$ Closed

\begin{tabular}{|c|c|c|c|c|c|c|c|c|}
\hline $\begin{array}{l}\text { RFP } \\
\text { No. }\end{array}$ & Description & Prepared by & $\begin{array}{l}\text { Issue Date } \\
\text { (Engineer) }\end{array}$ & $\begin{array}{c}\text { Reply Date } \\
\text { (Contractor) }\end{array}$ & Status & Comments & $\begin{array}{c}\text { Full Size } \\
\text { Drawings } \\
\text { Provided } \\
\end{array}$ & Cost \\
\hline 001 & $\begin{array}{l}\text { Plant } 2 \text { West Grit } \\
\text { Chamber Concrete } \\
\text { Coatings }\end{array}$ & EA/JA & 6/7/2013 & $10 / 14 / 2013$ & $\mathrm{O}$ & $\begin{array}{c}\text { With } \mathrm{CH} 2 \text { and } \\
\text { HandS }\end{array}$ & N/A & \\
\hline 002 & $\begin{array}{l}\text { Rectangular } \\
\text { Butterfly Valves }\end{array}$ & EA/JA & $8 / 13 / 2013$ & $8 / 18 / 2013$ & $\mathrm{O}$ & Approved & N/A & \\
\hline 003 & $\begin{array}{l}\text { Structural } \\
\text { Modifications at } \\
\text { Plant } 2 \text { Grit } \\
\text { Chamber }\end{array}$ & $\mathrm{EA} / \mathrm{JA}$ & $9 / 17 / 2013$ & & $\mathrm{O}$ & & $\begin{array}{l}\text { Yes (CAD } \\
\text { Pending) }\end{array}$ & \\
\hline 004 & $\begin{array}{l}\text { Electrical Building } \\
\text { Civil and } \\
\text { Structural } \\
\text { Modifications }\end{array}$ & $\mathrm{EA} / \mathrm{JA}$ & 9/20/2013 & & $\mathrm{O}$ & & $\begin{array}{l}\text { Yes (CAD } \\
\text { Pending) }\end{array}$ & \\
\hline 005 & $\begin{array}{l}\text { Electrical Conduits } \\
\text { in Corrosive } \\
\text { Locations }\end{array}$ & $\mathrm{EA} / \mathrm{JA}$ & $10 / 15 / 2013$ & & $\mathrm{O}$ & & N/A & \\
\hline & & & & & & & & \\
\hline & & & & & & & & \\
\hline
\end{tabular}




\section{APPENDIX G RFI Log}

Project No. S-863

Miami-Dade Water and Sewer Department

Project Name: Screens Improvement

\begin{tabular}{|c|c|c|c|c|c|c|}
\hline RFI No. & Subject & $\begin{array}{l}\text { Received } \\
\text { Date }\end{array}$ & $\begin{array}{l}\text { Contractor } \\
\text { Requested } \\
\text { Due Date }\end{array}$ & $\begin{array}{l}\text { Response } \\
\text { Sent }\end{array}$ & Status & Reviewer \\
\hline CONST0001 & MCC Bus Duct Tie at Plant 1 & 05/29/2013 & 06/06/2013 & 06/10/2013 & C & JFA \\
\hline CONST0002 & Door \#30101C Plant 1 Electrical Bldg & 06/18/2013 & 07/02/2013 & $06 / 25 / 2013$ & C & JFA \\
\hline CONST0003 & Added Construction Joint at 3'-9" Slab & $06 / 25 / 2013$ & 07/03/2013 & $07 / 23 / 2013$ & C & JFA \\
\hline CONST0004 & $\begin{array}{l}\text { Construction of } 16 \text { 'x22" Beams Below Bypass } \\
\text { Flumes }\end{array}$ & $06 / 25 / 2013$ & $07 / 03 / 2013$ & $07 / 10 / 2013$ & C & EA \\
\hline CONST0004S & Drawing Request in Response to RFI 004 & $07 / 24 / 2013$ & $07 / 31 / 2013$ & $07 / 30 / 2013$ & C & JFA \\
\hline CONST0005 & Relocation of HVAC Ducts & $06 / 25 / 2013$ & $07 / 03 / 2013$ & 07/03/2013 & c & EA \\
\hline CONST0006 & Elevation of Trench Bottom & $07 / 16 / 2013$ & $07 / 16 / 2013$ & 07/30/2013 & C & JFA \\
\hline CONST0007 & RBV Placement at Plant 2 and Bi-Directional Testing & $07 / 16 / 2013$ & $07 / 16 / 2013$ & 07/30/2013 & C & JFA \\
\hline CONST0007A & RBV Placement at Plant 2 and Bi-Directional Testing & $07 / 30 / 2013$ & - & $08 / 26 / 2013$ & c & JFA \\
\hline CONST0008 & Clarification to RFI No. 003 & $07 / 18 / 2013$ & $07 / 25 / 2013$ & $07 / 23 / 2013$ & $\mathrm{C}$ & JFA \\
\hline CONST0009 & Clearance for Screens & $07 / 18 / 2013$ & $07 / 25 / 2013$ & 08/06/2013 & C & JFA \\
\hline CONST0011 & Mix Design of Concrete & $07 / 19 / 2013$ & $07 / 26 / 2013$ & $07 / 31 / 2013$ & C & JFA \\
\hline CONST0012 & Conflict with Beam Below Bypass Channel @ Plant 2 & $07 / 30 / 2013$ & 08/05/2013 & $07 / 31 / 2013$ & $\mathrm{C}$ & DZM \\
\hline CONST0012A & Conflict with Beam Below Bypass Channel @ Plant 2 & $07 / 30 / 2013$ & $08 / 06 / 2013$ & $07 / 31 / 2013$ & C & DZM \\
\hline CONST0013 & $\begin{array}{l}\text { Conflict with Concrete Base Under Bypass Channel } \\
\text { @ Plant } 2\end{array}$ & 07/31/2013 & 08/07/2013 & 08/21/2013 & C & JA \\
\hline CONST0014 & Two Dimensions on Rebar Drawings & $08 / 19 / 2013$ & $08 / 26 / 2013$ & $09 / 03 / 2013$ & C & JA \\
\hline CONST0015 & Conduit Spacing & $08 / 21 / 2013$ & $08 / 28 / 2013$ & $08 / 25 / 2013$ & c & JA \\
\hline CONST0016 & Ball and Check Valves at Booster Pumps & $08 / 21 / 2013$ & $08 / 28 / 2013$ & $09 / 06 / 2013$ & C & JA \\
\hline CONST0017 & Piping at Screen's SV & $08 / 21 / 2013$ & $08 / 28 / 2013$ & $09 / 05 / 2013$ & c & JA \\
\hline CONST0018 & Gates Bulkhead Conflict with Screens & $08 / 26 / 2014$ & ASAP & 09/09/2013 & c & JA \\
\hline
\end{tabular}


APPENDIX H

\section{Construction Defect Log}

Miami-Dade Water and Sewer Department

Project Name: Screens Improvement Job No. S-863

Status: $\mathrm{O}=$ Open, $\mathrm{C}=$ Closed

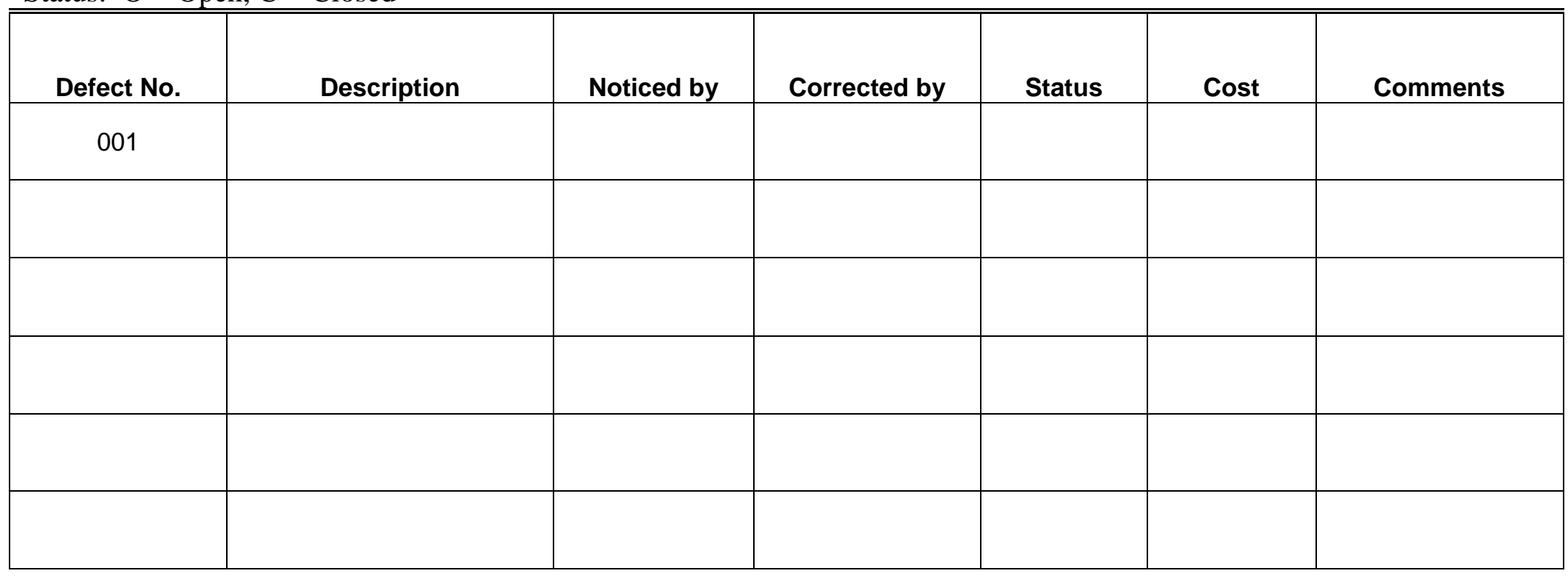


APPENDIX I

Construction Claims Log

Miami-Dade Water and Sewer Department

Project Name: Screens Improvement

Job No. S-863

Status: $\mathrm{O}=$ Open, $\mathrm{C}=$ Closed

\begin{tabular}{|c|l|l|l|l|l|l|}
\hline Claim No. & Description & $\begin{array}{c}\text { Issue Date } \\
\text { (Contractor) }\end{array}$ & $\begin{array}{c}\text { Reply Date } \\
\text { (Engineer) }\end{array}$ & Status & Settled & Cost \\
\hline \hline 001 & & & & & & \\
\hline & & & & & & \\
\hline & & & & & & \\
\hline & & & & & & \\
\hline & & & & & & \\
\hline
\end{tabular}




\section{APPENDIX J \\ Focus Group Introduction}

Good morning and welcome. Thanks for taking the time to join our discussion about the wastewater projects at Miami Dade South District Wastewater Treatment Plant (MD SDWWTP). My name is Elie G. Andary, and I will serve as the moderator for today's focus group discussion. Assisting me is Marie Bennett. The purpose of today's discussion is to get information from you about the effect of IPD principals on the DBB delivery method of the two construction projects at MD SDWWTP. You were invited because you have worked on these projects. There are no right or wrong answers to the questions I am about to ask. Please feel free to share your point of view even if it differs from what others have said. If you want to follow up on something that someone has said, or you want to agree, disagree, or give an example, feel free to do that. Don't feel like you have to respond to me all the time. Feel free to have a conversation with one another about these questions. I am here to ask questions, listen, and make sure everyone has a chance to share. We're interested in hearing from each of you. So if you're talking a lot, I may ask you to give others a chance. And if you aren't saying much, I may call on you. We just want to make sure we hear from all of you. Feel free to get up and get more refreshments if you would like.

Marie and I will both be taking notes to help us remember what is said. We are also audio recording the session to avoid missing any of your comments. No names will be included in any reports. 


\section{APPENDIX K \\ Consent to Participate in Focus Group Study as Part of the Miami Dade South District Wastewater Treatment Plant (MD SDWWTP)}

The purpose of the group discussion and the nature of the questions have been explained to me.

I consent to take part in a focus group about my experiences at the construction projects at MD- SDWWTP. I also consent to be audio-recorded during this focus group discussion.

My participation is voluntary. I understand that I am free to leave the group at any time. The information that I provide during the focus group will be grouped with answers from other people so that I cannot be identified.

Please Print Your Name and Date

Please Sign Your Name

Signature Date 


\section{APPENDIX L \\ Focus Group Questions and Discussion Points}

The study applies six IPD principles in conjunction with DBB in two construction projects at the Miami Dade South District Wastewater Treatment Plant (MD-SDWWTP). The performance of the projects was measured in terms of key performance indicators, such as: dollar amount of change orders (COs) as a percentage of total project cost, total number of Request for Information (RFIs) normalized by project size, construction delays as percentage of original project duration, defects, client satisfaction with the product, client satisfaction with the service, and construction claims.

Question No. 1 (Opening question): Would you please introduce yourself and tell us how long you have been working in the water and wastewater industry.

Question No. 2 (Transition question): What do you think of the contribution of IPD to DBB at the MD-SDWWTP projects and how would you describe your experience?

Question No. 3 (Key question): How would you characterize the effect, if any, of IPD principles on the construction schedule and total duration at MD-SDWWTP projects? Positive, negative, or no effect?

Question No. 4 (Key question): How would you characterize the effect, if any, of IPD principles on the amount of change orders at MD-SDWWTP projects? Was the effect a relative increase, decrease, or no effect?

Question No. 5 (Key question): How would you characterize the effect, if any, of IPD principles on the number of RFIs at MD-SDWWTP projects? A reduction, an increase, or no effect? 
Question No.6 (Key question): How would you characterize the effect, if any, of IPD principles on the owner's satisfaction at MD-SDWWTP projects?

Question No. 7 (Key question): How would you characterize the effect, if any, of IPD principles on the construction defects and claims at Miami Dade South District Treatment Plant projects?

Question No. 8: (Ending question): Is there anything we should have talked about, but did not?

At the end of the discussion, the main issues that were discussed during the session will be summarized and main points of agreement confirmed. 


\section{APPENDIX M Focus Group Questionnaire}

1) Please rank the KPIs from 1 to 6 based on which you felt was most effective in determining the success of a construction project, with 1 being the most effective and 6 being the least effective.

\begin{tabular}{|l|l|}
\hline \multicolumn{1}{|c|}{ Rank } & \\
\hline & KPIs \\
\hline & Change orders amount as a percentage of total project cost (COs) \\
\hline & Number of Request for Information (RFIs) \\
\hline & Construction duration \\
\hline & Number of construction defects \\
\hline & Client satisfaction with the product and services \\
\hline
\end{tabular}

2) Please indicate your opinion concerning the following characteristics based on your experience with MD-SDWWTP control projects.

\begin{tabular}{|l|c|c|c|c|c|}
\hline \multicolumn{1}{|c|}{ Job Characteristics } & $\begin{array}{c}(1) \\
\text { Strongly } \\
\text { Agree }\end{array}$ & $\begin{array}{c}(2) \\
\text { Agree }\end{array}$ & $\begin{array}{c}\text { (3) } \\
\text { Neutral }\end{array}$ & $\begin{array}{c}\text { (4) } \\
\text { Disagree }\end{array}$ & $\begin{array}{c}\text { Strongly } \\
\text { Disagree }\end{array}$ \\
\hline $\begin{array}{l}\text { Good client satisfaction } \\
\text { with the product }\end{array}$ & & & & & \\
\hline $\begin{array}{l}\text { Good client satisfaction } \\
\text { with the service }\end{array}$ & & & & & \\
\hline $\begin{array}{l}\text { Change order costs was } \\
\text { below average }\end{array}$ & & & & & \\
\hline $\begin{array}{l}\text { Number of construction } \\
\text { defects was below average }\end{array}$ & & & & & \\
\hline $\begin{array}{l}\text { Number of RFIs was below } \\
\text { average }\end{array}$ & & & & & \\
\hline Better working experience & & & & & \\
\hline
\end{tabular}


3) Please rank from 0 to 5 ( 0 being no effect and 5 being the most effect), the implemented IPD principles in the control projects as per their respective influence on each of the following aspects of the projects.

\begin{tabular}{|l|l|l|l|l|l|}
\hline \multirow{2}{*}{ IPD Principle } & \multicolumn{3}{|c|}{ Ranking of the Effect of IPD Principles on Changes in KPIs } \\
\cline { 2 - 6 } & $\begin{array}{c}\text { Reduced } \\
\text { Percentage } \\
\text { Cost } \\
\text { Growth }\end{array}$ & $\begin{array}{c}\text { Reduced } \\
\text { Percentage } \\
\text { Time } \\
\text { Growth }\end{array}$ & $\begin{array}{c}\text { Reduced } \\
\text { Percentage } \\
\text { Cost of } \\
\text { RFP }\end{array}$ & $\begin{array}{c}\text { Reduced } \\
\text { Percentage } \\
\text { Cost of } \\
\text { Claims }\end{array}$ & $\begin{array}{c}\text { Reduced } \\
\text { Number } \\
\text { of RFIs }\end{array}$ \\
\hline $\begin{array}{l}\text { Open } \\
\text { Communication } \\
\text { within the Project } \\
\text { Team and Ability to } \\
\text { Address Issues }\end{array}$ & & & & & \\
\hline $\begin{array}{l}\text { Integrated and } \\
\text { Collaborative } \\
\text { Teams }\end{array}$ & & & & & \\
\hline $\begin{array}{l}\text { Lean Construction } \\
\text { Techniques and } \\
\text { Principles }\end{array}$ & & & & & \\
\hline $\begin{array}{l}\text { Co-location of } \\
\text { Teams }\end{array}$ & & & & & \\
\hline $\begin{array}{l}\text { Performance } \\
\text { Evaluations }\end{array}$ & & & & & \\
\hline $\begin{array}{l}\text { Mutual Respect and } \\
\text { Trust }\end{array}$ & & & & & \\
\hline
\end{tabular}

4) Please rank the performance factors from 1 to 6 based on which you feel is most effective in measuring the project success of a construction project, with 1 being the most effective and 6 being the least effective. 


\begin{tabular}{|l|l|}
\hline \multirow{2}{*}{ Rank } & \\
\hline & Project Schedule \\
\hline & Early Involvement \\
\hline & Customer Satisfaction \\
\hline & Project Cost \\
\hline & Design Quality \\
\hline & Project Staff Performance Evaluation \\
\hline
\end{tabular}

5) Based on your experience, if MD-SDWWTP control projects were to be graded, please indicate your opinion concerning the following performance factors and their effect on the final score.

\begin{tabular}{|l|l|c|c|c|c|}
\hline \multicolumn{1}{|c|}{ Performance Factors } & $\begin{array}{c}(1) \\
\text { Excellent }\end{array}$ & $\begin{array}{c}\text { Very } \\
\text { Good }\end{array}$ & $\begin{array}{c}(3) \\
\text { Good }\end{array}$ & $\begin{array}{c}(4) \\
\text { Fair }\end{array}$ & $\begin{array}{c}\text { (5) } \\
\text { Poor }\end{array}$ \\
\hline Project Schedule & & & & & \\
\hline Early Involvement & & & & & \\
\hline Customer Satisfaction & & & & & \\
\hline Project Cost & & & & & \\
\hline Design Quality & & & & & \\
\hline $\begin{array}{l}\text { Project Staff Performance } \\
\text { Evaluation }\end{array}$ & & & & & \\
\hline
\end{tabular}


VITA

\section{ELIE G. ANDARY}

Born, Lebanon

$1995-2000$

B.E. Civil Engineering

Lebanese American University

Byblos, Lebanon

2001-2003

M.S. Construction Management

University of Florida

Gainesville, FL

2003-2007

Principal Engineer

Hazen and Sawyer

Hollywood, FL

2007

Licensed Professional Engineer P.E.

License No. 67503

Florida Board of Professional Engineers

2008-2013

2011-2019

2014-2017

2018-2019

Senior Principal Engineer

Hazen and Sawyer

Hollywood, FL

Doctoral Candidate

Florida International University

Miami, Florida

Associate

Hazen and Sawyer

Hollywood, FL

Senior Associate

Head of Construction Management in the South East

Hazen and Sawyer

Hollywood, FL 


\section{PUBLICATIONS AND PRESENTATIONS}

Muszynski, L., Chini, A., Andary, E. Nondestructive Testing Methods to Detect Voids in Bonded Post-Tensioned Ducts. Transportation Research Board, pp. 135, September 2003.

Andary, G.E., (April, 2003). Nondestructive Testing Methods to Detect Voids in Bonded Post-Tensioned Ducts. Paper presented at The Fourteenth Annual Graduate and Professional Forum, University of Florida, Gainesville, Florida.

Abi Shdid, C. and Andary, E., Improving the Delivery Process of Water and Wastewater Treatment Plant Public Projects through the use of IPD Principles: A Case Study. Water Environment Federation, Utilities Management Conference, 2015, pp. 1-11(11) San Diego, California, February 23-27, 2016.

Abi Shdid, C., Andary, E., Chowdhury, A. and Ahmad, I., Project Performance Rating Model for Water and Wastewater Treatment Plant Public Projects. Journal of Management in Engineering, ASCE. Vol 35, Issue 2 March 2019.

Andary, E., Abi Shdid, C., Chowdhury, A. and Ahmad, I., An IPD implementation Guideline Metric for Water and Wastewater Treatment Plant Projects. Journal of Engineering, Construction, and Architectural Management. In review. 